Florida International University

FIU Digital Commons

7-10-2019

\title{
Exploring the Potential of Endophytes and Medicinal Plants as Sources of Antimicrobials to Control Citrus Greening
}

Jessica Dominguez

Florida International University, jdomi022@fiu.edu

Follow this and additional works at: https://digitalcommons.fiu.edu/etd

Part of the Agricultural Science Commons, and the Environmental Microbiology and Microbial Ecology Commons

\section{Recommended Citation}

Dominguez, Jessica, "Exploring the Potential of Endophytes and Medicinal Plants as Sources of Antimicrobials to Control Citrus Greening" (2019). FIU Electronic Theses and Dissertations. 4368. https://digitalcommons.fiu.edu/etd/4368

This work is brought to you for free and open access by the University Graduate School at FIU Digital Commons. It has been accepted for inclusion in FIU Electronic Theses and Dissertations by an authorized administrator of FIU Digital Commons. For more information, please contact dcc@fiu.edu. 


\section{FLORIDA INTERNATIONAL UNIVERSITY}

Miami, Florida

EXPLORING THE POTENTIAL OF ENDOPHYTES AND MEDICINAL PLANTS AS SOURCES OF ANTIMICROBIALS TO CONTROL CITRUS GREENING

A thesis submitted in partial fulfillment of the requirements for the degree of MASTER OF SCIENCE in ENVIRONMENTAL STUDIES

by

Jessica Dominguez

2019 
To: Dean Michael R. Heithaus

College of Arts, Sciences and Education

This thesis, written by Jessica Dominguez and entitled Exploring the Potential of Endophytes and Medicinal Plants as Sources of Antimicrobials to Control Citrus Greening, having been approved in respect to style and intellectual content, is referred to you for judgment.

We have read this thesis and recommend that it be approved.

Krishnaswamy Jayachandran

$\begin{array}{r}\hline \text { Mahadev Bhat } \\ \hline \text { Kateel Shetty, Major Professor }\end{array}$

Date of Defense: July 10, 2019

The thesis of Jessica Dominguez is approved.

Dean Michael R. Heithaus College of Arts, Sciences, and Education

Andrés G. Gil Vice President for Research and Economic Development and Dean of the University Graduate School

Florida International University, 2019 


\section{DEDICATION}

I would like to dedicate my thesis to my mom, Gloria Becerra.

My mother taught me the importance of education from very early on. Still, I did not exactly love school while growing up, so it was because of her perseverance that I always did fairly well. When I started my undergraduate degree, I remember feeling confused as to where I was headed and doubtful as to whether it would all even be worth it. Nonetheless, my mother always encouraged me to keep going and ultimately played an enormous role on the completion of my bachelor's degree. Apart from education, my mom always taught me to be the best person that I could be (in all aspects). Yet it wasn't what she said, it was what she did (and still does) that has taught me the most. Her dedication, honesty and loyalty in life in general, is what I admire the most and thus, what has motivated and molded me to be the person I am today. She is my role model. Additionally, the amount of love and support that my mother has given me throughout the entire 30 years of my life, is more than I could ever put into words. Not because she is my mom, but I truly believe that she is one of the most sincere, caring and loving persons on this planet, and I can barely believe that I am so fortunate as to be this awe-inspiring, incredible person's daughter. Nonetheless, it has been only in recent years that I have been able to truly understand the value of this emotional support. I am truly blessed to have and continue to receive so much love from a single person. It is all these variables that she put in place that have resulted in this achievement. I would not be who I am nor where I am today without her. Thank you mom, this accomplishment was possible because of you. I love you with all my heart. 


\section{ACKNOWLEDGMENTS}

First and foremost, I would like to thank my three advisors, Dr. Kateel Shetty, Dr. Krishnaswamy Jayachandran and Dr. Mahadev Bhat, for their continuous support throughout my graduate career. I would also like to give an additional thanks to Dr. Shetty for his consistent guidance and commitment every step of the way.

Next, I would like to thank Ben McLean III and Benny McLean for allowing me to take samples from their organic orchards (Uncle Matt's Organic orchard as well as Benny McLean's home orchard), and for so willingly and kindly answering all of my questions about the orchards. I would also like to thank Dr. Arasu for all of his help and advice concerning AlamarBlue and the microplate reader, as well as for allowing me to use the autoclave in his lab every time I needed it. I'd also like to thank Dr. Fagen for all the back and forth emails also regarding AlamarBlue, and the growth of L. crescens.

I would also like to thank a few USDA-ARS scientists at the U.S. Horticultural Research Laboratory in Fort Pierce. I'd like to thank Dr. Mark Hilf for his advice as well as for providing me with sweet orange seeds. Dr. Duan YongPing and Christina Latza for sending me CLas+ periwinkle as well as information regarding grafting periwinkle, including all the necessary materials and step-by-step procedures. Also, I want to thank Spencer Marshall for sending me the protocol for the BM-7 media and even providing me with a couple initial plates to begin maintaining L. crescens. Furthermore, I'd like to give a special thanks to Dr. Ed Stover, Dr. Joseph Krystel, and Jefferson Shaw for allowing me into their lab and assisting me with the leaf-disc assay, the psyllid homogenate assay, and with the statistical analysis for the results of each of these assays. During 4 consecutive, long days of lab work, Jeff patiently guided me every step of the way, and continued to 
help me with my never-ending questions even after I had returned to Miami; so, I would like to give him an extra special thanks.

Next, I'd like to thank all of the agroecology members. In particular, Maria Ayusco for helping me isolate endophytes for almost 17 hours straight on the first day, for helping me graft the periwinkle on more than one occasion, for taking literally hundreds of pictures of my endophytes, and for cutting what seemed like infinite amounts of parafilm throughout the entire year. Also, I want to thank Daniel Calzadilla and Jazmin Locke for helping water my periwinkle and citrus plants throughout the year. Thank you to Myles Covington for taking repeated readings of the microplate reader for me. I am also extremely grateful for all of students/ members in the agroecology lab: Eric Betancourt, Claudia Garcia, Ariel Freidenreich, Daphne Sugino, Saoli Chanda, Shagufta Gaffar, Mary Tiedeman, Jazmine Locke, Christina Brown, Ganesh Khadka, Nicholas Charles and Jordan Prats. The amount of support I have received from each and every one of them is beyond what any words can say. Also, a special thanks to Eric Betancourt for helping me with any and all lab equipment failures, for ordering countless supplies, helping with all travel documentation, and for everything else that he constantly does to ensure that everything always runs smoothly in our program. I also want to thank my family, in particular my mom and my step dad (Moises) for allowing me to move into their home during the first year of this journey in order to help me financially, and my husband for his patience and understanding throughout this entire process, including putting up with all kinds of bacteria and fungi in our refrigerator. Lastly, I would like to thank the United States Department of Agriculture for funding my project USDA-NIFA-HSI Grants Program 2016-38422-25549. 


\begin{abstract}
OF THE THESIS
EXPLORING THE POTENTIAL OF ENDOPHYTES AND MEDICINAL PLANTS AS SOURCES OF ANTIMICROBIALS TO CONTROL CITRUS GREENING
\end{abstract}

\author{
by \\ Jessica Dominguez \\ Florida International University, 2019 \\ Miami, Florida \\ Professor Kateel G. Shetty, Major Professor
}

Citrus greening is an economically disastrous bacterial disease that infects all species of citrus, and currently has no cure. It is caused by Candidatus Liberibacter asiaticus (CLas), an unculturable phloem-limited bacteria vectored by the sap-sucking insect Diaphorina citri. Citrus greening has spread to every citrus-producing county in Florida; thus, there is a crucial need to develop environmentally safe treatments to reduce or eliminate CLas. It was hypothesized that endophytic microorganisms isolated from survivor citrus trees would show antagonistic activity against CLas; also, that plant extracts with known antimicrobial properties could suppress CLas. Oregano, thyme and turmeric extracts in the concentration of $1 \%$ and cell-free culture supernatants of endophytic isolates B-25, B-9, B-24 and B-27 at a concentration of $10 \%$ were found to be highly potent inhibitors of CLas. These results provide strong impetus for further characterization of endophyte and plant extracts, and their potential application as disease management tools for citrus greening. 


\section{TABLE OF CONTENTS}

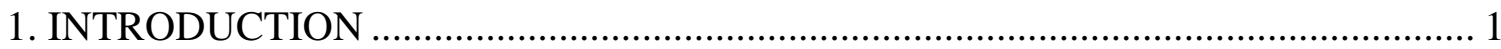

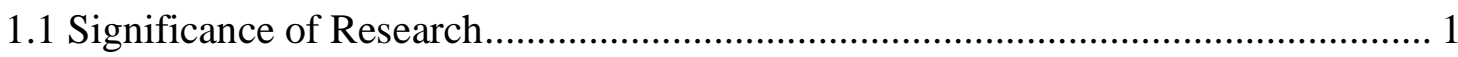

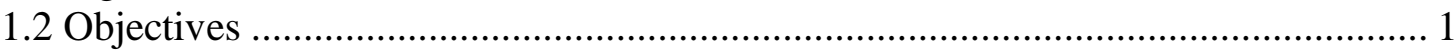

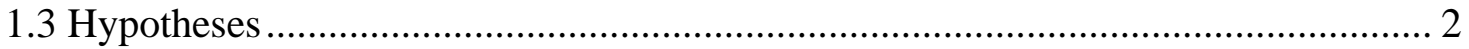

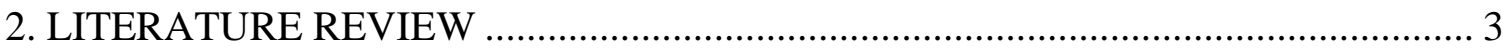

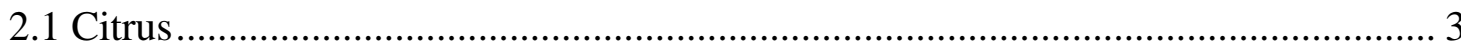

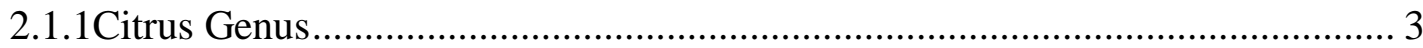

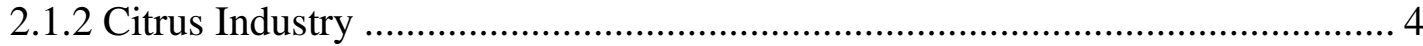

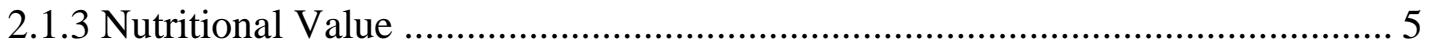

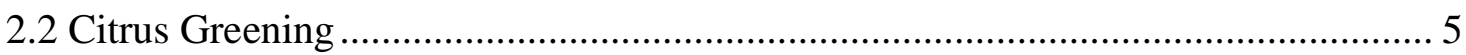

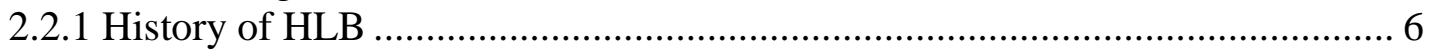

2.2.2 Arrival to the Western World .................................................................. 8

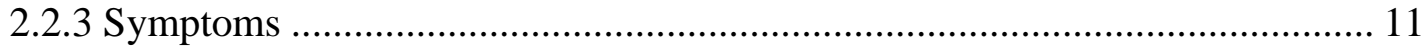

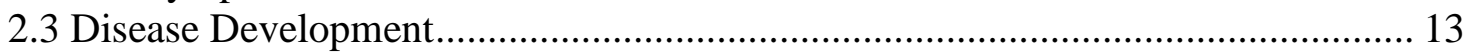

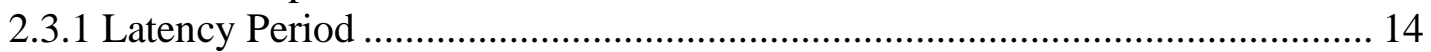

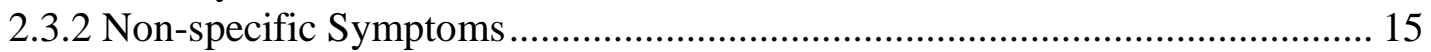

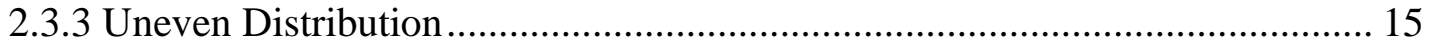

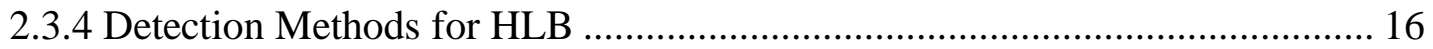

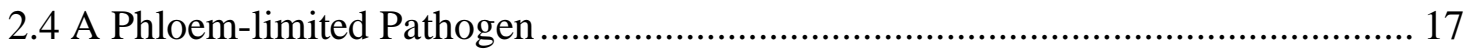

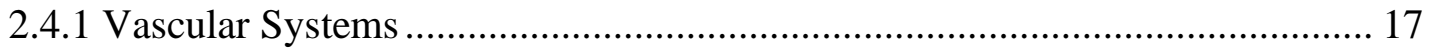

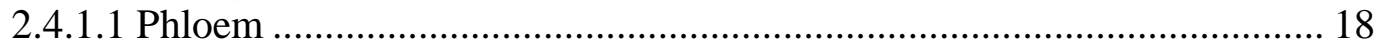

2.4.2 Genomic Adaptations ............................................................................. 19

2.4.3 Uncultured Bacteria ............................................................................. 20

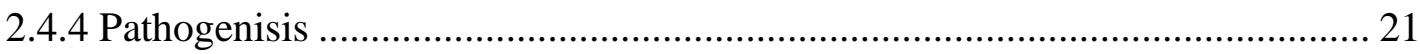

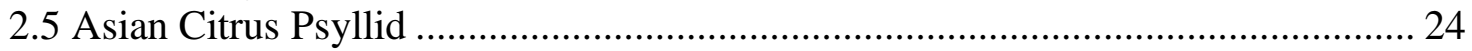

2.5.1 Primary Mode of Transmission …………………................................ 24

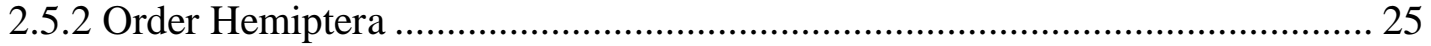

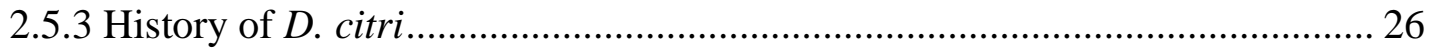

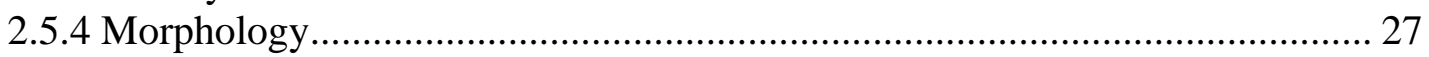

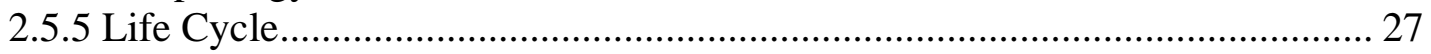

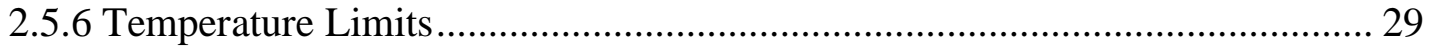

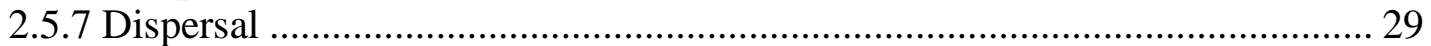

2.5.8 Transmission Pathway (between psyllids) ……………................................... 30

2.5.9 Location and Retention of CLas within D. citri .......................................... 30

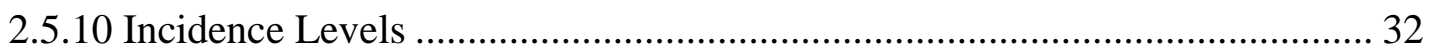

2.5.11 Transmission Efficiency ………………………................................ 32

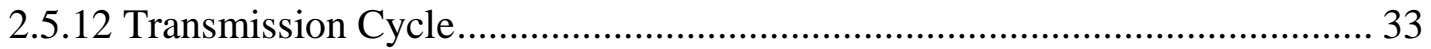

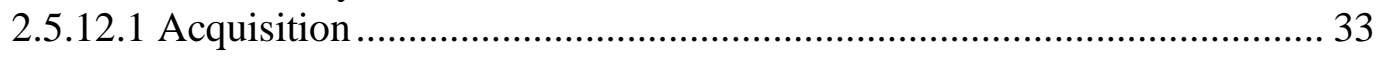




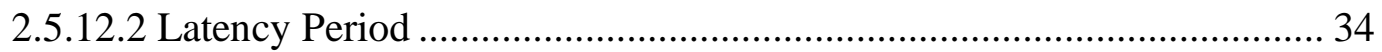

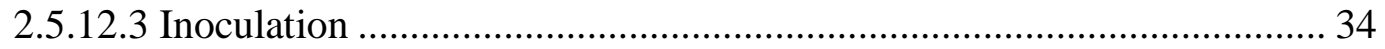

2.5.13 Relationship between D. citri and CLas .................................................. 35

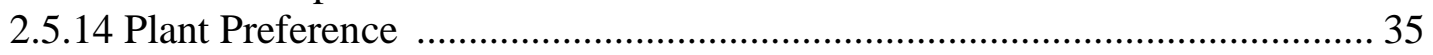

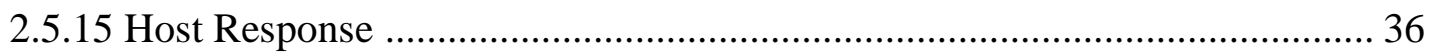

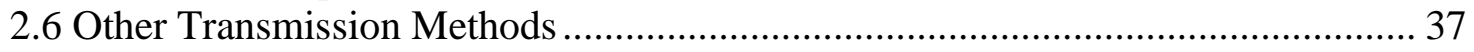

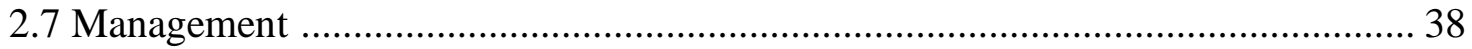

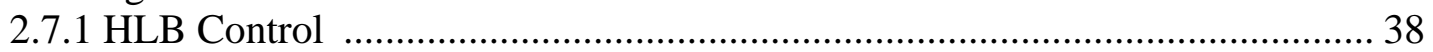

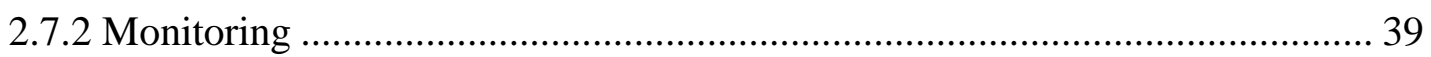

2.7.3 The Three-pronged Approach.................................................................. 40

2.8 Biological Control ................................................................................. 42

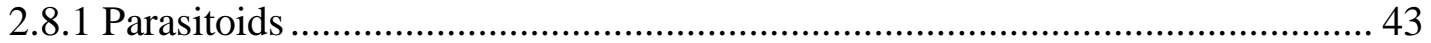

2.8.2 Natural Enemies .................................................................................. 44

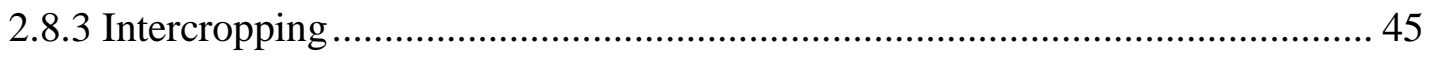

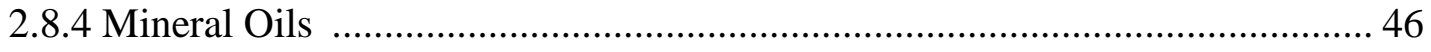

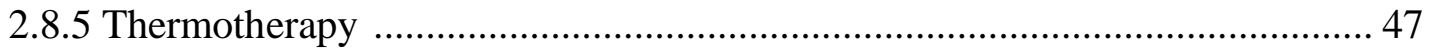

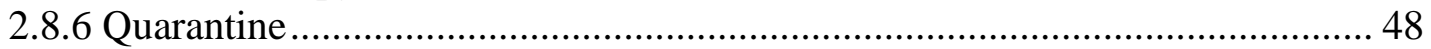

2.8.7 Enhanced Nutrient Program ......................................................................... 48

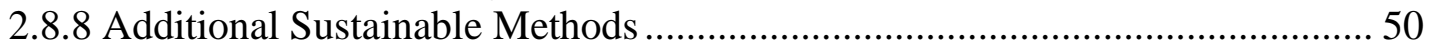

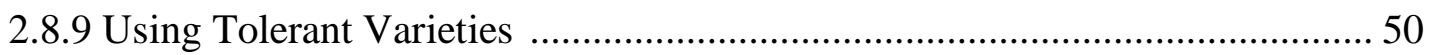

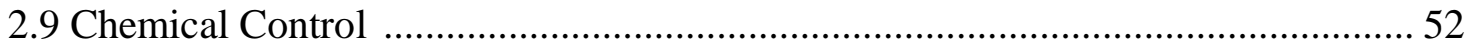

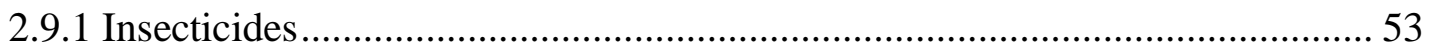

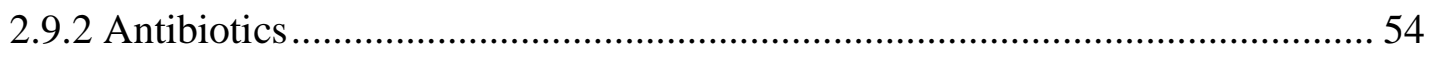

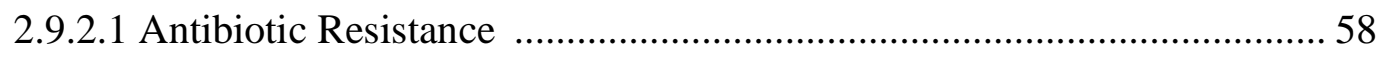

2.10 Antimicrobial Compounds Derived from Natural Sources .................................. 59

2.10.1 Plant Extracts with Known Antimicrobial Properties...................................... 61

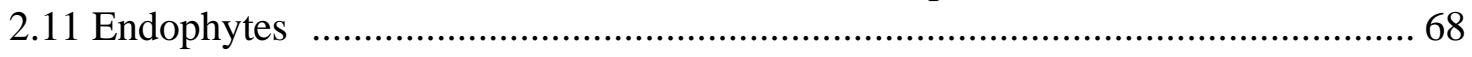

2.11.1 Antimicrobial Activity of Endophytes ....................................................... 70

2.11.2 Citrus Endophytes ................................................................................... 74

2.11.3 Benefits of Endophytes ........................................................................... 75

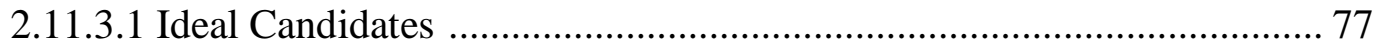

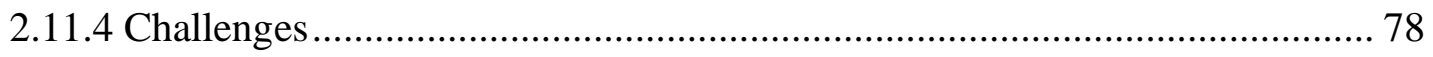

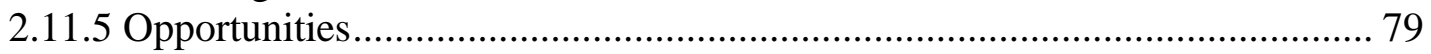

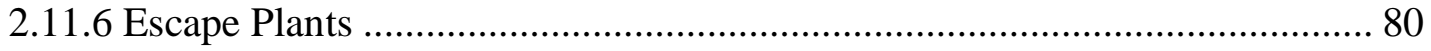

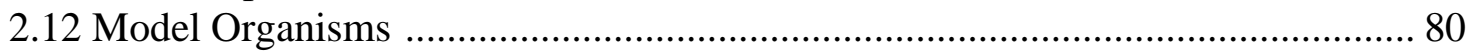

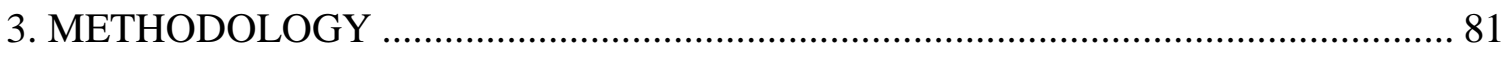

3.1 Bacterial Strains and Culture Conditions........................................................... 81

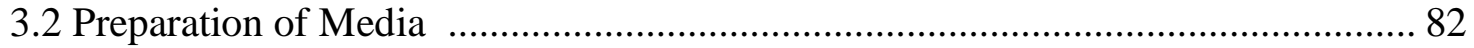

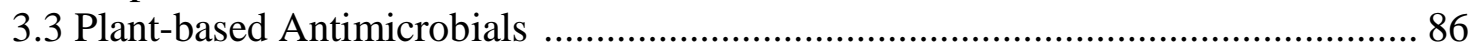

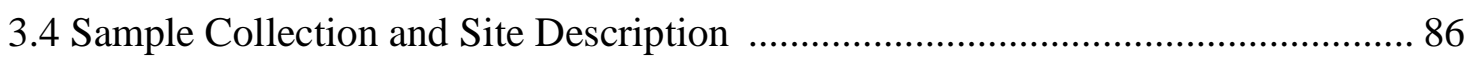

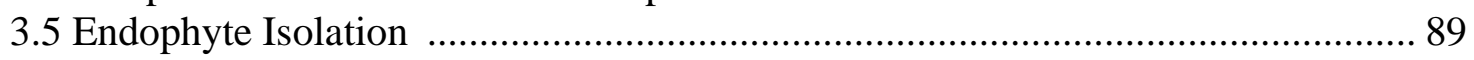

3.5.1 Pure Culture Isolations ………………………..................................... 90

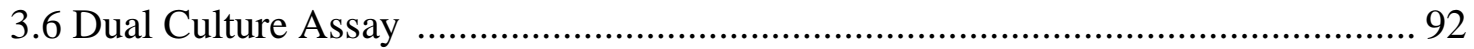

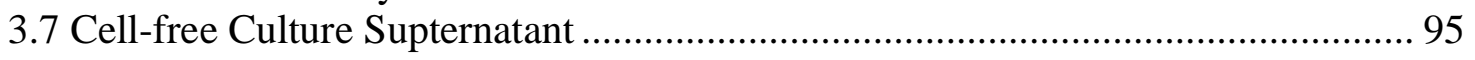




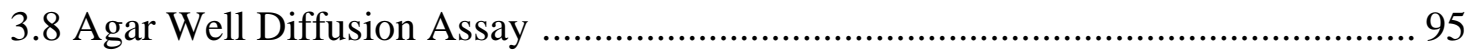

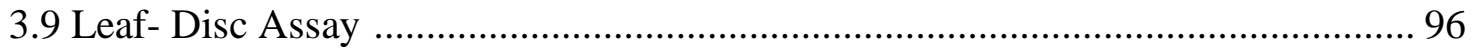

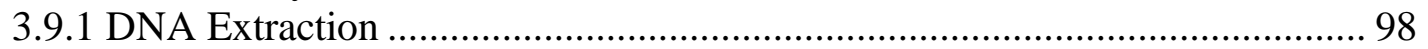

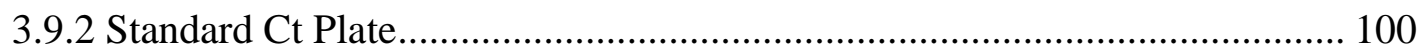

3.9.2 Statistical Analysis JMP Genomics ………………............................... 100

3.10 Psyllid Homogenate Assay .......................................................................... 100

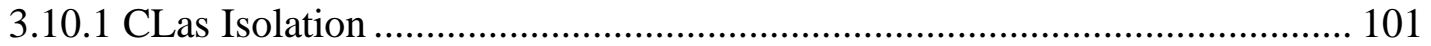

3.10.2 Isolation and PMAxx Treatment.............................................................. 102

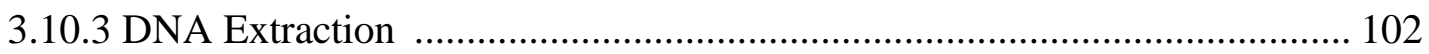

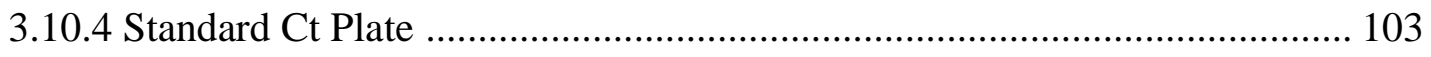

3.10.5 Statistical Analysis JMP Genomics ............................................................ 103

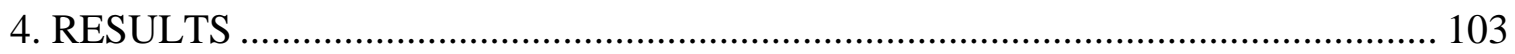

4.1 Endophyte Isolation .................................................................................... 103

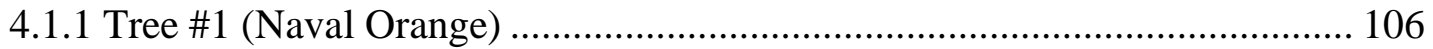

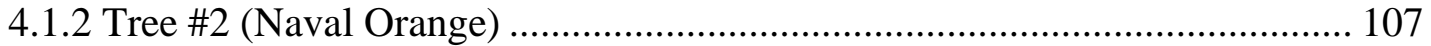

4.1.3 Tree \#3 (Naval Orange) ............................................................................. 109

4.1.4 Tree \#4 (Valencia Orange)............................................................................ 111

4.1.5 Tree \#5 (Blood Orange) ................................................................................ 113

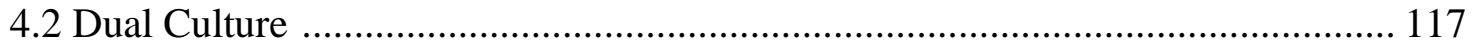

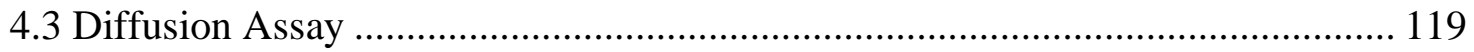

4.3.1 Bacterial Extracts ............................................................................ 119

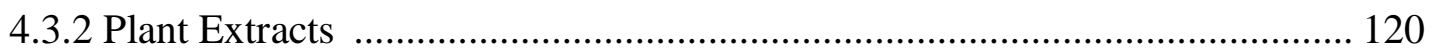

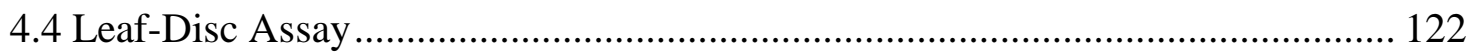

4.4.1 LL Ct Raw Data (each extract on each leaf-disc) ........................................ 122

4.4.2 CD Ct Raw Data (each extract on each leaf-disc) ....................................... 123

4.4.3 Average LL Ct Values for Bacterial Extracts ................................................. 124

4.4.4 Average LL Ct Values for Plant Extracts .................................................... 125

4.4.5 Average CD Ct Values for Bacterial Extracts ............................................. 126

4.4.6 Average CD Ct Values for Plant Extracts ................................................... 127

4.5 Psyllid Homogenate Assay ………........................................................... 128

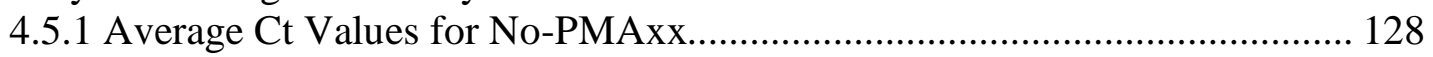

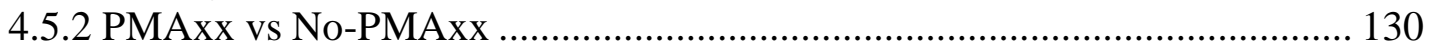

4.5.3 Live Cell Assays ................................................................................... 132

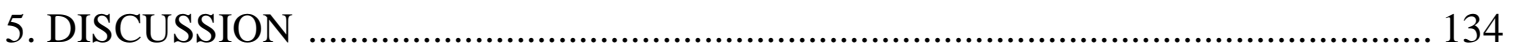

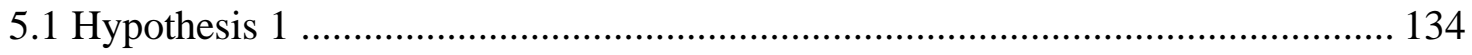

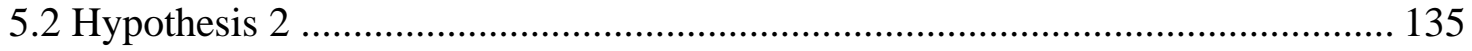

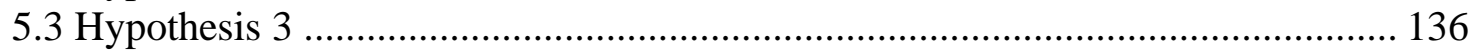

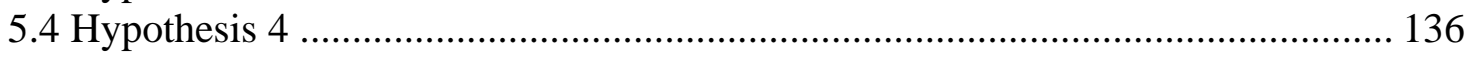

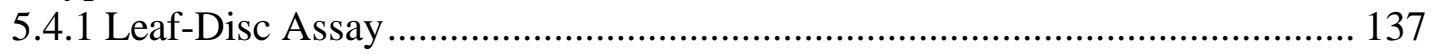

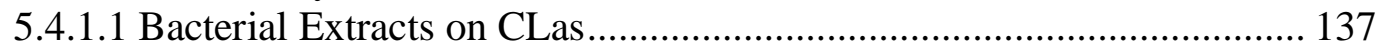

5.4.1.2 Bacterial Extracts on Citrus ................................................................... 137

5.4.1.3 Plant Extracts on CLas ................................................................... 138 


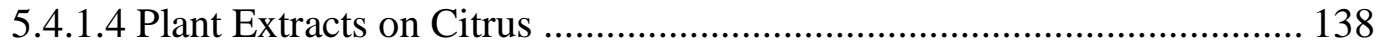

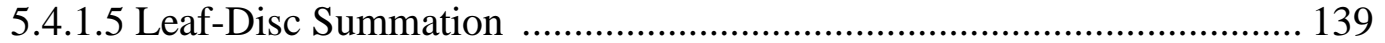

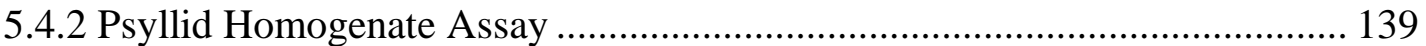

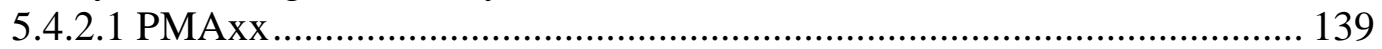

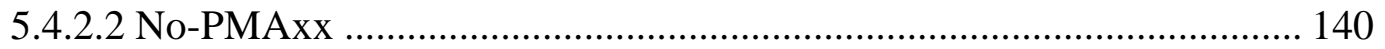

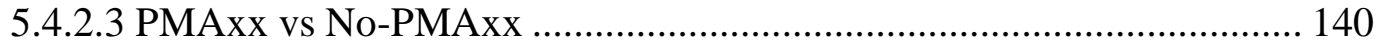

5.4.2.4 Live Cell Assay Plate 1 .................................................................... 141

5.4.2.5 Live Cell Assay Plate 2 ..................................................................... 142

5.4.2.6 Psyllid Homogenate Assay Summation ............................................ 142

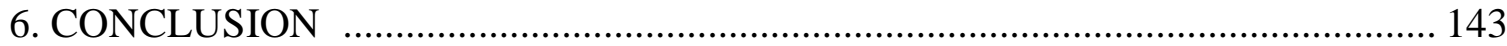

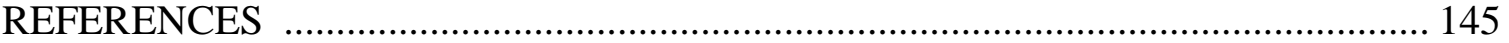




\section{LIST OF TABLES}

TABLE

PAGE

Table 1: The resposne of different citrus genotypes to grafting with buds from CLas+

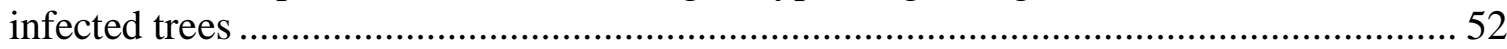

Table 2: List of some reported endophytes with antimicrobial activity ........................ 73

Table 3: Densitites of endohytic bacteria isolated from 8 citrus rootstocks .................... 75

Table 4: Colony morphology for all bacteria isolated from Tree \#1 ............................. 106

Table 5: Colony morphology for all fungi isolated from Tree \#1 .................................. 107

Table 6: Colony morphology for all bactera isolated from Tree \#2 ……...................... 108

Table 7: Colony morphology for all fungi isolated from Tree \#2 …………………..... 109

Table 8: Colony morphology for all bacteria isolated from Tere \#3 ……..................... 110

Table 9: Colony morphology for all fungi isolated from Tree \#3 …………………..... 111

Table 10: Colony morphology for all bacteria isolated from Tree \#4 ........................... 112

Table 11: Colony morphology for all fungi isolated from Tree \#4 ……….................... 113

Table 12: Colony morphology for all bacteria isolated Tree \#5 ..................................... 114

Table 13: Colony morphology for all fungi isolated from Tree \#5 ………………….... 115

Table 14: Successful inhibition of S. meliloti by dual culture ...................................... 118

Table 15: Inhibition zone of CFCS on $L$. crescens by diffusion assay .......................... 120

Table 16: The inhibition of $S$. meliloti and L. crescens from each plant extract............ 122

Table 17: LL Ct values for citrus cells after 48 hours of incuabtion in each extract...... 123

Table 18: CD Ct values for citrus cells after 48 hours of incubation in each extract ..... 124

Table 19: Data comparison between PMAxx and No-PMAxx samples on Plate 1....... 130

Table 20: Data comparison between PMAxx and No-PMAxx samples on Plate 2........ 132 


\section{LIST OF FIGURES}

Figure 1: Citrus Production - United States and Florida: Crop Years 1997-1998

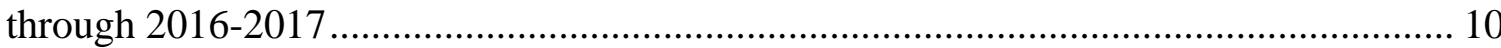

Figure 2: Characteristic symptom of HLB: blotchy mottled leaves ............................... 13

Figure 3: Adult Diaphorina citri feeding on the phloem of a citrus stem ........................ 25

Figure 4: Antimicrobials that have been tested against HLB infection in studies that incorporated quantification of the phytopathogen ……….............................................5 57

Figure 5: Uncle Matt's Organic Orchard (Satellite image of site 1) ……........................ 87

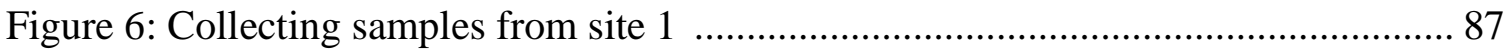

Figure 7: Uncle Matt's Organic Orchard (Satelite image of site 2) ................................ 88

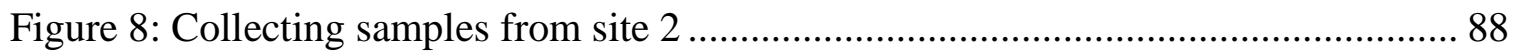

Figure 9: Preparation of 45 branch samples (from which endophytes were isolated) ..... 90

Figure 10: Endophyte Isolation Procedure: Grinding $5 \mathrm{~mm}$ segments in a sterile mortar and pestel with $1 \mathrm{~mL}$ of sterilized water ...................................................... 90

Figure 11: An example of how pure cultuers were isolated from orignal endophyte

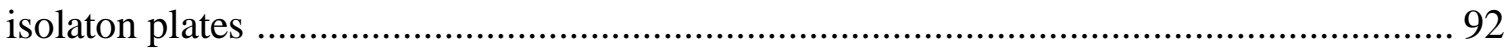

Figure 12: Dual culture preparation for bacterial endophytes ......................................... 93

Figure 13: Dual culture control plates: for fungi (left) and for bacteria (right) ............... 93

Figure 14: Dual culture preparation for fungal endophytes........................................... 94

Figure 15: Removing the supernatant from bacterial endophytes grwon in TSB ............ 95

Figure 16: Six mm diameter wells being punched out of agar for well diffusion assay... 96

Figure 17: ACP inoculated Rough Lemon leaves (21) …………………..................... 97

Figure 18: Leaf-disc 96-well plate set-up ...................................................................... 97 
Figure 19: Leaf-disc punched out of a CLas+ Rough Lemon leaf 98

Figure 20: All leaf-discs incubating in treatment, as well as the first and last leaf-discs of each leaf (no treatment) in Eppendorph tubes

Figure 21: Nanodrop spectrophotometer: used to quantify nucleic acids in prepartaion for qPCR

Figure 22: The isolation of CLas from infected psyllids

Figure 23: Plate 1 (left) and plate 2 (right) containing treatments with CLas cells exposed to PMAxx light 102

Figure 24: Examples of bacterial endophyte isolations 105

Figure 25: Examples of fungal endophyte isolations 105

Figure 26: Examples of how each dual culture result was categorized 118

Figure 27: Examples of inhibition zones on L. crescens caused by bacterial CFCS's.... 119

Figure 28: Diffusion assay example: The effect of cinnamon extracts on S. meliloti .... 120

Figure 29: Diffusion assay example 2: The effect of oregano on L. crescens $(100 \%$ inhibition)

Figure 30: Average LL Ct values after bacterial extract treatments, as compared to $0.5 \mathrm{mM}$ of streptomycin (positive control), TSB (control), and initial (no treatment). Bacterial extracts 6-10 are isolates B-25, B-9, B-17, B-24 and B-27, respectively. ...... 125

Figure 31: Average LL Ct values after plant extract treatments, as compared to $0.5 \mathrm{mM}$ of streptomycin (positive control), and initial (no treatment). Plant extracts 15 are oregano, alchorena, thyme, cinnamon, and turmeric, respectively. 126

Figure 32: Average CD Ct values after bacterial extract treatments, as compared to $0.5 \mathrm{mM}$ of streptomycin (positive control), TSB (control) and initial (no treatment). Bacterial extracts 6-10 are isolates B-25, B-9, B-17, B-24 and B-27, respectively.

Figure 33: Average CD Ct values after plant extract treatments as compared to $0.5 \mathrm{mM}$ streptomycin (positive control) and initial (no treatment). Plant extracts 1-5 are oregano, alchornea, thyme, cinnamon, and turmeric, respectively

Figure 34: Average Ct values for No-PMAxx on plate 1. Extracts 1-10 are oregano, alchornea, thyme, cinnamon, turmeric, B-25, B-9, B-17, B-24 and B-27, respectively. 
Figure 35: Average $\mathrm{Ct}$ values for No-PMAxx on plate 2. Extracts 1-10 are oregano, alchornea, thyme, cinnamon, turmeric, B-25, B-9, B-17, B-24 and B-27, respectively.

Figure 36: Changes in Ct value between PMAxx and No-PMAxx for each treatment on Plate 1. Extracts 1-10 are oregano, alchornea, thyme, cinnamon, turmeric, B-25, B-9, B-17, B-24 and B-27, respectively.

Figure 37: Changes in Ct value between PMAxx and No-PMAxx for each treatment on Plate 2. Extraccts 1-10 are oregano, alchornea thyme, cinnamon, turmeric, B-25, B-9, B-17, B-24 and B-27, respectively.

Figure 38: Ct values of live cells remaining after PMAxx treatment for Plate 1. Extracts 110 are oregano, alchornea, thyme, cinnamon, turmeric, B-25, B-9, B-17, B-24 and B-2, respectively. 133

Figure 39: Ct values of live cells remaining after PMAxx treatment for Plate 2. Extracts 110 are oregano, alchornea, thyme, cinnamon, turmeric, B-25, B-9, B-17, B-24 and B-27, respectively. 134 


\section{ABBREVIATIONS AND ACRONYMS}

\begin{tabular}{|c|c|}
\hline $\mathrm{ACP}$ & Asian citrus psyllid \\
\hline BLO & Bacterium-like organism \\
\hline $\mathrm{C}$ & Celsius \\
\hline C. albicans & Candida albicans \\
\hline $\mathrm{CD}$ & Citrus Dehydrogenase \\
\hline CFCS & Cell-Free Culture Supernatant \\
\hline CLas & Candidatus Liberibacter asiaticus \\
\hline CTV & Citrus tristeza virus \\
\hline CUPS & Citrus Undercover Production Systems \\
\hline CVC & Citrus Variegated Chlorosis \\
\hline D. citri & Diaphorina citri \\
\hline D. aligarhensis & Diaphorencyrtus aligarhensis \\
\hline DI & Deionized water \\
\hline DNA & Deoxyribonucleic acid \\
\hline DPE2 & DNA polymerase epsilon 2 \\
\hline DPI & Division of Plant Industry \\
\hline DSMZ & Deutsche Sammlung von Mikroorganismen und Zelkulturen \\
\hline ELISA & Enzyme-linked immunosorbent assay \\
\hline EMA & Ethidium mono-azide \\
\hline E. coli & Escherichia coli \\
\hline FIU & Florida International University \\
\hline FAO & Food and Agricultural Organization \\
\hline
\end{tabular}




\begin{tabular}{|c|c|}
\hline FBS & Fetal Bovine Serum \\
\hline FDACS & Florida Department of Agriculture and Consumer Services \\
\hline $\mathrm{g} / 1$ & Grams per liter \\
\hline H. pylori & Heliobacter pylori \\
\hline HLB & Huanglongbing \\
\hline HMO & Horticultural mineral oils \\
\hline L. africanus & Liberibacter africanus \\
\hline L. americanus & Liberibacter americanus \\
\hline L. asiaticus & Liberibacter asiaticus \\
\hline LL & Liberibacter asiaticus- Long \\
\hline mg g-1 & Milligrams per gram \\
\hline $\mathrm{ml}$ & Milliliter \\
\hline $\mathrm{mm}$ & Millimeter \\
\hline $\mathrm{mM}$ & Mili Molar \\
\hline MLO & Mycoplasma-like organism \\
\hline mol & Mole \\
\hline p-Value & Probability Value \\
\hline PCR & Polymerase chain reaction \\
\hline PDA & Potato Dextrose Agar \\
\hline PDB & Potato Dextrose Broth \\
\hline PMA & Propidium Monoazide \\
\hline PMAxx & A Biotium proprietary PMA formulation \\
\hline PPM & Parts Per Million \\
\hline
\end{tabular}




\begin{tabular}{|c|c|}
\hline PPU & Plasmodesmata pore units \\
\hline P. mirabilis & Proteus mirabilis \\
\hline P. vulgaris & Proteus vulgaris \\
\hline P. aeruginosa & Pseudomonas aeruginosa \\
\hline qPCR & Quantitative Polymerase Chain Reaction \\
\hline $\mathrm{R} 2 \mathrm{~A}$ & Reasoner's 2A agar \\
\hline S. aureus & Staphylococcus aureus \\
\hline S. enteritidis & Salmonella enteritidis \\
\hline S. flexnierii & Shigella flexnerii \\
\hline S. marcescens & Serratia marcescens \\
\hline S. meliloti & Sinorhizobium meliloti \\
\hline S. paratyphi & Salmonella paratyphi \\
\hline S. typhimurium & Salmonella typhimurium \\
\hline T. dryi & Tamaraxia dryi \\
\hline T. erytreae & Trioza erytreae \\
\hline TMN-FH & Hink's medium is a modification of Grace's formulation \\
\hline TSA & Trypticase Soy Agar \\
\hline TSB & Trypticase Soy Broth \\
\hline UNDP & United Nations Development Program \\
\hline USDA & United States Department of Agriculture \\
\hline$\mu g$ & Micrograms \\
\hline$\mu \mathrm{L}$ & Microliter \\
\hline$\mu \mathrm{m}$ & Micrometer \\
\hline VOC & Volatile organic compounds \\
\hline
\end{tabular}


YMA

Yeast Mannitol Agar

xviii 


\section{INTRODUCTION}

\subsection{Significance of Research}

Citrus greening, also known as Huanglongbing (HLB) is the most economically devastating disease of citrus worldwide. It is a very destructive disease that currently has no cure, and infects all species of citrus (Chung \& Brlansky, 2009). Huanglongbing is caused by a bacterial pathogen known as Candidatus Liberibacter asiaticus (CLas) (UkudaHosokawa et al., 2015). In just the state of Florida, citrus is a $\$ 10$ billion industry! It encompasses almost 4,000 citrus groves, more than 74 million trees, and about 437,000 acres of land (LeFevre, 2018). Huanglongbing was first detected in Florida in 2005, and has undoubtedly resulted in a steady decline of citrus production. That is, in the 2004-2005 crop year 13 million tons of citrus were produced in Florida, whereas in the 2017-2018 crop year, only 3.5 million tons were produced (Hudson, et al., 2018), reducing revenues by $\$ 4.54$ billion (LeFevre, 2018). Florida was once responsible for $68.7 \%$ of the total citrus production in the United States (Strategic planning, 2010); today, HLB is found present in all of its 34 citrus producing counties (Alvarez 2016 and Court \& Hodges, 2017). Moreover, since there is no known cure that can eradicate the bacteria, all current management practices involve heavy insecticidal use (to control its vector). Thus, the development of effective HLB prevention and/or treatment methods are urgently needed to alleviate the ongoing crisis of the citrus industry.

\subsection{Objectives}

1. Isolate and characterize endophytic microorganisms from surviving citrus trees

2. Assess the endophyte isolates for in vitro antagonistic activity against Sinorhizobium meliloti, (a proxy for CLas) using dual-culture technique 
3. Isolate the potential antimicrobial compounds by means of cell-free culture supernatant (CFCS) from endophytes demonstrating antagonistic activity

4. Assess the in vitro antimicrobial activity of the CFCS's against Liberibacter crescens (as a proxy for CLas) using the agar well diffusion assay

5. Assess the in vitro antimicrobial activity of the CFCS's against Liberibacter crescens (as a proxy for CLas) using the agar well diffusion assay

6. Assess the in vitro antimicrobial activity of selected plant extracts against Liberibacter crescens (as a proxy for CLas) using the agar well diffusion assay

7. Determine the in-planta control potential of selected CFCS's and plant extracts using leaf-disc assay and psyllid homogenate assay

\subsection{Hypotheses}

1. Endophytes isolated from survivor citrus trees are a valuable source of antimicrobials, capable of completely inhibiting (100\% inhibition) S. meliloti growth in vitro.

2. The CFCS of endophytes exhibiting antimicrobial properties against S. meliloti are equally capable of inhibiting the in vitro growth of L. crescens

3. Plant derived antimicrobials that inhibit the growth of $S$. meliloti are also capable of inhibiting the growth of L. crescens in vitro 
4. Antimicrobial agents (whether from endophytes or from plant extracts) that inhibit the growth of $L$. crescens in vitro, are also likely to show activity against the growth of CLas in planta and in vivo (inside psyllid).

\section{LITERATURE REVIEW}

\subsection{Citrus}

\subsubsection{Citrus Genus}

Citrus is a genus in the Rutaceae family (Liu, Heying, \& Tanumihardjo, 2012), which now includes dozens of species and hybrids. Plants in the citrus genus are perennial (Halbert \& Manjunath, 2004), flower-bearing, evergreen shrubs or small trees that produce citrus fruits. The fruits vary in shape (oblong, round, elongated) and size (3.8 to $25 \mathrm{~cm}$ in diameter) (Liu et al., 2012). Citrus plants normally grow in tropical and subtropical regions reaching latitudes of up to $40^{\circ} \mathrm{N}$ and $40^{\circ}$ South (Abdullah, Shokrollah, Sijam, Nor, \& Abdullah, 2009; Gottwald, 2010; Liu et al., 2012). This extensive range of viable habitat has resulted in the production of citrus in more than 140 countries around the world (Abdullah et al., 2009). Genetic analysis shows that most current citrus varieties are hybrids that came from just a few ancestral species, although the exact number of how many natural ancestral species remains unknown (Liu et al., 2012). The origin of citrus is full of controversy. Some believe citrus is native to Southeast Asia, possibly China, India, or Malay Archipelago while others believe it is native to Australia, New Caledonia and New Guinea (Gottwald, 2010; Liu et al., 2012). Still, the cultivation of citrus is thought to have begun in Southeast Asia approximately 4,000 years ago (Strategic Planning for the Florida Citrus Industry, 2010). Today, in terms of commercial production and global trade, citrus 
is one of the most important commodities in the world (Blaustein, Lorca, \& Teplitski, 2018).

\subsubsection{Citrus Industry}

Citrus ranks first place in fruit crop international trade value (Abdullah et al., 2012; Strategic Planning, 2010), and has the second highest production volume in the world (after banana and plantain) (Paudyal, 2015a). The world's largest citrus producers are Brazil, United States, Mexico, India, and China, producing 32\%, 14\%, 7\%, 6\%, and 5\%, respectively (Strategic Planning, 2010). Countries in the Mediterranean basin also contribute substantially to citrus production (almost $15 \%$ combined). Approximately $65 \%$ of the worlds citrus production is sweet orange, followed by tangerines $(21 \%)$, lemons $(6 \%)$, and grapefruit (5\%). Other commonly grown species are lime, pomelo, and citron (Abdullah et al., 2009).

Within the United States, all commercially produced citrus occurs in four states: Florida, California, Texas, and Arizona, producing 68.7\%, 27.5\%, 2.7\%, and 1.1\%, respectively. Additionally, virtually all the orange juice produced in the US comes from Florida: where about $84 \%$ of the production are sweet oranges, of which $95 \%$ is processed into juice (Strategic Planning, 2010). The citrus industry in Florida has been estimated to have a $\$ 9$ to $\$ 10$ billion economic impact for the state (Doud et al., 2017 and LeFevre, 2018). It is responsible for approximately 80,000 full-time equivalent jobs, who earn a combined annual wage of $\$ 2.7$ billion, which represents $1.5 \%$ of the state's wage income (Strategic Planning, 2010). 


\subsubsection{Nutritional Value}

Although citrus is most well-known for its high vitamin C content (Abdullah et al., 2009) it offers an array of nutrients beyond that. Citrus is rich in macronutrients such as simple sugars and dietary fiber, as well as many micronutrients including but not limited to folate, thiamin, niacin, vitamin B6, riboflavin, pantothenic acid, potassium, calcium, phosphorous, magnesium, and copper. Citrus also has phytochemicals such as carotenoids, flavonoids and limonoids, is low in fat, and is free of sodium and cholesterol. In fact, citrus has even been linked to a number of health benefits, including against cancer, osteoporosis, and cardiovascular disease (Liu et al., 2012).

\subsection{Citrus Greening}

Citrus greening, also known as huanglongbing (HLB) is the most destructive disease of citrus worldwide (Bové, 2006; Dewdney, Rogers, \& Brlansky, 2016; Duan et al., 2009; Gottwald, 2007; Nannapanenl et al., 2008; Nehela, Hijaz, Elzaawely, El-Zahaby, \& Killiny, 2018), and there is currently no cure (Doud et al., 2017; Grafton-Cardwell, Stelinski, \& Stansly, 2013) nor effective treatment for it. It is a bacterial disease that infects all species of citrus with no exceptions (Moffis, Burrow, Dewdney, \& Rogers, 2016). Huanglongbing disease is caused by three Candidatus Liberibacter species: Liberibacter asiaticus (L.asiaticus), Liberibacter africanus (L.africanus), and Liberibacter americanus (L. americanus) (Abdullah et al., 2012, 2009; Bové, 2006). The term is used for bacteria that cannot be cultured (Halbert \& Manjunath, 2004), and the Liberibacter genus is a pathogenic genus that threatens several economically important crops (Fagen et al., 2014; Wang et al., 2017) such as Liberibacter solanacearum, which causes zebra chip disease (Duan et al., 2009) to tomato and potato crops (Nakabachi et al., 2013). 
Liberibacter asiaticus (CLas), L. africanus and L. americanus are the three known casual agents of HLB. However, CLas and L. africanus are widespread and have been long identified, while L. americanus was only first discovered in 2004. The HLB causing agent found in Brazil in 2004 was originally thought to be a mutation of CLas, but after genetic analysis, major differences in 16sDNA confirmed the presence of a new species: $L$. americanus. As for CLas and L. africanus, they are believed to have originated in Asia and Africa respectively (Bové, 2006). Apart from their distinctions in genomic sequencing (Wang et al., 2017), these species can also be distinguished by their temperature sensitivity. Liberibacter africanus is heat sensitive and is only found in cool areas with temperatures below $30^{\circ} \mathrm{C}$, while CLas is heat tolerant, thriving in temperatures well above $30^{\circ} \mathrm{C}$ (Bové, 2006; Chung \& Brlansky, 2009). Correspondingly, L. africanus is usually found at elevations above 700m while CLas is found in much lower elevations (Gottwald, 2007). Given that most citrus production lies in warm areas (near the equator) it is not surprising that CLas is the most widespread of the three HLB pathogens (Johnson, Wu, Bright, \& Graham, 2014). Furthermore, although these Liberibacter species cause similar initial symptoms to their host plant (Fletcher \& Wayadanda, 2002; Wang et al., 2017), CLas causes the most severe symptoms, which may ultimately results in the death of the tree (Gottwald, 2007; Graca, 1991). Subsequently, CLas is the most studied of all the Liberibacter pathogens (Tamborindeguy, Huot, Ibanez, \& Levy, 2017), and thus, is the species of focus for the present thesis.

\subsubsection{History of HLB}

There are many theories about the origin of HLB. Some agree that the earliest reports of HLB-like symptoms came from India in the 1700's, where they called the disease 
"dieback" and believed that the death of the citrus was caused directly by the psyllids (Gottwald, 2010). Others believe that HLB actually originated in China in the early 1900's (Bové, 2006; Duan et al., 2009; Graca, 1991). Yet others have more recently proposed that it may have originated in Africa, presumably in an asymptomatic host, such as Verpris lanceolate, and was later on transmitted to citrus (Paudyal, 2015a). The Chinese were the first to name the disease which had symptoms similar to those we see today. They called it "huanglongbing" (HLB), which has been translated in English to "yellow dragon disease" (Bové, 2006) or "yellow shoot disease" (Gottwald, 2010) because of the primary symptomatic characteristic of yellow shoots that are caused by the disease (Halbert \& Manjunath, 2004).

By the 1920s citrus diseases with the same symptoms were beginning to appear throughout Asia (Gottwald, 2007) and by 1935 HLB had become a serious problem in China (Bové, 2006; Graca, 1991). In 1956, the Liberibacter species was successfully transferred through grafting (LIN, 1956), which put an end to the beliefs that HLB was caused by mineral deficiencies, water logging, or the psyllid itself (Gottwald, 2007). It then became accepted that HLB was caused by a mycoplasma-like organism (MLO) (Bové, 2006), which is a bacterium that infects plants and that lacks a cell wall; today we call these phytoplasmas (Strategic Planning, 2010). However, Jagoueix, Bove, \& Garnier, (1994) showed that HLB was caused by a gram-negative, walled bacterium-like organism (BLO) rather than an MLO. The 16S rDNAs of the BLOs were sequenced and compared (using GenBank data), and it was found that CLas belonged to an alpha subdivision of proteobacteria. However, it shared only $87.5 \%$ homology with its closest relative, which was in the alpha-2 subgroup. This was not enough for CLas to be placed in the same 
subgroup; thus, CLas was put into a new lineage of the $\alpha$ subdivision of proteobacteria (Jagoueix et al., 1994), a subdivision which includes several plant and human pathogens (Bové, 2006).

Jagoueix et al. (1994) also proposed a new name "liberobacter" for this new group of bacteria. The word "Liberobacter" came from the Latin word liber meaning bark, and bacter meaning bacterial (Jagoueix et al., 1994). However, in 2000, (Garnier, JagoueixEveillard, Cronje, Le Roux, \& Bové, 2000), changed the name from Liberobacter to Liberibacter because according to the International Code of Nomenclature of Bacteria, the connecting vowel from "bacter" to "Liber" should have been an "i" and not an "o". Duan et al. (2009) successfully extracted DNA from an infected psyllid and completed the first genome sequence of the uncultured pathogen. Finally, it was confirmed that the HLB causing pathogen was indeed a bacterium (Duan et al., 2009). Today we know that CLas (as all Liberibacter species) is a gram-negative (Bové, 2006), endogenous, phloem-limited bacterium (Martinelli \& Dandekar, 2017) in the Rhizobiaceae family (Duan et al., 2009).

Huanglongbing infects all species of citrus (Moffis et al., 2016), though the level of susceptibility varies (Blaustein et al., 2018). These bacteria can infect most species in the Rutaceae family, though they do not necessarily cause disease in all of them (Duan et al., 2009). Furthermore, CLas has also been found to be able to infect other non-rutaceae families (Moffis et al., 2016), including species such as periwinkle (Catharan roseus) and dodder (Cuscuta campestris) (Zhang et al., 2010).

\subsubsection{Arrival to the Western World}

In 2004 the first report of HLB appeared in the Americas, specifically Sao Paulo, Brazil, which is the largest citrus producing state in Brazil (Bové, 2006; Gottwald, 2010; 
Grafton-Cardwell et al., 2013; Paudyal, 2015). One year later, in August 2005, the first detection of HLB was found in Florida (Miami) (Hall, 2018; Zhang et al., 2011, 2014). Thus, in one year the two leading citrus producing countries had become infected and caused huge economic losses within five years of detection (Paudyal, 2015a).

Ever since, Florida's citrus production has been in a steady decline (Hudson, 2018), producing 13 million tons of citrus (excluding lemons) in the 2003 - 2004 crop year and only 3.5 million tons in the 2016 - 2017 crop year Figure 1 (Florida Department of Agriculture and Consumer Services, 2018). By 2016 more than $80 \%$ of citrus trees in Florida were infected (Hu \& Wang, 2016). Citrus acreage has now decreased by $40 \%$ (Alvarez, Rohrig, Solís, \& Thomas, 2016), and production by more than $70 \%$. Huanglongbing is now present in all 34 citrus producing counties in Florida (Alvarez et al., 2016; Court \& Hodges, 2017; Spreen, 2013; Strategic Planning, 2010; Zhang et al., 2011) and has been estimated that the economic damage caused to Florida by HLB accounts for $\$ 10$ billion dollars per year (Munir et al., 2018). Moreover, employment rates in the Florida citrus industry have also suffered, declining by 40\% (75,828 to 45,422) between 2007 and 2016 (Court \& Hodges, 2017). 


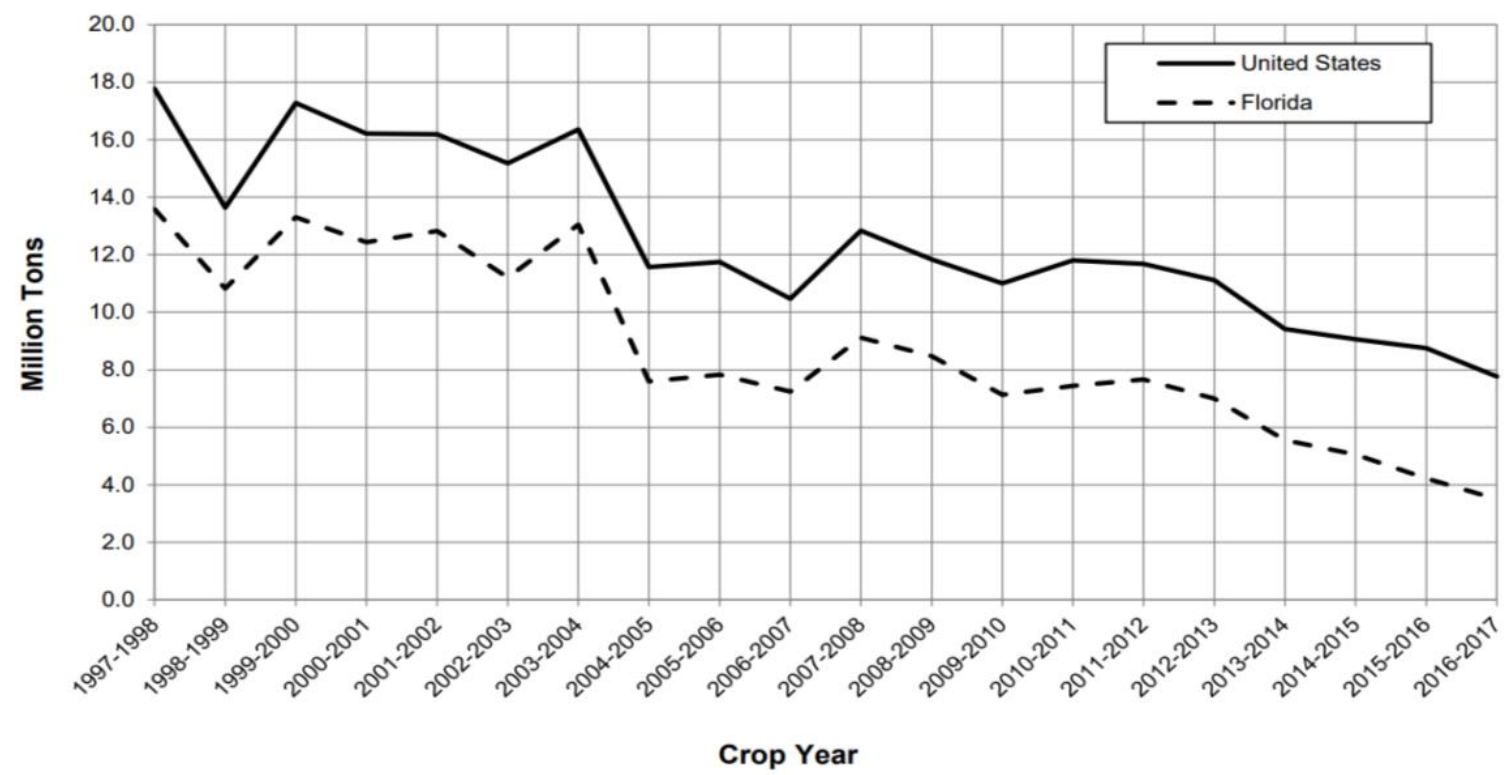

Figure 1: Citrus Production - United States and Florida: Crop Years 1997-1998 through 2016 - 2017.

The incidence levels of HLB in Florida are higher than ever before. Growers have reported that more than $90 \%$ of the acres and more than $80 \%$ of their trees are infected with HLB (Alvarez et al., 2016). Still, it is often difficult to convince farmers to take part in HLB management programs because the first recommended management practice is to eliminate diseased trees (Paudyal, 2015a). It takes a long time to recover the costs of planting and caring for the trees until they produce revenue high enough to cover the cost. In fact, it has been estimated that it takes about 10 years before a grower begins to receive profit from citrus production (Halbert \& Manjunath, 2004; Paudyal, 2015; Roistacher, 1996). Some additional costs growers may encounter while producing infected citrus trees, are: the decline yield and fruit quality of trees, infection detection surveys, insecticides for psyllid control, removing affected trees, increased cost of production for a disease-free nursery, the cost of replacement trees, care of replanting, and loss of production until the new plant begins bearing fruit (National Research Council (U.S.): Addressing Citrus Greening Disease (Huanglongbing), 2010). 
In 2012, HLB was detected in the two second highest producing States in the United States: California and Texas. Threating virtually all the citrus production in the US (Doud et al., 2017; Ramsey et al., 2017). However, in states other than Florida HLB is contained (not controlled) and has not yet caused significant damage (Alvarez et al., 2016), though it is likely that with time, they will have consequences similar to those in Florida (Blaustein et al., 2018). Today HLB is present in all major citrus producing countries worldwide, with the exception of the Mediterranean region and Australia (Croxton \& Stansly, 2014), who have implemented quarantine measures to keep HLB from coming near their citrus producing areas (Wang et al., 2017).

\subsubsection{Symptoms}

Citrus plants may show a variety of symptoms as a result of being infected with HLB. One of the primary characteristic symptoms is blotchy mottle leaves (Bové, 2006; Chung \& Brlansky, 2009; Martinelli \& Dandekar, 2017; Zhang, Powell, Guo, Doud, \& Duan, 2012), which are leaves that appear to have patterns of asymmetrical yellow blotches. In time, these blotches turn entire leaves yellow (Zhang et al., 2012), and are followed by yellow shoot development (Bové, 2006). Eventually the yellowing spreads throughout the entire tree (Chung \& Brlansky, 2009). Leaves may also become thicker with enlarged veins and have a corky appearance (Gottwald, 2007).

Characteristic symptoms of the fruit include smaller and lopsided growth, with a bent fruit axis (Folimonova, Robertson, Garnsey, Gowda, \& Dawson, 2009). Fruit color may be weakened or lightened (greening). Fruits also exhibit color inversion, which means that as they change color, they do so in the opposite direction than a healthy fruit. An uninfected fruit begins to change color at the stylar end (not-connected end) and works its 
way in towards the peduncular end (connected end), but an HLB infected fruit colors from the peduncular end towards the stylar end. Furthermore, when the fruit is cut open, you can see small brown/black aborted seeds, as well as discoloration (brown/orange) of the vascular bundles (Bové, 2006). The fruits may also appear mottled, and if the peel is pushed down with the finger, a silvering spot where the finger was placed will be seen. As disease severity increases, fruit quality degrades and yield decreases (Gottwald, 2007).

Other symptoms may include off-season blooms, premature defoliation and twig dieback (Martinelli \& Dandekar, 2017), low rate of vegetative growth, decreased dry matter, root dry matter, plant height and stem diameter (Shokrollah, Abdullah, Sijam, \& Abdullah, 2011), weakened root systems and ultimately death of the entire plant (Hu \& Wang, 2016). As the disease progresses the yield and quality of fruit decrease accordingly (Zhang et al., 2012) resulting in poor juice quality (Chung \& Brlansky, 2009; Fagen et al., 2014; Folimonova et al., 2009) which merits low or no economic value (Spreen, 2013). Correspondingly, consumer surveys on the overall acceptability of flavor, have shown that juice from HLB affected fruit was always significantly less acceptable $(\mathrm{P}<0.05)$ that that of healthy fruit (Paudyal, 2015a). In fact, one study characterized and compared the flavor components of orange juice between HLB-infected juice and control (uninfected) juice, and found that the HLB-infected juice had higher concentrations of acids and lower concentrations of sugars, and suggested that this was the reason for the consistent reports of the "off-flavor" taste produced from HLB-infected juice (Dagulo et al., 2010). Similarly, other studies have also found that HLB caused changes in the amino acids, sugars and other metabolites including the bitter compound limonin (Tamborindeguy et al., 2017). 
Symptom severity seems to be affected by temperature, being more noticeable during cooler winter months and less so during hotter summer months (Hall, 2018). Severely infected HLB trees may become non-productive within just two (Bové, 2006) to three (Chung \& Brlansky, 2009) years. However, HLB infected trees are said to survive from about five to eight years (Stokstad, 2006), and no longer than ten years (Bové, 2006).

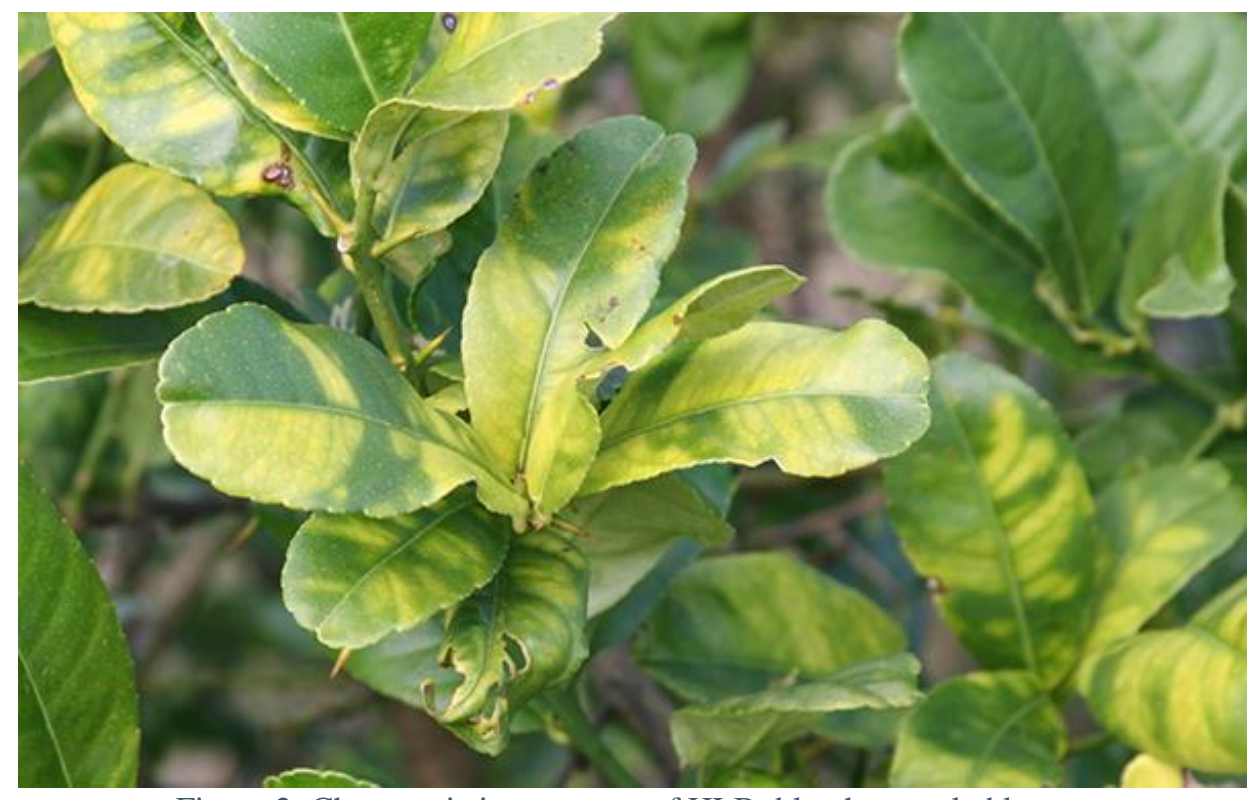

Figure 2: Characteristic symptom of HLB: blotchy mottled leaves http://www.mckeany-flavell.com/huanglongbing-citrus-greening-disease-psyllid-08-17-18/

\subsection{Disease Development}

Latency period, symptoms developed, and the severity of the disease are all depend on a number of factors such as: the age and health of the tree at the time of infection, the number of infections on the tree, local vector populations, extent of inoculum reservoir, and several environmental conditions (Gottwald, 2010). Additionally, the slow development of the disease along with its variety of symptoms makes detection of HLB particularly challenging (Bendix \& Lewis, 2018). 


\subsubsection{Latency Period}

The symptoms of HLB have a long latency period, which is the time gap between infection and the first symptom (also known as incubation period). The latency period provides ample time for the pathogen to spread throughout the tree prior to detection; thus the reason it is almost impossible to detect the emergence of the disease in a new area by means of visual cues (Grafton-Cardwell et al., 2013). In most cases, by the time the disease is discovered the bacterium is already widespread (Spreen, 2013; Stokstad, 2006), the roots are severely damaged (Moffis et al., 2016), and it is no longer possible to control or eradicate CLas (Gottwald, 2010). In fact, up until 2010, all HLB cases were too severe at the time of detection, for eradication (Gottwald, 2010); prime examples of this are the HLB outbreaks that occurred in both Brazil and Florida. In both cases, by the time HLB was discovered (somewhere between five and ten years after the pathogen had been introduced), it was already widespread and was too late to take action (Manjunath, Halbert, Ramadugu, Webb, \& Lee, 2008). In fact, HLB has not been eradicated from any region where infection has been reported (Zhang et al., 2011).

The latency period may also vary significantly depending on tree age, since tree age is a critical factor in both disease development and symptom development (Strategic planning, 2010). On average, established orchards (7 to 10 years old) have latency periods

of about one to two and one-half years, while younger orchards have a latency period of about six to 12 months (Gottwald, 2010). Moreover, visible symptoms of HLB have been seen as early as six months after inoculation on young trees (less than three years) (Johnson et al., 2014; Wang et al., 2017), whereas older HLB-infected trees can have no visual symptoms for up to five years (Gottwald, 2010). 
Furthermore, even trees that are the same age experience some variability in the latency period, which makes it that much harder to use visual symptoms to monitor HLB even on young trees (Gottwald, 2010). Additionally, when a young tree becomes infected with HLB, it will never produce a commercial crop of fruit. On the other hand, the disease progression of an older tree is largely dependent on the number of infections it has (Strategic planning, 2010).

\subsubsection{Non-specific Symptoms}

In addition to the latency period, it is difficult to diagnose HLB by simple observation because HLB has several symptoms that resemble that of other diseases (Bové, 2006). The HLB symptoms are often easily confused with that of other diseases (Gottwald, 2007) such as citrus tristeza virus (CTV), phytophthora infection, and/or citrus blight (Shokrollah et al., 2011). Trees that are highly infected also appear to have zinc-like (or manganese) deficiency symptoms (Chung \& Brlansky, 2009; Halbert \& Manjunath, 2004). In fact, it has been estimated that when nursery inspectors rely on visual cues, they overlook about $15 \%-20 \%$ of infected plants (Halbert \& Manjunath, 2004), whether the severity of symptoms is directly correlated with severity of disease is controversial, as it has been stated that severity of symptoms do not necessarily

represent the true severity of the disease (Johnson et al., 2014), as well as the opposite, that leaves with more mottle have higher bacterial titer than those with mild mottle symptoms (Bové, 2006).

\subsubsection{Uneven Distribution}

The distribution of CLas within the phloem is not uniform. The bacteria are distributed unevenly and have been found to aggregate in patches. The highest bacterial 
titers are said to be found in petioles (Martinelli \& Dandekar, 2017), leaf midribs, and stems (Munir et al., 2018). Nonetheless, CLas have been found (at highly variable densities) in all plant tissues, such as: leaf veins, petioles, bark, roots, and even fruit peel (Martinelli \& Dandekar, 2017). Significant variations of bacterial titer are commonly found in different samples of the same tree, to the extent that both positive and negative samples are given from a single tree. Thus, current methods for determining bacterial densities can give false negatives (Gottwald, 2010). Limitations in the detection of HLB are thought to be caused by low titers (Duan et al., 2009) or uneven distribution (Folimonova et al., 2009; Gottwald, 2010; Grafton-Cardwell et al., 2013) of the L. asiaticus within the plant (Manjunath et al., 2008). In many cases, PCR does not detect bacterial titers for several weeks or even months after being infected (Tamborindeguy et al., 2017). While false negative readings are caused by bacterial titers that are lower than the PCR threshold, it is most probable that those same bacterial titers are enough for ACPs to acquire and transmit the bacteria (spread the infection) (Gottwald, 2010).

\subsubsection{Detection Methods for HLB}

Historical methods used to detect HLB were visual symptoms and biological indexing (Manjunath et al., 2008), both of which yield variable results (Paudyal, 2015a). Later, thin layer chromatography was used through the use of a compound (gentisoyl-betaglucoside) that HLB infected plants produce (Gottwald, 2007) as well as in a UV light test (compound glows violet under UV light) ( Halbert, \& Manjunath, 2004). With time, more advanced methods were developed, such as electron microscopy (Shokrollah et al., 2011), DNA hybridization (Gottwald, 2007) and enzyme-linked immunosorbent assay (ELISA) (Manjunath et al., 2008). Eventually spectroscopy gained popularity, as it was a more 
efficient (about 92\% in one study) and cost-effective alternative at detecting HLB; thus, it began being widely used for the detection of HLB in Florida (Paudyal, 2015a). The most common method used today is now PCR (polymerase chain reaction) (Gottwald, 2007), which primarily uses the 16s ribosomal DNA sequence (Manjunath et al., 2008). Even more recently, an even more promising method was developed which is said to quantify viable bacterial cells (using ethidium mono-azide, EMA) and qPCR that differentiates between live and dead cells (Pankaj Trivedi, Spann, \& Wang, 2011). Most studies use culture-independent techniques that use PCR and qPCR to detect and quantify CLas (Ukuda-Hosokawa et al., 2015). Nonetheless, some diagnostics are currently done though the Iodine test, which is a fast, affordable, and simple field diagnostic that can be used to prescreen samples; they have even shown up to $90 \%$ agreement with PCR analysis (Paudyal, 2015a).

\subsection{A Phloem-limited Pathogen}

\subsubsection{Vascular Systems}

A plants vascular system is composed of the xylem and phloem, both of which are essential to the plants survival. In fact, pathogens that infect plant vascular systems are said to be of the most destructive because they can disrupt these transport systems to the point where nutrients and/or water can no longer be delivered effectively (Vinatzer, 2012), many times resulting in death of the plant. The xylem is generally poor in nutrients and contains mostly water and minerals (Fatima \& Senthil-Kumar, 2015). It is composed of dead plant cells, its fluids are transported in a single direction (from roots to leaves), and its pathogens can usually also adapt to environments outside of the xylem (Vinatzer, 2012). 


\subsubsection{Phloem}

Liberibacter species are found in the phloem of their host plant (Bové, 2006). The phloem is composed of living interconnected plant cells, is microaerophilic and seems to be a niche for many plant pathogens (Bendix \& Lewis, 2018). One phloem's function is to transport sugars that are manufactured during photosynthesis (photosynthates) to other parts of the plant which are in need of those sugars to fuel metabolism (Vinatzer, 2012). This movement is called translocation, and normally moves sugars from sources to sinks. Sources are areas where sugars are produced and thus, are usually leaves. Sinks are areas where sugars are delivered, and may include parts such as roots, tubers, (Fatima \& SenthilKumar, 2015) fruits, flowers, and young leaves and shoots (Fan, Chen, Brlansky, Gmitter, \& Li, 2010). Nonetheless, under certain conditions, sugars may also be stored in places such as the fruit and roots. During this time, these organs (fruits and/or roots) will become the source while the leaves will become the sink (Johnson et al., 2014). Furthermore, sources tend to send their sugars to nearby sinks: for example, leaves located toward the top will send their sugars higher towards new growing shoot tips, while leaves closer to the ground will send their sugars towards the roots. For these reasons, the flow of the phloem, and hence that of the Liberibacter pathogens, can be described as multidirectional. Accordingly, CLas can be found in any and all plant tissues (within the phloem) (Riera, Handique, Zhang, Dewdney, \& Wang, 2017b).

The end product of photosynthetic carbon is usually sucrose, and thus is normally the dominate carbohydrate transported throughout the phloem from sources to sinks (Fan et al., 2010). Apart from sugars, the phloem also contains organic acids, amino acids, sugar alcohols and several minerals (Fatima \& Senthil-Kumar, 2015). The phloem is found in all 
tissues of a plant, which means that phloem-residential bacteria can also travel to any and all plant tissues (Johnson et al., 2014). Furthermore, sugar concentrations in the phloem may vary significantly depending on a variety of factors such as: the species, which tissue, time of day, and season. These changes in sap composition cause changes in osmotic pressure. Thus, phloem pathogens, such as CLas, must constantly respond to these osmotic pressure changes (Pagliai et al., 2014).

Liberibacter species are phloem-limited, residing specifically in the sieve tubes (Abdullah et al., 2009; Bové, 2006) and are thus, intracellular pathogens (Duan et al., 2009; Vinatzer, 2012); this corresponds with that of most other plant pathogenic bacterium, who are almost always intracellular (Fletcher \& Wayadanda, 2002). It is thought that these pathogens use the exogenous carbon sources as their energy source (Bendix \& Lewis, 2018). The phloem provides favorable conditions for pathogens to grow and reproduce easily (Fatima \& Senthil-Kumar, 2015). It is extremely rich in nutrients and its pathogens are so adapted to this environment that they can no longer survive freely outside the cellular environment (Vinatzer, 2012). Thus, most phloem-limited bacteria are unable to be cultured in vitro (Bendix \& Lewis, 2018).

\subsubsection{Genomic Adaptations}

All known phloem-limited pathogens lack necessary genes for core metabolic processes, which is thought to be an adaptation to the unique environment of the phloem (Bendix \& Lewis, 2018). The CLas bacterium is no exception. Genetic sequencing has shown that the CLas genome is small in comparison to most bacterial plant pathogens, and also lacks several important genes that code for major pathways including key metabolic pathways (Gottwald, 2010). Furthermore, CLas cells were also found to have many 
transporter systems (genes encoding transporter systems) which suggests that they are highly dependent on their host (Trivedi, Grinyer, Anderson, \& Singh, 2016). It is believed that the evolution of Liberibacter species has resulted in a loss of genes which no longer allows these species to grow independently (Abdullah et al., 2009; Duan et al., 2009; Fleites, Jain, Zhang, \& Gabriel, 2014; Tamborindeguy et al., 2017; Vinatzer, 2012). In other words, their evolutionary relationship has made them adapted to the nutrient rich phloem environment and therefore are almost impossible to be cultured (grown in a laboratory) (Bendix \& Lewis, 2018; Vinatzer, 2012).

\subsubsection{Uncultured Bacterium}

Not being able to culture a bacterium significantly hinders the process of understanding its physiology, ecological roles, and its effects on the health of the host (Stewart, 2012). Surprisingly, only a tiny fraction of existing bacterium have been cultured (Stewart, 2012), and it has been estimated that only about $0.001-1 \%$ of plant associated bacteria are culturable (Eevers et al., 2015), and the reason for this, is simply that microbiologist have not been able to replicate their environment exactly (Stewart, 2012).

When bacterial species are not able to be cultured, they are given the preface “candidatus" (Bendix \& Lewis, 2018; Halbert \& Manjunath, 2004). To date, none of the HLB-causing species have been cultured (Bové, 2006; Chung \& Brlansky, 2009; Gottwald, 2010; Halbert \& Manjunath, 2004; Zhang et al., 2010), and thus, are commonly referred to as Candidatus Liberibacter (Abdullah et al., 2009). As a result, Koch's postulates have not yet been completed for any of the HLB causing pathogens (Bendix \& Lewis, 2018; Bové, 2006; Gottwald, 2010; Halbert \& Manjunath, 2004). 
Multiple approaches have been attempted to grow CLas cells in the laboratory. For example, the addition of citrus juice, co-cultivation with insect feeder cells, co-cultivation with actinobacteria from citrus, and agar that included citrus vein extract have all been reported to improve CLas cultivation success (Bendix \& Lewis, 2018). Still, none of the HLB causing pathogens have been effectively cultured to date (Bendix \& Lewis, 2018; Bové, 2006).

The required nutrients for these bacteria may be extremely specific. A metabolomic comparative analysis was done to compare the differences between the phloem saps of orange jasmine, Valencia sweet orange, and curry leaf trees. All three trees are in the Rutaceae family; however, curry leaf does not host the CLas pathogen. The study found that curry sap had fewer sugars, amino acids, organic acids, and total metabolites than did the two orange trees. These analyses suggest that the reason these pathogens are not growing in the phloem of their curry leaf relative is because of the nutrient inadequacy of its phloem sap (Killiny, 2016).

\subsubsection{Pathogenesis}

Little is known about the movement of Liberibacter species within the host plant nor the exact mechanism of how they cause the disease and death of the host plant (Johnson et al., 2014). Still, several studies have taken distinct approaches in the attempt to understand the pathogenesis (manner in which disease develops) of HLB.

The most commonly recognized cause for the symptoms associated with HLB are related to "phloem-plugging" (blockage of the phloem pathway) (Fagen et al., 2014; Folimonova et al., 2009; Munir et al., 2018). It is believed to be caused by the replication of CLas within the phloem which disrupts the natural flow of nutrients, resulting in rapid 
tree decline (Hu \& Wang, 2016). In general, phloem-plugging is thought to lead to metabolic imbalances of the host plant by interfering with the transportation of nutrients or depleting nutrients altogether (Duan et al., 2009; Fan et al., 2010). Alterations in the metabolism of carbohydrates (Munir et al., 2018), imbalances of carbohydrates in sourcesink tissues (Tamborindeguy et al., 2017), and starch accumulation in specific tissues (Koh et al., 2012) have all been found.

It has been suggested that an early consequence of HLB is excessive starch accumulation in leaf chloroplast (Koh et al., 2012). Where studies have shown that infected leaves accumulate up to six times more starch than healthy leaves do (Paudyal, 2015a). One study found that infected citrus had an accumulation of starch in the aerial tissues and a depletion of starch in the roots (Tamborindeguy et al., 2017), this is consistent with (Graca, 1991) who stated HLB causes the ultimate carbohydrate starvation of the roots. Starch accumulation in HLB-infected leaves has also been attributed to the downregulation of the transcription of the enzyme that converts starch into sucrose (DPE2) (Fan et al., 2010). Given that HLB has been found to causes excessive starch accumulation in leaf chloroplasts, one study compared callose accumulation in plasmodesmata pore units (PPUs) and in sieve pores in both infected and uninfected trees. Results indicated that HLB lead to significantly larger callose deposits in the PPUs as well as in the sieve pores, concluding that the buildup of callose reduced pore size causing phloem plugging and thus inhibited nutrient transportation through the phloem (Koh et al., 2012). The incubation of infected plants with continuous light was also found to greatly affect HLB symptoms, by inducing a shorter latency period (symptoms developed faster) and significantly increasing the severity of chlorosis of the leaves. It was suggested that there is a correlation between 
the disruption of phloem translocation of carbohydrates (caused by HLB) and the appearance of chlorotic symptoms in leaves of infected trees (Folimonova et al., 2009).

While many believe the pathogenesis of CLas is caused by phloem-plugging leading to starch accumulation, other studies have suggested otherwise. Johnson et al. (2014) found that CLas colonized the roots before the leaves, concluding that the roots were damaged as a result of root infection rather than carbohydrate starvation. According to their model, the bacteria use passive movement of the phloem sap to move towards the sinks. Given that roots are usually sinks, the bacteria were found to initially colonize the roots. When new flush became a sink tissue the bacteria were transported there. Similarly, if the bacteria were initially transmitted onto new flush (a sink), the bacteria would stay there until that new shoot became mature (a source) and only then would the bacteria be transported down towards the roots (sink). The conclusion was that early root damage was not caused by phloem plugging, but rather to direct root infestation (Johnson et al., 2014). Another study suggested that changes seen in nutrient flow are the result of CLas modulating key genes that are involved in the metabolism of carbohydrates (Martinelli \& Dandekar, 2017).

The nutrient resorption efficiency of $\mathrm{P}$ and $\mathrm{N}$, of CLas infected plants has also been studied. No correlation was found between nutrient resorption efficiency and HLB infected plants. Nutrient resorption on HLB infected plants has been shown to affect different species differently. Relative to uninfected plants, the $\mathrm{P}$ resorption efficiency on Citrus reticulata decreased significantly, while the $\mathrm{P}$ resorption efficiency on Citrus limon increased, and the P resorption efficiency of Citrus maxima was not affected (Cao, Cheng, Yang, \& Wang, 2015). 
All in all, it is thought that HLB symptoms occur as a result of one of the following three disfunctions: a disruption in the phloem's source and sink relationship, a problem with the plants immune responses (hormonal crosstalk), or changes in detoxifying pathways (Martinelli \& Dandekar, 2017). Virulence traits (secretion systems, putative effectors, and lipopolysaccharides) of Liberibacter have also been reviewed. It was found that some virulence factors lead to localized cell responses such as premature cell death, necrosis, or phloem protein accumulation; thus, leading to systemic malfunction of the phloem. Furthermore, other host responses facilitated disease development by promoting pathogen growth or suppressing host immune responses. Also suggested was that the physical presence of the bacteria itself could cause changes in osmotic gradients and conductivity, which disrupts the function of the phloem (Wang et al., 2017).

\subsection{Asian Citrus Psyllid}

\subsubsection{Primary Mode of Transmission}

The HLB-causing Liberibacter species are naturally transmitted by two vector Asian Citrus Psyllid (ACP) species: Diaphorina citri and Trioza erytreae (Bové, 2006; Zhang et al., 2012). These two psyllids are the primary means of natural transmission of HLB ( Halbert, \& Manjunath, 2004). They transmit the bacterium as they feed on the phloem sap (Killiny \& Hijaz, 2016). Diaphorina citri is the natural vector of CLas and $L$. americanus, while T. erytreae is the natural vector of L. africanus (Gottwald, 2007; Nakabachi et al., 2013). Accordingly, D. citri is the principal vector in Asia, Brazil, and the United States while T. erytreae is the principal vector in Africa (Manjunath et al., 2008; Ukuda-Hosokawa et al., 2015). Additionally concerning is that the psyllid-pathogen association is not as specific as previously believed (Tamborindeguy et al., 2017), that is, 
under experimental conditions both vector species $D$. citri and $T$. erytreae are also able to transmit both $L$. africanus and $L$. asiaticus, respectively (da Graça \& Korsten, 2004; Gottwald, 2007; Halbert \& Manjunath, 2004). Still, D. citri is the most prevalent HLB vector (Gottwald, 2010) and thus the most serious pest of citrus worldwide (GraftonCardwell et al., 2013). Because D. citri is also the principal vector in Florida, the literature reviewed is focused on this species (Figure 3).

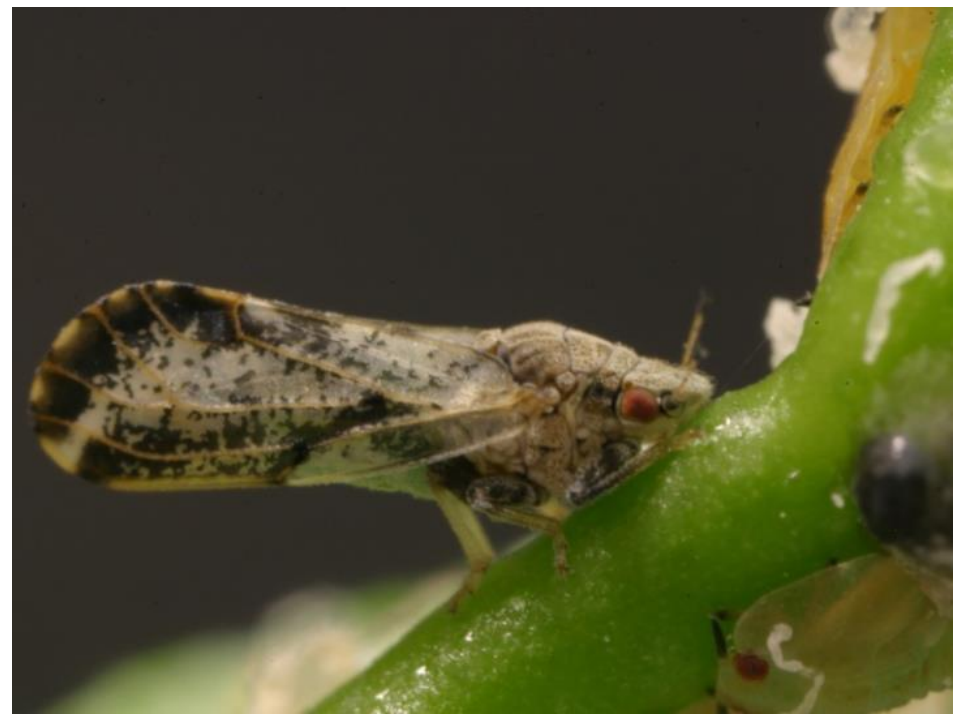

Figure 3: Adult Diaphorina citri feeding on the phloem of a citrus stem http://californiacitrusthreat.org/pest-disease

\subsubsection{Order Hemiptera}

Diaphorina citri is in the Order Hemiptera (Ammar, Walter, \& Hall, 2013; GraftonCardwell et al., 2013), and the Liviidae family (Ukuda-Hosokawa et al., 2015). Hemiptera species have piercing and sucking mouthparts that allow them to feed from the phloem and/or xylem (Lòpez-Fernàndez, Mazzoni, Pedrazzoli, Pertot, \& Campisano, 2017), where most (including D. citri) use the phloem sap as their dominant or sole food source (Douglas, 2006). Insects vectoring phloem-limited pathogens, use their stylets to feed; during which time they inject their saliva (containing the pathogen) directly into the phloem sieve tube 
cells, where the bacteria begin to replicate (Ramsey et al., 2017). This process allows the pathogens to bypass several plant barriers and defense mechanisms (Bendix \& Lewis, 2018), and also makes it easy to acquire and transmit phytopathogens (Lòpez-Fernàndez et al., 2017). Furthermore, once the psyllid is infected, it can continue to transmit the bacterium for the rest of its life (Chung \& Brlansky, 2009). It is important to note that while the ACP is necessary for initial infection, it is not needed for continued infection because the pathogen spreads internally on its own (Chiyaka, Singer, Halbert, Morris, \& van Bruggen, 2012).

\subsubsection{History of $D$. citri}

D. citri was first mentioned in 1907 in Taiwan, though its infections nature was not described (Grafton-Cardwell et al., 2013). It was later reported in Brazil in 1942, India in 1967 and then in North America (Florida) in 1998 (Grafton-Cardwell et al., 2013; Halbert \& Manjunath, 2004; Hall, 2018; Strategic Planning, 2010). The first report of D. citri in Florida occurred in Palm Beach County (1998) (Strategic Planning, 2010), where the exact means of its arrival is unknown. Still, there have been 2 suggested possibilities: one is that it spread naturally though central America and the Caribbean and the other is that it was imported directly from Asia ( Halbert, \& Manjunath, 2004). Furthermore, it has been commonly accepted that $D$. citri became widespread in Florida as a result of shipments of ornamental orange jasmine plants (Murraya paniculate) that were produced in MiamiDade County, infested with ACP's, and then distributed to discount chain stores throughout Florida (Alvarez et al., 2016; Halbert \& Manjunath, 2004). By 2000, D. citri was found in 31 (of 67) counties in Florida, and eradication was no longer possible (Strategic Planning, 2010). In 2001, psyllids arrived in Texas on Murraya plants that had been shipped from 
Florida (John V Da Graca, Setamou, \& Salas, 2008; French, Kahlke, \& da Graca, 2001; Strategic Planning, 2010). Currently, D. citri is found in all citrus growing states in North America (Ramsey et al., 2017), including all counties in Florida where citrus is produced.

\subsubsection{Morphology}

Adult ACP's range between 2.7 (Strategic Planning, 2010) and 4 millimeters long (Halbert \& Manjunath, 2004; Moffis et al., 2016). They stand at an angle between $30^{\circ}$ (Moffis et al., 2016) and $45^{\circ}$, but jump quickly when disturbed ( Halbert, \& Manjunath, 2004). The wings of D. citri are mottled brown (Strategic Planning, 2010) and can give a flattened X-pattern when viewed laterally (unlike T. eryteae who have clear and pointed forewings) (Halbert \& Manjunath, 2004). Diaphorina citri prefer to feed and lay eggs on new flush (Moffis et al., 2016), preferably 1-5 days after budbreak (Grafton-Cardwell et al., 2013). Diaphorina citri nymphs are even smaller and more difficult to see. They can be green or orange and have large wing pads. They are flat and prefer to feed on new flush, therefore they wrap themselves around new shoots while they feed. Eggs are bright yellow or orange with a pointed shape that attaches to the plant tissue from one end. Also, they are so small that they are difficult to see with the naked eye ( Halbert, \& Manjunath, 2004).

\subsubsection{Life Cycle}

The lifespan of $D$. citri generally ranges between 15 and 47 days (depending on the temperature) (Alvarez et al., 2016; Grafton-cardwell \& Kearney, 2003; Halbert \& Manjunath, 2004). During this time D. citri females can lay up to 800 eggs (Alvarez et al., 2016; Halbert \& Manjunath, 2004). Once laid, eggs hatch approximately two to four days later. The newborns then go through five nymphal instars that are completed between 11 15 days (Alvarez et al., 2016; Grafton-cardwell \& Kearney, 2003; Halbert \& Manjunath, 
2004). Adults reach reproductive maturity two to three days after emerging from the nymphal stage (Strategic Planning, 2010).

Diaphorina citri females mate multiple times with different partners (Strategic Planning, 2010) in order to achieve maximum reproductive output (Grafton-Cardwell et al., 2013). Oviposition (egg laying) begins one to two days after mating, and both mating and oviposition occur only during daylight hours (Grafton-Cardwell et al., 2013; Strategic Planning, 2010). Copulation occurs strictly on new flush, and ranges between 20 and 100 minutes. Tender tissue is required for egg laying, with young leaves and shoots preferred (Grafton-Cardwell et al., 2013), thus nymphal development occurs on new flush (Alvarez et al., 2016), which typically harbor the highest densities of each life stage (GraftonCardwell et al., 2013). Therefore, D. citri populations are strongly influenced by the amount of young flush present (Alvarez et al., 2016; Strategic Planning, 2010), a behavior exemplifies the reason why young trees are especially susceptible to ACP infestations and thus HLB infections (Alvarez et al., 2016).

Correspondingly, peaks of $D$. citri in Florida often occur exactly during the months of new flush growth (Bové, 2006; Gottwald, 2010). That is, citrus trees actively produce new shoots during April and May and again in November, and these months are also exactly when D. citri populations are known to peak (Ukuda-Hosokawa et al., 2015). Nonetheless, D. citri peaks have also been observed to occur with warm temperatures during late spring and throughout the summer (Strategic Planning, 2010). Conversely, in winter months, the low temperatures slow down the ACP life cycles to near dormancy (Alvarez et al., 2016). 


\subsubsection{Temperature Limits}

The temperature tolerance and sensitivity of both ACPs is consistent to that of their respective Liberibacer pathogens. That is, D. citri is heat tolerant as is CLas, and T. erytrae is heat sensitive as is L. africanus (Bové, 2006; Gottwald, 2007). Even though D. citri has adapted to mostly tropical and subtropical climates, it is also capable of surviving extreme temperatures. Diaphorina citri has been reported to survive temperatures as high as $45^{\circ} \mathrm{C}$ as well as in temperatures as low as $-6.5^{\circ} \mathrm{C}$ (Grafton-Cardwell et al., 2013). showing the capability to survive even through severe freezes (Halbert \& Manjunath, 2004). Even so, these extreme temperatures are not favorable to the ACPs and thus are generally correlated with low psyllid counts (Strategic Planning, 2010). However, D. citri cannot tolerate humidity levels close to the saturation point because it promotes fungal epizootics which infect nymphs (Halbert \& Manjunath, 2004).

\subsubsection{Dispersal}

The normal dispersal distance of adult $D$. citri has been reported to be between 25 to $50 \mathrm{~m}$ (Grafton-Cardwell et al., 2013), with some evidence of occasional mass migrations (Strategic Planning, 2010). An immuno-marking technique has been commonly used to track D. citri's movement, and has found that D. citri is capable of moving up to $2000 \mathrm{~m}$ in 12 days (Grafton-Cardwell et al., 2013). They are able to fly continuously for about 50 minutes and up to 1,241 meters. Though they can easily fly $2000 \mathrm{~m}$ on their own, they can also be carried, and thus dispersed more quickly, by the wind (Moffis et al., 2016). In fact,

the longest recorded distance flown by $D$. citri was 470,000 miles, which was thought to be mediated by lower jet streams (Grafton-Cardwell et al., 2013). Therefore, their long- 
range dispersal is said to be aided by prevailing winds and unintended human transport (Alvarez et al., 2016).

Additionally, research has shown that the dispersal behavior of male D. citri is affected when they are infected with Liberibacter species. The CLas infected adult males have higher dispersal rates than uninfected males. However, infection does not seems to not affect female dispersal in any way (Martinelli \& Dandekar, 2017).

\subsubsection{Transmission Pathway (between psyllids)}

Transmission of CLas from psyllid to psyllid may occur through horizontal transmission (sexual transmission), (Tamborindeguy et al., 2017). However, transmission occurs at low rates, between $2-4 \%$ and only from males to females (not females to males nor pairs of the same sex) (Pelz-Stelinski, Hermann, Tiwari, \& Stelinski, 2011). Vertical transmission (from mother to offspring) however, has had conflicting reports (Halbert \& Manjunath, 2004; Ramsey et al., 2017). Some report that CLas is not vertically transmitted (Chung \& Brlansky, 2009; Hung, Hung, Chen, Hsu, \& Su, 2004; Xu, Xia, \& Li, 1988), while others have reported that CLas is indeed transmitted vertically (Tamborindeguy et al., 2017), though at rates as low as 3.6\% (Grafton-Cardwell et al., 2013).

\subsubsection{Location and Retention of CLas within $D$. citri}

Candidatus Liberibacter asiaticus as is a systemic disease in D. citri (Zhang et al., 2012) it affects the entire body rather than a single organ. The two primary places where CLas are found in large numbers are the hemolymphs (analogous to the blood) and the salivary glands (Bové, 2006; Manjunath et al., 2008). However, CLas has also been found in several other areas such as the midgut, filter chamber, fat tissues, muscle tissues, ovaries

(Ammar et al., 2013; Munir et al., 2018), alimentary canal and malpighian tubules; it 
circulates these organs within one to two days after psyllid acquisition (Grafton-Cardwell et al., 2013), though infection density can be affected by insect sex, host tree, and collection date (Tamborindeguy et al., 2017; Ukuda-Hosokawa et al., 2015).

Many agree that CLas replicates within D. citri (Fletcher \& Wayadanda, 2002; Halbert \& Manjunath, 2004; Manjunath et al., 2008; Pelz-Stelinski \& Killiny, 2016). While some suggest that CLas is only propagative in nymphs and not in adults (Bendix \& Lewis, 2018). Others have found that CLas is capable of multiplying in both nymphs and adults (though titer increased at a faster rate when CLas was acquired by nymphs) (Ammar et al., 2013). Successful transmission of CLas to citrus trees requires a certain density of CLas within D. citri (Ukuda-Hosokawa et al., 2015), therefore, it has been suggested that propagation of CLas within the D. citri is essential for efficient transmission (Tamborindeguy et al., 2017). Furthermore, it was reported that CLas located inside $D$. citri gut cells induce the formation of endoplasmic reticulum associated bodies and then recruit them into vacuoles containing CLas; suggesting that CLas propagate within the gut cells of D. citri (Ghanim et al., 2017). Conversely, it has also been reported: that CLas titer decreases over time in D. citri when not exposed to infected plants, suggesting that CLas does not replicate in D. citri (Pelz-Stelinski \& Killiny, 2016).

Phloem-limited pathogens can be internally maintained by their insect vector either for a few days (semi-persistent) or for the duration of their life (persistent) (Bendix \& Lewis, 2018). Retention of CLas by D. citri has been commonly described as persistent, with the ability to transmit CLas for the duration of its life (Gottwald, 2007; Strategic Planning, 2010). Still, some views differ, reporting decreases in titer of CLas over time (Pelz-Stelinski \& Killiny, 2016). 


\subsubsection{Incidence Levels}

Incidence (infection density) of CLas in D. citri can be significantly affected by season (Hall, 2018; Ukuda-Hosokawa et al., 2015). In general, CLas incidence levels are highest during the spring and late fall (Strategic Planning, 2010). Psyllids collected during the fall and winter were found to have incidence levels of $40 \%$ vs $1 \%$, respectively (Manjunath et al., 2008). Incidence levels can also be affected by various other factors such as environmental conditions, number of infected trees, population levels of CLas (Hall, 2018), insect sex, and host tree (Ukuda-Hosokawa et al., 2015). In fact, it has been suggested that female $D$. citri may play a more significant role in the transmission of CLas than males. That is, in one study significantly more females tested positive for CLas than males. In addition, females live longer than males and are also sometimes found in greater abundances than males (Hall, 2018)

\subsubsection{Transmission Efficiency}

The transmission efficiency of CLas, from adult D. citri to host tree, varies significantly: anywhere between 1\% and 80\% (Alvarez et al., 2016; Halbert \& Manjunath, 2004). Transmission efficiency has been correlated with the number of infected $D$. citri (Grafton-Cardwell et al., 2013), the infection density of CLas within D. citri (Ammar et al., 2013; Ukuda-Hosokawa et al., 2015), the number of psyllids present, amount of feeding time, and the amount of incubation time. In particular, one study showed that CLas titer in leaves was greater when there were higher densities of psyllids present, when the psyllid had longer inoculation times, and when the leaves had longer incubation periods (one week post inoculation) (Ammar et al., 2013). Furthermore, D. citri who acquire CLas during nymph stages have significantly higher transmission efficiencies than $D$. citri who acquired 
it as adults (Alvarez et al., 2016; Grafton-Cardwell et al., 2013; Ramsey et al., 2017; Tamborindeguy et al., 2017). Still, since adults are the ones who can fly, they are ones responsible for transmitting the bacterium to other trees (Strategic Planning, 2010).

\subsubsection{Transmission Cycle}

The transmission cycle of CLas by D. citri is composed of three parts: acquisition, retention, and inoculation (Strategic Planning, 2010). The acquisition period is when the nymphs and/or adults acquire CLas through feeding. The retention or latency period is the when CLas is already inside the psyllid but needs time to multiply and enter the salivary gland. Lastly, the inoculation period is the time during which D. citri introduces CLas into the plant (Grafton-Cardwell et al., 2013).

\subsubsection{Acquisition}

Asian citrus psyllids require a certain amount of feeding time before they can acquire CLas (Bendix \& Lewis, 2018). Acquisition of CLas by the D. citri occurs as they feed on the phloem sap of infected plants (Pelz-Stelinski \& Killiny, 2016). Acquisition times for D. citri have been reported to range from 15 minutes (Grafton-Cardwell et al., 2013), to 30 minutes (Fletcher \& Wayadanda, 2002; Halbert \& Manjunath, 2004; Killiny, 2016; Pelz-Stelinski \& Killiny, 2016), and up to 5 hours (up to 24 hours for T. erytraea) (Gottwald, 2007). Acquisition efficiency has also been found to be directly proportional to the amount of time D. citri spends feeding (Grafton-Cardwell et al., 2013; Pelz-Stelinski \& Killiny, 2016), as well as on the developmental stage of D. citri (Ramsey et al., 2017). A $20 \%$ greater acquisition rate of CLas by nymphs than by adults has been reported. Where adult acquisition efficiencies have been found to range from 13-90\% (Grafton-Cardwell et al., 2013). Most reports indicate that nymphs are able to acquire and retain the CLas as 
early as their fourth and fifth instars (Gottwald, 2007; Halbert \& Manjunath, 2004; Xu, Xia, \& Li, 1988), though one study was able to detect the pathogen in the 3rd instar (Hung et al., 2004).

\subsubsection{Latency Period}

Once the psyllid acquires the pathogen there is a latency period before the pathogen can be transmitted into a healthy tree (Alvarez et al., 2016). A certain amount of bacterium must reach the salivary glands of the psyllid in order for transmission to occur (Munir et al., 2018). However, it seems that there is yet to be a consensus on a latency range time period. Several studies have reported different latency periods within the psyllid: seven to ten days (Fletcher \& Wayadanda, 2002; Graca, 1991), eight to 12 days (Strategic Planning, 2010), three to 20 days (Pelz-Stelinski \& Killiny, 2016), one to 25 days (Grafton-Cardwell et al., 2013; Halbert \& Manjunath, 2004). Moreover, Munir et al. (2018) reported that the longer latency periods lead to more effective transmissions; stating that a 14-day latent period was necessary for effective transmission.

\subsubsection{Inoculation}

Whether nymphs are able to transmit CLas or not remains controversial. The inoculation of CLas into citrus plant has been reported to occur only by adult psyllids (Alvarez et al., 2016). Likewise, nymphs that acquire the pathogen during the fourth and fifth instars are able to inoculate immediately after they emerge as adults (Gottwald, 2007; Halbert \& Manjunath, 2004; Strategic Planning, 2010). Xu et al. (1988) found that 4th and 5th instar nymphs were able to transmit CLas. Feeding times required for transmission have also been reported with some variation: within one hour (Pelz-Stelinski \& Killiny, 2016), five hours (Strategic Planning, 2010), and from 15 minutes to 7 hours (Grafton-Cardwell 
et al., 2013). Once inoculated, young flush tissue may become infectious as early as 15 days later (Ramsey et al., 2017).

\subsubsection{Relationship between $D$. citri and CLas}

The relationship between $D$. citri and CLas is still not fully understood and has shown opposing views in different studies (Tamborindeguy et al., 2017). One study found that CLas negatively affected $D$. citri by reducing their feeding efficiency and impairing their nutritional quality (Mann et al., 2012); thus, CLas has been considered a pathogen of D. citri (Halbert \& Manjunath, 2004). On the other hand, others have called this relationship a symbiotic one (Duan et al., 2009). One study compared and evaluated the fitness of $D$. citri with and without CLas. They found that nymphal development rate and adult survival both decreased in infected psyllids. However, they also found that infected psyllids were more fecund, and that overall the population of infected psyllids increased more than that of the population of uninfected psyllids. With these results they suggested that $D$. citri and CLas have evolved a mutually beneficial relationship (Pelz-Stelinski \& Killiny, 2016), and thus some have labeled the relationship between CLas and D. citri a symbiotic one (Duan et al., 2009).

\subsubsection{Plant Preference}

Asian Citrus Psyllid's have a narrow host range of mainly citrus, and occasionally close citrus relatives. There are approximately ten additional genera that are known ACP host plants (Grafton-Cardwell et al., 2013). Several studies have reported certain preferences by the ACP, with variations in preference being due to the fact that different studies compare different plant species. Still, the following seem to be the most commonly preferred: sweet orange (Citrus sinesis) orange jasmine (Marraya paniculate) (Hijaz, 
Nehela, \& Killiny, 2016; Killiny \& Hijaz, 2016; Strategic Planning, 2010), grapefruit (Halbert \& Manjunath, 2004; Hijaz et al., 2016), sour orange (citrus aurantifolia) and grapefruit (Citrus paradise) (Munir et al., 2018). D. citri has been found to avoid colonizing trifoliate orange (Poncirus trifoliata) and white sapote (Casimiroa edulis) (though the latter is a citrus relative) (Grafton-Cardwell et al., 2013).

\subsubsection{Host Response}

Many plants release volatile organic compounds (VOCs) as a defense mechanism to help protect them from insect and pathogen attack. Furthermore, it was reported that tolerant citrus varieties contained relatively higher amounts of volatiles, as well as different types of volatiles, than the susceptible varieties did (Hijaz et al., 2016).

Insect vectored pathogens are able to manipulate the interactions between their host plant and vector in order to benefit themselves; they generally do this in one of two ways: they either manipulate the resource quality of the host to benefit the vector, or they induce host mediated cues that attract the vector (Trivedi et al., 2016). Studies have shown that as soon as citrus trees are infected with CLas, they begin to express changes in plant defenses (Tamborindeguy et al., 2017), which make the psyllids more attracted to them (GraftonCardwell et al., 2013). More specifically, CLas manipulate their host tree to release a volatile organic compound known as methyl salicylate, which attract D. citri adults (Alvarez et al., 2016; Munir et al., 2018).

However, since infected trees are likely to be less nutritious, psyllids feed on the attractive infected tree and quickly move on to nearby healthy trees, a behavior which accelerates and intensifies the spread of HLB (Alvarez et al., 2016; Grafton-Cardwell et al., 2013; Mann et al., 2012). An example of this behavior was seen by Munir et al., 2018, 
where $D$. citri were initially attracted to the volatile profiles of CLas infected sweet orange trees, and after some feeding time, dispersed and switched over to noninfected plants; furthermore, host selection was not influenced by whether the psyllid was infected or not (Mann et al., 2012). Another behavior that was found by citrus (Valencia sweet oranges) was that they produce more amino acids when infected with CLas, which was thought to be a defense mechanism of citrus (Killiny \& Hijaz, 2016).

\subsection{Other Transmission Methods}

Apart from the ACP, HLB has also been reported to be transmissible through grafting, dodder (Zhang et al., 2012), and seed ( Halbert, \& Manjunath, 2004). Dodder (Cuscuta campestris) is able to carry and transmit the pathogens to periwinkle (Catharan roseus) (Fleites et al., 2014; Killiny, 2016; Zhang et al., 2010) and tobacco (Nicotina xanthii) (Garnier \& Bove, 1983; Halbert \& Manjunath, 2004; Shokrollah et al., 2011). In fact, periwinkle is often used as an indicator plant to screen directly on CLas (Fleites et al., 2014; Jain, Fleites, \& Gabriel, 2017; Zhang et al., 2010). While these transmissions have been observed only under laboratory conditions (Abdullah et al., 2009; Shokrollah et al., 2011), it has been suggested that this might be caused by the restricted host ranges of the psyllid vector rather than the inability to do so naturally (Halbert \& Manjunath, 2004).

Candidatus Liberibacter asiaticus has also been transmitted through grafting (Hilf \& Lewis, 2016a; Zhang et al., 2012) a common propagation practice. The first report of a Liberibacter pathogen being transmitted by graft-inoculation occurred in 1956 (Strategic Planning, 2010). Grafting is normally done by taking the rootstock from a disease-free tree and the scion from and HLB infected tree and joining the two together (Abdullah et al., 2009). Given that this is one of the few methods available to target CLas directly, the 
grafting methods have begun to diversify in recent years. Apart from the traditional scion - rootstock grafting, twig side grafts (Shokrollah et al., 2011), single leaf grafts (Hilf \& Lewis, 2016b) and leaf-disc grafts (Tabay Zambon, Plant, \& Etxeberria, 2017) have also been reported. Nonetheless, there is variability in graft transmissions, which is dependent on the species being used, the plant part used for grafting, the amount of tissue used, the pathogen isolate (Halbert \& Manjunath, 2004), and the amount of tissue used (Shokrollah et al., 2011).

\subsection{Management}

\subsubsection{HLB Control}

Given that there is currently no available cure for HLB (Alvarez et al., 2016; Duan et al., 2009), nor effective treatment, the best option growers have is to apply a variety of management strategies (Bové, 2006; Zhang et al., 2011). Better yet, prevention is the best way to fight the disease (Zhang et al., 2011). Still, there are no practical nor effective measures to efficiently control HLB in commercial groves (Cao et al., 2015; Zhang et al., 2014). In fact, HLB is not completely successfully managed anywhere in the world (Halbert \& Manjunath, 2004), and genetic and transgenic approaches are still far from application (Hu \& Wang, 2016). Nonetheless, even though current control measures are only partially effective (Hu \& Wang, 2016), it is still an absolute necessity to implement

some type of control measure. Groves that do not implement any kind of control and/or management strategy reach more than 95\% incidence levels in just 3 years (GraftonCardwell et al., 2013).

Obstacles to HLB management include: unmanaged groves, urban areas, and noncitrus hosts of D. citri (Grafton-Cardwell et al., 2013). Also, when the psyllids are 
widespread and well established, management becomes even more difficult (Paudyal, 2015a). Other difficulties include: symptoms are not specific, a long latency period, uneven distribution in the phloem, native environment of citrus trees favor the ACP and $L$. asisaticus, $\mathrm{ACP}$ and host plant tolerance levels are highly variable, and the fastidious nature of CLas (Manjunath et al., 2008).

Managing HLB is not only difficult and expensive (Duan et al., 2009; Paudyal, 2015a), but requires considerable understanding of the interactions that occur within and amongst crops, insects and bacteria. There is no one management strategy that fits all. Different strategies have varying levels of effectiveness depending on a number of factors (Wang et al., 2017). Therefore, citrus growers around the world have adopted a variety of management strategies.

\subsubsection{Monitoring}

Monitoring is a key component in the management of HLB, as this is the best way to detect infection at early stages (Cao et al., 2015). It is recommended to monitor either overwintered adults to see when they are about to lay eggs (abdomen turns orange) and also, (scouting gin the spring) to monitor the buildup of nymphs on shoots because once they emerge as adults, they are already spreading the disease (Halbert \& Manjunath, 2004). Monitoring the activity of adult ACPs is mainly done through yellow sticky traps (GraftonCardwell et al., 2013), primarily for more efficient time control (Abdullah et al., 2009), however, in Florida, this is method is not really efficient because it is still too slow (Halbert \& Manjunath, 2004). Monitoring of the ACP is also done through methyl salicylate-based

attractants (prior to insecticide applications), which may also be used to attract D. citri to other crops, and away from citrus (Munir et al., 2018). 


\subsubsection{The Three-pronged Approach}

In the 1980s and 1990s The United Nations Development Program Food and Agricultural Organization (UNDP FAO) conducted a citrus rehabilitation project and the resulting recommendations were: 1. To control psyllid populations, 2. To remove all HLBinfected trees, 3 . To create certification programs to ensure disease free budwood sources, 4. The geographical isolation of nurseries, and 5. To require that all citrus nursery production be done in insect-proof screen houses (Gottwald, 2010). On the basis of these findings, it is widely accepted that the most effective management strategies for HLB infected trees consists of a three-pronged approach: 1. Eliminating all HLB infected trees in order to eliminate new sources of bacterial inoculum, 2. Plant disease-free nursery stocks, and 3. Control the insect vector populations as much as possible through the use of insecticides (or biocontrol if applicable) (Abdullah et al., 2009; Alvarez et al., 2016; Chung \& Brlansky, 2009; Doud et al., 2017; Grafton-Cardwell et al., 2013; Halbert \& Manjunath, 2004; Hall, 2018; Puttamuk, Zhang, Duan, Jantasorn, \& Thaveechai, 2014; Shokrollah, Lee Abdullah, Sijam, \& Nor Akmar Abdullah, 2010; Wang et al., 2017; Zhang et al., 2011).

Nonetheless, eradication of HLB inoculums is not always successful. The level of success of eradication depends on the severity of the infection. Areas where HLB is widespread have little to no chance of eradicating the disease successfully; thus, early detection is crucial (Abdullah et al., 2009; Halbert \& Manjunath, 2004). The seedlings used for replanting must be obtained from certified HLB-free nurseries, which are now required to be completely enclosed in order to prevent ACP contact. In the U.S. and in China, they now have designated areas called citrus undercover production systems (CUPSs), where they grow mature citrus trees in completely enclosed structures; these areas are now being 
used commercially on a small scale. Thus, in order save time and money, it is recommended to plant seedlings that are already two or three years old, especially since younger trees are more susceptible (Wang et al., 2017).

The management of $D$. citri is heavily reliant on insecticides to limit initial infection and reinfection of trees (Grafton-Cardwell et al., 2013). However, some believe that control must include a variety of strategies derived from that of integrated pest management programs ( Halbert, \& Manjunath, 2004). That these integrated strategies can lead to the possibilities of citrus still being produced, even in the presence of HLB (Wang et al., 2017).

While these three steps have been strongly recommended in Florida (Alvarez et al., 2016; Zhang et al., 2011), many producers refuse to follow the approach (Alvarez et al., 2016; Grafton-Cardwell et al., 2013). Since removing, replanting and keeping new trees disease free is extremely difficult and expensive (Alvarez et al., 2016), farmers have no assurance that their costs will be recovered (Grafton-Cardwell et al., 2013). Therefore, instead they hold on to their symptomatic trees for as long as they are able to bear usable fruit (Alvarez et al., 2016), and attempt to prolong productivity of infected trees by using intense foliar nutrition, rigorous vector control, and any other known management strategy (Grafton-Cardwell et al., 2013). Unfortunately, not applying the tree-pronged approach will only lead to productivity steadily declining until the grove is completely infected and no longer yielding, at which point it will be that much more difficult to eradicate the bacteria.

Nonetheless, while the three-pronged approach is the most widely accepted, an array of other control strategies including both biological and chemical, are implemented around the world. One literature review discussed the most commonly used treatment 
options for HLB, and found that the following were the major treatment options currently used: broad spectrum antimicrobial compounds, CLas specific antimicrobial compounds, thermotherapy, and compounds that stimulate plant growth and/or boost host defenses (Blaustein et al., 2018). Moreover, many of these management strategies may overlap, as living with HLB requires the use of multiple strategies (Grafton-Cardwell et al., 2013).

\subsection{Biological Control}

Biological control occurs when pests or diseases are controlled through the importation, augmentation, and conservation of natural enemies (Alvarez et al., 2016; Strategic Planning, 2010). Since the populations are generally reduced rather than eliminated, it is considered a slow mode of action; thus, its effectiveness its often questioned (Munir et al., 2018).

Controlling ACP populations is one of the primary control strategies used for HLB management (Blaustein et al., 2018; Grafton-Cardwell et al., 2013; Wang et al., 2017), since reducing their populations prevents new infections (Doud et al., 2017). Thus, a variety of biological and chemical strategies are implemented with the intent to control psyllid populations. However, vector control alone cannot reduce the long-term effects of the disease, especially where HLB is well established, there it can only slow the spread and lessen the severity (Blaustein et al., 2018).

Biological control of the ACP is only possible in groves that do not favor high populations of psyllids (Chung \& Brlansky, 2009). Even when psyllid control is working and psyllid count is low, it still is not enough for HLB not to spread (Giles, 2017). Controlling ACP populations is challenging because they have a fast growth rate and rapid development, are short-lived, mobile, tolerant to extreme temperatures, exhibit high 
transmission efficiency of nymphs, and females have high fecundity (Grafton-Cardwell et al., 2013). Additionally, the fact that citrus is a perennial crop makes it that much more challenging to control the ACP through biological control (Halbert \& Manjunath, 2004). Even with limited success (Strategic Planning, 2010), direct correlation has been observed between vector control and CLas titer (Blaustein et al., 2018).

\subsubsection{Parasitoids}

One of the major biological control methods used is the introduction of the parasitic wasps into the citrus groves. Commonly used parasitic wasps are Tamaraxia dryi (Bové, 2006; Chu \& Chien, 1991), Diaphorencyrtus aligarhensis and Tamaraxia radiate (Alvarez et al., 2016; Grafton-Cardwell et al., 2013; Halbert \& Manjunath, 2004; Michaud, 2002). The most efficient at parasitizing D. citri and thus most commonly released in citrus groves, is T. radiata (Giles, 2017). Tamaraxia radiata are diurnal (Chu \& Chien, 1991) annual wasps (Giles, 2017), ectoparasitoid, and a Hymenoptera in the Eulophidae family (Grafton-Cardwell et al., 2013).

Although they are the most efficient parasitoid wasp of citrus, and have shown some success at significantly reducing psyllid populations (Abdullah et al., 2009; Gottwald, 2010), their effectiveness has been variable, showing as little as 1-3\% parasitism ( Michaud, 2002; Qureshi, Rogers, Hall, \& Stansly, 2009) as well as psyllid population reductions ranging from 4 to 70\% (in Florida) (Abdullah et al., 2009), and have also been reported to attack $60-70 \%$ of $D$. citri nymphs ( Halbert, \& Manjunath, 2004). Furthermore, the effectiveness of $T$. radiata parasitism have also been correlated to the growing season, averaging less than $20 \%$ during the spring and summer, but parasitizing more than $50 \%$ of D. citri during the fall (Grafton-Cardwell et al., 2013; Qureshi et al., 2009). 
Tamaraxia radiata actually require the presence of ACP nymphs in order to complete their life cycle. They have a preference for the 5 th instar of $D$. citri nymphs (Chu $\&$ Chien, 1991). They lay their eggs on the underside of the D. citri larval nymphs. As soon as the wasp eggs hatch, the larva can immediately parasitize $D$. citri nymphs, where they continue to develop until they become adults; the process kills the $D$. citri nymphs (Alvarez et al., 2016).

Tamaraxia radiata was imported from Taiwan and released in many sites throughout Florida around 2001 (Michaud, 2002). In fact, it was chosen by the Florida Department of Agriculture and Consumer Services (FDACS) Division of Plant Industry (DPI) to be reared for mass release among citrus producers in Florida. Consequently, Florida now has a mass rearing program of approximately 3.3 million wasps are produced and released each year at a cost of about $\$ 361,529$ each year. These parasitoid wasps are then offered to producers and homeowners for free (Alvarez et al., 2016).

The limited success of biocontrol via parasites (Gottwald, 2010; Michaud, 2002) has been attributed to the fact that $T$. radiata are susceptible to hyper-parasites (Chung \& Brlansky, 2009; Halbert \& Manjunath, 2004). That is, the reason for some of their low percentages in parasitizing psyllids is because of their mortality by predation (GraftonCardwell et al., 2013). Additionally, T. radiata are only parasitoids to the psyllids during their nymph stage, and thus are only partially effective (Abdullah et al., 2009).

\subsubsection{Natural Enemies}

The use of natural enemies as biocontrol on D. citri had been used as early as 1991, at which time natural enemies seemed promising (Chu \& Chien, 1991). Nonetheless, Florida has a large number of native organisms that are taking advantage of the high 
populations of D. citri, and do in fact use them as a food source (Alvarez et al., 2016). Many of these natural enemies of D. citri attack their juvenile stages. The two which have been said to cause the primary source of mortality are two coccinellid species: Olla vnigrum and Harmonia axyridis, of which have an exclusive diet of D. citri and thus depend on D. citri for growth and development (Michaud, 2002). Other natural enemies used on D. citri include various species of beetles, hunting spiders, lacewings (Michaud, 2002), and ants (Alvarez et al., 2016), which have all been used as a means of biological control. While no biological enemy can sufficiently restrict ACP populations on their own (Trivedi et al., 2016), it has been suggested that these natural enemies may contribute significantly to control psyllid populations (Michaud, 2002) and should be considered as part of longterm control strategies for HLB management (Fletcher \& Wayadanda, 2002).

\subsubsection{Intercropping}

Intercropping has been used an effective management strategy for hundreds of years. Citrus intercropped with guava has proven to be an effective means to reduce psyllid populations and thus exhibit low incidence levels of HLB (Hall \& Albrigo, 2007). In one study, citrus that was not intercropped showed symptoms four months after planting and reached 30\% incidence within a year, whereas the citrus that was intercropped with guava remained disease free for the whole year (Paudyal, 2015). Furthermore, citrus intercropped with guava has also lead to significant differences in life span, when compared to a citrus monoculture (Gottwald, 2010). The average life of citrus monocultures vs citrus intercropped with white guava was from two to four years vs 15 years, respectively (Gottwald, 2010; Paudyal, 2015). 
While the exact mechanism driving this biocontrol is unknown, several suggestions have been proposed: a disruption in the ability of the psyllid to recognize the host, as well as that the compounds produced by the guava alter the volatile compounds normally emitted by citrus (Paudyal, 2015a). Also proposed, was that the psyllids become directly attracted to the guava who then release toxic compounds to the psyllid, or the "push-pull" concept where compounds released cause the psyllid to move away from the citrus (push) and become more attracted to the guava (pull). More recently, a study was done where psyllids were secluded with guava in a "no-choice" situation, and they found that within six to nine days there was a $95 \%$ mortality rate. They then suggested that guava produces volatile compounds that are deleterious to ACPs (Gottwald, 2010; Paudyal, 2015). Nevertheless, intercropping with guava in large orchards is not a very practical solution. Instead, the potential use of repellents from guava volatiles to repel ACPs in citrus orchards is currently being investigated (Strategic Planning, 2010).

\subsubsection{Mineral Oils}

Horticultural mineral oils (HMOs) are also commonly used as a control method. It has also been suggested that HMOs can suppress attractant plant volatiles, cause the leaves to release repellent volatiles and/or directly repel adults (Grafton-Cardwell et al., 2013). In fact, in certain cases HMOs are more effective than synthetic chemicals, (having fewer pests on foliage and fruit). Mineral oils have demonstrated effectiveness in controlling the ACP by suppressing the oviposition of adult females. The ACPs do not lay eggs on the oil deposits because the oils move into the spiracles of the insect. In addition to being an efficient control method, HMOs do not cause negative effects on the surrounding 
environment, have minimal effects on the biocontrol of other pests, and are not phytotoxic (Abdullah et al., 2009).

\subsubsection{Thermotherapy}

Thermotherapy has been used for decades as a control method for many plant diseases (Wang et al., 2017), and has shown some encouraging results in the control of CLas. While CLas are heat tolerant and known to be able to withstand temperatures of up to $35 \mathrm{deg} \mathrm{C}$ (Munir et al., 2018), when exposed to temperatures between 40 and $42{ }^{\circ} \mathrm{C}$ for at least 48 hours, CLas was reduced or eliminated in HLB infected citrus pots in greenhouse conditions (Doud et al., 2017). Since the experimental conditions are not realistic for commercial growers, a similar study was done using solar thermotherapy (in the field using portable plastic enclosures). Because temperatures exceeding 40 deg C can only occur for short periods of time ( 3 to 8.5 hours per day), the duration of the study was much longer. During the first six weeks significant new growth was observed, followed by significant reductions in CLas titer between one and two years post treatment. However, these results were not permanent, after 30 months CLas populations had reached the levels of the populations in control trees (Doud et al., 2017). Thermotherapy studies reaching 45 degrees Celsius have shown conflicting results, showing a decrease in CLas and also causing severe plant tissue damage (Blaustein et al., 2018).

Thermotherapy has shown to be effective but is considered impractical for largescale use (Fletcher \& Wayadanda, 2002; Graca, 1991), and even though it has only been confirmed in small-scale settings, it appears to be one of the most effective measures against CLas (Blaustein et al., 2018). Thus, thermotherapy may be useful in small scale 
(potted plants) nurseries and greenhouses (Hoffman et al., 2013). Benefits of thermotherapy are that it can be used by organic (and conventional) farmers, as it is environmentally friendly, and it also does not require a regulatory permit (Doud et al., 2017). On the other hand, a drawback of thermotherapy is that the heat treatment does not reach the roots, and therefore can serve as a reservoir for CLas; then when the tree starts to flush, reinfection is likely to occur (Wang et al., 2017). As a result, the combination of thermotherapy and antibiotics has been recommended for a more efficient, more long-term treatment (Munir et al., 2018). Although thermotherapy is time consuming and expensive, some efforts are being put into developing commercial equipment to make thermotherapy more plausible in large scale groves (Blaustein et al., 2017).

\subsubsection{Quarantine}

Quarantine measures have also been implemented as a biological control strategy (Wang et al., 2017). For areas where HLB has not been introduced, quarantine is the first line of defense. It ensures that the bacteria will not be introduced and hence established in a new area (Gottwald, 2010). Quarantine has remained successful in Australia and the Mediterranean citrus producing areas (Wang et al., 2017). Nonetheless, as international trade and travel continue to increase, the likelihood of unintentional introduction also continues to increase (Gottwald, 2010). Furthermore, quarantine within a regulated area has also been suggested. That is, the quarantine of all citrus plant material including yard trash and fruit within a regulated area (Halbert \& Manjunath, 2004).

\section{Enhanced Nutrient Program}

The enhancement of tree nutrition is commonly used as a management strategy (Grafton-Cardwell et al., 2013). Nearly all growers in Florida have reported to have 
adopted some variation of nutrient enhancement; some of which have reported success (Spreen, 2013). Nutritional supplements such as micronutrients, macronutrients, SA, and/or phosphites (many times combined) are generally used (Wang et al., 2017), and most often applied though foliar sprays (Alvarez et al., 2016). Some growers use enhanced nutrient programs to suppress disease symptoms (Alvarez et al., 2016), while others use it to help mineral deficiencies that are induced by HLB (Wang et al., 2017).

Nonetheless, effectiveness is controversial, having no consistent evidence supporting this practice to result in improved productivity of HLB-infected trees (Paudyal, 2015a). One study showed that zinc sulfate heptahydrate applications actually increased CLas titer in leaves by 1.5 times more than in controls (after 4 months) (Blaustein et al., 2018). It is possible that promoting vigorous growth of new flush may also promote increases pin syllid populations (Trivedi et al., 2016). On the other hand, others have reported that after three years of application, the enhanced nutritional program reduced CLas titer and also increased leaf size and weight (Wang et al., 2017). Still, most studies have actually shown that micronutrient amendments are generally inconsequential (Blaustein et al., 2018), finding no significant effects on tree health, CLas titer, fruit yield, or juice quality (Blaustein et al., 2017; Gottwald, Graham, Irey, McCollum, \& Wood, 2012; Wang et al., 2017). Others have concluded that the enhanced nutritional program promotes tree growth in asymptomatic trees and in trees with an early stage of infection, however they have not shown to have significant effects on trees with advanced stages of HLB (Wang et al., 2017). Still, the effectiveness of nutrient enhancement remains highly debatable, as it has also been stated that most reports on enhanced nutritional applications do not have sufficient statistical validity (Paudyal, 2015a). Thus, it has been suggested that 
micronutrient amendments be used in combination with other control methods rather than on their own (Blaustein et al., 2018).

\subsubsection{Additional Sustainable Methods}

Coordinated sprays among growers of different orchards has also shown success in reducing psyllid populations (Grafton-Cardwell et al., 2013; Spreen, 2013; Wang et al., 2017). Other sustainable strategies used include: producing uninfected citrus in protected environments such as "closed" insect-proof nurseries (Zhang et al., 2011) or screen-house nurseries (Paudyal, 2015a) as well as the use of natural products such as neem products (Giles, 2017), antifeedants (Grafton-Cardwell et al., 2013), 24-eBL (Munir et al., 2018), and fungal based products (Giles, 2017). Although there is no evidence regarding effectiveness, windbreaks have also been used in the attempt to protect the plants from ACPs (Halbert \& Manjunath, 2004). Lastly, removing symptomatic limbs or trees (pruning) is a common practice (Doud et al., 2017), however, HLB's latency period makes pruning difficult (Grafton-Cardwell et al., 2013) and if not done properly can actually increase the spread of both CLas and D. citri (Abdullah et al., 2009). Brassinosteroids (plant hormones) and metalized polyethylene mulch have been reported to be potentially

valuable as an additional control measure (Blaustein et al., 2018; Croxton \& Stansly, 2014).

\subsubsection{Using Tolerant Varieties}

Using disease resistant varieties is one of the most effective and sustainable method used to control most plant diseases (Wang et al., 2017). The HLB-resistant varieties would be the most effective control strategy for HLB (Munir et al., 2018). Breeding "HLBresistant citrus varieties has been hindered as a result of a lack of HLB-resistant germplasm, polyembryony, pollen-ovule sterility, sexual and graft incompatibilities, and extended 
juvenility" (Wang et al., 2017). Nonetheless, genetically modified citrus trees with resistance to HLB are being developed. Unfortunately, it will take several years before commercial applications can occur (Munir et al., 2018).

While there are no known HLB-resistant citrus varieties (Bendix \& Lewis, 2018; Bové, 2006; Paudyal, 2015b; Wang et al., 2017) the susceptibility and/or tolerance of citrus varieties was assessed and found to be associated with physical characteristics. That is, the CLas titer was similar in all varieties; thus, there is no correlation between bacterial titer and severity of disease (Trivedi et al., 2016). Nonetheless, the tolerance of thirty genotypes of citrus were examined and grouped into 4 categories: sensitive, moderately tolerant, tolerant, and variable reactions (Folimonova et al., 2009). The results were determined on the basis of the response of each citrus to grafted CLas+ buds (Table 1). 
Symptom description

\begin{tabular}{|c|c|c|}
\hline Citrus halimii B. C. Stone & ht & Sensitive-chlorosis, vein corking, death \\
\hline Nules clementine (C. reticulata Blanco) & +t & Sensitive-chlorosis to tip leaves, reduced growth, death \\
\hline Minneola tangelo (C. x tangelo J. Ingram \& H. E. Moore) & t+ & Sensitive-chlorosis to tip leaves, reduced growth \\
\hline Valencia sweet orange $(C$. sinensis $(\mathrm{L}$.$) Osbeck)$ & t+t & Sensitive-chlorosis including tip, reduced growth, death \\
\hline Madam Vinous sweet orange (C. sinensis (L.) Osbeck) & t+t & Sensitive-chlorosis including tip, reduced growth, death \\
\hline Duncan grapefruit (C. paradisi MacFadyen) & t+ & Sensitive-chlorosis including tip, reduced growth, death \\
\hline Ruby red grapefruit (C. paradisi MacFadyen) & +t & Sensitive-chlorosis to tip leaves, reduced growth \\
\hline Siamese Sweet pummelo (C. maxima (Burm.) Merr.) & t+ & Variable-mild symptoms in $\mathrm{GH}$, strong under $24 \mathrm{~h}$ of light \\
\hline Ling Ping Yau pummelo (C. maxima (Burm.) Merr.) & ht & Variable-mild symptoms in $\mathrm{GH}$, strong under $24 \mathrm{~h}$ of light \\
\hline Hirado Buntan Pink pummelo (C. maxima (Burm.) Merr.) & t+ & Variable-strong symptoms in young and old leaves \\
\hline C. amblycarpa (Hassk.) Ochse & t+t & Variable-chlorosis and some reduction of growth \\
\hline Cleopatra mandarin (C. reticulata Blanco) & t+t & Variable-chlorotic leaves, some reduction of growth \\
\hline C. indica Tanaka & t+ & Variable-early chlorosis, severe under $24 \mathrm{~h}$ of light \\
\hline Meiwa kumquat (Fortunella crassifolia Swingle 'Meiwa') & t+ & Variable-chlorotic leaves, plant growth reduced \\
\hline Sun Chu Sha mandarin(C. reticulata Blanco) & t+t & Moderately tolerant-scattered chlorotic groups of leaves \\
\hline Sour orange (C. aurantium L.) & t+t & Moderately tolerant-chlorosis under high light only \\
\hline Volkamer lemon (C. limonia Osbeck 'Volkameriana') & t+t & Moderately tolerant-scattered chlorotic groups of leaves \\
\hline C. macrophylla Wester & t+t & Moderately tolerant-scattered chlorotic groups of leaves \\
\hline Swingle citrumelo (X Citroncirus webberi J. Ingram \& H. E. Moore) & t+t & Moderately tolerant-some yellowing of older leaves \\
\hline Citron (Citrus medica L.) & t+ & Moderately tolerant-strong symptoms on older leaves \\
\hline Palestine Sweet lime (C. aurantifolia (Christm.) Swingle) & t+t & Moderately tolerant-some chlorosis on older leaves \\
\hline Mexican lime(C. aurantifolia (Christm.) Swingle) & tht & Moderately tolerant-scattered chlorotic groups of leaves \\
\hline Calamondin (X Citrofortunella microcarpa (Bunge) Wijnands) & t+t & Moderately tolerant-mild symptoms on older leaves \\
\hline Citrus micrantha Wester & t+t & Moderately tolerant-mild symptoms on older leaves \\
\hline Eureka lemon (C. limonia Osbeck) & H+ & Tolerant-no symptoms, chlorosis under $24 \mathrm{~h}$ of light only \\
\hline Persian lime (C. aurantifolia (Christm.) Swingle) & t+t & Tolerant-little or no symptoms \\
\hline Carrizo citrange (X Citroncirus webberi J. Ingram \& H. E. Moore) & + & Tolerant-little or no chlorosis \\
\hline Severinia buxifolia (Poiret) Ten. & + & Tolerant-no distinct symptoms \\
\hline Poncirus trifoliata (L.) Raf. & $+1-$ & Inconsistent \\
\hline Citrus latipes (Swingle) & +- & Inconsistent \\
\hline
\end{tabular}

Table 1: The response of different citrus genotypes to grafting with buds from CLas+ infected trees

\subsection{Chemical Control}

Chemical controls include a variety of insecticides, many of which contain highly toxic and sometimes even banned ingredients. Though a number of these chemicals may show some reductions in ACP populations, they also include a variety of secondary effects, such as being toxic to humans, pets, and livestock, contaminating soil, water, and other vegetation, and can also destroy natural enemies which may result in outbreaks of minor pests (Abdullah et al., 2009). Aside from the various environmental threats, pesticide use in general is expensive and not suitable for all producers (Abdullah et al., 2009). Chemical 
treatments are applied though a variety of methods, such as trunk injections, root soaking, foliar sprays, and soil application (Puttamuk et al., 2014), with each method having its own benefits and limitations.

\subsubsection{Insecticides}

Insecticide use to control the ACP populations, is the principal management strategy used (Alvarez et al., 2016; Cao et al., 2015; Croxton \& Stansly, 2014; GraftonCardwell et al., 2013), and is often considered to be the best management option of HLB (Blaustein et al., 2018; Munir et al., 2018). Citrus groves are known to apply heavy pesticides to control D. citri (Alvarez et al., 2016). On average, Florida uses 8 to 12 insecticide treatments per year (Grafton-Cardwell et al., 2013).

Pesticide timing is critical ( Halbert, \& Manjunath, 2004). The best time to for insecticide applications is said to be right before spring flush (Abdullah et al., 2009; Halbert \& Manjunath, 2004). Insecticide applications during the winter months, on overwintering psyllids, have shown to have the greatest impacts because during this time the trees are dormant and produce no flush (Strategic Planning, 2010). Thus, psyllids have low reproduction rates (Grafton-Cardwell et al., 2013) and their populations are at their lowest (Strategic Planning, 2010). Additionally, natural predators are either absent or in protected stages, and therefore applying during this time has less impact on these species. In addition to timing of application, the effectiveness of the insecticide also depends on the type of insecticide being used, as well as the life stage of the insect (Grafton-Cardwell et al., 2013). Regionally coordinated insecticide sprays may maximize their effectiveness (Alvarez et al., 2016). 
Nonetheless, using chemical insecticides as the main control method is far from sustainable and has several negative environmental and biological effects (Pankaj Trivedi et al., 2016). Florida's sub-tropical climate and year-round vegetation promotes many generations of ACP, which leads to the need of more intensive management practices such as more frequent application of insecticides (than in temperate zones). In fact, as a result of such excessive applications, D. citri have already become less susceptible to many insecticides (Grafton-Cardwell et al., 2013). Insecticides destroy natural enemies, resulting in outbreaks of minor pests (Abdullah et al., 2009), may result in insecticide drift (Munir et al., 2018), and altogether reduce the effectiveness of any biological control (Strategic Planning, 2010). For example, many commonly used insecticides are toxic to T. radiata (Grafton-Cardwell et al., 2013). Additionally, many insecticides are systemic (Munir et al., 2018), which means they require the psyllids to feed a certain amount in order to acquire the lethal levels of the insecticide. Thus, they can transmit the CLas while feeding, prior to being affected by the insecticide (Gottwald, 2010). Aside from their negative environmental effects, insecticide use alone is not enough for appropriate psyllid control (Croxton \& Stansly, 2014), and the need for more sustainable control methods is urgent (Grafton-Cardwell et al., 2013).

\subsubsection{Antibiotics}

The 1950s to 1970s are remembered as the golden era for the discovery of novel antibiotics. At that time, antibiotics significantly reduced the numbers of human deaths resulting from infectious diseases (Gupta \& Birdi, 2017). Since then, about 40 antibiotics have been screened for their control in plant diseases. Less than ten of those have been used commercially, and only two (streptomycin and tetracycline) are applied to fruit trees 
(Munir et al., 2018; Zhang, Guo, Powell, \& Duan, 2014; Zhang et al., 2011). Using new antibiotics is heavily inspected because their many associated risks (Blaustein et al., 2018), such as the development of antibiotic resistance (Puttamuk et al., 2014). Controversy struck in 2016 when the EPA granted an "emergency exemption" (Conner, 2017), approving streptomycin sulfate, OTC hydrochloride, and OTC calcium complex control HLB via foliar sprays in Florida. The benefits and efficacy of these bactericides in the Florida citrus industry via foliar spray remain to be determined (Wang et al., 2017).

Before antibiotics are considered potential candidates for HLB, they must meet certain criteria. That is, they should be active inside of the plant, be tolerant of oxidation, UV irradiation, rainfall, and high temperatures, be non-phytotoxic to citrus, must have either low or non-detectable rates of resistant pathogens (Zhang et al., 2014), and must be easily delivered to the phloem (Munir et al., 2018). Furthermore, the efficacy of antimicrobial compounds can be influenced by many factors such as: the responsiveness of bacteria, the physiochemical environment at the infection site, and the interaction with the host (Zhang et al., 2014).

Antimicrobial compounds are categorized according to their mechanism of action. Some mechanisms of action include: interference with cell wall synthesis, DNA and RNA synthesis, lysis of the bacterial membrane, inhibition of protein synthesis, and inhibition of metabolic pathways (Chandra et al., 2017). Since the understanding of the HLB pathosystem remains limited, broad-spectrum antimicrobial peptides are the main focus of most current work (Stover et al., 2013). The discovery of CLas genomic sequence (Duan et al., 2009), has provided a better understanding of some targets specific to CLas, but much more remains to be understood (Stover et al., 2013). 
Several studies have tested antimicrobial compounds in different concentrations and combinations; some of which have shown quantifiable reductions of CLas (Figure 4).

Figure 4 summarizes the broad-based antimicrobial classes used and their target activity, the antimicrobial compound name, whether it was used in a field or a greenhouse setting, the application method used, the impact on CLas, the detection method, the impact on HLB symptoms (though many were not discussed), and the potential side effects (Blaustein et al., 2018).

\begin{tabular}{|c|c|c|c|c|c|c|}
\hline \multicolumn{7}{|c|}{$\begin{array}{c}\text { Antimicrobials that have been tested against huanglongbing (HLB) infection in studies that incorporated quantification } \\
\text { of the phytopathogen }\end{array}$} \\
\hline $\begin{array}{l}\text { Broad antimicrobial } \\
\text { class (target activity) }\end{array}$ & $\begin{array}{l}\text { Antimicrobial } \\
\text { compound(s) }\end{array}$ & $\begin{array}{l}\text { Field/ } \\
\text { greenhouse } \\
\text { (application } \\
\text { method) }\end{array}$ & $\begin{array}{c}\text { Impact on } \\
\text { 'Ca. Liberibacter } \\
\text { asiaticus' } \\
\text { (detection method) }\end{array}$ & $\begin{array}{l}\text { Impact on HLB } \\
\text { symptoms }\end{array}$ & Potential side effects & Reference \\
\hline $\begin{array}{l}\text { Aminoglycosides } \\
\text { (inhibit protein } \\
\text { synthesis) }\end{array}$ & Streptomycin & $\begin{array}{l}\text { Greenhouse } \\
\text { (root drench) }\end{array}$ & $\begin{array}{l}\text { Reduction in population } \\
\text { density in leaves by } \\
\text { more than } 3 \text { log units } \\
\text { within } 3 \text { months after } \\
\text { treatment, yet } \\
\text { regrowth to a level } \\
\text { close to the starting } \\
\text { concentration by the } \\
\text { 6-month time point } \\
\text { (qPCR) }\end{array}$ & Not discussed & No phytotoxicity & $\begin{array}{l}\text { (Zhang et al. } \\
\text { 2011a) }\end{array}$ \\
\hline \multirow[t]{2}{*}{$\begin{array}{l}\text { B-Lactams linhibit } \\
\text { transpeptidation } \\
\text { cell wall } \\
\text { modification) }\end{array}$} & Penicillin G & $\begin{array}{c}\text { Field (trunk } \\
\text { injection) }\end{array}$ & $\begin{array}{l}\text { Concentration- } \\
\text { dependent reduction } \\
\text { in titer by } 6 \text { - to } 12 \text {-fold } \\
\text { in leaves of treated } \\
\text { trees compared with } \\
\text { untreated controls at } \\
\text { the } 3 \text {-month time point } \\
\text { after treatment (qPCR) }\end{array}$ & $\begin{array}{l}\text { Slight increases } \\
\text { in canopy size }\end{array}$ & $\begin{array}{l}\text { No phytotoxicity; little } \\
\text { or no impact on } \\
\text { native bacterial } \\
\text { populations and } \\
\text { penicillin resistance } \\
\text { within populations }\end{array}$ & $\begin{array}{l}\text { (Shin et al. } \\
\text { 2016) }\end{array}$ \\
\hline & & $\begin{array}{l}\text { Greenhouse } \\
\text { (root drench) }\end{array}$ & $\begin{array}{l}\text { Reduction in population } \\
\text { density in leaves by } \\
\text { more than } 3 \text { log units } \\
\text { within } 3 \text { months after } \\
\text { treatment, yet } \\
\text { regrowth to a level } \\
\text { close to the starting } \\
\text { content by the 6- } \\
\text { month time point } \\
\text { (qPCR) }\end{array}$ & Not discussed & No phytotoxicity & $\begin{array}{l}\text { (Zhang et al. } \\
\text { 2011a) }\end{array}$ \\
\hline \multirow[t]{2}{*}{$\begin{array}{l}\text { Sulfonamides } \\
\text { (inhibit metabolic } \\
\text { pathway for folic } \\
\text { acid synthesis) }\end{array}$} & Sulfadimethoxine & $\begin{array}{l}\text { Greenhouse } \\
\text { (root drench) }\end{array}$ & $\begin{array}{l}\text { Approximately a } \\
9 \% \text { lower relative } \\
\text { abundance } \\
\text { (Phylochip), but about } \\
\text { twice as high titer } \\
\text { (qPCR), in leaves of } \\
\text { treated seedlings than } \\
\text { controls at the } 2 \text { - } \\
\text { month time point after } \\
\text { treatment }\end{array}$ & $\begin{array}{l}\text { Slightly less } \\
\text { chlorosis } \\
\text { development } \\
\text { in canopy of } \\
\text { treated } \\
\text { seedlings than } \\
\text { in that of } \\
\text { controls }\end{array}$ & $\begin{array}{l}\text { Partial deleterious } \\
\text { effects on relative } \\
\text { abundances of } \\
\text { native bacteria }\end{array}$ & $\begin{array}{l}\text { (Yang et al. } \\
\text { 2016) }\end{array}$ \\
\hline & Sulfathiazole & $\begin{array}{l}\text { Greenhouse } \\
\text { (root drench) }\end{array}$ & $\begin{array}{l}\text { Approximately a } \\
7 \% \text { lower relative } \\
\text { abundance } \\
\text { (Phylochip), but about } \\
\text { twice as high titer } \\
\text { (qPCR), in leaves of } \\
\text { treated seedlings than } \\
\text { controls at the } 2 \text { - } \\
\text { month time point after } \\
\text { treatment }\end{array}$ & $\begin{array}{l}\text { Slightly less } \\
\text { chlorosis } \\
\text { development } \\
\text { in canopy of } \\
\text { treated } \\
\text { seedlings than } \\
\text { in that of } \\
\text { controls }\end{array}$ & $\begin{array}{l}\text { Partial deleterious } \\
\text { effects on relative } \\
\text { abundances of } \\
\text { native bacteria }\end{array}$ & $\begin{array}{l}\text { (Yang et al. } \\
\text { 2016) }\end{array}$ \\
\hline
\end{tabular}




\begin{tabular}{|c|c|c|c|c|c|c|}
\hline $\begin{array}{l}\text { Tetracyclines } \\
\text { (inhibit protein } \\
\text { synthesis) }\end{array}$ & Oxytetracycline & $\begin{array}{l}\text { Field (trunk } \\
\text { injection) }\end{array}$ & $\begin{array}{l}\text { Depending on the } \\
\text { amount of injection } \\
\text { ports used for } \\
\text { application, the } \\
\text { population density in } \\
\text { leaves decreased } 1 \text { to } \\
3 \text { log units within } 1 \\
\text { month after treatment } \\
\text { (qPCR). It remained } \\
\text { lower in treated trees } \\
\text { than controls for } 9 \\
\text { months, although } \\
\text { population regrowth } \\
\text { occurred during this } \\
\text { time }\end{array}$ & $\begin{array}{l}\text { New flushes did } \\
\text { not display } \\
\text { chlorosis, so } \\
\text { the overall } \\
\text { canopy } \\
\text { appeared } \\
\text { healthier }\end{array}$ & $\begin{array}{l}\text { Moderate } \\
\text { phytotoxicity-brown } \\
\text { discoloration to leaf } \\
\text { burning on some } \\
\text { young flushes }\end{array}$ & $\begin{array}{l}\text { (Hu and Wang } \\
\text { 2016) }\end{array}$ \\
\hline $\begin{array}{l}\text { Small molecules } \\
\text { (irhibit } \\
\text { transcription } \\
\text { factors produced } \\
\text { by that may be } \\
\text { essential for } \\
\text { pathogenesis and } \\
\text { stress tolerance) }\end{array}$ & Tolfenamic acid & $\begin{array}{l}\text { Greenhouse } \\
\text { (foliar spray; } \\
\text { root drench) }\end{array}$ & $\begin{array}{l}\text { Approximately an } 80 \text { to } \\
95 \% \text { reduction in the } \\
\text { expression of } L \text {. } \\
\text { asiaticus genes rpU } \\
\text { and gyrA in } 75 \% \text { of the } \\
\text { treated seedlings, } \\
\text { indicating substantial } \\
\text { reduction in viable } \\
\text { population (RT-qPCR) }\end{array}$ & $\begin{array}{l}\text { Substantial } \\
\text { improvements } \\
\text { in fibrous root } \\
\text { development } \\
\text { and foliage } \\
\text { appearance }\end{array}$ & No phytotoxicity & $\begin{array}{l}\text { (Gardnet et al. } \\
\text { 2016) }\end{array}$ \\
\hline \multirow[t]{3}{*}{$\begin{array}{l}\text { Combination } \\
\text { treatments } \\
\text { including } \\
\beta \text {-lactams, } \\
\text { aminoglycosides, } \\
\text { and/or } \\
\text { tetracyclines } \\
\text { (see above) }\end{array}$} & $\begin{array}{l}\text { Penicillin G + } \\
\text { streptomycin }\end{array}$ & $\begin{array}{l}\text { Greenhouse } \\
\text { (root drench) } \\
\text { and field } \\
\text { (trunk } \\
\text { injection) }\end{array}$ & $\begin{array}{l}\text { In the greenhouse } \\
\text { study, there was } \\
\text { reduction in population } \\
\text { density by more than } 2 \\
\text { log units within } 2 \\
\text { months following } \\
\text { treatment, which } \\
\text { continued to slightly } \\
\text { decrease during the } 6- \\
\text { month monitoring } \\
\text { period (qPCR). In the } \\
\text { field study, the } \\
\text { population density in } \\
\text { leaves of treated trees } \\
\text { was anywhere from } \\
3.5 \text { to } 5 \text { log units lower } \\
\text { than in those of } \\
\text { controls during } 14 \\
\text { months of monitoring: } \\
\text { however, there were } \\
\text { about } 2 \text { log unit } \\
\text { increases between the } \\
4 \text { - and } 14 \text {-month time } \\
\text { points (qPCR). }\end{array}$ & Not discussed & $\begin{array}{l}\text { Slight phytotoxicity in } \\
\text { both studies }\end{array}$ & $\begin{array}{l}\text { (Zhang et al. } \\
2011 \text { a) }\end{array}$ \\
\hline & & $\begin{array}{l}\text { Field (trunk } \\
\text { injection) }\end{array}$ & $\begin{array}{l}\text { The titer in leaves of } \\
\text { treated trees, which } \\
\text { correlated with relative } \\
\text { abundance } \\
\text { (PhyloChip), was } \\
\text { anywhere from } 3 \text { - to } \\
\text { 30-fold lower than in } \\
\text { those of controls } \\
\text { during } 14 \text { months of } \\
\text { monitoring; however, } \\
\text { seasonal fluctuations } \\
\text { indicated regrowth } \\
\text { (qPCR) }\end{array}$ & $\begin{array}{l}\text { Fluctuating titer } \\
\text { was described } \\
\text { to somewhat } \\
\text { correlate with } \\
\text { symptom } \\
\text { appearance }\end{array}$ & $\begin{array}{l}\text { Partial deleterious } \\
\text { effects on relative } \\
\text { abundances of } \\
\text { native bacteria }\end{array}$ & $\begin{array}{l}\text { (Zhang et al. } \\
\text { 2013a) }\end{array}$ \\
\hline & $\begin{array}{l}\text { Kasugarnycin }+ \\
\text { oxytetracycline }\end{array}$ & $\begin{array}{l}\text { Field (trunk } \\
\text { injection) }\end{array}$ & $\begin{array}{l}\text { The titer in laaves of treated } \\
\text { trees, which correlated } \\
\text { with relatve abundance } \\
\text { (PhyloChip), was } \\
\text { anywhere from } 3 \text { - to } 30- \\
\text { fold lower than in those } \\
\text { of controls during } 14 \\
\text { months of monitoring } \\
\text { however, seasonal } \\
\text { fluctuations indicated } \\
\text { regrowth (qPCR) }\end{array}$ & $\begin{array}{l}\text { Fluctuating titer } \\
\text { was described } \\
\text { to somewhat } \\
\text { correlate with } \\
\text { symptom } \\
\text { appearance }\end{array}$ & $\begin{array}{l}\text { Partial deleterious } \\
\text { effects on relative } \\
\text { abundances of } \\
\text { native bacteria }\end{array}$ & $\begin{array}{l}\text { (Zhang et al. } \\
\text { 2013a) }\end{array}$ \\
\hline
\end{tabular}

Figure 4: Antimicrobials that have been tested against HLB infection in studies that incorporated quantification of the phytopathogen

While all of these studies show initial decrease of CLas concentrations, eventually all levels return to the same or greater than initial concentrations. Thus, all of these "effective" treatments are only temporarily effective (Paudyal, 2015a). The effectiveness 
of antibiotics on phloem-limited pathogens has been limited (Fletcher \& Wayadanda, 2002) because of the difficulties involved in getting the antibiotic to enter the phloem. Additionally, when properly used, antibiotics often lead to the production of small fruit as a result of their phytotoxicity and antibiotic residues in the fruit (Munir et al., 2018). In addition to being far from sustainable (Bové, 2006; Paudyal, 2015a) antibiotics are associated with many risks such as changes in microbial communities in trees or rhizospheres, susceptibility to diseases (Puttamuk et al., 2014; Zhang, Powell, Guo, Benyon, \& Duan, 2013), the fate of the chemicals in the environment, selective pressures associated with evolution, and the spread of antibiotic-resistant pathogens (Blaustein et al., 2018).

\subsubsection{Antibiotic Resistance}

Antibiotic resistance in bacteria occurs as a natural adaptation to antimicrobial agents. Once a single bacterium becomes resistant to some antibiotic, it can then pass

on the resistance through horizontal or vertical transfer. In fact, the effectiveness of many commonly used antibiotics may be lost within a period of 5 years as a consequence of extremely fast genetic evolution in these resistant bacteria (Chandra et al., 2017).

There are six known mechanisms associated with the development of antibiotic resistance. These mechanisms are: through plasmids, antibiotic inactivation, modification of the target site, prevention of drug uptake, efflux pumps, or the formation of biofilm. 1. Plasmids are small strands of DNA (not chromosomal) that replicate independently. Plasmids may carry the transferable resistance which may have several genes coding for multiple drug resistance. 2. Antibiotic inactivation occurs when bacteria produce specific enzymes that can chemically modify or degrade the antibiotics, thus, inactivating the drug. 
3. Target site modification occurs when the sites that would normally be targeted by the antibiotic are altered or replaced. 4. Bacteria have the capacity to alter their permeability, thus they can eliminate the entry ports of the antibiotic, preventing antibiotic uptake. 5. Efflux pumps are normally responsible for moving numerous compounds out of the cell. In terms of antibiotic resistance, these efflux pumps are able to export the antibiotic out of the cell before they can find their intracellular targets. 6. Lastly, the formation of biofilms, occurs when an aggregation of microbes is embedded in a matrix of extracellular substance, which can lead to failure of the antibiotic to penetrate (Chandra et al., 2017; Gupta \& Birdi, 2017).

The use of antibiotics in agriculture is one of the major contributors to resistant diseases in human medicine (Chang, Wang, Regev-Yochay, Lipsitch, \& Hanage, 2014). Additionally, our improper use of antibiotics has resulted in the evolution of stronger than ever resistant bacteria in humans (Gupta \& Birdi, 2017). In 2016 the United Nations stated that the unprecedented acceleration of antibiotic resistance was the world's most urgent global threat. The Centers for Disease Control and Prevention estimate that more than two million people are infected with antibiotic-resistant organisms every year, leading to an estimated 23,000 deaths (Conner, 2017). Meanwhile, there is no known way to reverse antibiotic resistance (Chandra et al., 2017).

\subsection{Antimicrobial Compounds Derived from Natural Sources}

As a result of the negative impacts and limited lifespans of antibiotics (Sher, 2009), there is a growing public concern for environmentally friendly disease control methods (Cazorla \& Mercado-Blanco, 2016). Nonetheless, the antimicrobial properties of naturally occurring plant compounds have been documented for years (Cowan, 1999). In 
fact, somewhere between $25 \%$ and $50 \%$ of all current pharmaceuticals are derived from plants (Gupta \& Birdi, 2017). Plant sources are not only readily available, but they have fewer or no side effects in general (Chandra et al., 2017), including being less likely to be phytotoxic to host plants (Raut \& Aruna, 2017). Furthermore, pathogenic organisms are unlikely to develop resistance to these naturally produced active compounds (Gupta \& Birdi, 2017; Raut \& Aruna, 2017).

Plants harbor vast amounts of active compounds known as secondary metabolites. It is now known that these metabolites are responsible for the antimicrobial properties in plants. Examples of these metabolites are tannins, terpenoids, alkaloids, flavonoids quinines, phenols, lectins, lignans, polypeptides coumarin, and essential oil (Chandra et al., 2017; Sher, 2009). Plant sources may have a broad spectrum of activity against bacterial species (Chandra et al., 2017). These phytochemicals act through different mechanisms (usually targeting multiple biochemical pathways), which may be different than those used by traditional antibiotics (Santos et al., 2016). Nonetheless, synergistic effects have been seen between plant extracts and antibiotics (compared to extracts alone) (Stefanović, Stanojević, \& Čomić, 2012).

The antimicrobial activity of plant sources on microorganisms has been documented (Algamal, Marei, Saad, \& Abdelgaleil, 2013; Biba, Amily, Sangeetha, \& Remani, 2014; Chakraborty, Chowdhury, \& Bhattacharyya, 1995; Hufford et al., 1993; Kadota, Basnet, Ishii, Tamura, \& Namba, 1997; Sher, 2009; Theophilus et al., 2015). Subsequently, there is currently a growing interest in testing plant sources against bacterial species that are resistant to other drugs (Chandra et al., 2017; Gupta \& Birdi, 2017). Thus, crude plant extracts are now being screened all over the world for their 
potential antimicrobial activity (Chandra et al., 2017; Panda et al., 2016). Still, research on the application of naturally occurring antimicrobial compounds on CLas is limited.

\subsubsection{Plant Extracts with Known Antimicrobial Properties}

Given that CLas is a gram-negative bacterium, several plant extracts that have shown inhibition of other gram-negative bacteria were reviewed.

\section{Thyme}

Thyme is an herb in the Thymus genus, and the oils from these plants have shown antimicrobial properties for years (Cowan, 1999; Dorman \& Deans, 2000; Farag, Daw, Hewedi, \& El- Baroty, 1987; Sher, 2009). Thymus oils are known to have stronger antimicrobial properties against gram-positive bacteria, but nonetheless have also shown inhibitory effects against several gram-negative bacteria (Dorman \& Deans, 2000; Marino, Bersani, \& Comi, 1999). Thymus essential oils have shown both bactericidal and bacteriostatic properties (Rota, Herrera, Martínez, Sotomayor, \& Jordán, 2008). Thymus vulgaris has demonstrated antimicrobial activity against the following Gram-negative bacteria: Escherichia coli (E. coli), Proteus mirabilis (P. mirabilis), Proteus vulgaris (P. vulgaris), Salmonella typhimurium (S. typhimurium), Serratia marcescens (S. marcescens), Yersinia enterocolitica, Pseudomonas fluorescens, Pseudomonas putida (Marino et al., 1999), and Pantoea species (Imelouane et al., 2009). Thymus zygis and thymus hyemalis have also shown antimicrobial activity against gram-negative pathogens: Salmonella enteritidis (S. enteritidis), Shigella flexneri, Shigella sonnei (Rota et al., 2008).

\section{Oregano}

Oregano (Origanum vulgare) is a Mediterranean herb that is well known for its antimicrobial properties (Chun, Vattem, Lin, \& Shetty, 2005). In fact, oregano oils 
containing carvacrol are considered to be one of the most active plant extracts against numerous pathogens (Zinoviadou, Koutsoumanis, \& Biliaderis, 2009). Oregano oils have shown strong inhibition against pathogens such as Aeromonas hydrophila and Pseudomonas aeruginosa (P. aeruginosa) (Dorman \& Deans, 2000), Salmonella enteritidis (S. enteritidis) (Govaris, Solomakos, Pexara, \& Chatzopoulou, 2010) and Heliobacter pylori (H. pylori) (Chun et al., 2005). Additionally, oregano oils have shown inhibition on the growth of several fungus such as Aspergillus niger, Fusarium oxysporum and penicillium spp. (Marino et al., 1999), and even shown 100\% inhibit of lactic acid bacteria (which is used to increase the shelf life of fresh beef) (Zinoviadou et al., 2009).

\section{Banderol and Cat's Claw}

Cat's claw is an extract that comes from the vines of Uncaria tomentosa and Uncaria guianensis (Sandoval et al., 2002). These extracts have demonstrated antimicrobial, antidiabetic, anticancer (Weiss, 2019), antioxidative and ant-inflammatory properties (Sandoval et al., 2002), and are thus, used as medicinal sources for array of health problems (Sandoval-Chacón et al., 1998). These extracts are commonly used to treat digestive problems and inflammatory disorders (Sandoval-Chacón et al., 1998) including rheumatoid arthritis (Weiss, 2019).

Banderol is an extract that comes from the bark of a tree known as Otova parvifolia and has been traditionally used to treat infections caused by mites and fungi (Weiss, 2019). Banderol and Cat's claw are both well-known for having significant antimicrobial effects (as well as anti-inflammatory), against all forms of Borrelia burgdorferi (bacteria that causes Lyme disease) (Datar, Navroop, Patel, Luecke, \& Sapi, 2010), and are thus used by patients suffering from Lyme disease (Weiss, 2019). 


\section{Usnea}

Usnea is a lichen that grows epiphytically on trunks and branches of trees (Madamombe \& Afolayan, 2003). Usnea extracts have shown antimicrobial activity against both human and plant pathogens (Cansaran, Kahya, Yurdakulol, \& Atakol, 2006). These extracts have shown antimicrobial activity against many gram-negative and grampositive bacteria. For example, Usnea barbata significantly inhibited E. coli, Proteus vulgaris (P. vulgaris), and Pseudomonas aeruginosa (P. aeruginosa), and Proteus mirabilis (P. mirabilis) (gram negative) and Bacillus subtilis (B. subtilis), Bacillus megaterium, Enterococcus faecalis, Micrococcus viradans, and Staphylococcus aureus (S. aureus) (gram-positive) (Cansaran et al., 2006; Madamombe \& Afolayan, 2003). Similarly, a microlichen, Usnea pictoides, showed strong antimicrobial activity against $S$. aureus and Pseudomonas aeruginosa (P. aeruginosa) as well as some fungal species (Pavithra et al., 2013). Usnea derived extracts also have antiviral, antiprotozoal, antiinflammatory and analgesic activities and are commonly used as an active and/or preservative ingredient in products such as creams, toothpaste, mouthwash, deodorants and sunscreen (Cansaran et al., 2006).

\section{Turmeric}

Turmeric comes from the rhizome of the Curcuma longa plant, and while it is commonly used as a spice, a food preservative, and food coloring, it also has a long history of therapeutic uses (Singh \& Jain, 2012). Turmeric extracts have shown strong antimicrobial properties on a number of microorganisms, such as Candida albicans $(C$. albicans), Cryptococcus neoformans (Ungphaiboon et al., 2005), S. aureus, Salmonella paratyphi (S. paratyphi), Shigella flexnerii, E. coli, Klebsiella pneumoniae, B. subtilis and 
P. aeruginosa (Ferdinand, 2009). Curcumin is the major constituent of turmeric and was found to have antimicrobial effects against the biofilm formation of Streptococcus mutans (the main microorganism involved in the formation of dental plaque) ( $\mathrm{Li}, \mathrm{Li}, \mathrm{Lin}, \&$ Zhou, 2018). Trumeric extract has also reported the inhibition of numerous bacteria such as $S$. aureus, S. paratyphi, Trichophyton gypseum, Mycobacterium tuberculosis and even a number of drug-resistant strains (Teow, Liew, Ali, Khoo, \& Peh, 2016).

\section{Artemisia annuna}

Artemisia annuna is a medicinal herb, in which artemisinin is the main bioactive compound (Appalasamy et al., 2014), which no other plant species produces (Knudsmark Jessing, Duke, \& Cedergreeen, 2014). Artemisinin is most commonly known for its antibacterial properties against the resistant strains of Plasmodium falciparum (Jessing et al., 2014), the protozoan parasite better known as malaria (Goswami et al., 2012). Nonetheless, it also effectively inhibits both Gram-positive and Gram-negative bacteria at

levels similar to that of the antibiotic streptomycin (Appalasamy et al., 2014). Artemisinin has shown significant inhibitory activity against Heliobacter pylori (the pathogen responsible for peptic ulcer diseases) (Goswami et al., 2012). Artemisia annuna extract is also able to significantly inhibit phytopathogenic bacteria such as Agrobacterium tumefaciens, and Erwinia carotovoravar, as well as phytopathogenic fungi and has therefore been suggested as a potential compound in the use of pesticides (Algamal et al., 2013).

\section{Holy Basil}

Holy basil, Ocimum sanctum, has been used for its medicinal properties for hundreds of years. It is known as a general promotor for health, as it exhibits antimicrobial, 
anti-stress, adaptogenic, anticancer, anti-inflammatory (Jaggi, Madaan, \& Singh, 2003), antipyretic, analgesic and anti-arthritic properties (S. Singh \& Majumdar, 1999). Other therapeutic properties include cardiopathy, hemopathy, asthma, bronchitis, catarrhal fever, vomiting, gastropathy, ringworm, skin diseases (Gupta \& Birdi, 2017). Additionally, holy basil has also been found to have significant antiulcer activities (against aspirin-, alcohol-, serotonin, histamine, and stress-induced ulcerations) (Singh \& Majumdar, 1999).

\section{Stevia}

Stevia (rebaudiana) is mostly known as a sweetener which has some medicinal properties (Gamboa \& Chaves, 2012). Stevia has more than 100 phytochemicals and is known known for its antioxidant and antimicrobial properties (Ortiz-Viedma et al., 2017). It has also been used to treat several diseases such as diabetes, candidacies, high blood pressure and weight loss (Ghosh, Subudhi, \& Nayak, 2008). Additionally, it's antimicrobial properties have been reported to effect both Gram-positive and Gramnegative bacteria, as well as fungi (Gamboa \& Chaves, 2012), including pathogens such as E. coli, B. subtilis, P. aeruginosa, S. aureus (Ghosh et al., 2008), and even Streptococcus mutant strains and S. sobrinus (involved in dental caries) (Gamboa \& Chaves, 2012).

Stevia extracts are also able to inhibit some of the UTI-causing, Gram-negative bacterium: Generas: Klebsiella, Escherichia, Pseudomonas, Proteus, and Citrobacter (Raut \& Aruna, 2017). Additional reports have shown that stevia has anti-hipertensive, anti-hyperglycaemic and antiviral activities (Ortiz-Viedma et al., 2017). Its whole leaf extract is effective against all known morphological forms of Burrelia burgdoferi (cause of Lyme disease), and can even eliminate spirochetes and persister cells, and reducing biofilm mass (Theophilus et al., 2015). 


\section{Bidens}

Bidens pilosa is used for its medicinal properties in many parts of the world (Ashafa \& Afolayan, 2009), and very commonly used in herbal tea (Wu et al., 2004). It has a multitude of uses such as: anti-inflammatory, antiseptic, liver-protective, hypotensive, antitumor and hypoglycemic (Wu et al., 2004), anti-influenza, anti-ulcerogenic, vasodilative, antimalarial, antipyretic, anticancer, antioxidant, diabetic control and treatment of gastroenteritis (Ashafa \& Afolayan, 2009). Extracts have shown significant inhibitory activity against Gram-positive S. aereus, S. epidermidus, bacillus cereus, Micrococcus kristinae, S. faecalis) and Gram-negative (E. coli, P. aeruginosa, Shigelia flexneri, Klebsella pneumoniae and Serratia m.) bacteria (Ashafa \& Afolayan, 2009), with stronger inhibition seen on Gram-negative species (Falowo, Muchenje, Hugo, \& Charimba, 2016). Apart from its anti-bacterial properties, it has also been found to have antifungal and antiviral effects (Ashafa \& Afolayan, 2009). Similarly, Bidens tripartite is used to treat fevers, skin diseases, bladder and/or kidney problems, and to treat ruptured blood vessels or bleeding of any kind. It is also used to treat microbial infections and has antifungal activity (Tomczykowa, Tomczyk, Jakoniuk, \& Tryniszewska, 2008).

\section{Cryptolepsis}

Cryptolepis sanguinolenta extracts shown strong antimuscarinic, vasodilating, noradrenergic, antithrombotic, anti-inflammatory, and hypoglycemic activities (MillsRobertson, Tay, Duker-Eshun, Walana, \& Badu, 2012). It has been traditionally used in Guinea-Bissau as a remedy plant to treat jaundice and hepatitis (Silva et al., 1996). It has also been used to treat fever, malaria (Mills-Robertson et al., 2012) upper respiratory tract infections (Paulo, Duarte, \& Gomes, 1994) and 3 urinogenital pathogens: Neisseria 
gonorrhoeae, E. coli, and C. albicans (Boakye-Yiadom, 1979). Furthermore, studies have shown it has strong antimicrobial activity, where it has inhibited several species in the following genera: Salmonella, Proteus, Pseudomonas, Klebsiella, Escherichia, Staphylococcus (Mills-Robertson et al., 2012), Campylobacter, Candida, Shigella (Silva et al., 1996), Streptococcus and Vibrio (Paulo et al., 1994).

\section{Cinnamon}

Cinnamomum zeylanicum (cinnamon) is most commonly known as an Indian spice (Sofia, Prasad, Vijay, \& Srivastava, 2007), which has many applications in flavoring, perfumery, and pharmaceutical industries (Singh, Maurya, deLampasona, \& Catalan, 2007). Cinnamon has also reported to have excellent medicinal properties on nervous problems and stomach/intestine infections (Sofia et al., 2007). The active compound in cinnamon is cinnamaldehyde (Matan et al., 2006), which has shown inhibition against various pathogenic bacteria (both Gram-positive and Gram-negative bacteria) (Gupta \& Birdi, 2017), as well as yeast, fungal spores, and even several mycotoxigenic molds (Matan et al., 2006). Some examples of the microbes it has inhibited are: species in the Bacillus, Staphylococcus, Listeria, and Micrococcus genera (Gram-positive), E. coli and Klebsiella (Gram-negative) (Gupta \& Garg, 2008; Sofia et al., 2007), and Lactobacillus sp., Salmonella sp., Corynebacteri um michiganense, Pseudomonas striafaciens, Clostridium botulinum, Alternaria sp., Aspergillus sp., Canninghamella sp., Fusarium sp., Mucor sp., Penicillium sp., A. flavus, A. parasiticus, A. ochraceus and Fusarium moniliforme (Matan et al., 2006). 


\section{Alchornea}

Alchornea cordifolia has been widely used for an array of medicinal purposes such as: in the treatment of venereal diseases, conjunctivitis, dermatoses, stomach ulcers, bronchitis, toothache, urinary tract infection, infected wounds, diarrhea, cough, dental caries, chest pain, anaemia, gonorrhea, and rheumatic pain (Adeshina, Onaolapo, Olorunmola, \& Odama, 2010). In addition, alchornea has also shown a broad spectrum of activity in the microbial world, inhibiting Gram-negative and Gram-positive bacteria (representing aerobic, facultative and anaerobic bacteria) (Okeke, Ogundaini, Ogungbamila, \& Lamikanra, 1999), as well as fungi and yeast (Adeshina et al., 2010), with the greatest activity shown against Gram-positive bacteria and yeast (Okeke et al., 1999). It has shown significant inhibition against $S$. aureus, $S$. albus, E. coli, P. aeruginosa, B. subtilis, K. pneumoniae; A. niger, and C. albicans (Ebi, 2001), showing $100 \%$ kill of $P$. aeruginosa, E. coli and S. aureus (at low concentrations) (Adeshina et al., 2010).

\subsection{Endophytes}

Endophytes are organisms (generally bacteria or fungi) that inhabit plant tissues for at least some stage of their life cycle (intercellularly or intracellularly), without causing any apparent symptoms or disease (Araújo et al., 2001; Hallmann, Quadt-Hallmann, Mahaffee, \& Kloepper, 1997; Menpara and Chanda 2013; Soliman, Trobacher, Tsao, Greenwood, \& Raizada, 2013; Wang \& Dai, 2011). They are ubiquitous, having been found in virtually every plant studied (Ryan, Germaine, Franks, Ryan, \& Dowling, 2007), including trees, palms, sea grasses, lichens (Hyde \& Soytong, 2008), and algae (Ho, Chung, Huang, Chung, \& Chung, 2012). Furthermore, they may also be categorized as obligate or facultative endophytes (Eevers et al., 2015). 
Endophytes are believed to originate from epiphytic bacterial communities of the rhizosphere, the phylloplane, endophyte-infested seeds of planting material (Hallmann et al., 1997), or through natural plant openings and/or wounds (Eljounaidi, Lee, \& Bae, 2016). Endophytes can potentially colonize $100 \%$ of their host (Gond, Verma, Kumar, Kumar, \& Kharwar, 2007), and have been isolated from diverse plant tissues including: seeds, tubers, roots, stems, leaves, and fruits (Eljounaidi et al., 2016). While it is clear that their distribution within plants is uneven, some have found that plants have higher numbers of endophytes in the roots than in above-ground tissue (Eljounaidi et al., 2016; Gond et al., 2007), it was also found that there were greater abundances in the leaves, followed by roots, and lastly stems ( $\mathrm{Li}$ et al., 2014). Furthermore, population fluctuations of endophytes within a host species have been found to vary, depending on the citrus host species they inhabit (Andreote et al., 2008). Still, endophytes generally occur at lower population densities than pathogens (Hallmann et al., 1997), and/or rhizospheric bacteria (Rosenblueth \& Martínez-Romero, 2007).

Endophytes are most often classified as beneficial symbionts of their host plant (Prior, Görges, Yurkov, \& Begerow, 2014). They secrete varieties of extracellular enzymes that contribute to colonization and growth (Wang \& Dai, 2011b), and produce an array of compounds (discussed later) that ultimately benefit the life of the host plant (Ho et al., 2012). Meanwhile, the endophyte benefits from the plant because they are in a protected niche with relatively little competition, and have a consistent source of nutrition (Chanway, 1998; Menpara et al., 2013). An example of a symbiotic endophyte-host relationship is that of with Neotyphodium coenophialum (fungal endophyte), who protects its host against herbivory through the production of alkaloids (Soliman et al., 2013). Nonetheless, 
endophyte-plant host relationships have also been described as commensal, trophobiotic (Ryan et al., 2007), temporary residents, latent saprotrophs, and latent pathogens 2016). An example of an endophyte known to become a pathogen is Fusarium verticillioides, which is a common symptomless biotrophic endophyte of maize. However, under less than ideal conditions, the fungus may become a pathogen, and enter wounds in the roots (autoinfection) or though insects (alloinfection) (Bacon \& Hinton, 2011).

It is now known that endophytic community diversity and structure is altered when the host tree is infected with pathogens (Araújo et al., 2002; Lacava, Araújo, Marcon, Maccheroni, \& Azevedo, 2004) and/or is treated with insecticidal applications (Shen et al., 2013). For example, the diversity of endophytic communities between symptomatic (with phytopathogenic bacterium Xylella fastidiosa) and asymptomatic citrus trees was evaluated (Araújo et al., 2002); it was found that asymptomatic plants had higher frequencies of $C$. flaccumfaciens, whereas symptomatic plants had higher frequencies of Methylobacterium species. Additionally, long-term insecticidal applications have been found to decrease the diversity of endophytic bacteria in the citrus leaves (Shen et al., 2013). Similarly, endophyte community assemblages between two adjacent avocado orchards (one organic and one conventional) were also found to differ, showing differences in endophytic species frequencies (Shetty, Rivadeneira, Jayachandran, \& Walker, 2016).

\subsubsection{Antimicrobial Activity of Endophytes}

Several studies have shown significant antimicrobial activities of endophytes and have discussed their potential to be used as biocontrol agents. Examples of these studies include the following: Mejía et al., (2008) found that the fungal endophyte Colletotrichum gloeosporioides, (isolated from healthy Theobroma cacao leaves), significantly reduced 
the number of pod losses in Theobroma cacao that was infected with a Phytophthora pathogen. Bacon \& Hinton, (2011) found that seedling blight on Maize caused by Fusarium verticillioides was reduced (lesion size) with the endophyte (Bacillus mojavensis). Lacava, Li, Araújo, Azevedo, \& Hartung, (2007) found that Curtobacterium flaccumfaciens (most commonly isolated endophyte from asymptomatic trees), was able to reduce the severity of symptoms (no stunting and more flowers) in CVC (pathogen Xylella fastidiosa) infected periwinkle. Also, the endophyte Pseudomonas fluorescens has shown effective biocontrol (reduction of necrotic tumors) on the woody plant disease (olive knot), caused by the bacterial pathogen Pseudomona savastanoi (Cazorla \& Mercado-Blanco, 2016).

Table 2 provides a list of endophytes that have been reported to show antimicrobial activity; it includes the host plant it was isolated from, the potential endophyte, the kind of activity that was shown, and the organism it was tested against (Menpara \& Chanda, 2013). Like plant-derived antimicrobials, endophytic-derived antimicrobials represent naturally occurring compounds which are known to have minimal to no side effects, and thus hold immense potential as biocontrol agents. 


\begin{tabular}{|c|c|c|c|}
\hline Host plant & Potent endophytes & $\begin{array}{l}\text { Activity } \\
\text { shown }\end{array}$ & Tested organisms \\
\hline Panax ginseng & $\begin{array}{l}\text { Paenibacillus } \\
\text { polymyxa GS01, } \\
\text { Bacillus sp. GSO7, } \\
\text { and Pseudomonas } \\
\text { poae JAOI }\end{array}$ & Antifungal & Phytopathogenic fungi \\
\hline $\begin{array}{l}\text { T. grandiflora } \\
\text { Polyalthia sp. } \\
\text { Mapania sp. }\end{array}$ & $\begin{array}{l}\text { Streptomyces } \\
\text { fulvoviolaceus, } \\
\text { Streptomyces } \\
\text { coelicolor, } \\
\text { Streptomyces } \\
\text { caelestis }\end{array}$ & Antifungal & Phytopathogenic fungi \\
\hline $\begin{array}{l}\text { Scutellaria } \\
\text { baicalensis Georgi }\end{array}$ & $\begin{array}{l}\text { Bacillus } \\
\text { amyloliquefaciens }\end{array}$ & $\begin{array}{l}\text { Antibacterial, } \\
\text { Antifungal }\end{array}$ & $\begin{array}{l}\text { Phytopathogenic, } \\
\text { food-borne pathogenic and } \\
\text { spoilage bacteria and fungi }\end{array}$ \\
\hline Panax notoginseng & $\begin{array}{l}\text { Bacillus } \\
\text { amyloliquefaciens } \\
\text { subsp. plantarum, } \\
\text { Bacillus } \\
\text { methylotrophicus }\end{array}$ & Antifungal & $\begin{array}{l}\text { Phytopathogenic fungi and } \\
\text { nematode }\end{array}$ \\
\hline $\begin{array}{l}\text { Azadirachta } \\
\text { indica A. Juss. }\end{array}$ & $\begin{array}{l}\text { Streptomyces sp., } \\
\text { Nocardia sp. }\end{array}$ & $\begin{array}{l}\text { Antibacterial, } \\
\text { Antifungal }\end{array}$ & $\begin{array}{l}\text { Phytopathogenic fungi, } \\
\text { Human pathogenic bacteria } \\
\text { and fungus }\end{array}$ \\
\hline $\begin{array}{l}\text { Plectranthus } \\
\text { tenuiflorus }\end{array}$ & $\begin{array}{l}\text { Bacillus sp. } \\
\text { Pseudomonas sp. }\end{array}$ & $\begin{array}{l}\text { Antibacterial, } \\
\text { Antifungal }\end{array}$ & $\begin{array}{l}\text { Human pathogenic bacteria } \\
\text { and fungus }\end{array}$ \\
\hline Wheat & Bacillus subtilis & Antifungal & Phytopathogenic fungi \\
\hline Anthurium & B. amyloliquefaciens & Antibacterial & Phytopatogenic bacteria \\
\hline $\begin{array}{l}\text { Platycodon } \\
\text { grandiflorum }\end{array}$ & $\begin{array}{l}\text { Bacillus } \\
\text { licheniformis, } \\
\text { Bacillus pumilus, } \\
\text { Bacillus sp. }\end{array}$ & $\begin{array}{l}\text { Antibacterial, } \\
\text { Antifungal }\end{array}$ & $\begin{array}{l}\text { Phytopathogenic fungi and } \\
\text { anti-human food-borne } \\
\text { pathogenic organisms }\end{array}$ \\
\hline Artemisia anпиa & Streptomyces & $\begin{array}{l}\text { Antibacterial, } \\
\text { Antifungal }\end{array}$ & $\begin{array}{l}\text { pathogenic bacteria, yeast and } \\
\text { fungal phytopathogens }\end{array}$ \\
\hline Centella asiatica & $\begin{array}{l}\text { Bacillus subtilis, } \\
\text { Pseudomonas } \\
\text { fluorescens }\end{array}$ & Antifungal & Phytopathogenic fungi \\
\hline $\begin{array}{l}\text { Panicum } \\
\text { virgatum } L .\end{array}$ & $\begin{array}{l}\text { Bacillus subtilis, } C \text {. } \\
\text { flaccumfaciens, } P \text { s. } \\
\text { Fluorescens, } P \text {. } \\
\text { ananatis }\end{array}$ & Antifungal & Phytopathogenic fungi \\
\hline Raphanus sativus $\mathrm{L}$ & $\begin{array}{l}\text { Enterobacter sp., } B . \\
\text { subtilis }\end{array}$ & $\begin{array}{l}\text { Antibacterial, } \\
\text { Antifungal }\end{array}$ & $\begin{array}{l}\text { Phytopathogenic fungi, Human } \\
\text { pathogenic bacteria }\end{array}$ \\
\hline $\begin{array}{l}\text { Memecylon edule, } \\
\text { Tinospora } \\
\text { cordifolia, }\end{array}$ & $\begin{array}{l}\text { Bacillus } \\
\text { amyloliquefaciens }\end{array}$ & $\begin{array}{l}\text { Antibacterial, } \\
\text { Antifungal }\end{array}$ & $\begin{array}{l}\text { Human pathogenic bacteria } \\
\text { and fungus }\end{array}$ \\
\hline
\end{tabular}




\begin{tabular}{|c|c|c|c|}
\hline $\begin{array}{l}\text { S. lavandulifolia, } \\
\text { H. scabrum, R. } \\
\text { pulcher }\end{array}$ & Bacillus sp. & $\begin{array}{l}\text { Antibacterial, } \\
\text { Antifungal }\end{array}$ & $\begin{array}{l}\text { Human pathogenic bacteria } \\
\text { and saprophytic fungi }\end{array}$ \\
\hline Aloe chinensis & Paenibacillus species & $\begin{array}{l}\text { Antibacterial, } \\
\text { Antifungal }\end{array}$ & Pathogenic bacteria and fungi \\
\hline $\begin{array}{l}\text { Epimedium } \\
\text { brevicornu Maxim. }\end{array}$ & $\begin{array}{l}\text { Phyllobacterium } \\
\text { myrsinacearum }\end{array}$ & $\begin{array}{l}\text { Antibacterial, } \\
\text { Antifungal }\end{array}$ & $\begin{array}{l}\text { Phytopathogenic fungi and } \\
\text { phytopathogenic bacterium }\end{array}$ \\
\hline $\begin{array}{l}11 \text { mangrove } \\
\text { halophytic plants }\end{array}$ & $\begin{array}{l}\text { Bacillus } \\
\text { Thuringiensis and } \\
\text { Bacillus pumilus }\end{array}$ & Antibacterial & Shrimp pathogens \\
\hline Kandelia candel & $\begin{array}{l}\text { Streptomyces } \\
\text { sp. }\end{array}$ & Antibacterial & Several pathogenic bacteria \\
\hline $\begin{array}{l}\text { Codonopsis } \\
\text { lanceolata }\end{array}$ & $\begin{array}{l}\text { Bacillus pumilus } \\
\text { B. subtilis } \\
\text { B. licheniformis }\end{array}$ & Antifungal & Phytopathogenic fungi \\
\hline $\begin{array}{l}\text { Polygonum } \\
\text { cuspidatum }\end{array}$ & Streptomyces sp. & Antifungal & Pathogenic fungi \\
\hline Manihot esculenta & Paenibacillus sp. & Antifungal & Phytopathogenic fungus \\
\hline $\begin{array}{l}\text { Bruguiera } \\
\text { gymnorrhiza } \\
\text { Rhizophora stylosa } \\
\text { Kandelia candel }\end{array}$ & $\begin{array}{l}\text { Bacillus } \\
\text { amyloliquefaciens }\end{array}$ & $\begin{array}{l}\text { Antibacterial, } \\
\text { Antifungal }\end{array}$ & $\begin{array}{l}\text { Phytopathogenic fungi and } \\
\text { phytopathogenic bacteria }\end{array}$ \\
\hline Monstera sp. & Streptomyces sp. & $\begin{array}{l}\text { Antifungal, } \\
\text { Antimalarial }\end{array}$ & $\begin{array}{l}\text { Pythiaceous fungi } \\
\text { and the human fungal } \\
\text { pathogen, malarial } \\
\text { parasite }\end{array}$ \\
\hline Piper nigrum $L$ & $\begin{array}{l}P . \text { aeruginosa, } P \text {. } \\
\text { putida and } B . \\
\text { megaterium }\end{array}$ & Antifungal & Phytopathogenic fungus \\
\hline Huperzia serrata & Burkholderia sp. & Antifungal & Phytopathogenic fungi \\
\hline $\begin{array}{l}300 \text { plants from } \\
\text { upper Amazonian } \\
\text { Rainforests }\end{array}$ & $\begin{array}{l}\text { Streptomyces sp. } \\
\text { Micromonospora sp. } \\
\text { Amycolatopsis sp. }\end{array}$ & $\begin{array}{l}\text { Antibacterial, } \\
\text { Antifungal }\end{array}$ & $\begin{array}{l}\text { Range of potential fungal and } \\
\text { bacterial pathogens }\end{array}$ \\
\hline $\begin{array}{l}\text { Lycopersicon } \\
\text { esculentum }\end{array}$ & $\begin{array}{l}\text { Streptomyces sp., } \\
\text { Microbispora sp., } \\
\text { Micromonospora sp. } \\
\text { and Nocardia sp. }\end{array}$ & $\begin{array}{l}\text { Antibacterial, } \\
\text { Antifungal }\end{array}$ & $\begin{array}{l}\text { Phytopathogenic fungi and } \\
\text { phytopathogenic bacteria }\end{array}$ \\
\hline
\end{tabular}

Table 2: List of some reported endophytes with antimicrobial activity 
In fact, many endophytes are already being used to control several pathogens and/or diseases, such as: vascular pathogen $V$. dahlia (in olive trees), Cytospora chrysosperma, Phomopsis macrospora and Fusicoccum aesuli (all cause poplar canker), Xylella fastidiosa (causes CVC -citrus variegated chlorosis), and several cacao pod diseases (Cazorla \& Mercado-Blanco, 2016). Some fungi that have been isolated from Chinese herbs are used as biocontrol for agricultural crops (Ho et al., 2012), and several endophytes have been considered potential biocontrol agents for vascular wilt disease (Eljounaidi et al., 2016).

\subsubsection{Citrus Endophytes}

The isolation and characterization of endophytes originating in citrus have been studied in order to better understand the endophytic communities inhabiting citrus. One study isolated bacterial and fungal endophytes from 8 citrus rootstocks (Welington Luiz Araújo et al., 2001). They found that "the principal bacterial species isolated were Alcaligenes sp., Bacillus sp. (including B. cereus, B. lentus, B. megaterium, B. pumilus, and B. subtilis), Burkholderia cepacia, Curtobacterium flaccumfaciens, Enterobacter cloacae, Methylobacterium extorquens, and Pantoea agglomerans, with P. agglomerans and B. pumilus being the most frequently isolated species." The most abundant fungal species were Colletotrichum gloeosporioides, Guignardia citricarpa, and Cladosporium

$s p$. Table 3 shows the densities of the major endophytic bacteria isolated (Welington Luiz Araújo et al., 2001). 


\begin{tabular}{|c|c|c|c|c|c|c|c|c|c|c|}
\hline \multirow[b]{2}{*}{ Citrus rootstocks* } & \multicolumn{10}{|c|}{ Endophytic bacteria $\left(10^{3} \mathrm{CFU}_{\mathrm{g}}{ }^{-1}\right.$ fresh weight tissue) } \\
\hline & $\begin{array}{l}\text { Pantoea } \\
\text { agglomerans }\end{array}$ & $\begin{array}{l}\text { Enterobacte } \\
r \text { cloacae }\end{array}$ & $\begin{array}{l}\text { Burkholderia } \\
\text { cepacia }\end{array}$ & $\begin{array}{l}\text { Curtabacterium } \\
\text { flaccumfaciens }\end{array}$ & $\begin{array}{l}\text { Methylabacteri } \\
\text { um extorquens }\end{array}$ & $\begin{array}{l}\text { Bacillus } \\
\text { pumilus }\end{array}$ & B. subtilis & $\begin{array}{l}\text { Bacillus } \\
\text { spp. }\end{array}$ & $\begin{array}{l}\text { Alcaligenes } \\
\text { sp. }\end{array}$ & Total $^{+}$ \\
\hline Citrus volkameriana & $6.7^{\ddagger}$ & 1.2 & 0.0 & 0.0 & 0.2 & 1.9 & 2.1 & 0.6 & 0.0 & $12.7 \mathrm{a}$ \\
\hline C. sinensis & 1.4 & 2.6 & 1.6 & 1.8 & 1.3 & 2.4 & 1.3 & 0.0 & 0.1 & $12.5 \mathrm{a}$ \\
\hline C. sunki & 3.7 & 0.0 & 0.2 & 0.0 & 0.0 & 1.2 & 1 & 1.1 & 0.0 & $7.2 \mathrm{~b}$ \\
\hline P. trifoliata $\times C$ sinensis & 2.1 & 0.4 & 0.9 & 0.0 & 0.0 & 3.4 & 0.0 & 0.0 & 0.3 & $7.1 \mathrm{~b}$ \\
\hline C. paradisi $\times C$ reticulata & 3.4 & 0.2 & 0.0 & 0.0 & 0.9 & 0.8 & 0.9 & 0.0 & 0.1 & $6.3 \mathrm{~b}$ \\
\hline C. resnhi & 0.4 & 0.0 & 2.2 & 0.7 & 0.0 & 0.4 & 0.0 & 1.3 & 0.0 & $5.0 \mathrm{c}$ \\
\hline C. limonia & 0.2 & 0.0 & 0.0 & 0.6 & 0.3 & 2.6 & 0.7 & 0.2 & 0.0 & $4.6 \mathrm{~cd}$ \\
\hline Poncinus trifoliata & 1.4 & 0.0 & 0.0 & 0.0 & 1.1 & 0.7 & 0.0 & 0.5 & 0.0 & $3.7 \mathrm{~d}$ \\
\hline
\end{tabular}

Table 3: Densities of endophytic bacteria isolated from 8 citrus rootstocks

Similarly, the most commonly isolated endophytic bacteria in citrus orchards located in Brazil have been described as: Methylobacterium spp., Curtobacterium flaccumfaciens, Pantoea agglomerans, Bacillus spp., Pseudomonas spp., Alcaligenes spp. and Enterobacter cloacae (Andreote et al., 2008). Durán et al., (2005) isolated fungal endophytes from Citrus limon in Argentina, and also found that Colletotrichum gloeosporioides (responsible for anthracnose) was a consistently dominant species; though, they also found that Guignardia citricrpa (another pathogenic fungi) was also common.

Other species of endophytes that have been found in citrus are Physoderma citri, (one of the first to be reported in healthy $C$. sinensis plants) (Welington Luiz Araújo et al., 2001). As well as an Eupenicillium species that was isolated from healthy leaves of Murraya paniculata (Barros \& Rodrigues-Filho, 2005). As noted, endophytic communities vary based on a variety of factors, such as host species and environmental factors. Still, the most commonly isolated endophytic bacteria (of all tree species) have been found to be the following genera: Pseudomonas, Bacillus, Enterobacter, and Agrobacteium (Eljounaidi et al., 2016).

\subsection{Benefits of Endophytes}

Endophytes are capable of providing an array of benefits to their host plant, which ultimately enhances the host's fitness (Anjum \& Chandra, 2015a). Endophytes can 
synthesize biologically active substances that are similar to the secondary metabolites produced by plants (Wang \& Dai, 2011b), many with therapeutic functions such as phenols, flavonoids, terpenoids, lignans (Ho et al., 2012), alkaloids, phenolic compounds, etc. (Anjum \& Chandra, 2015a).

These secondary metabolites have demonstrated significant antimicrobial activity (antibiotic, antifungal, and antiviral) (Anjum \& Chandra, 2015a; Eevers et al., 2015; Ho et al., 2012; Paulo Teixeira Lacava, Araújo, \& Azevedo, 2007; Menpara et al., 2013; Wang \& Dai, 2011). Some endophytes also produce other bioactive metabolites such as antitumor, antioxidant, anti-inflammatory, immunosuppressive drugs (Anjum \& Chandra, 2015a), and even anticancer properties. For example, Taxomyces andreanae is a fungal endophyte that produces taxol with anticancer activity (Ho et al., 2012). Thus, many of these metabolites can be applied in medicine and also as biocontrol (Menpara \& Chanda, 2013).

Additionally, the secondary metabolites produced by endophytes also directly promote plant growth (Prior et al., 2014) and yield (Hallmann et as 1., 1997). The production of secondary metabolites may occur either through direct antagonism of pathogens or by inducing the systemic host resistance or immunity (Chanway, 1998; Rosenblueth \& Martínez-Romero, 2007). More specifically, they can prevent disease development (Disha Menpara \& Chanda, 2013; Rosenblueth \& Martínez-Romero, 2007; Sturz, Christie, \& Nowak, 2000), by controlling parasitic insects and nematodes (Araújo et al., 2002; Chanway, 1998) suppressing pathogens (Hallmann et al., 1997), and inducing resistance to herbivores, parasites, drought, and other abiotic stresses (Anjum \& Chandra, 2015b; Prior et al., 2014). For example, they may release compounds that render plant 
tissue less attractive to herbivores (Chanway, 1998). Also, beneficial host-endophyte allelopathy forms, which lead to fertile and disease-suppressive soils (Sturz et al., 2000). It is for these reasons that endophytes are often considered biological control agents ( $\mathrm{Li}$ et al., 2014; Ryan et al., 2007).

Endophytes are also capable of increasing nutrient availability (Rosenblueth \& Martínez-Romero, 2007; Soliman et al., 2013), by solubilizing phosphate, producing siderophores (Rosenblueth \& Martínez-Romero, 2007), or by suppling fixed nitrogen (Anjum \& Chandra, 2015b) in non-legumes; which can increase nitrogen economy of the crop and reduce nitrogen fertilizers inputs (Sturz et al., 2000). In some cases, they can also accelerate seedling emergence and promote plant establishment under adverse conditions (Araújo et al., 2002).

Endophytes can also degrade xenobiotics or may act as vectors to introduce degradative traits (Ryan et al., 2007), thus helping to remove contaminants (Rosenblueth \& Martínez-Romero, 2007). In fact, some are resistant to heavy metals and/or antimicrobials, which is thought to be a result of their exposure to diverse compounds in the plant/soil niche (Ryan et al., 2007). Hence, they have been described as potential resources for biosynthesis, biotransformation, and biodegradation (Wang \& Dai, 2011b), and can be used as food preservatives to control food spoilage and food-borne diseases (Menpara \& Chanda, 2013).

\subsubsection{Ideal Candidates}

Novel endophytic bacterial strains have unique biological systems (Menpara \& Chanda, 2013), which are likely to contain new genes and thus, increases the chances of finding novel pharmaceutical bioactive compounds (Menpara \& Chanda, 2013; Wang \& 
Dai, 2011b). Additionally, endophytes offer a natural means of control that is potentially self-sustaining and able to spread its own (after initial establishment); thus, promoting long term disease suppressions and reducing chemical inputs (Eljounaidi et al., 2016). Moreover, since they reside in an ecological niche extremely similar to that of many phytopathogens it makes them ideal candidates for biocontrol agents (Araújo et al., 2002; Eljounaidi et al., 2016; Hallmann et al., 1997; Ryan et al., 2007), especially for long-living woody plant diseases (Cazorla \& Mercado-Blanco, 2016). Endophytes are a storehouse full of potential products waiting to be harnessed for use in medicine, agriculture and/or industry (Ryan et al., 2007).

\subsubsection{Challenges}

While endophytes harbor immense biocontrol potential, successful applications involve numerous challenges (Trivedi et al., 2016). To begin with, some endophytic antimicrobial compounds have unspecific toxicity, which means they may be potentially toxic to humans or other organisms (Menpara \& Chanda, 2013). Certain human pathogens, like salmonella species, have been found as endophytes; which cannot be removed through the disinfection procedures that are used for superficial bacteria (Rosenblueth \& MartínezRomero, 2007). Thus, it is crucial to identify endophytes that are potentially pathogenic in early stages of research, so that they are not even considered for biocontrol. Also, since the biological activity of endophytes is based on their metabolites, some have argued that pathogens can also develop resistance to these metabolic extracts as quickly as they can with human-made synthesized compounds (Eljounaidi et al., 2016).

There are also challenges in the implementation of endophytes as biocontrol when dealing with trees (opposed to herbaceous, annual plants). These challenges occur because 
they have a larger biomass, more complex anatomy, and greater longevity; also, the difficulty of reaching the pathogen within the vascular vessels (Cazorla \& MercadoBlanco, 2016). Another possible challenge to consider is the successful colonization of the endophyte (resulting from competition from the diverse microflora). For this, it has been suggested to establish the endophyte community early on, into rhizosphere or host tissue. Lastly, while certain endophytes may show bioactivity in the lab and greenhouse, the same may not necessarily occur in the field due to poor viability during storage, poor colonization, or because they produce very low yields in cultures (Eljounaidi et al., 2016). Nevertheless, in vitro studies are particularly useful for identifying likely candidates for biocontrol and attempting to understand the mechanisms by which they work (Mejía et al., 2008).

\subsubsection{Opportunities}

Genetic engineering tools which focus on the regulatory gene in the synthesis path of antimicrobial compounds could be helpful at increasing the yield of the active substance synthesized by the endophytes. Also, they can modify the structure of the metabolite to improve its efficacy and enhance the antimicrobial's activity, as well as potentially reduce any antimicrobial toxicity of the compounds (Menpara \& Chanda, 2013). Through genetic engineering, the possibility of introducing nonpathogenic endophytes systemically into the host plant tissue would provide protected and sustained activity of the inhibitory compound (Fahey, Dimock, Tomasino, Taylor, \& Carlson, 1991). Lastly, given that the vector of CVC (Bucephalogonia xanthophys) is able to transport the endophytic biocontrol bacterium Methylobacterium mesophilicum, it seems that this may also be an interesting avenue to 
consider for new biocontrol approaches of other pathogenic diseases (Cazorla \& MercadoBlanco, 2016).

\subsubsection{Escape Plants}

Escape plants are known as plants that live in areas that are heavily infected with pathogens and vectors, yet are somehow surviving (Trivedi et al., 2011). The microbial community of escape plants has been found to be enriched in beneficial traits (compared to symptomatic plants) (Riera, Handique, Zhang, Dewdney, \& Wang, 2017a; Pankaj Trivedi et al., 2011), and in several cases these escape plants have been associated with certain endophytes (Trivedi et al., 2009; Trivedi et al., 2011). Healthy "escape" citrus plants within heavily HLB-infected groves have been reported (Zhang et al., 2013). In fact, one study isolated endophytes from the healthy citrus rhizospheres of escape trees, and found six that showed inhibition against S. melilot and A. tumefaciens (both who closely related to CLas) (Riera et al., 2017b).

\subsection{Model Organisms}

The inability to culture CLas severely limits our understanding of its physiology, molecular biology, biochemistry (Doud et al., 2017) and mechanism of infection; making it that much more difficult to develop treatments for (Lai, Davis-Richardson, Dias, \& Triplett, 2016). The un-culturable nature of these pathogens also limits our methods of testing possible disease control strategies to in-planta studies (Doud et al., 2017).

Nonetheless, its complete genome sequence (Duan et al., 2009) contributed significantly to our understanding of the pathogen (Trivedi et al., 2016). For example, that CLas has a small genome that lacks genes that would normally encode pathogenicity determinants (Pagliai et al., 2014; Pan, Gardner, Pagliai, Gonzalez, \& Lorca, 2017). This 
also allowed the comparison of its genome to that of other species, where it was determined that CLas phylogenetically related to was Sinorhizobium meliloti (S. meliloti) (Duan et al., 2009). As a result, $S$. meliloti is now commonly used as a surrogate (Pagliai, Gonzalez, \& Lorca, 2015; Stover et al., 2013), where it is used in-vitro to test for any potential antimicrobial activity against CLas (Hu \& Wang, 2016; Pagliai et al., 2014; Riera et al., 2017a).

In 2012, Liberibacter crescens, (L. crescens) isolate BT-1, became the first and only Liberibacter species to be cultured (holds true today) (Fagen et al., 2014). It was recovered from the phloem sap of defoliating mountain papaya in Puerto Rico, and was found to be a Gram-negative, rod-shaped, $\alpha$-proteobacterium (Leonard, Fagen, DavisRichardson, Davis, \& Triplett, 2012; Nakabachi et al., 2013). Genomic sequencing revealed that $L$. crescens shares $94.7 \%$ 16S rRNA gene sequence with CLas (Leonard et al., 2012). Liberibacter crescens is currently the closest cultured relative of CLas (Lai

et al., 2016); thus, has subsequently become another frequently used model organism for CLas (Blaustein et al., 2018; Gardner et al., 2016; Jain, Munoz-Bodnar, \& Gabriel, 2017; Lai et al., 2016; Pagliai et al., 2015).

\section{METHODOLOGY}

\subsection{Bacterial strains and Culture Conditions}

1. Liberibacter crescens (DSM 26877), was obtained from DSMZ, Germany. The strain was grown in BM-7 liquid media (Fagen et al., 2014) or on BM-7 agar, incubated at $28 \mathrm{oC}$ for 6 - 7 days. The BM-7 liquid culture tubes were kept in an incubator shaker (Excela, New Brunswick Scientific, N.J.) at $150 \mathrm{rpm}$. The bacterial strain was periodically transferred into new media. 
2. Sinorhizobium meliloti (1011), was obtained from the USDA ARS National Rhizobium Germplasm Collection (Beltsville, MD). The strain was grown on yeast extract mannitol agar and incubated at 28 oC. The bacterial strain was transferred to fresh media every 12 to 14 days.

\subsection{Preparation of Media}

The following microbial culture mediums were used throughout the course of the work. The composition of each of the following mediums is expressed for the preparation of $1000 \mathrm{~mL}$, with the exception of BM-7 media which is listed to prepare that of $100 \mathrm{~mL}$ (due to its expensive ingredients and high probabilities of contamination).

\section{BM-7}

One hundred grams of TMN-FH insect medium (Sigma-Aldrich, St. Louis, MO) were dissolved in $1000 \mathrm{~mL}$ of DI water and filtered sterilized. The sterile TMN-FH medium was then distributed into sterile centrifuge tubes containing $30 \mathrm{~mL}$ each. The centrifuge tubes were stored at $4^{\circ} \mathrm{C}$ until individual tubes were needed to prepare media (removed 2 hours prior to using). Fetal Bovine Serum or FBS (HyClone, GE Healthcare USA) was purchased (100 mL bottles), and distributed into sterilized test tubes containing $15 \mathrm{~mL}$ each. The tubes were stored at $-20^{\circ} \mathrm{C}$ until needed for media preparation (removed 24 hours prior to using).

One hundred milliliters of BM-7 media was prepared by adding $55 \mathrm{~mL}$ of DI water to a beaker (no less than $200 \mathrm{~mL}$ ), followed by the addition of 0.2 grams of alpha keto glutaric aid, 1 gram of ACES, and 0.375 grams of Potassium hydroxide pellets. The solution was stirred until dissolved, and the $\mathrm{pH}$ was adjusted (if necessary) to 6.9. Next the solution was autoclaved at $121^{\circ} \mathrm{C}$ for 15 minutes, and then kept in a water bath at $90^{\circ} \mathrm{C}$. 
One tube of prepared TMN-FH $(30 \mathrm{~mL})$ and one tube of FBS $(15 \mathrm{~mL})$ are then added under a fume hood. Lastly, the media is then poured into desired sized petri dishes (either $90 \mathrm{~mm}$ or $60 \mathrm{~mm})$.

TSA

Forty grams of Tryptic Soy Agar (BD, Difco Laboratories, Detroit, USA) medium were dissolved in $1000 \mathrm{~mL}$ of DI water. The medium was autoclaved for 15 minutes at $121^{\circ} \mathrm{C}$ and placed in a water bath at $50^{\circ} \mathrm{C}$ for approximately 15 minutes. The media could then be poured into the desired sized petri dishes.

\section{TSA + Cycloheximide (100 ppm)}

Forty grams of Tryptic Soy Agar medium were dissolved in $1000 \mathrm{~mL}$ of DI water. The medium was autoclaved for 15 minutes at $121^{\circ} \mathrm{C}$ and placed in a water bath at $50^{\circ} \mathrm{C}$ for approximately 15 minutes. One hundred milligrams of cycloheximide (100 ppm) were then dissolved in $10 \mathrm{~mL}$ of DI water and then filter sterilized through a $0.2 \mu \mathrm{m}$ filter into the TSA media bottle. The media could then be poured into the desired sized petri dishes. TSA + Sucrose + Cycloheximide (50 ppm)

Forty grams of Tryptic Soy Agar medium and 34.23 grams of sucrose (100 mM) were dissolved in DI water in a final volume of 1 Liter. The solution was autoclaved for 15 minutes at $121^{\circ} \mathrm{C}$ and placed in a water bath at $50^{\circ} \mathrm{C}$ for approximately 15 minutes. Fifty milligrams of cycloheximide (50 ppm) were then dissolved in $10 \mathrm{~mL}$ of DI water and then filter sterilized through a $0.2 \mu \mathrm{m}$ filter into the media bottle. The media could then be poured into the desired sized petri dishes. 


\section{TSB}

Forty grams of Tryptic Soy Broth were dissolved in $1000 \mathrm{~mL}$ of DI water in a 2000 $\mathrm{mL}$ bottle. The solution was autoclaved for 15 minutes at $121^{\circ} \mathrm{C}$ and placed in a water bath at $50^{\circ} \mathrm{C}$ for approximately 15 minutes. The media was then distributed into Erlenmeyer flasks at the desired volume (varied).

\section{PDA / dilute PDA}

Thirty-nine grams of Potato Dextrose Agar (BD, Difco Laboratories, Detroit, USA) were dissolved in $1000 \mathrm{~mL}$ of DI water in a $2000 \mathrm{~mL}$ bottle. The media was autoclaved for 15 minutes at $121^{\circ} \mathrm{C}$ and placed in a water bath at $50^{\circ} \mathrm{C}$ for approximately 15 minutes. The media could then be poured into the desired sized petri dishes.

Similarly, dilute (1/10) PDA was prepared by dissolving 3.9 grams of PDA into $1000 \mathrm{~mL}$ of DI water in a $2000 \mathrm{~mL}$ bottle. Followed by the same procedures as for the full-strength PDA (autoclave, cool and pour).

\section{PDA + Streptomycin (100 ppm)}

Thirty-nine grams of Potato Dextrose Agar were dissolved in $990 \mathrm{~mL}$ of DI water in a $2000 \mathrm{~mL}$ bottle. The solution was autoclaved for 15 minutes at $121^{\circ} \mathrm{C}$ and placed in a water bath at $50^{\circ} \mathrm{C}$ for approximately 15 minutes. One hundred milligrams of streptomycin (100 ppm) were then dissolved in $10 \mathrm{~mL}$ of DI water and then filter sterilized through a 0.2 $\mu \mathrm{m}$ filter into the PDA media bottle. The media could then be poured into the desired sized petri dishes.

\section{YMA}

Yeast Mannitol Agar (specific media for S. meliloti) was prepared by dissolving the following ingredients in $1000 \mathrm{~mL}$ of DI water: 1 gram of yeast extract, 10 grams of 
mannitol, 0.5 grams of dipotassium phosphate, 0.2 grams of magnesium sulfate, 0.1 gram of sodium chloride, 1 gram of calcium carbonate, and 15 grams of agar. Once dissolved, the solution was autoclaved for 15 minutes at $121^{\circ} \mathrm{C}$ placed in a water bath at $50^{\circ} \mathrm{C}$ for approximately 15 minutes and poured into $90-\mathrm{mm}$ sterile petri dishes.

\section{YMA + PDA}

Yeast Mannitol Agar was combined with Potato Dextrose Agar (for the dual culture assay using fungi). This media was prepared as follows: 0.5 grams of yeast extract, 5 grams of mannitol, 0.25 grams of dipotassium phosphate, 0.1 gram of magnesium sulfate, .05 grams of sodium chloride, 0.5 grams of calcium carbonate, 19.5 grams of PDA and 15 grams of agar were dissolved in $1000 \mathrm{~mL}$ of DI water. Once dissolved, the solution was autoclaved for 15 minutes at $121^{\circ} \mathrm{C}$, placed in a water bath at $50^{\circ} \mathrm{C}$ for approximately 15 minutes and poured into $60 \mathrm{~mm}$ sterile petri dishes.

\section{R2A}

Reasoner's 2A agar was prepared by dissolving 18.2 grams of R2A media (BD, Difco Laboratories, Detroit, USA) in $1000 \mathrm{~mL}$ of DI water. The solution was then autoclaved for 15 minutes at $121^{\circ} \mathrm{C}$, and placed in a water bath at $50^{\circ} \mathrm{C}$ for approximately 15 minutes. The media was then be poured into the $90 \mathrm{~mm}$ petri dishes.

\section{Coconut Water}

Coconut water media was prepared by cutting open a coconut, collecting coconut water in a sterile beaker after passing it through a $0.2 \mu \mathrm{L}$ filter, and then transferring $2 \mathrm{~mL}$ of the sterile coconut water into each of 10 sterilized vials. 


\subsection{Plant-based Antimicrobials}

Commercial ethanol extract samples from 13 different medicinal plant species were purchased. The first was Herb Pharm Certified Organic Artemisia Аnnиa (Sweet Annie). The second, third and fourth extracts were each natural extract tinctures from Montana Farmacy, and were the following: Cryptolepis Sanguinolenta, Alchornea Cordifolia and Bidens Pilosa. The fifth extract was Teasel (Dipsacus fullonum) Dried Root Glycerite, an alcohol-free liquid extract, ordered from HawaiiPharm. The sixth extract was alcohol-free Cat's Claw Inner Bark (Uncaria tomentosa). The seventh was 100\% pure wild essential oregano oil (Origanum vulgare), with Min 95\% Carvacrol. The eight was 100\% pure, undiluted, therapeutic grade, plant therapy thyme thymol essential oil (Thymus vulgaris). The ninth was herb pharm certified organic cinnamon extract (Cinnamomum aromatioum) for cardiovascular and circulatory support. The tenth was herb pharm certified organic turmeric root extract (Curcuma longa) for musculoskeletal system support. The eleventh was herb pharm certified organic holy basil (Tulsi) (Ocimum tenuiflorum) extract for energy and vitality. The twelfth was herb pharm usnea extract for cleaning and detoxification, and the thirteenth and final was banderol (Otoba parvifolia) microbial defense, from NutraMedix.

\subsection{Sample Collection and Site Description}

Samples were collected from two sites. The first site was Uncle Matt's Organic Farm located at 12351 Sullivan Rd, Clermont, FL 34715 (coordinates 28³6'38.9"N $\left.81^{\circ} 45^{\prime} 00.3^{\prime \prime} \mathrm{W}\right)$. The site includes ten acres of Naval orange trees, and has been organic since 1999. Young branch samples were collected from three Naval orange survivor trees expressing minimal HLB-like symptoms. Three branches were collected from each tree for 
a total of nine branches from this site (later cut into three further segments). Beginning from the South end, and from east to west the three trees from which the samples were collected were located were chosen as follows: Tree 1 was found in row 3 tree 6 , Tree 2 was found in row 4 tree 13, and Tree 3 was found in row 2 tree 7.

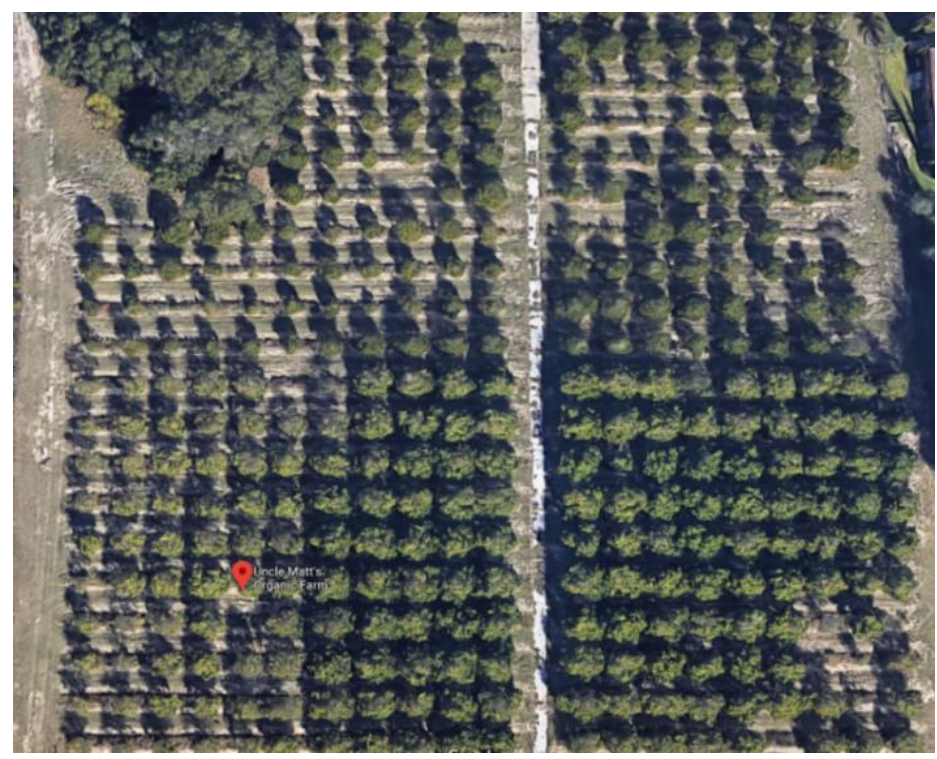

Figure 5: Uncle Matt's Organic Orchard (Satellite image of site 1)

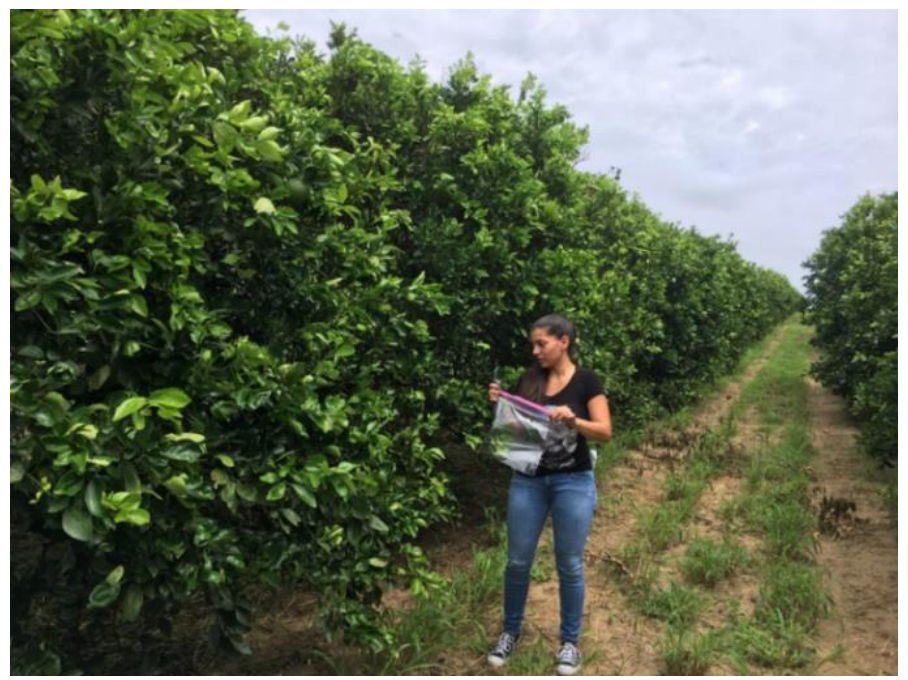

Figure 6: Collecting samples from site 1

The second site is also Uncle Matt's Organic property and was the first of their groves to become certified organic (in 1998). This site is located at 20574 Sugarloaf 
Mountain Road, Clermont Florida 34715 (coordinates $28^{\circ} 38^{\prime} 54.4^{\prime \prime N} 81^{\circ} 44^{\prime} 1.44^{\prime \prime} \mathrm{W}$ ). It is a half-acre site consisting of mostly Valencia trees, as well as red Valencia, flying dragon, and blood orange hybrids. Young, symptom free branch samples were collected from two distinct trees. Tree 4 was a Valencia orange tree located in row 6 tree 5, and Tree 5 was a Blood orange tree located in row 3 tree 20.

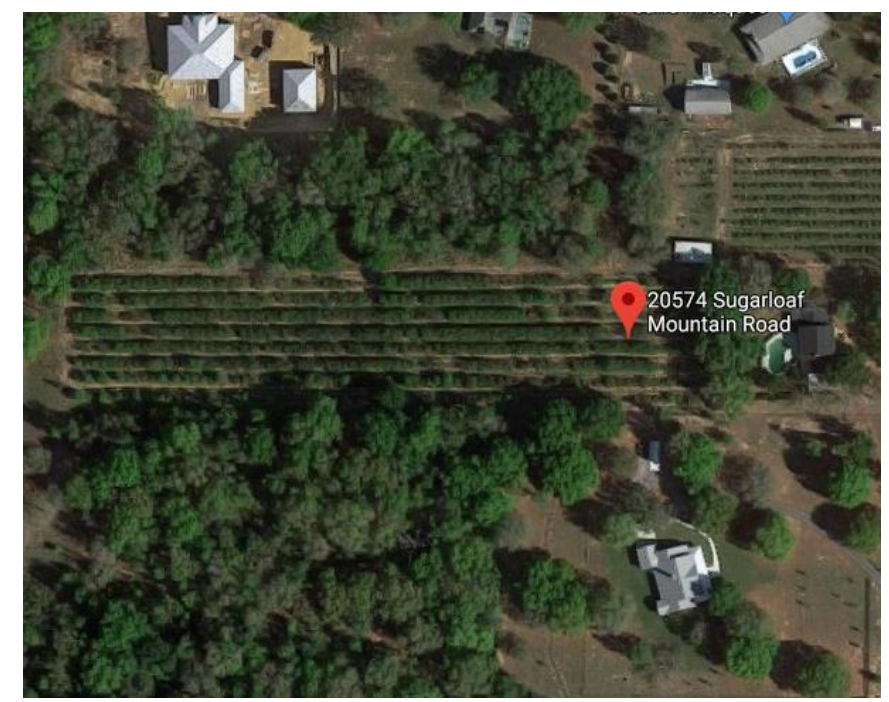

Figure 7: Uncle Matt's Organic Orchard (Satellite image of site 2)

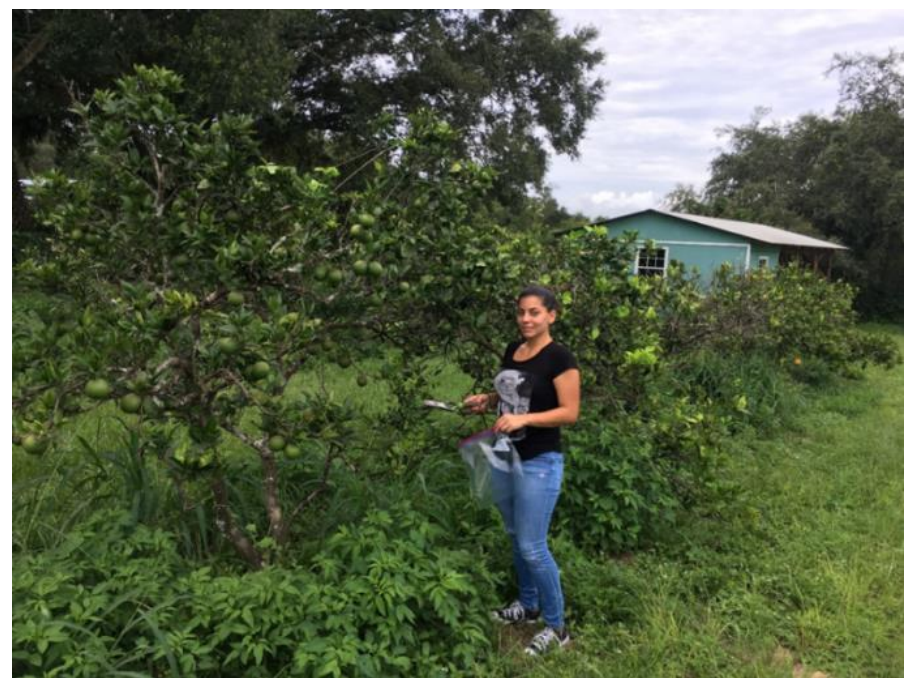

Figure 8: Collecting samples from site 2 


\section{5 Endophyte Isolation}

The branches were washed to clear dust and debris using dish soap and water. Branch samples were divided into 3 segments each, for a total of 45 branch segments: 5 trees, 3 branches from each and 3 segments from each branch (Figure 9). Each segment was then surface sterilized using $70 \%$ ethanol (70\% of $99.5 \%$ ethanol and $30 \%$ sterile DI water) for 1 minute followed by $10 \%$ Clorox for 3 minutes and then rinsed three times with sterile DI water. The surface sterilization process was verified by pressing the random samples of disinfected plant material onto fresh tryptic soy and potato dextrose agar plates and observing the plates for $3-15$ days for bacterial and fungal growth. Once the surfaces were sterilized, multiple thin pieces (approx. $5 \mathrm{~mm}$ ) were cut from each segment to be transferred into 4 distinct media types. Three $5 \mathrm{~mm}$ pieces were transferred on to a $90 \mathrm{~mm}$ petri dish containing dilute PDA amended with streptomycin $(100 \mu \mathrm{gml}-1)$. Another $5 \mathrm{~mm}$ piece was cut and ground with $1 \mathrm{~mL}$ sterile DI water using sterile mortar and pestle (Figure 10). One hundred $\mu 1$ of homogenate (ground tissue) was then transferred on to a $90 \mathrm{~mm}$ petri dish containing TSA amended with cycloheximide (100 $\mu \mathrm{gml}-1)$. Also, $100 \mu \mathrm{l}$ of homogenate from another $5 \mathrm{~mm}$ segment from each branch (chosen at random) was transferred on to a $90 \mathrm{~mm}$ TSA petri dish containing $100 \mathrm{mM}$ (millimolar) sucrose solution, as well as cycloheximide $(100 \mu \mathrm{gml}-1)$. Furthermore, $100 \mu 1$ of homogenate from two $5 \mathrm{~mm}$ segments from each tree (chosen at random) were also transferred into the vials containing pure coconut water. The reason for the use of different media was to increase both the quantity and diversity of endophytes isolates. Once all segments and homogenates were transferred, TSA plates, TSA + sucrose plates and coconut water vials (total of 115 plates) 
were incubated at $28{ }^{\circ} \mathrm{C}$, and dPDA plates (total of 45) were wrapped with aluminum and incubated at $25^{\circ} \mathrm{C}$.

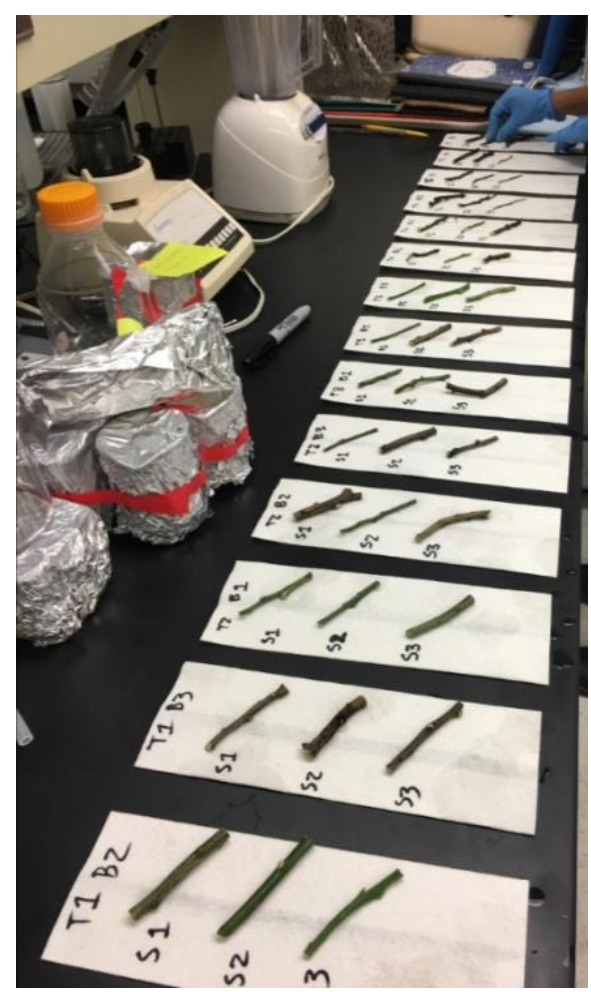

Figure 9: Preparation of 45 branch samples (from which endophytes were isolated)

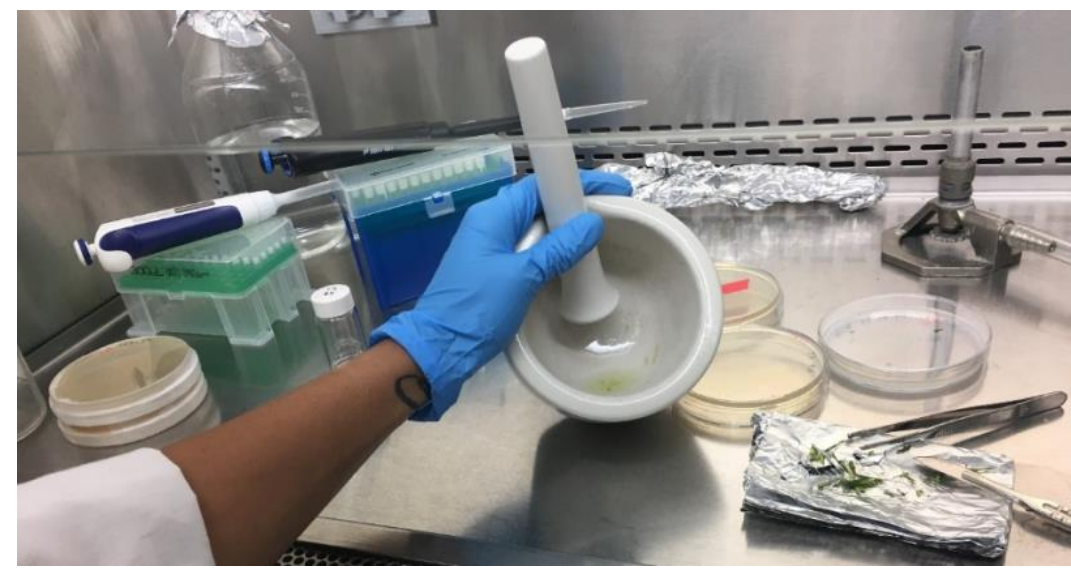

Figure 10: Endophyte Isolation Procedure: Grinding $5 \mathrm{~mm}$ segments in a sterile mortar and pestel with 1

\subsubsection{Pure Culture Isolations} $\mathrm{mL}$ of sterilized water

Beginning one week after the endophyte isolation procedure, the different fungal and bacterial colonies that emerged from the branch fragments were sub-cultured and 
purified. Each distinct colony was subculture into individual $90 \mathrm{~mm}$ plates until pure isolates were obtained from each distinct colony. Bacterial colonies grown on TSA plates with cycloheximide were isolated onto TSA only plates. Similarly, fungal colonies grown on IPDA plates amended with streptomycin were isolated onto full strength PDA plates (no streptomycin). Colonies that grew on TSA+S plates were sub-cultured/ isolated onto two distinct plates: another TSA+S plate, as well as TSA only plates; this was done to see if those isolates were also able to grow in pure TSA media, or if their isolation was made possible specifically because of the additional sugar added to the TSA. Coconut vials showing growth were transferred into R2A media. All sub-cultured isolates were then incubated again at $28{ }^{\circ} \mathrm{C}$. Once each endophyte was successfully isolated, endophyte characteristics were described and put into a table. An example of how the pure culture isolations were derived from the original endophyte isolation plates is shown in figure 11. 

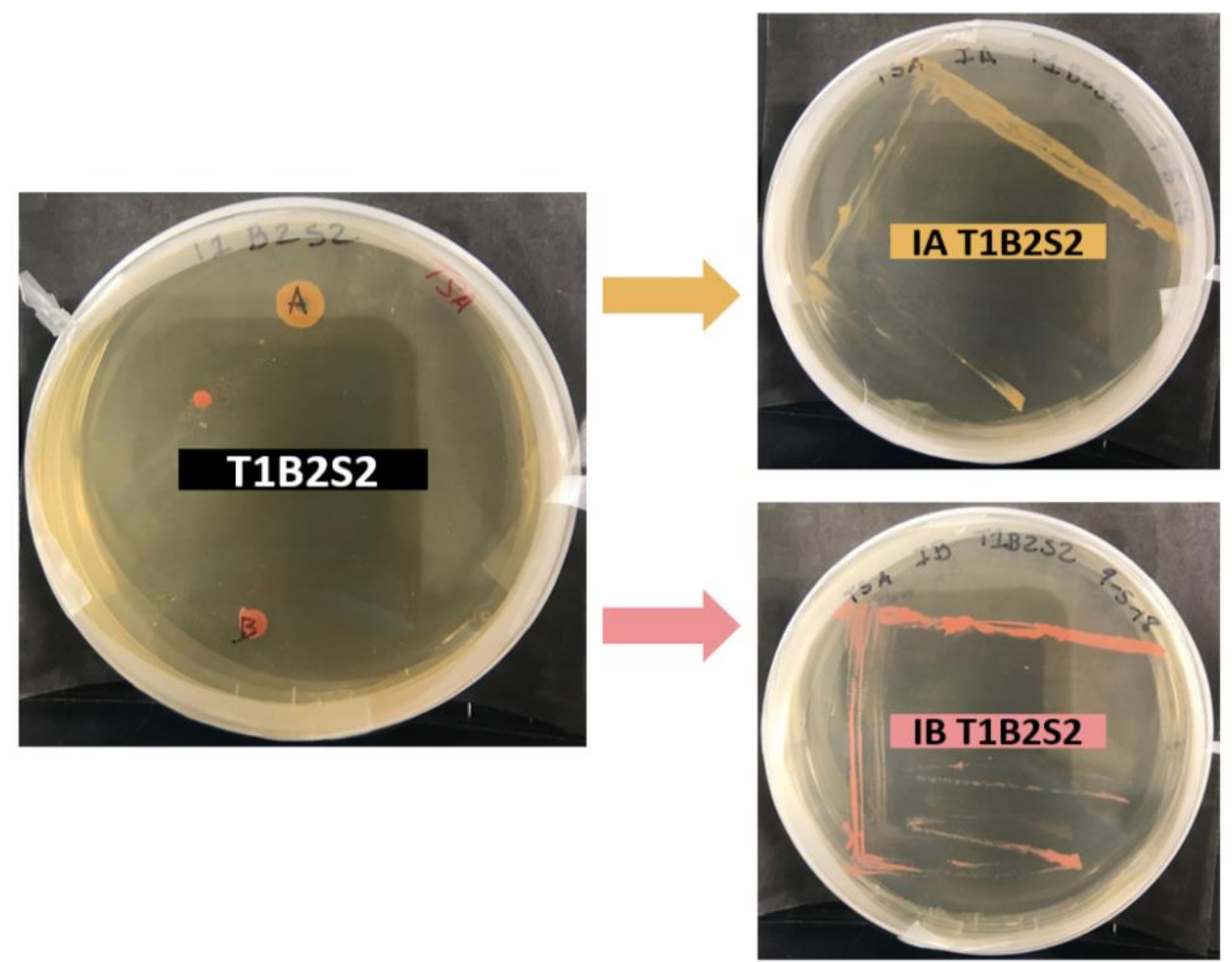

Figure 11: An example of pure culture isolations (IA T1B2S2 and IB T1B2S2) from original endophyte isolation plates (T1B2S2)

\subsection{Dual Culture Assay}

Each isolated endophyte was screened for antagonistic activity using the dualculture technique. Sinorhizobium meliloti (culturable proxy for CLas) was used as the proxy organism for CLas. Bacterial endophytic isolates were screened on petri dishes containing TSA, (since S. meliloti is capable of growing on TSA as well). On day one individual endophytes were streaked on $60 \mathrm{~mm}$ petri plates approximately $24 \mathrm{~mm}$ from the edge, and incubated for 24 hours at $28{ }^{\circ} \mathrm{C}$. On day 2, S. meliloti (24-hour growth), was streaked approximately $24 \mathrm{~mm}$ away from the opposite edge of the plate, resulting in the endophyte and $S$. meliloti growing parallel to each other approximately $12 \mathrm{~mm}$ apart (Figure 12). Endophytes showing antagonistic activity against $S$. meliloti (with a 24-hours gap), were then re-evaluated. The second time, both $S$. meliloti and the endophyte being screened 
were simultaneously streaked parallel to each other approximately $20 \mathrm{~mm}$ apart on $90 \mathrm{~mm}$ petri dishes, and incubated at $28^{\circ} \mathrm{C}$.

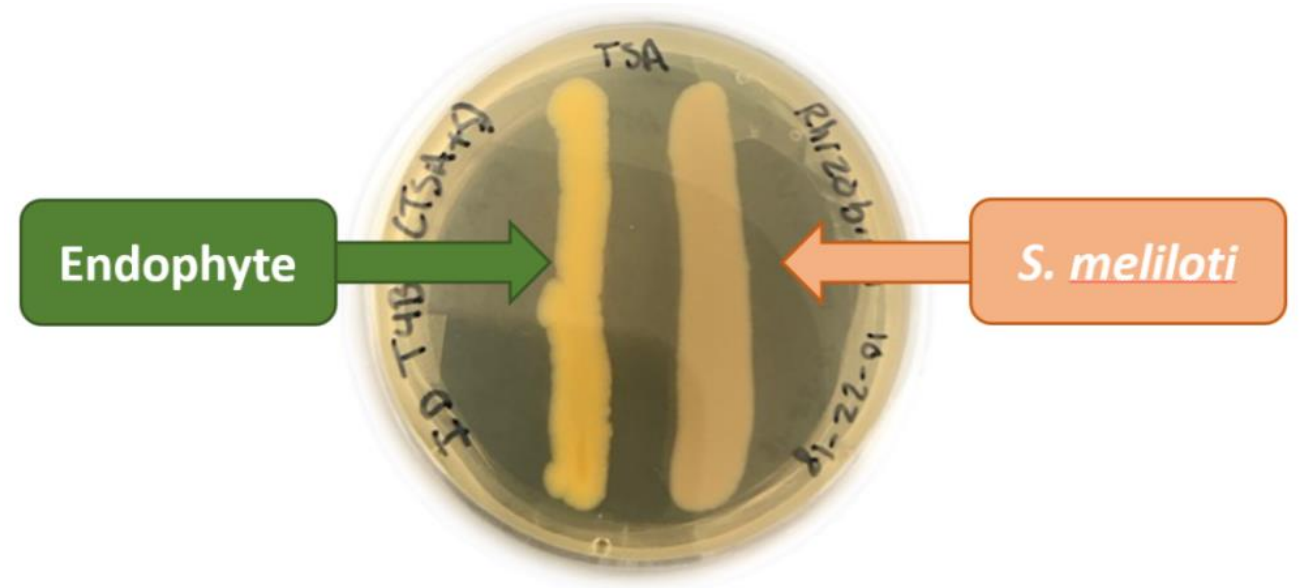

Figure 12: Dual culture preparation for bacterial endophytes

The incubation time for each bacterial endophyte (for both trials) varied between 12 and 48 hours. The majority were evaluated after 24 hours which was enough time for both the endophyte and S. meliloti to show substantial growth. However, some endophytes outgrew the plate by the 24-hour mark were thus re-streaked and removed from incubation after 12 hours. Similarly, other endophytes did not exhibit sufficient growth at the 24-hour mark and were thus left incubating until 48 hours. The inhibition of $S$. meliloti was determined by comparing its growth to that of the control plates (Figure 13) and was categorized as either no inhibition, low inhibition, moderate inhibition or $100 \%$ inhibition.

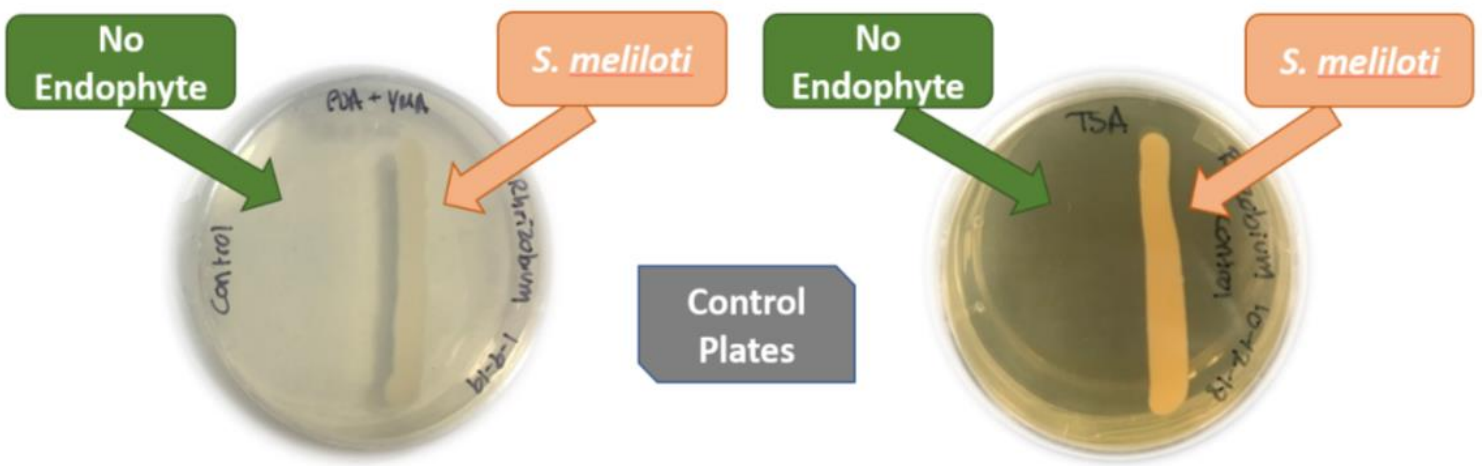

Figure 13: Dual culture control plates: for fungi (left) and for bacteria (right) 
As a result of the rapid growth of fungi, the fungal endophytes were not given 24hours of growth prior to the addition of S. meliloti; instead they were streaked at the same time. The simultaneous growth of the endophytic fungal isolates with that of S. meliloti (bacterium) on a single plate was successful after several trial and error attempts. Combinations of media (TSA + PDB, TSA + PDA, AND PDA + Mannitol) were prepared and streaked with fungal isolates and S. meliloti, but dual growth was not obtained. Nonetheless, the combination of Yeast Mannitol Agar and Potato Dextrose Agar allowed the successful and simultaneous growth of both organisms and was thus the media used to screen all endophytic fungal isolates. As a consequence of the rapid growth of fungi, fungal isolates were not streaked, instead a small segment $(<3 \mathrm{~mm})$ of mycelium was transferred into the YMA+PDA plate, approximately $20 \mathrm{~mm}$ apart from $S$. meliloti, which was streaked (Figure 14). The inhibition of S. meliloti was determined between 12 and 24 hours of incubation at $28^{\circ} \mathrm{C}$ (depending on fungal growth), by comparing its growth to that of the control plates, and was categorized as either no inhibition, low inhibition, moderate inhibition or $100 \%$ inhibition.

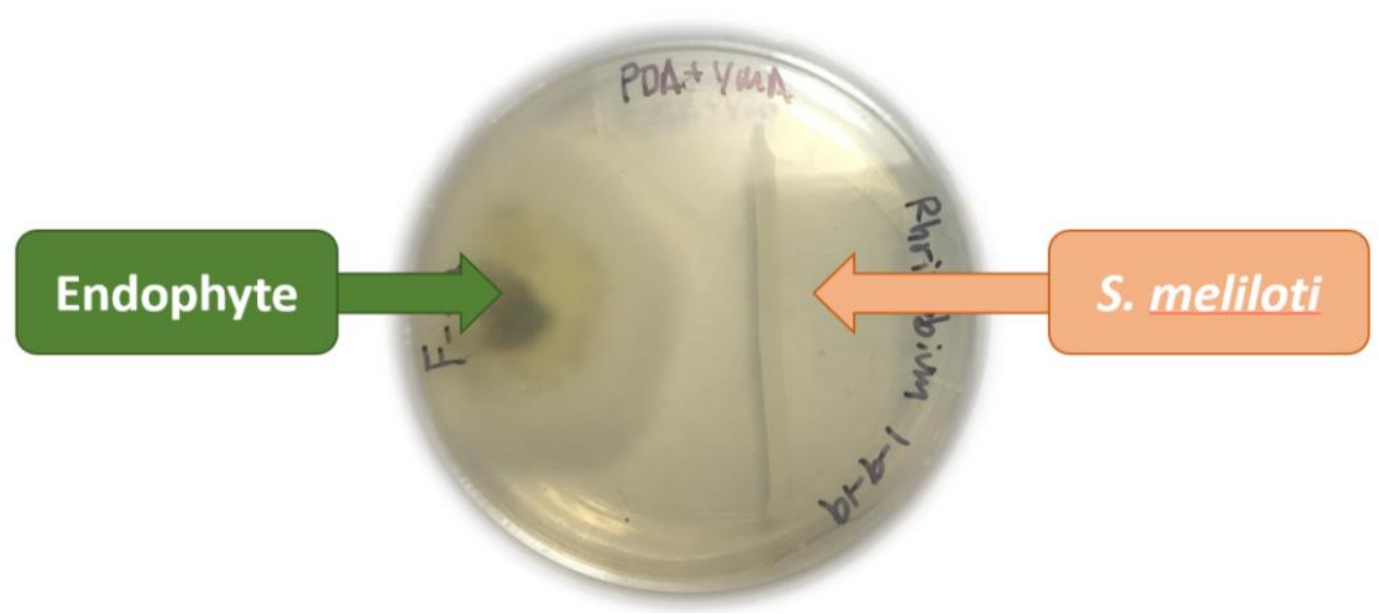

Figure 14: Dual Culture preparation for fungal endophytes 
The dual culture assay was also attempted using $L$. crescens (another, more closely related proxy for CLas) on BM-7 media. However, L. crescens is a very slow growing bacteria, taking approximately 10 days before the first colonies are seen. Since BM-7 is an extremely rich media, endophytes grown on this media would cover the entire petri plate in less than 24 hours.

\subsection{Cell-free Culture Supernatant}

The cell-free culture of endophytic bacteria showing strong antagonistic activity (moderate and/or 100\% inhibition) on the dual culture assay, were then obtained. These bacteria were sub-cultured and grown in flasks containing $30 \mathrm{ml}$ of TSB medium and incubated at $27^{\circ} \mathrm{C}$, on a rotary shaker at $160 \mathrm{rpms}$ for 48 hours. Cell-free culture supernatants were obtained by centrifuging each culture twice, at $4500 \mathrm{rpm}$ for 35 minutes at $4^{\circ} \mathrm{C}$. Then they were filtered through a $0.45 \mu \mathrm{m}$ filter followed by a $0.2 \mu \mathrm{m}$ filter and poured into sterile vials. All cell-free culture supernatants were stored in $-20^{\circ} \mathrm{C}$.

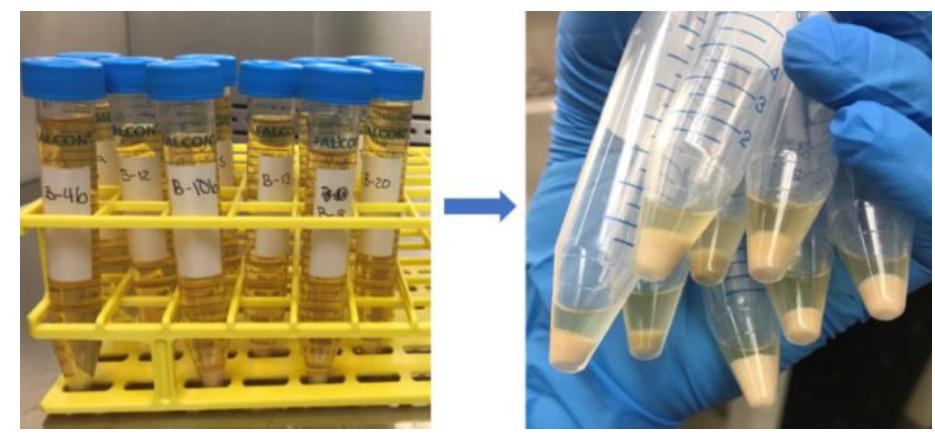

Figure 15: Removing the supernatants from bacterial endophytes grown in TSB

\subsection{Agar Well Diffusion Assay}

The antimicrobial activity of the cell-free culture supernatants was determined by the agar well diffusion assay. In this method, an $L$. crescens culture containing 108 cells mL-1 was used to inoculate a BM-7 media plate with $100 \mu \mathrm{L}$, by spread plate method. After spreading the $L$. crescens suspension, four cylindrical holes with a diameter of $6 \mathrm{~mm}$ was 
punched aseptically with a sterile cork borer, and a volume $75 \mu \mathrm{L}$ of cell free culture supernatants was introduced into each well. All plates were then incubated at $28^{\circ} \mathrm{C}$ for 12 days at which point the inhibition zone (if any) was measured to determine effectiveness.

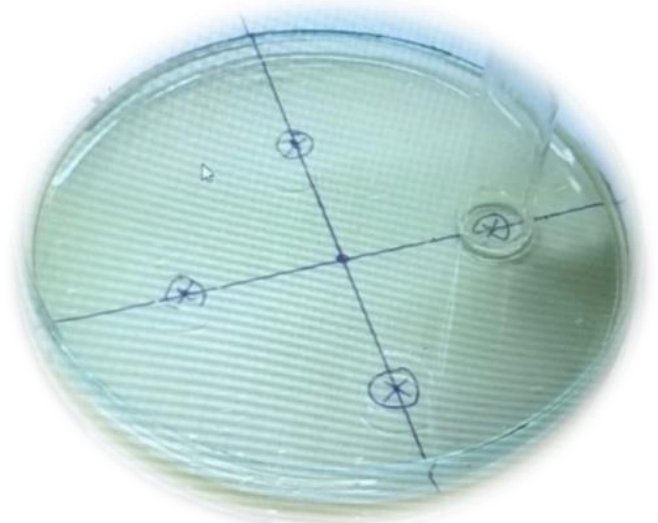

Figure 16: Six mm diameter wells being punched out of agar for well diffusion assay

The same process was used to fill the wells with $75 \mu \mathrm{L}$ of commercial plant extracts at four different dilutions: full strength, 30\%, 10\%, and 5\%. All plates were then incubated at $28^{\circ} \mathrm{C}$ for 12 days and the inhibition zones were measured to determine effectiveness. Disc diffusion was also attempted but no more than $15 \mu \mathrm{L}$ could be added because of the extracts excessively spreading throughout the plates (several had extremely low viscosity). Thus, the agar well diffusion assay was preferred.

\subsection{Leaf- Disc Assay}

All extracts showing antimicrobial activity (inhibition zone) against $L$. crescens (10), were screened for in planta activity using the leaf-disc assay. Five plant extracts (oregano, alchornea, thyme, cinnamon, and turmeric), and five bacterial extracts (B-25, B9, B-17, B-24, and B-27) were screened. HLB-infected leaves were collected from USDA Agricultural Research Service located in Fort Pierce, Florida. A total of 21 HLB 
symptomatic leaves were collected from three rough lemon trees (seven from each tree) (Figure 17).

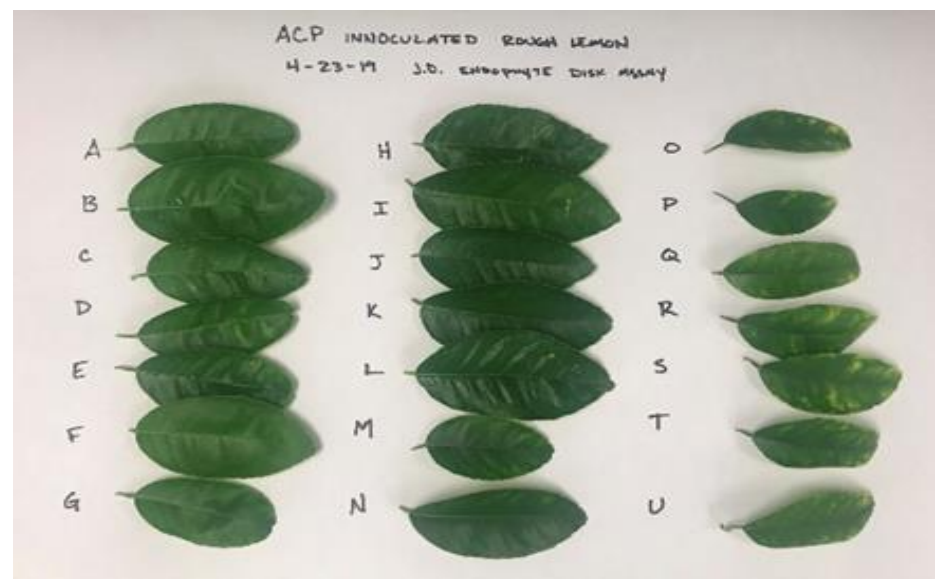

Figure 17: ACP inoculated Rough Lemon leaves (21)

Each tree (seven leaves) were assessed on a 96-well plate (total of three plates); Figure 14 shows the set up for each of the 96-well plates. The first 7 rows (A-G) correspond to each of the seven leaves collected from each tree. Row 8 (columns 1-7) contained the first and last disc from each of the seven leaves, respectively labeled A-G. Row 8 (columns 9-12) included two known CLas+ samples in rough lemon background, and two negatives containing nuclease free water and Master Mix (for qPCR purposes only).

\begin{tabular}{|c|c|c|c|c|c|c|c|c|c|c|c|c|}
\hline & Control & .5 Strep & Ext 1 & Ext 2 & Ext 3 & Ext 4 & Ext 5 & Ext 6 & Ext 7 & Ext 8 & Ext 9 & Ext 10 \\
\hline & 1 & 2 & 3 & 4 & 5 & 6 & 7 & 8 & 9 & 10 & 11 & 12 \\
\hline A & 1 & 8 & 15 & 22 & 29 & 36 & 43 & 50 & 57 & 64 & 71 & 78 \\
\hline B & 2 & 9 & 16 & 23 & 30 & 37 & 44 & 51 & 58 & 65 & 72 & 79 \\
\hline C & 3 & 10 & 17 & 24 & 31 & 38 & 45 & 52 & 59 & 66 & 73 & 80 \\
\hline D & 4 & 11 & 18 & 25 & 32 & 39 & 46 & 53 & 60 & 67 & 74 & 81 \\
\hline$E$ & 5 & 12 & 19 & 26 & 33 & 40 & 47 & 54 & 61 & 68 & 75 & 82 \\
\hline $\mathbf{F}$ & 6 & 13 & 20 & 27 & 34 & 41 & 48 & 55 & 62 & 69 & 76 & 83 \\
\hline \multirow[t]{2}{*}{ G } & 7 & 14 & 21 & 28 & 35 & 42 & 49 & 56 & 63 & 70 & 77 & 84 \\
\hline & A & B & $\mathrm{C}$ & D & E & $\mathrm{F}$ & G & & POS & POS & NEG & NEG \\
\hline
\end{tabular}

Figure 18: Leaf-disc 96-well plate set-up

Each column represents a treatment. Column 1 was the control (TSB), Column 2 the positive control ( $0.5 \mathrm{mM}$ streptomycin), and Columns 3-12 were the 10 extract treatments (3-7 were plant extracts and 8-12 were bacterial extracts). Each column was 
filled using $200 \mu \mathrm{L}$ of each extract and/or control. Using a sterile biopsy punch, leaf discs were punched through the midrib of each leaf moving from the base of the leaf towards the apex, (Figure 19) placing each disc in its designated row, in a randomized order. The first and last discs of each leaf were placed in separate Eppendorf tubes with no treatment (to be used later). All leaf-discs were then left in the 96-well plates (or Eppendorf tubes), soaked in their corresponding treatments, open and under a hood for 48 hours (Figure 20).

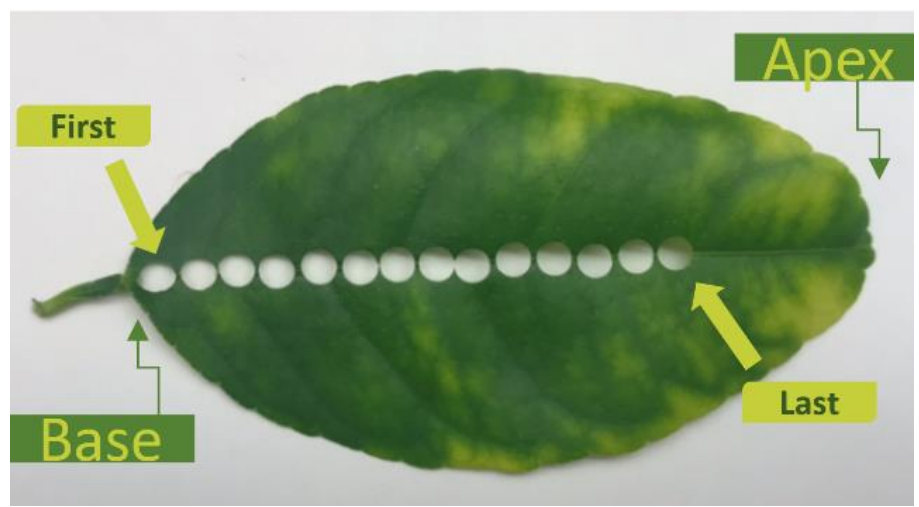

Figure 19: Leaf-discs punched out of a CLas+ Rough Lemon leaf

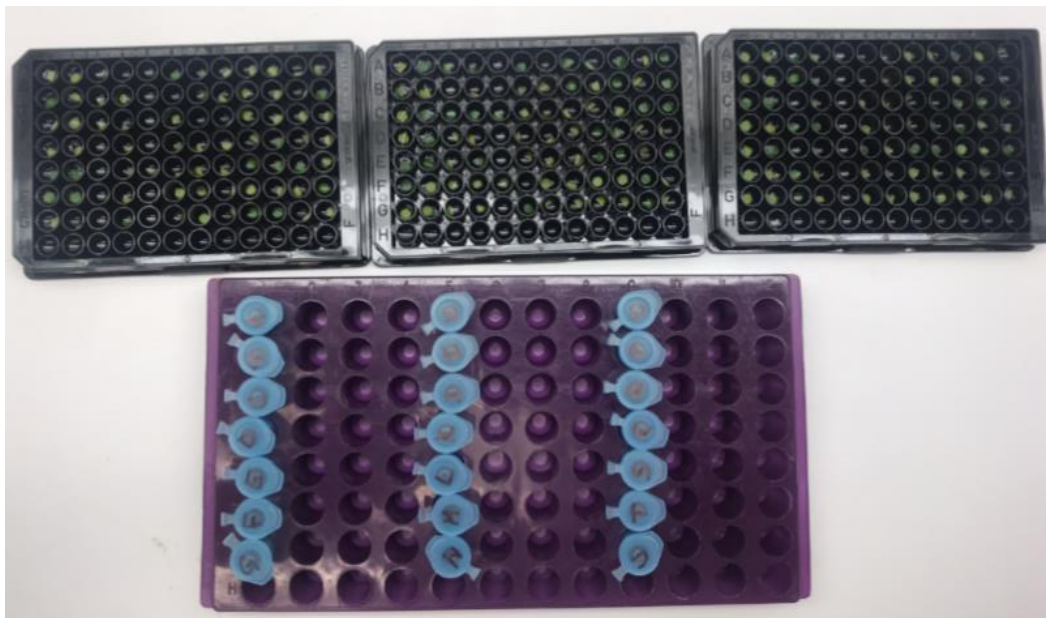

Figure 20: All leaf-discs incubating in treatments, as well as the first and last leaf-discs of each leaf (no treatment) in Eppendorf tubes

\subsubsection{DNA Extraction}

After 48 hours of incubation, a phenol DNA extraction was completed. Here, leafdiscs were transferred into $1.5 \mathrm{~mL}$ Eppendorf tubes where they were frozen in liquid 
nitrogen, and grinded into a fine powder using sterile pestles. Separately, $200 \mu \mathrm{L}$ of RNase A were mixed into a $19.8 \mathrm{~mL}$ solution of $1 \mathrm{X}$ TE buffer $(10 \mathrm{mM}$ Tris and $1 \mathrm{mM}$ EDTA at $\mathrm{pH}$ 8.0); $200 \mu \mathrm{L}$ of this solution was added to each of the $1.5 \mathrm{~mL}$ tube samples. All samples were then transferred into new tubes and incubated for 15 minutes at $37^{\circ} \mathrm{C}$. Next, $200 \mu \mathrm{L}$ of phenol was added to each tube, followed by a 15 second vortex, and centrifuged at 5700rpm for 10 minutes. The supernatants were transferred to new $1.5 \mathrm{~mL}$ tubes, where $100 \mu \mathrm{L}$ of ammonium acetate and $600 \mu \mathrm{L}$ of $95 \% \mathrm{EtOH}$ were added. The tubes were incubated at room temperature for 10 minutes, centrifuged (same parameters), and supernatants were discarded. Next, $300 \mu \mathrm{L}$ of ice cold $70 \% \mathrm{EtOH}$ was added, centrifuged, and supernatant were discarded once again. The remaining pellet was suspended in $27 \mu \mathrm{L}$ of nuclease-free water and gently vortexed to dissolve the pellet. Next, the Nanodrop spectrophotometer was used to quantify nucleic acids, using $2 \mu \mathrm{L}$ (Figure 21). The remaining $25 \mu \mathrm{L}$ were then diluted to $100 \mathrm{ng} / \mu \mathrm{L}$ and the samples were ready for $\mathrm{qPCR}$.

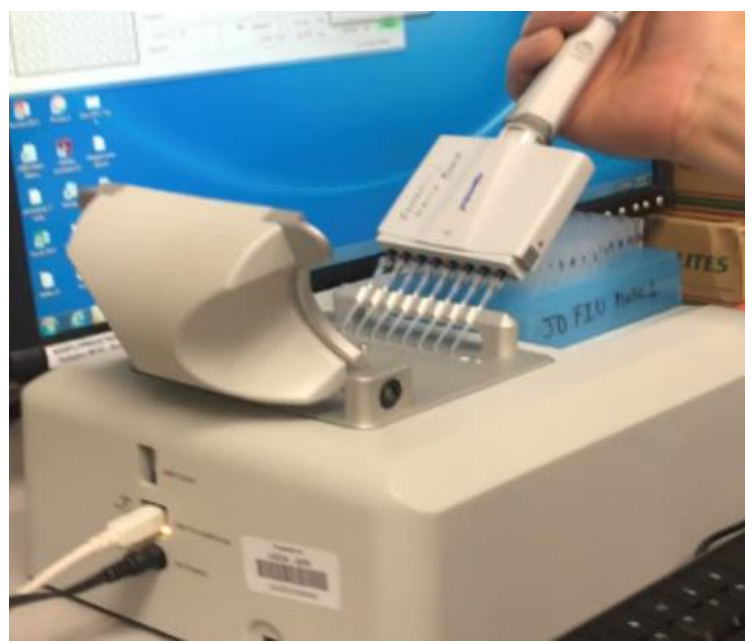

Figure 21: Nanodrop spectrophotometer: used to quantify nucleic acids in preparation for qPCR 


\subsubsection{Standard Ct Plate}

The qPCR Master Mix \#4312704 protocol (Master mix for Taqman) was prepared. Each reaction well received $18 \mu \mathrm{L}$ of master mix and $2 \mu \mathrm{L}$ of template sample $(20 \mathrm{ng} / \mu \mathrm{L})$. The 96-well plates were briefly placed to tap spin and then loaded into the AB 7500 RealTime PCR System. The qPCR temperature and time parameters were set as follows: holding stage at $95^{\circ} \mathrm{C}$ for 20 minutes, and the cycling stage at $95^{\circ} \mathrm{C}$ for 3 minutes and $60^{\circ} \mathrm{C}$ for 30 minutes. Antimicrobial compound control efficiency was then assessed by comparing changes in $\mathrm{Ct}$ values to that of the controls.

\subsubsection{Statistical Analysis JMP Genomics}

All data was analyzed with SAS with JMP genomics package. One-way ANOVA tests were performed to compare statistical means. The Hodges-Lehmann- Sen estimator was made to show significance between treatments. Data were considered significant when $\mathrm{p}<0.05$.

\subsection{Psyllid Homogenate Assay}

Extracts showing antimicrobial activity against $L$. crescens (inhibition zone) were also screened using the psyllid homogenate assay. The homogenate assay is an in-vitro protocol designed to assess the effects of antimicrobial compounds on Clas (Krystel, Shi, Shaw, Gupta, Hall, and Stover 2019). Five plant extracts (oregano, alchornea, thyme, cinnamon, and turmeric), and five bacterial extracts (B-25, B-9, B-17, B-24, and B-27) were screened. The following protocols (CLas isolation, PMAxx treatment, DNA extraction and qPCR) were duplicated (2 plates). 


\subsubsection{CLas Isolation}

One hundred and twenty CLas + psyllids were obtained and drowned in $600 \mu \mathrm{L}$ of 95\% EtOH/ sterile water. The psyllids were transferred into 4 (groups of 30) centrifugal filter tubes ( $0.65 \mu \mathrm{m}$ spin column $)$ which were spun on a tabletop centrifuge at $1,000 \mathrm{~g}$ for 10 seconds, washed with $600 \mu \mathrm{L}$ of sterile water and spun again (same time and $\mathrm{g}$ force). Next the 4 filter units were transferred into new centrifuge tubes (4) and $150 \mu \mathrm{L}$ of isolation buffer (USDA patented solution) was added to each tube. A pestle and handle were used to gently macerate the psyllids in each tube (Figure 22), which were then spun at approximately $1200 \mathrm{rpm}$ (no more than $1400 \mathrm{rpm}$ ) for 3 minutes. Each filter was discarded, and the remaining pellets were re-suspended (by pipetting) and combined into 1 tube (homogenous solution) which was vortexed once more for 10 seconds.
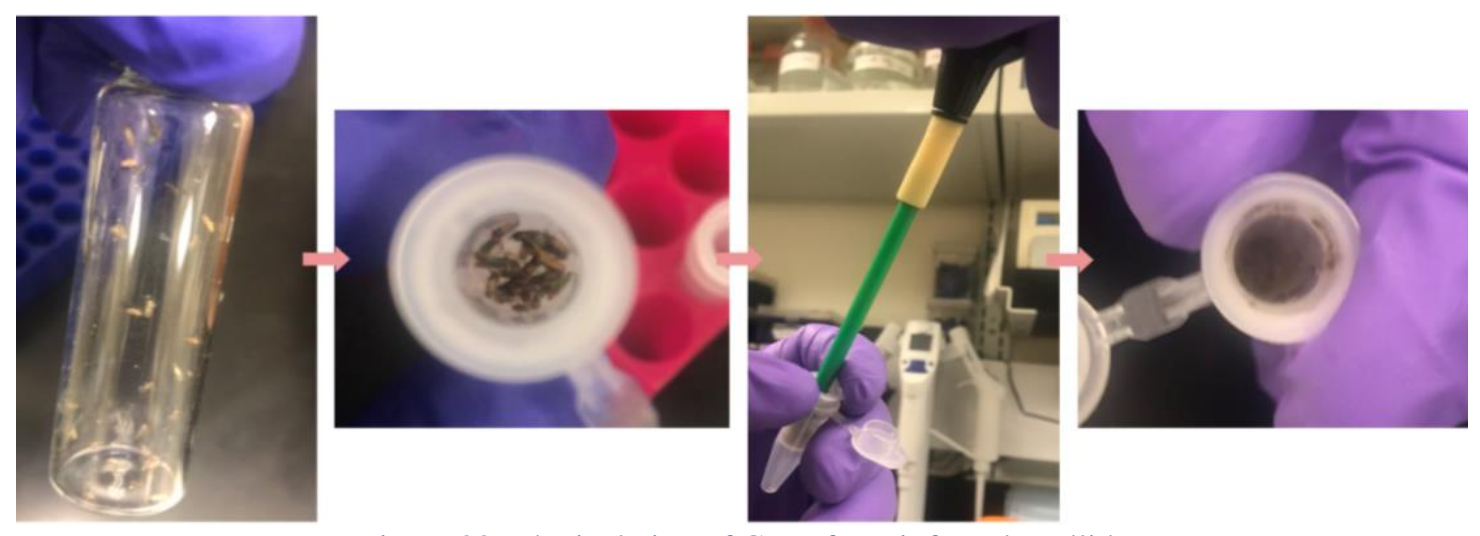

Figure 22: The isolation of CLas from infected psyllids

The homogenous solution was divided into $45 \mathrm{uL}$ samples to which $5 \mathrm{uL}$ of the assigned treatment was added. The treatments were: a control (TSB), a positive control $(0.1 \%$ triton $)$ and the extracts (5 bacterial and 5 plant-based). Bacterial extracts were not previously diluted and thus resulted in a final concentration of $10 \%$. However, plant extracts were diluted (1/10), resulting in a final concentration of $1 \%$. 


\subsubsection{Isolation and PMAxx Treatment}

The 12 treatments consisted of a control (TSB), a positive control ( $0.1 \%$ triton), and the 10 extracts ( 5 plant and 5 bacterial); seven $5 \mu \mathrm{L}$ isolations were aliquoted for each. All tubes (containing CLas cells and treatments) were incubated for four hours. Immediately after, five tubes of each extract (top five rows) were treated with $1 \mu \mathrm{L}$ PMAxx and two rows (rows 6 and 7) were treated with $1 \mu \mathrm{L}$ water. Isolates were spun and exposed to PMAxx light for 15 minutes (Figure 23).
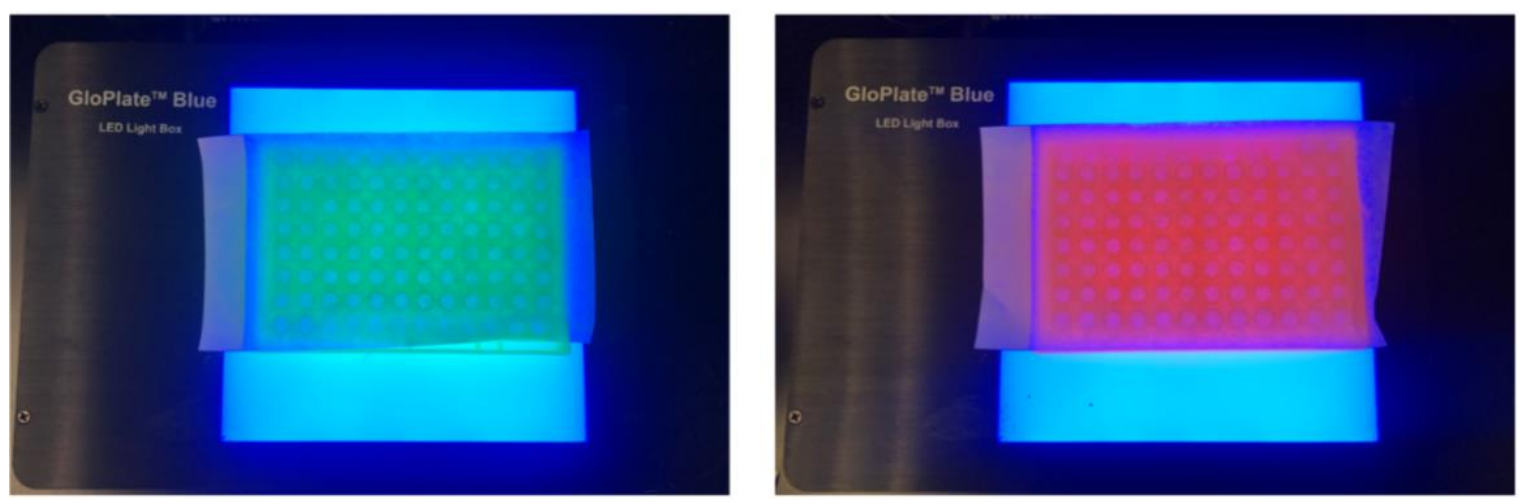

Figure 23: Plate 1 (left) and plate 2 (right) containing treatments with CLas cells exposed to PMAxx light

\subsubsection{DNA Extraction}

Forty-five $\mu \mathrm{L}$ of lysis buffer (.1\% SDS, .05\% Tween-20 and Tris-EDTA pH 8.0 Sigma-Aldrich \#93283), and $50 \mu \mathrm{L}$ of phenol (under fume hood) were added to each isolation. Tubes were briefly vortexed (approximately five seconds) and then centrifuged for 10 minutes at $5700 \mathrm{rpm}$. The supernatant was transferred to new tubes (as close to 50 $\mu \mathrm{L}$ as possible without getting phenol into the extraction). Then $25 \mu \mathrm{L}$ of ammonium acetate and $150 \mu \mathrm{L}$ of $95 \% \mathrm{EtOH}$ were added. The plates were gently inverted to mix the samples and incubated at room temperature for 10 minutes at $25^{\circ} \mathrm{C}$. Next, plates were centrifuged for 10 minutes at $5700 \mathrm{rpm}$, the supernatants were discarded (while being careful not to discard the remaining pellet which contains the DNA), and the sample tubes 
were inverted on Kim-wipes for approximately 15 minutes to allow EtOH to evaporate. Remaining pellets were then suspended in $50 \mu \mathrm{L}$ of nuclease-free water (provided by USDA ARS lab in Fort Pierce, Florida) and gently vortexed (approx. five seconds) to dissolve the pellet.

\subsubsection{Standard Ct Plate}

The qPCR Master Mix \#4312704 protocol (Master Mix for Taqman) was prepared. Each reaction well received $19 \mu \mathrm{L}$ of master mix and $1 \mu \mathrm{L}$ of template sample. This is volume normalization for $\mathrm{qPCR}$ caused by the homogenous nature of the starting samples and PMAxx changes in DNA quantities. The DNA normalizing would erase the effects. The 96-well plates were briefly placed to tap spin and then loaded into the AB 7500 RealTime PCR System. The qPCR temperature and time parameters were set as follows: holding stage at $95^{\circ} \mathrm{C}$ for 20 minutes, and the cycling stage at $95^{\circ} \mathrm{C}$ for 3 minutes and $60^{\circ} \mathrm{C}$ for 30 minutes. Antimicrobial compound control efficiency was then assessed by measuring changes in $\mathrm{Ct}$ values.

\subsubsection{Statistical Analysis JMP genomics}

All data were analyzed using SAS with JMP genomics package. One-way ANOVA tests were performed to compare statistical means. The Hodges-Lehmann-Sen estimator was made to show significance between treatments. Data were considered significant when $\mathrm{p}<0.05$.

\section{RESULTS}

\subsection{Endophyte Isolations}

A total of 179 bacterial colonies and 163 fungal colonies were successfully isolated and grown in pure cultures. Each isolate was given a code name, which was selected based 
on the tree, branch and segment number it came from. Tables 4-14 present the data on how many endophytes (bacterial and fungal) were isolated from each tree, the name they were assigned, and the colony morphology of each endophyte. Two tables were made for each tree, the first represents the isolated bacterial endophytes and the second represents the isolated fungal endophytes. Tables representing bacterial endophyte data (4,6,8,10 and 12) include: the number of pure isolates obtained, where they came from (tree, branch, and segment), name assigned to that isolate, color of the bacterial colonies, form (circular, irregular, filamentous, or rhizoid), elevation (raised, convex, flat, umbonate, or crateriform), margin (entire, undulate, filiform, curled or lobate), and number of streaks observed on the pure isolate cultures one month after being sub-cultured (anywhere between a single colony and a full plate). Tables representing fungal endophyte data $(1,3,5,7$ and 9$)$ include: the number of pure isolates obtained, where they came from (tree, branch, and segment), name assigned to that isolate, a description of the colonies which may include details such as the color, shape and/or whether mycelium was observed or not, elevation (raised, convex, flat, umbonate, crateriform), and margin (entire, undulate, filiform, curled, or lobate). Plates that had no growth after the endophyte isolation procedure are listed with number of isolates as 0 , and all descriptions are marked with N/A expressing that the data are not available. 

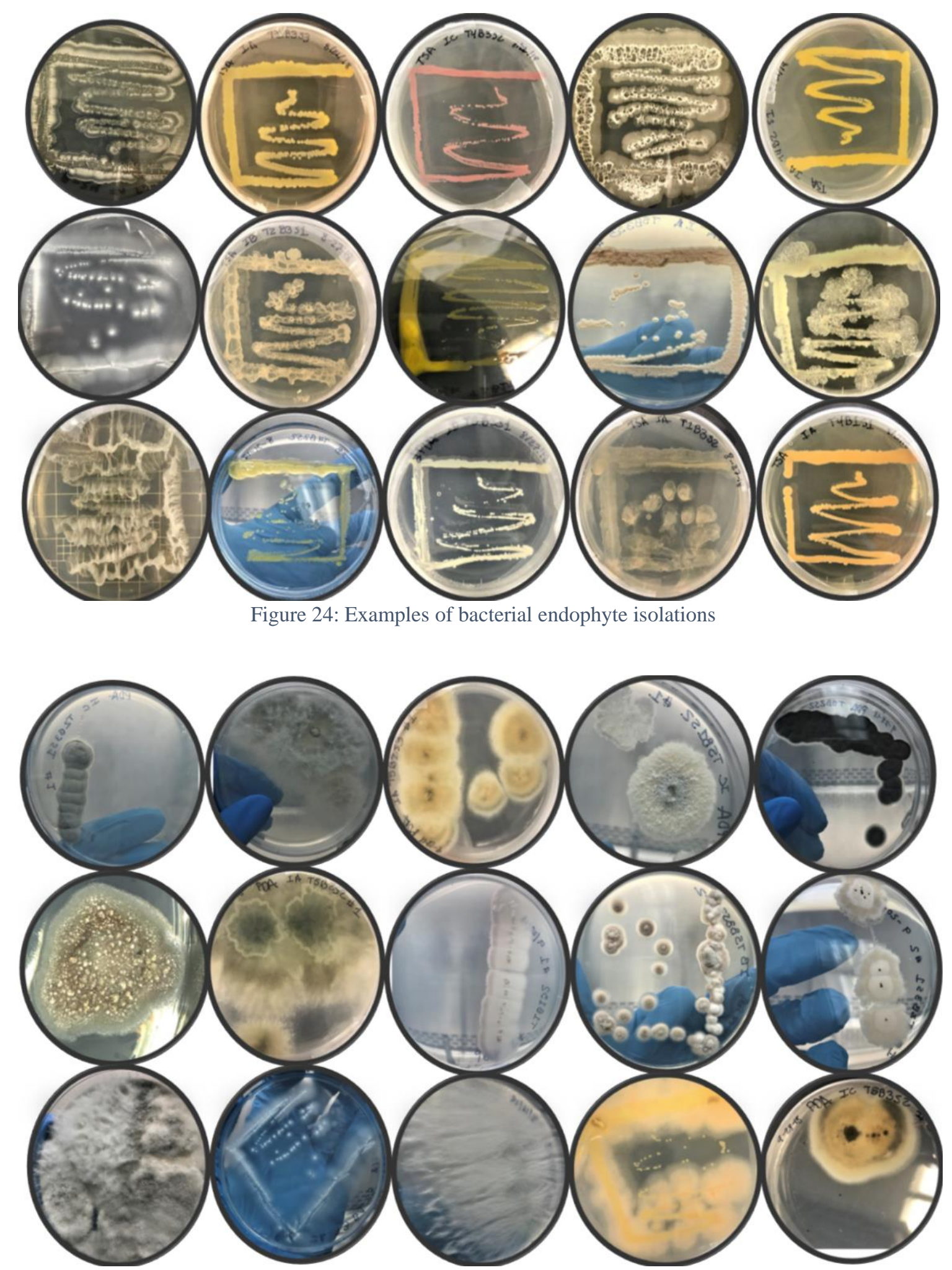

Figure 25: Examples of fungal ednohyte isolations 


\section{1.1 Tree \#1 (Navel Orange)}

Tables 4 and 5 below present the information obtained from Tree \#1. All nine plates selective for fungi (dPDA) had fungal growth, and 14 out of the 15 TSA-containing plates had bacterial growth. Still, fungal plates averaged more isolates per plate than bacterial plates: 2.8 and 2.4, respectively. A total of 10 bacteria and 11 fungi were isolated from branch 1, 12 bacteria and seven fungi were isolated from branch 2, and seven bacteria and seven fungi were isolated from branch 3 . A total of 29 bacteria and 25 fungi were isolated from Tree \#1 for a grand total of 54 isolated organisms.

\begin{tabular}{|c|c|c|c|c|c|c|c|}
\hline $\begin{array}{c}\text { Tree, Branch } \\
\text { and Segment } \\
\text { Numbers }\end{array}$ & $\begin{array}{c}\text { Number } \\
\text { of } \\
\text { Isolates }\end{array}$ & Isolate Name & Color & Form & Elevation & Margin & $\begin{array}{c}\text { Growth } \\
\text { (streaks) }\end{array}$ \\
\hline \multicolumn{8}{|l|}{ Tree \#1 } \\
\hline \multicolumn{8}{|l|}{ Tree 1 Branch 1} \\
\hline \multirow[t]{3}{*}{ T1B1S1 } & 3 & IA T1B1S1 & Pale yellow & Irregular & Raised & Undulate & $1<$ \\
\hline & & IB T1B1S1 & Light yellow & Irregular & raised & Undulate & 3 \\
\hline & & IC T1B1S1 & Light orange & Irregular & Convex & Entire & 1 \\
\hline \multirow[t]{2}{*}{ T1B1S2 } & 2 & IA T1B1S2 & Pink & Irregular & Flat & Entire & $2<$ \\
\hline & & IB T1B1S2 & Light orange & Circular & Convex & Entire & 1 \\
\hline T1B1S3 & 1 & (only iso) T1B1S3 & Off-white & Irregular & Flat & Raised & $1<$ \\
\hline \multirow[t]{2}{*}{ T1B1 TSA+S } & 2 & IA T1B1 & Pink & Circular & Flat & Entire & 3 \\
\hline & & IB T1B1 & Light orange & Circular & Flat & Entire & $3<$ \\
\hline \multirow[t]{2}{*}{$\mathrm{TSA}+\mathrm{S}$ to TSA } & 2 & IA T1B1 on TSA & Pink & Circular & Flat & Entire & 2 \\
\hline & & IB T1B1 on TSA & Light orange & Circular & Flat & Entire & $3<$ \\
\hline \multicolumn{8}{|l|}{ Tree 1 Branch 2} \\
\hline \multirow[t]{3}{*}{ T1B2S1 } & 3 & IA T1B2S1 & White translucent & Circular & Flat & Curled & 3 \\
\hline & & IB T1B2S1 & Translucent & Irregular & Flat & Lobate & 3 \\
\hline & & IC T1B2S1 & White translucent & Circular & Flat & Entire & 3 \\
\hline \multirow[t]{2}{*}{ T1B2S2 } & 2 & IA T1B1S2 & Translucent orange & Circular & Flat & Entire & $3<$ \\
\hline & & IB T1B2S2 & Pink & Circular & Flat & Entire & $3<$ \\
\hline T1B2S3 & 1 & (only iso) T1B2S3 & Pale yellow & Irregular & Flat & Entire & $2<$ \\
\hline \multirow[t]{3}{*}{$\mathrm{T} 1 \mathrm{~B} 2 \mathrm{TSA}+\mathrm{S}$} & 3 & IA T1B2 & Off-white & Circular & Flat & Entire & 3 \\
\hline & & IB T1B2 \#1 & Yellow & Circular & Flat & Entire & $2<$ \\
\hline & & IB T1B2 \#2 & Translucent yellow & Circular & Flat & Entire & 3 \\
\hline \multirow[t]{3}{*}{ TSA+S to TSA } & 3 & IA T1B2 on TSA & Yellow & Circular & Flat & Entire & 3 \\
\hline & & IB T1B2 \#1 on TSA & Light orange & Circular & Flat & Entire & 3 \\
\hline & & IB T1B2 \#2 on TSA & Translucent cream & Circular & Flat & Entire & 3 \\
\hline \multicolumn{8}{|l|}{ Tree 1 Branch 3} \\
\hline T1B3S1 & 1 & (only iso) T1B3S1 & Light orange & Irregular & Raised & Undulate & 1 \\
\hline \multirow[t]{2}{*}{ T1B3S2 } & 2 & IA T1B3S2 & Translucent pale yellow & Irregular & Convex & Undulate & 3 \\
\hline & & IB T1B3S2 & Translucent white & Irregular & Raised & Undulate & $1<$ \\
\hline \multirow[t]{4}{*}{ T1B3S3 } & 4 & IA T1B3S3 & Yellow & Circular & Flat & Entire & 3 \\
\hline & & IB T1B3S3 \#1 & Translucent & Irregular & Raised & Curled & 3 \\
\hline & & IB T1B3S3\#2 & Pale yellow & Circular & Flat & Entire & 3 \\
\hline & & IC T1B3S3 & Off-white & Undulate & Flat & Entire & 3 \\
\hline T1B3 TSA+S & 0 & $\mathrm{~N} / \mathrm{A}$ & $\mathrm{N} / \mathrm{A}$ & $\mathrm{N} / \mathrm{A}$ & $\mathrm{N} / \mathrm{A}$ & $\mathrm{N} / \mathrm{A}$ & $\mathrm{N} / \mathrm{A}$ \\
\hline
\end{tabular}

Table 4: Colony morphology for all bacteria isolated from Tree \# 1 


\begin{tabular}{|c|c|c|c|c|c|}
\hline $\begin{array}{c}\text { Tree, Branch, } \\
\text { and Segment } \\
\text { Numbers }\end{array}$ & $\begin{array}{c}\text { Number } \\
\text { of } \\
\text { isolates }\end{array}$ & Isolate name & Description (Color, shape etc.) & Elevation & Margin \\
\hline \multicolumn{6}{|l|}{ Tree \#1 } \\
\hline \multicolumn{6}{|l|}{ Tree 1 Branch 1} \\
\hline \multirow[t]{2}{*}{ T1B1S1 } & 2 & IA T1B1S1 & $\begin{array}{l}\text { Dark green circles in center with white mycelium surrounding them } \\
\text { (crystals on green portions) }\end{array}$ & Crateriform & Entire \\
\hline & & IB T1B1S1 & Light green center with white mycelium surrounding it in long strands & Flat & Undulate \\
\hline \multirow[t]{4}{*}{ T1B1S2 } & 4 & IA T1B1S2 \#1 & Dark green circles with ligher green mycelium surrounding them & Flat & Entire \\
\hline & & IA T1B1S2 \#2 & $\mathrm{N} / \mathrm{A}$ & $\mathrm{N} / \mathrm{A}$ & $\mathrm{N} / \mathrm{A}$ \\
\hline & & IB T1B1S2 \#1 & Wide, light green circles with foamy white surrounding the circles & Flat & Entire \\
\hline & & IB T1B1S2 \#2 & $\mathrm{N} / \mathrm{A}$ & $\mathrm{N} / \mathrm{A}$ & $\mathrm{N} / \mathrm{A}$ \\
\hline \multirow[t]{5}{*}{ T1B1S3 } & 5 & IA T1B1S3 & Green center with white mycelium surrounding it & Raised & Entire \\
\hline & & IB T1B1S3 \#1 & Green mycelium & Raised & Entire \\
\hline & & IB T1B1S3 \#2 & White mycelium & Raised & Entire \\
\hline & & IC T1B1S3\#1 & Green mycelium with crystals on top & Raised & Entire \\
\hline & & IC T1B1S3 \#2 & Yellow dots coming out of fungi (look like bacteria) & Flat & Entire \\
\hline \multicolumn{6}{|l|}{ Tree 1 Branch 2} \\
\hline \multirow[t]{3}{*}{ T1B2S1 } & 3 & IA T1B2S1 & $\begin{array}{l}\text { White mycelium covers most of the plate, though it has dark green dots } \\
\text { spots spread throughout }\end{array}$ & Flat fillaments & Undulate \\
\hline & & IB T1B2S1 \#1 & Light green fluff with lighter surroundings & Raised & Entire \\
\hline & & IB T1B2S1 \#2 & Dark green mycelium & Raised & Entire \\
\hline \multirow[t]{3}{*}{ T1B2S2 } & 3 & IA T1B2S2 & $\begin{array}{l}\begin{array}{l}\text { Forms rings along the streak with peach centers and white mycelium } \\
\text { spreading outward }\end{array} \\
\end{array}$ & Flat & Entire \\
\hline & & IB T1B2S2 & Off white mycelium extends to white mycelium on outside & Flat & Undulate \\
\hline & & IC T1B2S2 & $\begin{array}{l}\text { Light brown center circle, dark green middle portion and then offwhite } \\
\text { outer part }\end{array}$ & Flat & Entire \\
\hline T1B2S3 & 1 & IA T1B2S3 & Orange (bacteria-like) & Raised & Entire \\
\hline \multicolumn{6}{|l|}{ Tree 1 Branch 3} \\
\hline \multirow[t]{2}{*}{ T1B3S1 } & 2 & IA T1B3S1 & Off white fillaments- extends to white fillaments on outside & Flat & Entire \\
\hline & & IB T1B3S1 & Peach center with white mycelium surrounding it & Flat & Entire \\
\hline \multirow[t]{2}{*}{ T1B3S2 } & 2 & IA T1B3S2 & $\mathrm{N} / \mathrm{A}$ & $\mathrm{N} / \mathrm{A}$ & $\mathrm{N} / \mathrm{A}$ \\
\hline & & IB T1B2S2 & Thick white centers with light (white) mycelium covering whole plate & Flat & Entire \\
\hline \multirow[t]{3}{*}{ T1B3S3 } & 3 & IA T1B3S3 \#1 & $\begin{array}{l}\text { Green rings alternating between light and dark green with light green } \\
\text { mycelium around edges }\end{array}$ & Flat & Entire \\
\hline & & IB T1B3S3 \#2 & Dark green circled center with white mycelium surrounding it & Flat & Lobate \\
\hline & & IB T1B3S3 \#3 & light yellow (bacteria-like) & Flat & Entire \\
\hline
\end{tabular}

Table 5: Colony morphology for all fungi isolated from tree \#1.

\subsubsection{Tree \#2 (Naval Orange)}

Tables 6 and 7 present the information obtained from Tree \#2. All 9 plates selective for fungi had fungal growth, though 3 of 15 TSA-based plates had no bacterial growth. Fungal plates averaged 4.2 isolates per plate, while bacterial plates averaged 2.6 isolates per plate. A total of 12 bacteria and 9 fungi were isolated from branch 1, 5 bacteria and 14 fungi were isolated from branch 2, and 14 bacteria and 15 fungi were isolated from branch 3. Tree \#2 produced a total of 31 bacterial isolates and 38 fungal isolates, totaling 69 endophytic isolated organisms. 


\begin{tabular}{|c|c|c|c|c|c|c|c|}
\hline $\begin{array}{c}\text { Tree, Branch } \\
\text { and Segment } \\
\text { Numbers }\end{array}$ & $\begin{array}{c}\text { Number } \\
\text { of } \\
\text { Isolates }\end{array}$ & Isolate Name & Color & Form & Elevation & Margin & $\begin{array}{l}\text { Growth } \\
\text { (streaks) }\end{array}$ \\
\hline \multicolumn{8}{|l|}{ Tree \#2 } \\
\hline \multicolumn{8}{|l|}{ Tree 2 Branch 1} \\
\hline T2B1S1 & 0 & $\mathrm{~N} / \mathrm{A}$ & $\mathrm{N} / \mathrm{A}$ & $\mathrm{N} / \mathrm{A}$ & $\mathrm{N} / \mathrm{A}$ & $\mathrm{N} / \mathrm{A}$ & $\mathrm{N} / \mathrm{A}$ \\
\hline \multirow[t]{5}{*}{ T2B1S2 } & 5 & IA T2B1S2 & Pale orange & Irregular & Flat & Undulate & $1<$ \\
\hline & & IB T2B1S2 & Orange & Circular & Raised & Entire & 1 \\
\hline & & IC T2B1S2 & Orange inner/ yellow outer & Circular & Flat & Entire & 3 \\
\hline & & ID T2B1S2 & Orange & Circular & Flat & Entire & $2<$ \\
\hline & & IE T2B1S2 & Yellow & Irregular & Raiesed & Undulate & 3 \\
\hline \multirow[t]{2}{*}{ T2B1S3 } & 2 & IA T2B1S3 & Off-white & Circular & Flat & Entire & $3<$ \\
\hline & & IB T2B1S3 & Pink & Circular & Flat & Entire & $3<$ \\
\hline \multirow[t]{2}{*}{$\mathrm{T} 2 \mathrm{~B} 1 \mathrm{TSA}+\mathrm{S}$} & 2 & IA T2B1 & Yellow (watery) & Irregular & Raised & Entire & 3 \\
\hline & & IB T2B1 & Orange & Irregular & Flat & Entire & $3<$ \\
\hline \multirow[t]{3}{*}{ TSA+S to TSA } & 3 & IA T2B1 on TSA & Yellow & Irregular & Raised & Undulate & 3 \\
\hline & & IB T2B1 \#1 on TSA & Orange & Circular & Flat & Undulate & $3<$ \\
\hline & & IB T2B1 \#2 on TSA & Yellow & Circular & Flat & Entire & 3 \\
\hline \multicolumn{8}{|l|}{ Tree 2 Branch 2} \\
\hline T2B2S1 & 0 & $\mathrm{~N} / \mathrm{A}$ & $\mathrm{N} / \mathrm{A}$ & $\mathrm{N} / \mathrm{A}$ & $\mathrm{N} / \mathrm{A}$ & $\mathrm{N} / \mathrm{A}$ & $\mathrm{N} / \mathrm{A}$ \\
\hline \multirow[t]{4}{*}{ T2B2S2 } & 4 & IA T2B2S2 \#1 & Off-white & Circular & Flat & Entire & $3<$ \\
\hline & & IA T2B2S2 \#2 & Translucent & Circular & Flat & Entire & $3<$ \\
\hline & & IA T2B2S2 \#3 & Translucent \& off white mix & Both circular & Flat & Entire & 3 \\
\hline & & IB T2B2S2 & White translucent & Irregular & Flat & Undulate & $3<$ \\
\hline T2B2S3 & 1 & (only iso) T2B2S2 & Salmon & Circular & Flat & Entire & $3<$ \\
\hline T2B2 TSA+S & 0 & $\mathrm{~N} / \mathrm{A}$ & $\mathrm{N} / \mathrm{A}$ & $\mathrm{N} / \mathrm{A}$ & $\mathrm{N} / \mathrm{A}$ & $\mathrm{N} / \mathrm{A}$ & $\mathrm{N} / \mathrm{A}$ \\
\hline \multicolumn{8}{|l|}{ Tree 2 Branch 3} \\
\hline \multirow[t]{4}{*}{ T2B3S1 } & 4 & IA T2B3S1 \#1 & Off-white & filamentous & Umbonate & Filiform & 3 \\
\hline & & IA T2B3S1 \#2 & Translucent off-white & Irregular & Flat & Lobate & $3<$ \\
\hline & & IA T2B3S1 \#3 & Translucent (bubbles) & Irregular & Raised & Undulate & 3 \\
\hline & & IB T2B3S1 & White translucent & Irregular & convex & Curled & 3 \\
\hline \multirow[t]{3}{*}{ T2B3S2 } & 3 & IA T2B3S2 \#1 & Light orange & Circular & Flat & Undulate & 3 \\
\hline & & IA T2B3S2 \#2 & Salmon & Circular & Flat & Undulate & 3 \\
\hline & & IB T2B3S2 & Pale orange & Irregular & Flat & Undulate & 3 \\
\hline T2B3S3 & 1 & (only iso) T2B3S3 & Pink & Circular & Flat & Entire & 1 \\
\hline \multirow[t]{3}{*}{$\mathrm{T} 2 \mathrm{~B} 3 \mathrm{TSA}+\mathrm{S}$} & 3 & IA T2B3 & Light peach & filamentous & Flat & Undulate & 1 \\
\hline & & IB T2B3 & Light peach & filamentous & Flat & Undulate & 2 \\
\hline & & IC T2B3 & Orange translucent & Irregular & Flat & Undulate & $3<$ \\
\hline \multirow[t]{3}{*}{ TSA+S to TSA } & 3 & IA T2B3 on TSA & Translucent w/ pink center & Irregular & Flat & Curled & 2 \\
\hline & & IB T2B3 on TSA & Translucent white & Irregular & Flat & Curled & 2 \\
\hline & & IC T2B3 on TSA & Translucent & Circular & Flat & Entire & $3<$ \\
\hline
\end{tabular}

Table 6: Colony morphology for all bacteria isolated from Tree \# 2 


\begin{tabular}{|c|c|c|c|c|c|}
\hline $\begin{array}{c}\text { Tree, Branch, } \\
\text { and Segment } \\
\text { Numbers }\end{array}$ & $\begin{array}{c}\text { Number } \\
\text { of } \\
\text { isolates }\end{array}$ & Isolate name & Description (Color, shape etc.) & Elevation & Margin \\
\hline \multicolumn{6}{|l|}{ Tree \#2 } \\
\hline \multicolumn{6}{|l|}{ Tree 2 Branch 1} \\
\hline \multirow[t]{5}{*}{ T2B1S1 } & 5 & IA T2B1S1 & Thich off-white circles with orange dots in the centers & Raised & Undulate \\
\hline & & IB T2B1S1 & White circles (thicker in middle) covered plate & Flat & Entire \\
\hline & & IC T2B1S1 & $\begin{array}{c}\text { Extra thick off-white mycelium covered plate, though with green and } \\
\text { orange dots throughout }\end{array}$ & Umbunate & Undulate \\
\hline & & ID T2B1S1 & $\begin{array}{l}\text { Scattered beige dots of what looks like mycelium, with a few thick dark } \\
\text { black dots }\end{array}$ & Convex & Undulate \\
\hline & & IE T2B1S1 & White mycelial circles with orange dots & Umbunate & Undulate \\
\hline T2B1S2 & 1 & (only iso) T2B1S2 & Dark green center, light green fillaments outer & Flat & Entire \\
\hline \multirow[t]{3}{*}{ T2B2S3 } & 3 & IA T2B1S3 & White mycelium with orange dots & Umbunate & Undulate \\
\hline & & IB T2B1S3 \#1 & Green base with tiny white mycelium over it & Raised & Undulate \\
\hline & & IB T2B1S3 \#2 & Yellow circular dot (bacteria-like) & Flat & Entire \\
\hline \multicolumn{6}{|l|}{ Tree 2 Branch 2} \\
\hline \multirow[t]{2}{*}{ T2B2S1 } & 2 & IA T2B2S1 \#1 & Extreme dark green, to the point where it appears to be black & Raised & Undulate \\
\hline & & IA T2B2S1 \#2 & Pink dots (bacteria-like) & Flat & Entire \\
\hline \multirow[t]{4}{*}{ T2B2S2 } & 4 & IA T2B2S2 & Light white mycelium darker off-white centers & Flat & Entire \\
\hline & & IB T2B2S2 & $\begin{array}{l}\text { Thick tan mycelium in centers, containing a few green dots and lighter } \\
\text { white mycelium fills the rest of the plate }\end{array}$ & Umbonate & Undulate \\
\hline & & IC T2B2S2\#1 & Dark green center with off white surrounding it & Flat & Entire \\
\hline & & IC T2B2S2\#2 & $\begin{array}{l}\begin{array}{l}\text { Teal circles that look like bacteria from far, but seem to be mycelium } \\
\text { from close }\end{array} \\
\end{array}$ & Raised & Entire \\
\hline \multirow[t]{8}{*}{ T2B2S3 } & 8 & IA T2B2S3 & Dark green inside with lighter green surrounding it & Flat & Entire \\
\hline & & IB T2B2S3 \#1 & $\begin{array}{l}\text { Form rings of dark green and light green circles with white mycelium } \\
\text { extending outward }\end{array}$ & Flat & Entire \\
\hline & & IB T2B2S3 \#2 & $\begin{array}{l}\text { Rings of off-white and tan expanding from the center, which is an army } \\
\text { green dot }\end{array}$ & Flat & Entire \\
\hline & & IC T2B2S3\#1 & Off white circular, with mycelium in center & Flat & Entire \\
\hline & & IC T2B2S3 \#2 & Beige light circle with brown inner circle (bacteria-like) & Raised & Undulate \\
\hline & & ID T2B2S3 & $\begin{array}{c}\text { Dark green inside, with light green surrounding it, and a little white } \\
\text { mycelium }\end{array}$ & Umbunate & Entire \\
\hline & & IE T2B2S3 \#1 & $\begin{array}{l}\text { Dark Beige to brown rings that are lighter on inside and darker on the } \\
\text { outside, with some beige mycellium surrounding some colonies }\end{array}$ & Flat & Entire \\
\hline & & IE T2B2S3 \#2 & Dark brown oval shapes & Raised & Undulate \\
\hline \multicolumn{6}{|l|}{ Tree 2 Branch 3} \\
\hline \multirow[t]{10}{*}{ T2B3S1 } & 10 & IA T2B3S1 & Yellow/green centers surrounded by white mycelium & Raised & Entire \\
\hline & & IB T2B3S1 \#1 & Light brown and white mycelium cover plate & Flat & Undulate \\
\hline & & IB T2B3S1 \#2 & Whte mycelium & Flat & Entire \\
\hline & & IB T2B3S1 \#3 & Dark green circle surrounded by white mycelium & Flat & Entire \\
\hline & & IB T2B3S1 \#4 & Almost transparent circles that look like bacteria & Flat & Entire \\
\hline & & IC T2B3S1 \#1 & Green circles with white mycelium covering them (around and above) & Raised & Enitre \\
\hline & & IC T2B3S1 \#2 & Translucent tiny dots that look like bacteria & Raised & Enitre \\
\hline & & ID T2B3S1\#1 & Off-white circles that look like bactera & Flat & Entire \\
\hline & & ID T2B3S1 \#2 & White circles with brown center dot (bacteria-like) & Flat & Enitre \\
\hline & & IE T2B3S1 & Dots so thick that they appear to be black (but are really dark green) & Flat & Entire \\
\hline \multirow[t]{3}{*}{ T2B3S2 } & 3 & IA T2B3S2 & Small green circles surrounded by mycelium & Flat & Entire \\
\hline & & IB T2B3S2 & Yellow dots (bacteria-like) & Flat & Entire \\
\hline & & IC T2B3S2 & \begin{tabular}{|c|} 
Orange circles (bacteria-like) \\
\end{tabular} & Flat & Entire \\
\hline \multirow[t]{2}{*}{ T2B3S3 } & 2 & IA T2B3S3 & $\begin{array}{c}\text { Dark green mycelium with what appears to be white mycelial dots at the } \\
\text { ends }\end{array}$ & Umbonate & Undulate \\
\hline & & IB T2B3S3 & Dark green circular dots with white mycelium surrounding them & Umbonate & Entire \\
\hline
\end{tabular}

Table 7: Colony morphology for all fungi isolated from Tree \# 2

\subsubsection{Tree 3 (Naval Orange)}

Tables 8 and 9 present the information obtained from Tree \#3. Once again, all 9 fungi-selective plates had fungal growth. However, 4 of the 15 bacteria-selective plates had no growth. Sixteen bacteria and 12 fungi were isolated from branch 1, three bacteria and six fungi were isolated from branch 2 , and three bacteria and three fungi were isolated from branch 3. An average of 2.7 fungi, and 1.8 bacteria were isolated from each plate. All in 
all, there were 22 bacteria and 24 fungi isolated from Tree \#3, for a grand total of 46

isolated endophytic organisms.

\begin{tabular}{|c|c|c|c|c|c|c|c|}
\hline $\begin{array}{c}\text { Tree, Branch } \\
\text { and Segment } \\
\text { Numbers }\end{array}$ & $\begin{array}{c}\text { Number } \\
\text { of } \\
\text { Isolates }\end{array}$ & Isolate Name & Color & Form & Elevation & Margin & $\begin{array}{l}\text { Growth } \\
\text { (streaks) }\end{array}$ \\
\hline \multicolumn{8}{|l|}{ Tree \#3 } \\
\hline \multicolumn{8}{|l|}{ Tree 3 Branch 1} \\
\hline T3B1S1 & 1 & (only iso) T3B1S1 & White translucent & Circular & Flat & Entire & Full Plate \\
\hline \multirow{6}{*}{\begin{tabular}{|l|} 
T3B1S2 \\
\end{tabular}} & 6 & IA T3B1S2 & Pink & Circular & Flat & Entire & 3 \\
\hline & & IB T3B1S2 & Orange & Irregular & Raised & Undulate & $2<$ \\
\hline & & IC T3B1S2 & Pale Yellow & Circular & Flat & Entire & 3 \\
\hline & & ID T3B1S2 & Pink & Irregular & Flat & Undulate & Single colony \\
\hline & & IE T3B1S2 & Pale orange & Circular & Flat & Entire & $2<$ \\
\hline & & IF T3B1S2 & Light pink & Circular & Flat & Entire & $1<$ \\
\hline T3B1S3 & 1 & (only iso) T2B1S3 & White translucent & Circular & Flat & Undulate & $3+$ \\
\hline \multirow{4}{*}{ T3B1 TSA+S } & 4 & IA T3B1 & Translucent & Circular & Flat & Curled & 3 \\
\hline & & IB T3B1 & Translucent & Circular & Flat & Curled & 3 \\
\hline & & IC T3B1 & Translucent & Irregular & Flat & Curled & 3 \\
\hline & & ID T23B1 & Translucent & Circular & Flat & Entire & 3 \\
\hline \multirow[t]{4}{*}{$\mathrm{TSA}+\mathrm{S}$ to TSA } & 4 & IA T3B1 on TSA & Translucent & Irregular & Flat & Curled & $3<$ \\
\hline & & IB T3B1 on TSA & Translucent & Circular & Flat & Curled & 2 \\
\hline & & IC T3B1 on TSA & Translucent & Irregular & Flat & Curled & 3 \\
\hline & & ID T3B1 on TSA & Translucent & Circular & Flat & Entire & $3<$ \\
\hline \multicolumn{8}{|l|}{ Tree 3 Branch 2} \\
\hline T3B2S1 & 1 & (only iso) T3B2S1 & Translucent & Circular & Raised & Entire & 3 \\
\hline T3B2S2 & 0 & $\mathrm{~N} / \mathrm{A}$ & $\mathrm{N} / \mathrm{A}$ & $\mathrm{N} / \mathrm{A}$ & $\mathrm{N} / \mathrm{A}$ & $\mathrm{N} / \mathrm{A}$ & $\mathrm{N} / \mathrm{A}$ \\
\hline T3B2S3 & 0 & $\mathrm{~N} / \mathrm{A}$ & $\mathrm{N} / \mathrm{A}$ & $\mathrm{N} / \mathrm{A}$ & $\mathrm{N} / \mathrm{A}$ & $\mathrm{N} / \mathrm{A}$ & $\mathrm{N} / \mathrm{A}$ \\
\hline T3B2 TSA+S & 1 & IA T3B2 & Translucent & Irregular & Flat & Lobate & 3 \\
\hline TSA+S to TSA & 1 & T3B2 on TSA & Translucent & Circular & Flat & Entire & 3 \\
\hline \multicolumn{8}{|l|}{ Tree 3 Branch 3} \\
\hline T3B3S1 & 0 & $\mathrm{~N} / \mathrm{A}$ & $\mathrm{N} / \mathrm{A}$ & $\mathrm{N} / \mathrm{A}$ & $\mathrm{N} / \mathrm{A}$ & $\mathrm{N} / \mathrm{A}$ & $\mathrm{N} / \mathrm{A}$ \\
\hline \multirow{2}{*}{ T3B3S2 } & 2 & IA T3B3S2 & Translucent & Circular & Flat & Undulate & Full Plate \\
\hline & & IB T3B3S2 & Yellow & Circular & Flat & Undulate & $1<$ \\
\hline T3B3S3 & 1 & (only iso) T3B3S2 & Pink & Circular & Flat & Entire & $2<$ \\
\hline T3B3 TSA+S & 0 & $\mathrm{~N} / \mathrm{A}$ & $\mathrm{N} / \mathrm{A}$ & $\mathrm{N} / \mathrm{A}$ & $\mathrm{N} / \mathrm{A}$ & $\mathrm{N} / \mathrm{A}$ & $\mathrm{N} / \mathrm{A}$ \\
\hline
\end{tabular}

Table 8: Colony morphology for all bacteria isolated from Tree \# 3 


\begin{tabular}{|c|c|c|c|c|c|}
\hline $\begin{array}{c}\text { Tree, Branch, } \\
\text { and Segment } \\
\text { Numbers }\end{array}$ & $\begin{array}{c}\text { Number } \\
\text { of } \\
\text { isolates }\end{array}$ & Isolate name & Description (Color, shape etc.) & Elevation & Margin \\
\hline \multicolumn{6}{|l|}{ Tree \#3 } \\
\hline \multicolumn{6}{|l|}{ Tree 3 Branch 1} \\
\hline \multirow[t]{5}{*}{ T3B1S1 } & 5 & IA T3B1S1 & $\begin{array}{l}\text { Brown dots at the center, Off-white outer mycelium, and dark green dots } \\
\text { spread thorughout }\end{array}$ & Umbunate & Undulate \\
\hline & & IB T3B1S1 & \begin{tabular}{|c|} 
Round white mycelium \\
\end{tabular} & Flat & Filiform \\
\hline & & IC T3B1S1 & Yellow circular (bacteria-like) & Flat & Entire \\
\hline & & ID T3B1S1 & Brown centers with tan surroundings & Flat & Undulate \\
\hline & & IE T3B1S1 & Pink circles (bacteria-like) & Raised & Entire \\
\hline \multirow[t]{3}{*}{ T3B1S2 } & 3 & IA T3B1S2 & $\begin{array}{l}\text { Perfect circles of dark gren center and gray to off-white perfect circles } \\
\text { surrounding them }\end{array}$ & Flat & Entire \\
\hline & & IB T3B1S2 & Rings of brown, dark green and light green & Flat & Entire \\
\hline & & IC T3B1S2 & $\begin{array}{l}\text { Rings of off-white and tan expanding from the center, which is an army } \\
\text { green dot }\end{array}$ & Flat & Entire \\
\hline \multirow[t]{4}{*}{ T3B1S3 } & 4 & IA T3B1S3 & $\begin{array}{l}\text { Extremely shiny white dots (bacteira-like), with white mycelium } \\
\text { surrouding large colonies }\end{array}$ & Flat & Entire \\
\hline & & IB T3B1S3 & Dark army-green circles with light green mycelium surrouding them & Convex & Undulate \\
\hline & & IC T3B1S3 & Teal and white circles with & Flat & Entire \\
\hline & & ID T3B1S3 & Brown, tan and off-white circles & Raised & Undulate \\
\hline \multicolumn{6}{|l|}{ Tree 3 Branch 2} \\
\hline T3B2S1 & 1 & (only iso) T3B2S1 & Dark center lighter middle and outer white mycelium & Flat & Entire \\
\hline \multirow[t]{4}{*}{ T3B2S2 } & 4 & IA T3B2S2 & Thick, off-white almost patches & Flat & Undulate \\
\hline & & IB T3B2S2 & Thick dark brown centers with brown surroundings & Flat & Enitre \\
\hline & & IC T3B2S2 & Green centers surrounded by white mycelium & Flat & Undulate \\
\hline & & ID T3B2S2 & $\begin{array}{l}\text { Green circular centers with off-white patches of what looks like } \\
\text { mycelium and with orange dots spread throughout }\end{array}$ & Flat & Undulate \\
\hline T3B2S3 & 1 & (only iso) T3B2S1 & Very thin layer of almost transparent mycelium fills plate & Flat & Entire \\
\hline \multicolumn{6}{|l|}{ Tree 3 Branch 3} \\
\hline \multirow[t]{2}{*}{ T3B3S1 } & 2 & IA T3B3S1 & Circular green dots that look more like bacteria & Flat & Entire \\
\hline & & IB T3B3S1 & Orange dots (look like bacteria), but also filled with white mycelium & Flat & Entire \\
\hline \multirow[t]{3}{*}{ T3B3S2 } & 3 & IA T3B3S2 & Plate covered in what looks like tan/beige mycelium & Flat & Undulate \\
\hline & & IB T3B3S2 & Light yellow, creamy (bacteria-looking) & Flat & Entire \\
\hline & & IC T3B3S2 & Orange dots surrounded by white mycelium & Flat & Entire \\
\hline T3B3S3 & 1 & (only iso) T3B3S3 & $\begin{array}{l}\text { Dark green circles with a very thin layer of white mycilium surrounding } \\
\text { them }\end{array}$ & Flat & Entire \\
\hline
\end{tabular}

Table 9: Colony morphology for all fungi isolated from Tree \# 3

\subsubsection{Tree \#4 (Valencia Orange)}

Tables 10 and 11 present the data obtained from Tree \#4. The only fungi-selective petri dish (of 45) that did not have any growth was found in Tree \#4. Also, 3 of the 15 bacteria-selective petri plates did not have any growth. Still, endophytic fungal isolates averaged 2.9 per plate and bacterial isolates averaged 5.8 per plate. A total of 35 bacteria and 12 fungi were isolated from branch 1, 31 bacteria and 10 fungi were isolated from branch 2, and 3 bacteria and 4 fungi were isolated from branch 3. A total of 69 bacteria and 26 fungi were isolated from Tree \#4 for a total of 95 isolated endophytic organisms. 


\begin{tabular}{|c|c|c|c|c|c|c|c|}
\hline \multicolumn{8}{|l|}{ Tree \#4 } \\
\hline \multicolumn{8}{|l|}{ Tree 4 Branch 1} \\
\hline \multirow[t]{8}{*}{ T4B1S1 } & 8 & IA T4B1S1 & Peach & Circular & Flat & Entire & 3 \\
\hline & & IB T4B1S1 & Light yellow & Circular & Flat & Entire & 3 \\
\hline & & IC T4B1S1 & Translucent Yellow & Circular & Flat & Entire & 3 \\
\hline & & ID T4B1S1 & Light yellow & Circular & Flat & Entire & 3 \\
\hline & & IE T4B1S1 \#1 & Light yellow & Circular & Flat & Entire & $3<$ \\
\hline & & IE T4B1S1 \#2 & Light orange & Circular & Raised & Entire & $3<$ \\
\hline & & IF T4B1S1 & Off white & Circular & Flat & Entire & 3 \\
\hline & & IG T4B1S1 & Off white & Circular & Flat & Entire & 3 \\
\hline \multirow[t]{9}{*}{ T4B1S2 } & 9 & IA T4B1S2 \#1 & Light yellow & Irregular & Raised & Undulate & $2<$ \\
\hline & & IA T4B1S2 \#2 & Black & Irregular & Flat & Entire & 3 \\
\hline & & IA T4B1S2 \#3 & Translucent yellow & Circular & Raised & Entire & 3 \\
\hline & & IB T4B1S2 \#1 & Translucent yellow & Irregular & Flat & Undulate & 3 \\
\hline & & IB T4B1S2 \#2 & Translucent yellow & Circular & Flat & Entire & $3<$ \\
\hline & & IC T4B1S2 & Pale yellow & Circular & Raised & Entire & $3<$ \\
\hline & & ID T4B1S2 \#1 & White & Circular & Flat & Entire & 3 \\
\hline & & ID T4B1S2 \#2 & Translucent yellow & Circular & Flat & Entire & $3<$ \\
\hline & & ID T4B1S2 \#3 & Brown & filamentous & Flat & Entire & $3<$ \\
\hline \multirow[t]{2}{*}{\begin{tabular}{|l} 
T4B1S3 \\
\end{tabular}} & 2 & IA T4B1S3 \#1 & Light yellow & Circular & Flat & Entire & 3 \\
\hline & & IB T4B1S3 \#2 & Yellow & Circular & Convex & Undulate & $2<$ \\
\hline \multirow[t]{8}{*}{ T4B1 TSA+S } & 8 & IA T4B1 \#1 & Light Yellow & Circular & Flat & Entire & 3 \\
\hline & & IA T4B1 \#2 & Pale Peach & Circular & Flat & Entire & $3<$ \\
\hline & & IA T4B1 \#3 & Orange & Circular & Raised & Entire & Single colony \\
\hline & & IB T4B1 \#1 & Translucent yellow & Irregular & Flat & Entire & $2<$ \\
\hline & & IB T4B1 \#2 & Off white & Irregular & Flat & Entire & 3 \\
\hline & & IC T4B1 \#1 & Pink & Circular & Flat & Curled & $3<$ \\
\hline & & IC T4B1 \#2 & Yellow & Circular & Flat & Entire & 3 \\
\hline & & \begin{tabular}{|l|} 
ID T4B1 \\
\end{tabular} & Translucent & Circular & Raised & Curled & $3<$ \\
\hline \multirow[t]{6}{*}{ TSA+S to TSA } & 8 & IA T4B1 on TSA \#1 & Off white & Circular & Flat & Entire & 3 \\
\hline & & IA T4B1 on TSA \#2 & Light pink & Circular & Flat & Entire & 3 \\
\hline & & IB T4B1 on TSA & Translucent yellow & Circular & Flat & Curled & 3 \\
\hline & & IB T4B1 on TSA \#2 & Off white & Circular & Flat & Entire & 3 \\
\hline & & IC T4B1 on TSA & Pink with off white edges & Irregular & Flat & Curled & 2 \\
\hline & & ID T4B1 on TSA & Translucent off white & circular & Flat & Entire & 3 \\
\hline \multicolumn{8}{|l|}{ Tree 4 Branch 2} \\
\hline T4B2S1 & 9 & IA T4B2S1 & Light yellow & Irregular & Raised & Lobate & Single colony \\
\hline & & IB T4B2S1 & translucent white & Circular & Flat & Entire & 1 \\
\hline & & IC T4B2S1 & Translucent peach & Circular & Flat & Entire & 3 \\
\hline & & ID T4B2S1 & Yellow & Circular & Flat & Entire & 3 \\
\hline & & IE T4B2S1 & Peach & Irregular & Flat & Undulate & 2 \\
\hline & & IF T4B2S1 & Pink & Circular & Flat & Entire & $1<$ \\
\hline & & IG T4B2S1 & Light yellow & Circular & Flat & Entire & $2<$ \\
\hline & & IH T4B2S1 \#1 & Light yellow & Circular & Flat & Entire & $2<$ \\
\hline & & IH T4B2S1 \#2 & White & Circular & Flat & Entire & $1<$ \\
\hline T4B2S2 & 3 & IA T4B2S2 & Translucent yellow & Circular & Flat & Entire & 3 \\
\hline & & IB T4B2S2 \#1 & Translucent yellow & Circular & Flat & Entire & 2 \\
\hline & & IB T4B2S2 \#2 & Pink & Circular & Flat & Entire & 2 \\
\hline T4B2S3 & 5 & IA T4B2S3 \#1 & Off white & Irregular & Flat & Lobate & 1 \\
\hline & & IA T4B2S3 \#2 & Orange & Circular & Flat & Entire & 3 \\
\hline & & IA T4B2S3 \#3 & Light orange & Circular & Flat & Entire & $2<$ \\
\hline & & IA T4B2S3 \#4 & Light orange & Irregular & Flat & Undulate & 1 \\
\hline & & IA T4B2S3 \#5 & Orange & Circular & Flat & Entire & $3<$ \\
\hline T4B2 TSA+S & 7 & IA T4B2 \#1 & Yellow & Irregular & Flat & Undulate & 3 \\
\hline & & IA T4B2 \#2 & Light yellow & Irregular & Flat & Entire & $3<$ \\
\hline & & IB T4B2 & Pale peach & Circular & Flat & Curled & $3<$ \\
\hline & & IC T4B2 & Translucent & Circular & Flat & Entire & 3 \\
\hline & & ID T4B2 & Translucent yellow & Circular & Flat & Undulate & 3 \\
\hline & & IE T4B2 & Yellow & Circular & Flat & Entire & $2<$ \\
\hline & & IF T4B2 & Light yellow & Circular & Flat & Entire & 3 \\
\hline & & IG T4B2 & Orange & Irregular & Raised & Lobate & $1<$ \\
\hline TSA+S to TSA & 7 & IA T4B2 on TSA & Pale yellow & Circular & Flat & Entire & 3 \\
\hline & & IB T4B2 on TSA & Peach & Circular & Flat & Entire & $3<$ \\
\hline & & IC T4B2 on TSA & Off white & Circular & Flat & Entire & 3 \\
\hline & & ID T4B2 on TSA & Translucent yellow & Circular & Flat & Entire & 3 \\
\hline & & IE T4B2 on TSA & Translucent off white & Circular & Flat & Entire & 3 \\
\hline & & IF T4B2 on TSA & Yellow & Circular & Flat & Entire & 3 \\
\hline & & IG T4B2 on TSA & Light orange & Irregular & Raied & Lobate & 3 \\
\hline Tree 4 Branch 3 & & & & & & & \\
\hline T4B3S1 & 0 & $\mathrm{~N} / \mathrm{A}$ & $\mathrm{N} / \mathrm{A}$ & $N / A$ & $\mathrm{~N} / \mathrm{A}$ & $\mathrm{N} / \mathrm{A}$ & $\mathrm{N} / \mathrm{A}$ \\
\hline T4B3S2 & 3 & IA T4B3S2 & Yellow & Circular & Flat & Entire & 3 \\
\hline & & IB T4B3S2 & Pink & Circular & Flat & Entire & 3 \\
\hline & & IC T4B3S2 & Pink & Irregular & Flat & Lobate & $3<$ \\
\hline T4B3S3 & 0 & $\mathrm{~N} / \mathrm{A}$ & $\mathrm{N} / \mathrm{A}$ & $N / A$ & $\mathrm{~N} / \mathrm{A}$ & $\mathrm{N} / \mathrm{A}$ & $\mathrm{N} / \mathrm{A}$ \\
\hline T4B3 TSA+S & 0 & $\mathrm{~N} / \mathrm{A}$ & $\mathrm{N} / \mathrm{A}$ & $\mathrm{N} / \mathrm{A}$ & $\mathrm{N} / \mathrm{A}$ & $\mathrm{N} / \mathrm{A}$ & $\mathrm{N} / \mathrm{A}$ \\
\hline
\end{tabular}

Table 10: Colony morphology for all bacteria isolated from Tree \# 4 


\begin{tabular}{|c|c|c|c|c|c|}
\hline $\begin{array}{l}\text { Tree, Branch, } \\
\text { and Segment } \\
\text { Numbers }\end{array}$ & $\begin{array}{c}\text { Number } \\
\text { of } \\
\text { isolates }\end{array}$ & Isolate name & Description (Color, shape etc.) & Elevation & Margin \\
\hline \multicolumn{6}{|l|}{ Tree \#4 } \\
\hline \multicolumn{6}{|l|}{ Tree 4 Branch 1} \\
\hline \multirow[t]{6}{*}{ T4B1S1 } & 6 & IA T4B1S1 & White mycelium & Flat & Filiform \\
\hline & & IB T4B1S1 \#1 & Teal circles (bacteria-like) & Flat & Entire \\
\hline & & IB T4B1S1 \#2 & Green mycelium surrounded by white mycelium & Flat & Filliform \\
\hline & & IB T4B1S1 \#3 & Translucent yellow (bacteria-like) & Flat & Entire \\
\hline & & IA T4B1S1 \#1 & Green centers with white mycelium surrounding it & Flat & Filliform \\
\hline & & IA T4B1S1 \#2 & Translucent yellow (bacteria-like) & Flat & Entire \\
\hline \multirow[t]{3}{*}{ T4B1S2 } & 3 & IA T4B1S1 & $\begin{array}{l}\begin{array}{l}\text { Shinny white dots (bacteria-like), but with white mycelium surrounding } \\
\text { them }\end{array} \\
\text { the }\end{array}$ & Flat & Entire \\
\hline & & IB T4B1S2 \#1 & White mycelium covering plate & Flat & Entire \\
\hline & & IB T4B1S2 \#2 & Green mycelium & Flat & Entire \\
\hline \multirow[t]{3}{*}{ T4B1S3 } & 3 & IA T4B1S1 & Light orange translucent (bacteria-like) & Flat & Entire \\
\hline & & IB T4B1S2 \#1 & Pink translucent (bacteria-like) & Flat & Entire \\
\hline & & IB T4B1S2 \#2 & Yellow translucent (bacteria like) & Flat & Entire \\
\hline \multicolumn{6}{|l|}{ Tree 4 Branch 2} \\
\hline \multirow[t]{3}{*}{ T4B2S1 } & 3 & IA T4B2S1 & Light orange circles surrounded by green and white mycelium & Flat & Entire \\
\hline & & IB T4B2S1 & Green and orange dots surrounded by white mycelium & Flat & Entire \\
\hline & & IC T4B2S1 & Army-green mycelium with some orange dots throughout & Flat & Undulate \\
\hline \multirow[t]{4}{*}{ T4B2S2 } & 4 & IA T4B2S2 \#1 & Dark green mycelium covering plate & Flat & Entire \\
\hline & & IA T4B2S2 \#2 & Orange dots (bacteria-like) & Flat & Entire \\
\hline & & IB T4B2S2 & yellow creamy dots (bacteria-like) & Flat & Entire \\
\hline & & IC T4B2S2 & $\begin{array}{c}\text { Extremely dark green (almost look black), and tiny colonies of what look } \\
\text { like whiet mycelium }\end{array}$ & Flat & Undulate \\
\hline \multirow[t]{3}{*}{ T4B2S3 } & 3 & IA T4B2S3 & White mycelium & Flat & Filiform \\
\hline & & IB T4B2S3 \#1 & Army-green mycelium & Flat & Entire \\
\hline & & IB T4B2S3 \#2 & Yellow dots (bacteria-like) & Flat & Entire \\
\hline \multicolumn{6}{|l|}{ Tree 4 Branch 3} \\
\hline T4B3S1 & 1 & (only iso) T4B3S1 & Off-white circles surrouned by white mycelium & Flat & Entire \\
\hline \multirow[t]{3}{*}{ T4B3S2 } & 3 & IA T4B3S2 & Beige circles (some light some dark) & Flat & Entire \\
\hline & & IB T4B3S2 \#1 & Dark green circles surrounded by white mycelium & Flat & Filiform \\
\hline & & IB T4B3S2 \#2 & Brown circles surrounded by white mycelium & Flat & Filiform \\
\hline T4B3S3 & 0 & $\mathrm{~N} / \mathrm{A}$ & $\mathrm{N} / \mathrm{A}$ & $\mathrm{N} / \mathrm{A}$ & $\mathrm{N} / \mathrm{A}$ \\
\hline
\end{tabular}

Table 11: Colony morphology for all fungi isolated from Tree \# 4

\subsubsection{Tree \#5 (Blood Orange)}

Tables 12 and 13 present the information collected from Tree \#5. All plates selective for fungi had growth, however eight of 15 bacteria-selective plates had no growth. There was an average of 5.4 fungi isolated from each plate, which was the highest amongst all trees. The average bacteria isolated from each plate was 0.83 , which was the lowest average between all trees. A total of three bacteria and eight fungi were isolated from branch 1, five bacteria and 15 fungi from branch 2 and two bacteria and 26 fungi from branch 3. A total of 10 bacterial endophytes and 49 fungal endophytes were isolated from Tree \#5, for a grand total of 54 organisms. 


\begin{tabular}{|c|c|c|c|c|c|c|c|}
\hline $\begin{array}{c}\text { Tree, Branch } \\
\text { and Segment } \\
\text { Numbers }\end{array}$ & $\begin{array}{c}\text { Number } \\
\text { of } \\
\text { Isolates }\end{array}$ & Isolate Name & Color & Form & Elevation & Margin & $\begin{array}{l}\text { Growth } \\
\text { (streaks) }\end{array}$ \\
\hline \multicolumn{8}{|l|}{ Tree \#5 } \\
\hline \multicolumn{8}{|l|}{ Tree 5 Branch 1} \\
\hline T5B1S1 & 0 & $\mathrm{~N} / \mathrm{A}$ & $\mathrm{N} / \mathrm{A}$ & $\mathrm{N} / \mathrm{A}$ & $\mathrm{N} / \mathrm{A}$ & $\mathrm{N} / \mathrm{A}$ & $\mathrm{N} / \mathrm{A}$ \\
\hline T5B1S2 & 0 & $\mathrm{~N} / \mathrm{A}$ & $\mathrm{N} / \mathrm{A}$ & $\mathrm{N} / \mathrm{A}$ & $\mathrm{N} / \mathrm{A}$ & $\mathrm{N} / \mathrm{A}$ & $\mathrm{N} / \mathrm{A}$ \\
\hline T5B1S3 & 1 & (only iso) T5B1S3 & Pink & Circular & Flat & Entire & 3 \\
\hline T5B1 TSA+S & 1 & T5B1 & Light peach & Circular & Umbonate & Lobate & Single colony \\
\hline $\mathrm{TSA}+\mathrm{S}$ to TSA & 1 & T5B1 on TSA & $\mathrm{N} / \mathrm{A}$ & $\mathrm{N} / \mathrm{A}$ & $\mathrm{N} / \mathrm{A}$ & $\mathrm{N} / \mathrm{A}$ & $\mathrm{N} / \mathrm{A}$ \\
\hline \multicolumn{8}{|l|}{ Tree 5 Branch 2} \\
\hline T5B2S1 & 0 & $\mathrm{~N} / \mathrm{A}$ & $\mathrm{N} / \mathrm{A}$ & $\mathrm{N} / \mathrm{A}$ & $\mathrm{N} / \mathrm{A}$ & $\mathrm{N} / \mathrm{A}$ & $N / A$ \\
\hline \multirow[t]{5}{*}{ T5B2S2 } & 5 & IA T5B2S2 & Pale yellow & Circular & Flat & Entire & 3 \\
\hline & & IB T5B2S2 \#1 & translucent white & Circular & Flat & Entire & $1<$ \\
\hline & & IB T5B2S2 \#2 & Peach & Irregular & Flat & Entire & $2<$ \\
\hline & & IC T5B2S2 \#1 & Off white & Irregular & Flat & Undulate & $1<$ \\
\hline & & IC T5B2S2 \#2 & White & Irregular & Flat & Undulate & $1<$ \\
\hline T5B2S3 & 0 & $\mathrm{~N} / \mathrm{A}$ & $\mathrm{N} / \mathrm{A}$ & $\mathrm{N} / \mathrm{A}$ & $\mathrm{N} / \mathrm{A}$ & $\mathrm{N} / \mathrm{A}$ & $\mathrm{N} / \mathrm{A}$ \\
\hline T5B2 TSA+S & 0 & $\mathrm{~N} / \mathrm{A}$ & $\mathrm{N} / \mathrm{A}$ & $\mathrm{N} / \mathrm{A}$ & $\mathrm{N} / \mathrm{A}$ & $\mathrm{N} / \mathrm{A}$ & $\mathrm{N} / \mathrm{A}$ \\
\hline \multicolumn{8}{|l|}{ Tree 5 Branch 3} \\
\hline T5B3S1 & 0 & $\mathrm{~N} / \mathrm{A}$ & $\mathrm{N} / \mathrm{A}$ & $\mathrm{N} / \mathrm{A}$ & $\mathrm{N} / \mathrm{A}$ & $\mathrm{N} / \mathrm{A}$ & $\mathrm{N} / \mathrm{A}$ \\
\hline \multirow[t]{2}{*}{ T5B3S2 } & 2 & IA T5B3S2 & Off white & Circular & Flat & Entire & 3 \\
\hline & & IB T5B3S2 & Pale peach & Circular & Flat & Curled & $2<$ \\
\hline T5B3S3 & 0 & $\mathrm{~N} / \mathrm{A}$ & $\mathrm{N} / \mathrm{A}$ & $\mathrm{N} / \mathrm{A}$ & $\mathrm{N} / \mathrm{A}$ & $\mathrm{N} / \mathrm{A}$ & $\mathrm{N} / \mathrm{A}$ \\
\hline T5B3 TSA+S & 0 & $\mathrm{~N} / \mathrm{A}$ & $\mathrm{N} / \mathrm{A}$ & $\mathrm{N} / \mathrm{A}$ & $\mathrm{N} / \mathrm{A}$ & $\mathrm{N} / \mathrm{A}$ & $\mathrm{N} / \mathrm{A}$ \\
\hline
\end{tabular}

Table 12: Colony morphology for all bacteria isolated from Tree \# 5 


\begin{tabular}{|c|c|c|c|c|c|}
\hline $\begin{array}{c}\text { Tree, Branch, } \\
\text { and Segment } \\
\text { Numbers }\end{array}$ & $\begin{array}{l}\text { Number } \\
\text { of } \\
\text { isolates }\end{array}$ & Isolate name & Description (Color, shape etc.) & Elevation & Margin \\
\hline \multicolumn{6}{|l|}{ Tree \#5 } \\
\hline \multicolumn{6}{|l|}{ Tree 5 Branch 1} \\
\hline T5B1S1 & 1 & (only iso) T5B1S1 & Beige circles darker in the center and ligher on the outside & Raised & Lobate \\
\hline \multirow[t]{4}{*}{ T5B1S2 } & 4 & IA T4B1S1 & White mycelium (darker and lighter by layers) & Flat & Undulate \\
\hline & & IB T4B1S1 & Dark green on inside with a very thin white outline & Flat & Entire \\
\hline & & IC T4B1S1\#1 & White mycelium covers plate & Flat & Undulate \\
\hline & & IC T4B1S1 \#2 & Pink dots (bacteria-like) & Flat & Entire \\
\hline \multirow[t]{3}{*}{ T5B1S3 } & 3 & IA T5B1S3 & Small, dark green dots surrounded by thick, off-white mycelium & Umbonate & Undulate \\
\hline & & IB T5B1S3 & $\begin{array}{c}\text { Off-white patches of what looks like mycelium, with a streaked line of } \\
\text { orange dots (bacteria-like) }\end{array}$ & Crateriform & Undulate \\
\hline & & IC T5B1S3 & Mild light green circles beneth off-white mycelial patches & Umbonate & Undulate \\
\hline \multicolumn{6}{|l|}{ Tree 5 Branch 2} \\
\hline \multirow[t]{4}{*}{ T5B2S1 } & 4 & IA T5B1S3 & $\begin{array}{l}\text { Tiny light green dot in center with pale orange around it and white } \\
\text { mycelium surrouding both }\end{array}$ & Flat & Entire \\
\hline & & IB T5B1S1 & Green centers with white mycelium surrounding it & Flat & Filamentous \\
\hline & & IC T5B1S1 & Beige circles (darker on the inside and ligher on the outside) & Flat & Entire \\
\hline & & ID T5B1S1 & Off-white circles (bacteria-like) & Flat & Entire \\
\hline \multirow[t]{5}{*}{ T5B2S2 } & 5 & IA T5B2S2\#1 & $\begin{array}{l}\text { Green circles (darker in center, then becomes lighter), with random } \\
\text { patches of white mycelium }\end{array}$ & Flat & Filamentous \\
\hline & & IA T5B2S2 \#2 & Few dark green circles surrounded by white mycelium & Flat & Filamentous \\
\hline & & IB T5B2S2 \#1 & Dark green circles with thin white layer surrounding them & Flat & Entire \\
\hline & & IB T5B2S2 \#2 & Green circles with empty centers & Flat & Entire \\
\hline & & IC T5B1S2 & Gray and white mycelium cover plate (growth up to lid) & Raised & Filamentous \\
\hline \multirow[t]{6}{*}{ T5B2S3 } & 6 & IA T5B2S3 \#1 & Off-white mycelial patches with streaks of orange & Raised & Undulate \\
\hline & & IA T5B2S3 \#2 & $\begin{array}{l}\text { Off-white mycelial patches with streaks of orange (tried to separate the } \\
\text { two but could not) }\end{array}$ & Raised & Undulate \\
\hline & & IB T5B2S3 & $\begin{array}{l}\text { Patches of thick off-white mycelium } \\
\end{array}$ & Raised & Undulate \\
\hline & & IC T5B2S3 \#1 & Translucent white coming out of white bacterial center & Flat & Entire \\
\hline & & IC T5B2S3 \#2 & Pale yellow/ off-white circles (bacteria-like) & Flat & Entire \\
\hline & & IC T5B2S3 \#3 & Translucent circles (bacteria-like) & Flat & Entire \\
\hline \multicolumn{6}{|l|}{ Tree 5 Branch 3} \\
\hline \multirow[t]{3}{*}{ T5B3S1 } & 3 & IA T5B3S1 \#1 & Beige and off-white mycelium spread throughout & Raised & Filiform \\
\hline & & IA T5B3S1 \#2 & White mycelium & Flat & Entire \\
\hline & & IB T5B3S1 & White mycelium (some looks yellow), and a few green and orange dots & Flat & Undulate \\
\hline \multirow[t]{15}{*}{ T5B3S2 } & 15 & IA T5B3S1 & Dark green center, lighter green middle, white mycelium outer & Flat & Entire \\
\hline & & IB T5B3S1 \#1 & White, creamy-like circles (bactera-like) & Flat & Entire \\
\hline & & IB T5B3S1 \#2 & Dark green center lighter green outer & Flat & Entire \\
\hline & & IB T5B3S1 \#3 & Yellow mycelium in inner part and white mycelium on outer part & Raised & Undulate \\
\hline & & IC T5B3S1 \#1 & $\begin{array}{l}\text { White mycelium fills plate } \\
\end{array}$ & Flat & Entire \\
\hline & & IC T5B3S1 \#2 & Dark green circles surrounded by white mycelium & Flat & Enitre \\
\hline & & IC T5B3S1 \#3 & Pink single colony (bacteria-like), very strange looking & Umbonate & Currled \\
\hline & & ID T5B3S1 & $\begin{array}{l}\text { White mycelium covering plate with green and orange dots pread } \\
\text { throughout }\end{array}$ & Raised & Undulate \\
\hline & & IE T5B3S1\#1 & Thick, dark green (moss-looking) circles & Raised & Entire \\
\hline & & IE T5B3S1 \#2 & Thin white mycelium & Flat & Entire \\
\hline & & IE T5B3S1 \#3 & Light pink dots (bacteria-like) & Flat & Entire \\
\hline & & IE T5B3S1\#4 & Dark pink circles (bacteria-like) & Flat & Enitre \\
\hline & & IF T5B3S1\#1 & Off-white patchy mycelium & Raised & Undulate \\
\hline & & IF T5B3S1 \#2 & $\begin{array}{l}\text { Light green center, off white outer circle, like shinny white crystals over } \\
\text { green center }\end{array}$ & Flat & Entire \\
\hline & & IF T5B3S1 \#3 & Light pink dots (bacteria-like) & Flat & Entire \\
\hline \multirow[t]{8}{*}{ T5B3S3 } & 8 & IA T5B3S3 \#1 & Dark green circles inside, and lighter on the outside & Flat & Entire \\
\hline & & IA T5B3S3 \#2 & Off-white circles that look like they glow (bacterial-like) & Flat & Entire \\
\hline & & IB T5B3S3 \#1 & Beige and off-white mycelium spread throughout & Flat & Filiform \\
\hline & & IB T5B3S3 \#2 & Circular white mycelium with green centers & Flat & Entire \\
\hline & & IB T5B3S3 \#3 & Tiny pink dots (bacteria-like) & Flat & Entire \\
\hline & & IC T5B3S3 \#1 & Light green center with white mycelium surrounding it & Flat & Entire \\
\hline & & IC T5B3S3\#2 & Light pink dots (bacteria-like) & Flat & Enite \\
\hline & & ID T5B3S3 & $\begin{array}{l}\text { Several small thick, dark green (almost black) colonies, with a think } \\
\text { white layer around each one }\end{array}$ & Raised & Undulate \\
\hline
\end{tabular}

Table 13: Colony morphology for all fungi isolated from Tree \# 5

Since CLas is found in the phloem, TSA+S plates were prepared with the intent to

resemble that of the sugar rich phloem. The average number of bacteria that were grown

on TSA plates was 2.2, while the average number of bacteria grown on $\mathrm{TSA}+\mathrm{S}$ was 2.0; 
thus, no significant difference was observed between the number of bacteria that were grown on TSA versus $\mathrm{TSA}+\mathrm{S}$. In order to know if $\mathrm{TSA}+\mathrm{S}$ was selective for different species, relative to that of TSA, DNA tests would be necessary. Nonetheless, with the exception of one isolate (T1B1), all bacteria that was initially isolated on TSA+S was able to be successfully sub-cultured on TSA.

Endophytes were isolated from a total of 5 trees, consisting of three citrus species: Naval orange (Tree's \# 1, 2 and 3), Valencia (Tree \#4), and Blood orange (Tree \#5). The origin of the total 179 bacterial isolates were obtained as follows: 29 bacteria were isolated from Tree \#1; 31 from Tree \#2; 22 from Tree \#3; 69 from Tree \#4; and 10 from Tree \#5. The average number of endophytic bacteria isolated from Naval orange was 27. Among the 3 tree species, Valencia orange contains the greatest amounts of isolated bacterial endophytes (69), followed by Naval orange which averaged 27, and lastly Blood orange where only 10 bacterial endophytes were isolated.

As for the total 163 isolated fungal endophytes, the isolates were obtained as follows: Tree \#1 contributed 25, Tree \#2 contributed 38, Tree \#3 contributed 24, Tree \#4 contributed 26, and Tree \#5 contributed 49. Thus, the average number of isolated fungal endophytes in Naval trees was 29. Among the three species, Naval and Valencia orange trees contained similar quantities of fungal endophytes, averaging 29 and 26, respectively, while blood orange trees contain the greatest amount, 49.

The three sampled tree species contained different assemblages of endophytes. Naval trees averaged a total of 56 isolated endophytes per tree and had similar amounts of both bacterial and fungal endophytes: averaging 27 and 29, respectively. The Valencia tree had the greatest number of endophytes isolated (95), although there were significantly more 
bacteria (69) than fungi (26). On the other hand, the Blood orange tree contributed the fewest endophytic isolates (59); yet this species hosts much more fungi (49) than bacteria (10). Nonetheless, while different assemblages of endophytes were observed from the three citrus species, not enough replicates of each tree species were sampled in order to determine whether there was a statistical difference in endophyte community assemblages between the three sampled species, but this could be an area for future research.

\subsection{Dual Culture}

The growth of S. meliloti in the presence of each isolated endophyte was compared to that of the control plates ( $S$. meliloti streaked alone). When growth of $S$. meliloti was less than that of the control plates, the inhibition effect was termed "moderate". When there was no visible growth (complete inhibition) of $S$. meliloti, the inhibition effect was termed " $100 \%$." Examples of how each of the dual cultures was categorized (100\%, moderate or no inhibition) is shown in Figure 26. Out of the 179 bacterial isolates that were screened by the dual culture technique, $23(12.8 \%)$ showed either moderate or $100 \%$ inhibition of $S$. meliloti (Table 14). Fifteen (8.4\%) bacteria presented a moderate level of inhibition against S. meliloti, and $8(4.5 \%)$ of bacteria were able to completely inhibit (100\%) the growth of S. meliloti. Each isolate showing antimicrobial properties was then assigned a new name for more convenient reference (Table 14). Of the 23 isolates showing inhibition, 4 came from Tree \#1, 4 from Tree \#2, 10 from Tree \#3, 5 from Tree \#4, and 0 from Tree \#5. Furthermore, 9 of these bacteria were originally isolated on TSA+S medium, while 14 were originally isolated on regular TSA. 


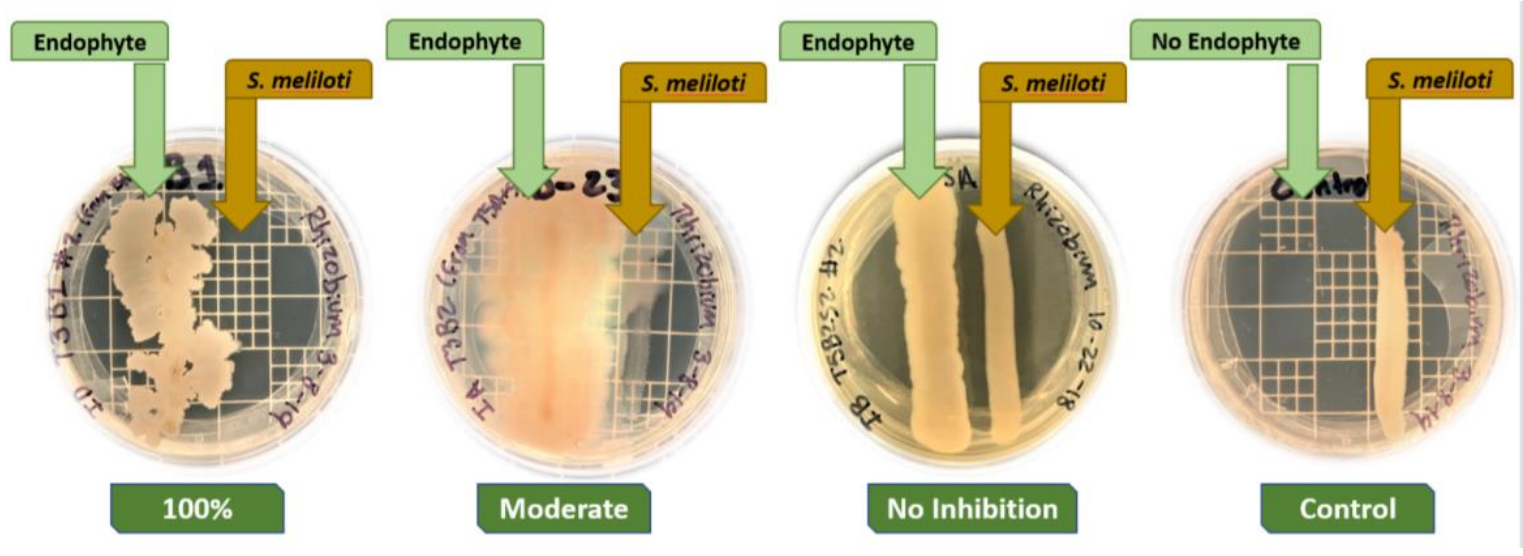

Figure 26: Examples of how each dual culture result was categorized

Although 163 isolated fungal endophytes were screened against S. meliloti using the dual culture technique, not a single one showed any inhibition. Thus, no further assessments were done with any of the fungal isolates.

\begin{tabular}{|l|c|c|}
\hline \multicolumn{1}{|c|}{ Isolate Name } & $\begin{array}{c}\text { Inhibition on } \\
\text { S. meliloti }\end{array}$ & New Name \\
\hline ID T3B1 \#2 (TSA+S) & Moderate & B-1 \\
\hline IB T4B1 \#2 & Moderate & B-2 \\
\hline IE T4B1S1 \#2 & Moderate & B-3 \\
\hline IB T2B2S2 & Moderate & B-4 \\
\hline IB T4B2S2 & Moderate & B-6 \\
\hline T3B2S1 (only) & Moderate & B-7 \\
\hline IA T2B3S1 \#1 & $100 \%$ & B-9 \\
\hline T1B3S1 (only) & $100 \%$ & B-10 \\
\hline IA T1B2S1 & Moderate & B-11 \\
\hline IA T2B3S1 \#2 & Moderate & B-12 \\
\hline IA T4B2 \#1 (TSA+S) & Moderate & B-13 \\
\hline IC T3B1 (TSA+S) & Moderate & B-15 \\
\hline IB T1B2 (TSA+S) & $100 \%$ & B-16 \\
\hline IB T2B3S1 & Moderate & B-17 \\
\hline IB T3B1 (TSA+S) & $100 \%$ & B-18 \\
\hline ID T3B1 \#1 (TSA+S) & Moderate & B-19 \\
\hline IA T3B1 (TSA+S) & Moderate & B-20 \\
\hline IA T4B2 \#2 (TSA+S) & Moderate & B-21 \\
\hline IB T1B3S2 & $100 \%$ & B-22 \\
\hline IA T3B2 (TSA+S) & Moderate & B-23 \\
\hline IA T3B3S2 & $100 \%$ & B-24 \\
\hline T3B1S1 & $100 \%$ & B-25 \\
\hline T3B1S1 & $100 \%$ & B-27 \\
\hline
\end{tabular}

Table 14: Successful inhibition of $S$. meliloti by dual culture 


\subsection{Diffusion Assay}

\subsubsection{Bacterial Extracts}

Cell-free culture supernatants (CFCS) were obtained from each of the 23 bacteria exhibiting antimicrobial activity against $S$. meliloti. Of the 23 CFCS's assessed via the diffusion assay, 15 showed no inhibition and eight showed at least some inhibition on $L$. crescens. A few examples of these results are shown in Figure 27. The inhibition zones were measured (diameter) for the 8 that showed effectiveness (Table 15). The zones of inhibition were as follows: B-7 8mm; B-9 37mm; B-13 14mm; B-17 40mm; B-20 10mm; B-24 47mm; B-25 33mm, and B-27 35mm.

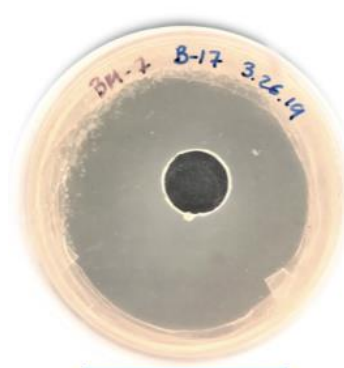

$40 \mathrm{~mm}$

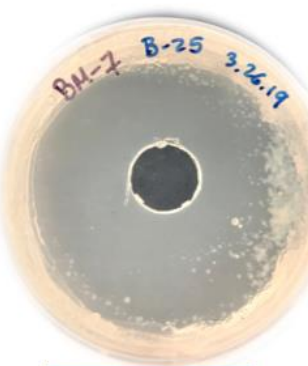

$33 \mathrm{~mm}$

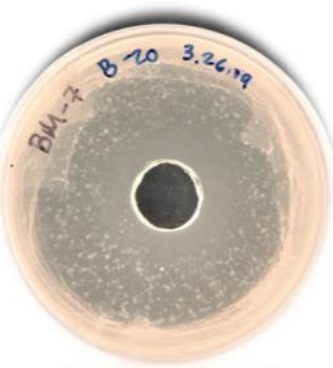

$10 \mathrm{~mm}$

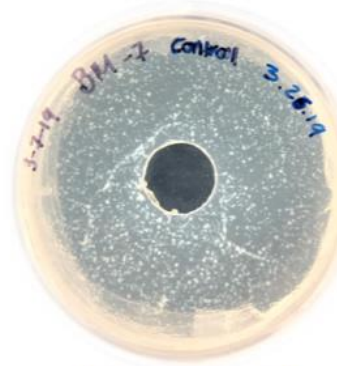

Control

Figure 27: Examples of inhibition zones on L. crescens caused by bacterial CFCS's

From the 15 bacteria that showed moderate inhibition of $S$. meliloti, four (26.7\%) also showed inhibition of L. crescens. From the eight bacteria that showed 100\% inhibition of $S$. meliloti, four (50\%) showed inhibition of L. crescens. The tree of origin of each of the final 8 bacteria are also shown on (Table 15); the total bacteria derived from each tree was as follows: Two bacteria came from Tree \#2, five bacteria came from Tree \#3, and one bacterium came from Tree \#4 (zero from Trees 1 and 5). 


\begin{tabular}{|c|c|c|}
\hline $\begin{array}{l}\text { Is olate } \\
\text { Name }\end{array}$ & $\begin{array}{l}\text { Inhibition } \\
\text { Zone }\end{array}$ & $\begin{array}{l}\text { Tree of } \\
\text { Origin }\end{array}$ \\
\hline B-7 & $8 \mathrm{~mm}$ & 3 \\
\hline B-9 & $37 \mathrm{~mm}$ & 2 \\
\hline B-13 & $14 \mathrm{~mm}$ & 4 \\
\hline B-17 & $40 \mathrm{~mm}$ & 2 \\
\hline B-20 & $10 \mathrm{~mm}$ & 3 \\
\hline B-24 & $47 \mathrm{~mm}$ & 3 \\
\hline B-25 & $33 \mathrm{~mm}$ & 3 \\
\hline B-27 & $35 \mathrm{~mm}$ & 3 \\
\hline
\end{tabular}

Table 15: Inhibition zone of CFCS on L. crescens by diffusion assay

\subsubsection{Plant Extracts}

The antimicrobial activity of 13 plant extracts were assessed against S. meliloti using the agar diffusion assay. The 13 plant extracts were the following: Alchornea, Artemisia Annuna, Banderol, Bidens, Cat's Claw, Cinnamon, Cryptolepsis, Holy basil,

Oregano, Stevia, Thyme, Turmeric, and Usnea. Nine extracts showed inhibition of $S$. meliloti; five of which showed 100\% inhibition (alchornea, artemisia, oregano, thyme, and tumeric), and four showed different levels of inhibition (cinnamon showed $32 \mathrm{~mm}$, cryptolepsis $14 \mathrm{~mm}$, holy basil $10 \mathrm{~mm}$, and usnea $8 \mathrm{~mm}$ ), an example is shown in Figure 28. Thus, the 4 extracts that did not show any inhibition on $S$. meliloti (banderol, bidens, cat's claw, and stevia) were not assessed against L. crescens.

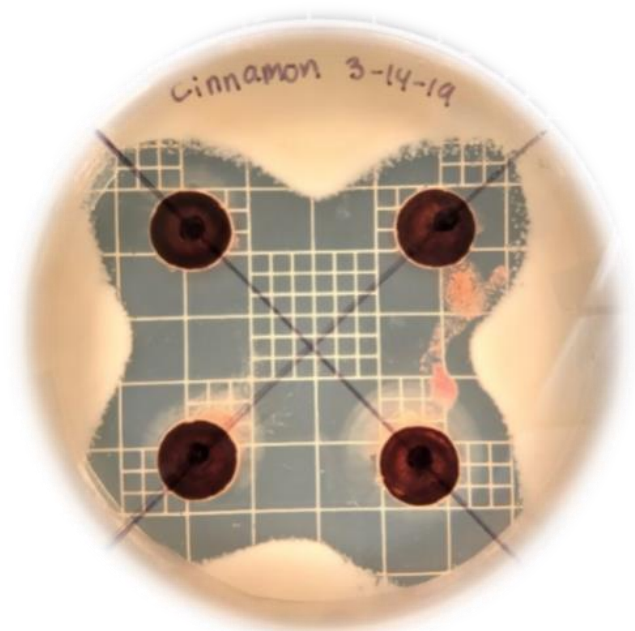

Figure 28: Diffusion Assay Example: The effect of cinnamon extract on S. meliloti 
The antimicrobial activity of the remaining nine extracts were evaluated at different concentrations $(100 \%, 30 \%, 10 \%$ and $5 \%)$ against $L$. crescens. The first diffusion assay on L. crescens was done without diluting the plant extracts (100\%). Here, three extracts did not show any inhibition (cryptolepsis, holy basil, and usnea), and were not assessed at any smaller concentrations. However, six of the undiluted plant extracts showed $100 \%$ inhibition of $L$. crescens. Therefore, those six plant extracts were tested at lower concentration levels $(30 \%, 10 \%$, and 5\%). One of the extracts (artemisia) showed $100 \%$ inhibition at 30\%, a $10 \mathrm{~mm}$ zone of inhibition at 10\%, and no inhibition at 5\%; this extract was eliminated from further assessments. However, the remaining five extracts all showed $100 \%$ inhibition of $L$. crescens, in all the concentrations tested. The five extracts that successfully inhibited $L$. crescens and were thus selected for further testing, were: alchornea, cinnamon, oregano, thyme, and turmeric. An example of the diffusion assay assessment using plant extracts on L. crescens is shown in Figure 29. Additionally, all results for plant extract inhibition on both S. meliloti and L. crescens are shown in Table 16. 


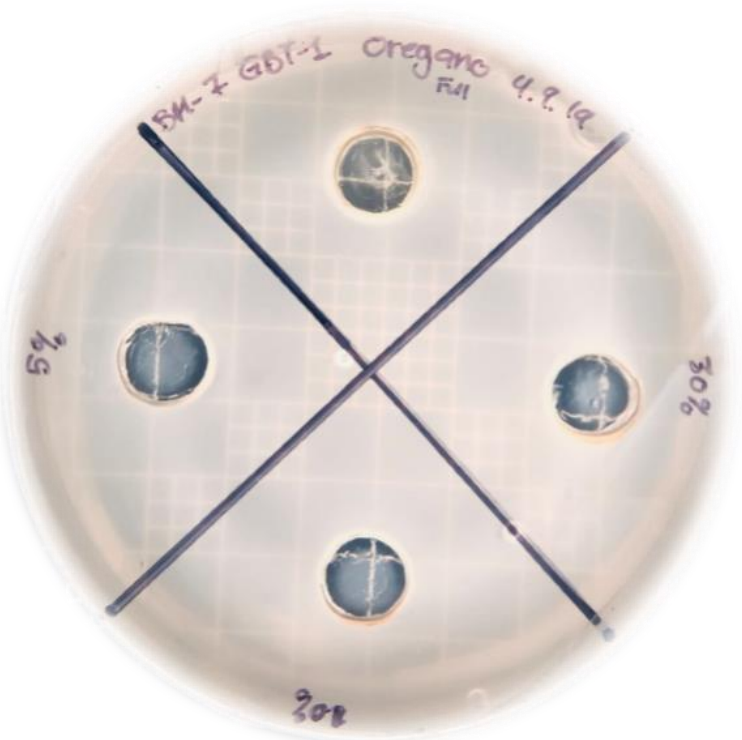

Figure 29: Diffusion assay example 2: The effect of oregano on L. crescens (100\% inhibition)

\begin{tabular}{|l|c|c|c|c|c|}
\hline \multicolumn{1}{|c|}{ Extract Name } & $\begin{array}{c}\text { Inhibition on S. } \\
\text { meliloti (Full Strength) }\end{array}$ & $\begin{array}{c}\text { Inhibiton on } \\
\text { L. crescens (100\%) }\end{array}$ & $\begin{array}{c}\text { Inhibition on } \\
\text { L. crescens (30\%) }\end{array}$ & $\begin{array}{c}\text { Inhibition on } \\
\text { crescens (10\%) }\end{array}$ & $\begin{array}{c}\text { Inhibition on } \\
\text { L. crescens (5\%) }\end{array}$ \\
\hline Alchornea & $\mathbf{1 0 0 \%}$ & $\mathbf{1 0 0 \%}$ & $\mathbf{1 0 0 \%}$ & $\mathbf{1 0 0 \%}$ & $\mathbf{1 0 0 \%}$ \\
\hline Artemisia Annuna & $\mathbf{1 0 0 \%}$ & $\mathbf{1 0 0 \%}$ & $\mathbf{1 0 0 \%}$ & $\mathbf{1 0 ~} \mathbf{m m}$ & No Inhibition \\
\hline Banderol & No Inhibition & - & - & - & - \\
\hline Bidens & No Inhibition & - & - & - & - \\
\hline Cat's Claw & No Inhibition & - & - & - & - \\
\hline Cinnamon & $\mathbf{3 2} \mathbf{~ m m}$ & $\mathbf{1 0 0 \%}$ & $\mathbf{1 0 0 \%}$ & $\mathbf{1 0 0 \%}$ & $\mathbf{1 0 0 \%}$ \\
\hline Cryptolepsis & $\mathbf{1 4} \mathbf{m m}$ & No Inhibition & - & - & - \\
\hline Holy Basil & $\mathbf{1 0 m m}$ & No Inhibition & - & - & - \\
\hline Oregano & $\mathbf{1 0 0 \%}$ & $\mathbf{1 0 0 \%}$ & $\mathbf{1 0 0 \%}$ & $\mathbf{1 0 0 \%}$ & $\mathbf{1 0 0 \%}$ \\
\hline Stevia & $\mathbf{N o ~ I n h i b i t i o n}$ & - & - & - & - \\
\hline Thyme & $\mathbf{1 0 0 \%}$ & $\mathbf{1 0 0 \%}$ & $\mathbf{1 0 0 \%}$ & $\mathbf{1 0 0 \%}$ & $\mathbf{1 0 0 \%}$ \\
\hline Turmeric & $\mathbf{1 0 0 \%}$ & $\mathbf{1 0 0 \%}$ & $\mathbf{1 0 0 \%}$ & $\mathbf{1 0 0 \%}$ & $\mathbf{1 0 0 \%}$ \\
\hline Usnea & $\mathbf{8 m m}$ & No Inhibition & - & - & - \\
\hline
\end{tabular}

Table 16: The inhibition of S. meliloti and L. crescens resulting from each plant extract

\subsection{Leaf-Disc Assay}

\subsubsection{LL Ct Raw Data (each extract on each leaf-disc)}

Ten extracts (five bacterial and five plant-based) were assessed using the leaf-disc assay. Table 17 shows the Ct values for the LL (Liberibacter asiaticus- Long) primer pair. The columns represent the LL Ct values for each treatment, which were: initial (first and last discs of each leaf under no treatment), TSB (control), $0.5 \mathrm{mM}$ of streptomycin (positive 
control), and each individual extract. The rows of the table include the average, standard deviation, change from zero hours (initial - each treatment), and effect (control - each treatment) of the LL Ct values for the 21 leaf samples (A-U). No effect is shown for the plant extracts since they were not grown in media and thus cannot be compared to TSB control.

\begin{tabular}{|c|c|c|c|c|c|c|c|c|c|c|c|c|c|}
\hline \multicolumn{14}{|c|}{ LL Ct Values 48 hours Incubation } \\
\hline Leaf & Initial & TSB & .5 Strep & Ext 1 & Ext 2 & Ext 3 & Ext 4 & Ext 5 & Ext 6 & Ext 7 & Ext 8 & Ext 9 & Ext 10 \\
\hline A & 29.63 & 30.71 & 31.04 & 40.00 & 33.50 & 33.15 & 35.59 & 36.02 & 31.96 & 32.50 & 31.24 & 31.37 & 36.98 \\
\hline B & 32.61 & 34.17 & 33.54 & 40.00 & 35.63 & 34.05 & 37.88 & 40.00 & 34.43 & 40.00 & 34.47 & 33.79 & 33.02 \\
\hline C & 33.68 & 31.24 & 33.20 & 40.00 & 34.48 & 40.00 & 40.00 & 40.00 & 36.10 & 40.00 & 35.61 & 36.60 & 40.00 \\
\hline D & 29.20 & 29.90 & 29.02 & 40.00 & 32.19 & 29.50 & 37.92 & 32.36 & 40.00 & 35.85 & 29.09 & 29.09 & 29.35 \\
\hline $\mathbf{E}$ & 40.00 & 40.00 & 40.00 & 40.00 & 40.00 & 40.00 & 40.00 & 40.00 & 40.00 & 40.00 & 40.00 & 40.00 & 40.00 \\
\hline $\mathbf{F}$ & 33.29 & 32.29 & 40.00 & 40.00 & 40.00 & 36.99 & 40.00 & 34.17 & 32.10 & 40.00 & 31.30 & 33.57 & 32.20 \\
\hline G & 33.55 & 33.00 & 40.00 & 40.00 & 40.00 & 31.13 & 40.00 & 40.00 & 32.22 & 31.89 & 31.37 & 36.03 & 30.27 \\
\hline H & 29.17 & 33.57 & 29.65 & 40.00 & 32.47 & 40.00 & 36.93 & 36.96 & 29.84 & 29.84 & 32.01 & 29.79 & 30.01 \\
\hline 1 & 29.67 & 35.95 & 30.86 & 40.00 & 32.43 & 40.00 & 40.00 & 40.00 & 32.15 & 30.98 & 35.97 & 30.14 & 33.83 \\
\hline J & 36.96 & 35.33 & 35.85 & 40.00 & 34.05 & 40.00 & 40.00 & 40.00 & 33.17 & 31.78 & 40.00 & 31.35 & 31.06 \\
\hline$K$ & 32.99 & 40.00 & 40.00 & 34.31 & 36.98 & 40.00 & 40.00 & 40.00 & 40.00 & 33.48 & 32.94 & 40.00 & 33.32 \\
\hline $\mathbf{L}$ & 32.83 & 40.00 & 26.62 & 40.00 & 40.00 & 36.37 & 40.00 & 40.00 & 31.19 & 40.00 & 30.92 & 31.13 & 34.80 \\
\hline$M$ & 32.42 & 33.27 & 40.00 & 30.14 & 36.54 & 40.00 & 36.98 & 40.00 & 32.59 & 32.68 & 40.00 & 40.00 & 31.97 \\
\hline $\mathbf{N}$ & 26.89 & 29.65 & 34.37 & 36.38 & 35.86 & 40.00 & 40.00 & 40.00 & 30.04 & 30.79 & 29.62 & 29.67 & 29.47 \\
\hline 0 & 26.57 & 32.45 & 31.74 & 40.00 & 30.43 & 40.00 & 32.59 & 34.15 & 26.94 & 33.33 & 30.46 & 31.46 & 35.13 \\
\hline $\mathbf{P}$ & 34.94 & 32.89 & 32.10 & 36.47 & 35.82 & 40.00 & 40.00 & 35.74 & 40.00 & 36.96 & 34.29 & 34.19 & 32.81 \\
\hline $\mathbf{Q}$ & 29.81 & 33.97 & 34.42 & 33.75 & 40.00 & 40.00 & 34.22 & 32.46 & 32.77 & 31.92 & 36.86 & 32.54 & 33.46 \\
\hline $\mathbf{R}$ & 32.65 & 34.35 & 30.38 & 40.00 & 31.21 & 30.62 & 33.06 & 32.41 & 31.53 & 32.85 & 32.69 & 34.00 & 33.40 \\
\hline$S$ & 31.87 & 33.87 & 28.96 & 32.98 & 32.51 & 40.00 & 32.98 & 30.67 & 33.66 & 33.26 & 32.83 & 33.17 & 33.94 \\
\hline$T$ & 34.15 & 35.26 & 31.82 & 37.72 & 33.02 & 40.00 & 34.86 & 40.00 & 31.88 & 35.55 & 33.52 & 32.01 & 32.06 \\
\hline U & 30.53 & 35.15 & 34.60 & 40.00 & 36.25 & 33.49 & 40.00 & 29.67 & 32.94 & 33.15 & 32.72 & 33.85 & 34.61 \\
\hline Avg & 32.07 & 34.14 & 33.72 & 38.18 & 35.40 & 37.40 & 37.76 & 36.89 & 33.60 & 34.61 & 33.71 & 33.51 & 33.41 \\
\hline STDdev & 3.17 & 2.99 & 4.20 & 2.99 & 3.17 & 3.75 & 2.77 & 3.70 & 3.65 & 3.50 & 3.30 & 3.36 & 2.93 \\
\hline \multicolumn{2}{|c|}{ Change from $0 \mathrm{hr}$} & -2.08 & -1.66 & -6.11 & -3.33 & -5.33 & -5.70 & -4.82 & -1.53 & -2.54 & -1.64 & -1.44 & -1.35 \\
\hline \multicolumn{3}{|c|}{ Effect: Control - Tx } & 0.42 & $\mathrm{~N} / \mathrm{A}$ & $\mathrm{N} / \mathrm{A}$ & N/A & N/A & N/A & 0.55 & -0.47 & 0.43 & 0.63 & 0.73 \\
\hline
\end{tabular}

Table 17: LL Ct values for citrus cells after 48 hours of incubation in each extract

\subsubsection{Ct Raw Data (each extract on each leaf-disc)}

Table 18 shows the $\mathrm{Ct}$ values for citrus dehydrogenase (CD), a stable endogenous gene of citrus that is normally expressed at constant levels; thus, this gene (and its Ct value) is commonly used as a representation of that of citrus cells. Table 18 is set up in the exact same way as Table 17: columns represent the CD Ct values for all treatments: initial (first and last discs of each leaf under no treatment), TSB (control), $0.5 \mathrm{mM}$ of streptomycin (positive control), and each individual extract. The rows include the average, standard deviation, change from zero hours (initial - each treatment), and effect (control - each 
treatment) of the CD Ct values for the 21 leaf samples (A-U). Again, no effect is shown for plant extracts due to lack of an appropriate control.

\begin{tabular}{|c|c|c|c|c|c|c|c|c|c|c|c|c|c|}
\hline \multicolumn{14}{|c|}{ CD Ct Values 48 hours Incubation } \\
\hline Leaf & Initial & TSB & .5 Strep & Ext 1 & Ext 2 & Ext 3 & Ext 4 & Ext 5 & Ext 6 & Ext 7 & Ext 8 & Ext 9 & Ext 10 \\
\hline A & 24.48 & 26.79 & 26.16 & 40.00 & 28.37 & 27.94 & 31.75 & 30.47 & 27.18 & 26.79 & 25.91 & 26.82 & 32.86 \\
\hline B & 27.16 & 26.43 & 27.36 & 33.69 & 26.86 & 28.12 & 32.74 & 31.33 & 28.10 & 32.85 & 25.42 & 27.12 & 27.20 \\
\hline C & 26.89 & 26.41 & 28.47 & 36.79 & 30.74 & 33.99 & 30.92 & 29.43 & 25.77 & 27.59 & 27.21 & 26.91 & 27.21 \\
\hline D & 26.62 & 26.79 & 27.13 & 40.00 & 28.74 & 28.23 & 36.76 & 30.58 & 24.94 & 33.47 & 26.53 & 26.76 & 26.72 \\
\hline$E$ & 26.27 & 26.25 & 26.67 & 36.23 & 30.00 & 36.66 & 31.96 & 30.44 & 28.10 & 33.50 & 26.43 & 26.72 & 26.40 \\
\hline$F$ & 28.35 & 27.11 & 33.09 & 40.00 & 30.00 & 38.48 & 38.22 & 30.61 & 26.84 & 32.99 & 25.67 & 27.58 & 26.41 \\
\hline G & 28.53 & 27.34 & 33.71 & 40.00 & 28.77 & 28.07 & 30.72 & 30.00 & 26.64 & 26.75 & 27.01 & 33.40 & 26.16 \\
\hline H & 27.88 & 33.04 & 28.88 & 40.00 & 31.32 & 40.00 & 37.05 & 40.00 & 28.14 & 27.37 & 29.41 & 29.08 & 28.46 \\
\hline 1 & 26.96 & 33.15 & 28.29 & 36.51 & 30.91 & 40.00 & 40.00 & 40.00 & 29.14 & 28.09 & 34.44 & 28.06 & 32.05 \\
\hline J & 33.45 & 32.99 & 28.10 & 36.49 & 29.66 & 30.06 & 36.87 & 35.39 & 29.54 & 28.00 & 33.17 & 27.44 & 27.49 \\
\hline K & 30.71 & 33.39 & 25.65 & 30.49 & 32.07 & 40.00 & 40.00 & 37.86 & 27.18 & 29.17 & 27.32 & 36.53 & 30.76 \\
\hline $\mathbf{L}$ & 31.08 & 37.80 & 24.07 & 40.00 & 36.98 & 34.54 & 40.00 & 32.46 & 28.95 & 40.00 & 27.65 & 28.91 & 32.32 \\
\hline$M$ & 28.66 & 27.63 & 28.76 & 26.68 & 29.28 & 40.00 & 31.42 & 36.00 & 28.54 & 28.02 & 26.74 & 40.00 & 28.04 \\
\hline $\mathbf{N}$ & 24.93 & 27.99 & 30.70 & 40.00 & 33.91 & 40.00 & 40.00 & 38.10 & 28.02 & 29.01 & 27.10 & 28.28 & 28.30 \\
\hline 0 & 25.21 & 27.94 & 30.15 & 40.00 & 28.12 & 37.68 & 32.21 & 30.07 & 26.88 & 26.80 & 28.10 & 26.70 & 28.92 \\
\hline $\mathbf{P}$ & 27.28 & 29.31 & 27.92 & 27.98 & 29.02 & 36.83 & 40.00 & 30.25 & 32.62 & 26.93 & 28.14 & 28.76 & 26.12 \\
\hline $\mathbf{Q}$ & 26.29 & 28.19 & 27.30 & 30.49 & 30.73 & 35.79 & 30.54 & 28.28 & 26.61 & 27.07 & 29.12 & 25.47 & 28.09 \\
\hline $\mathbf{R}$ & 25.48 & 29.17 & 27.15 & 40.00 & 28.71 & 28.69 & 31.14 & 30.37 & 27.38 & 29.35 & 26.94 & 27.79 & 28.32 \\
\hline$S$ & 25.33 & 28.24 & 27.58 & 28.26 & 28.63 & 35.93 & 31.56 & 28.66 & 27.65 & 27.72 & 27.68 & 28.99 & 29.48 \\
\hline$T$ & 26.67 & 27.30 & 27.71 & 38.63 & 29.40 & 40.00 & 28.94 & 32.70 & 27.15 & 28.53 & 28.10 & 28.21 & 28.00 \\
\hline $\mathbf{U}$ & 26.93 & 27.70 & 27.31 & 36.92 & 30.06 & 27.92 & 40.00 & 29.08 & 27.22 & 28.56 & 29.27 & 27.77 & 28.25 \\
\hline Avg & 27.39 & 29.09 & 28.20 & 36.15 & 30.11 & 34.71 & 34.89 & 32.48 & 27.74 & 29.46 & 27.97 & 28.92 & 28.46 \\
\hline STDdev & 2.20 & 3.11 & 2.24 & 4.63 & 2.20 & 4.91 & 4.09 & 3.78 & 1.56 & 3.32 & 2.24 & 3.51 & 2.01 \\
\hline \multicolumn{2}{|c|}{ Change from $0 \mathrm{hr}$} & -1.70 & -0.81 & -8.76 & -2.72 & -7.32 & -7.51 & -5.09 & -0.35 & -2.07 & -0.58 & -1.53 & -1.07 \\
\hline \multicolumn{3}{|c|}{ Effect: Control - Tx } & 0.89 & N/A & $\mathrm{N} / \mathrm{A}$ & $\mathrm{N} / \mathrm{A}$ & $\mathrm{N} / \mathrm{A}$ & N/A & 1.35 & -0.36 & 1.12 & 0.17 & 0.64 \\
\hline
\end{tabular}

Table 18: CD Ct values for citrus cells after 48 hours of incubation in each extract

\subsubsection{Average LL Ct Values for Bacterial Extracts}

Figure 30 compares the average $\mathrm{Ct}$ values of the LL primers, after treatments with bacterial extracts. The $\mathrm{Ct}$ values represent CLas quantities (inversely). The LL Ct value of discs that were not treated had an average $\mathrm{Ct}$ of 32.07 , indicating relatively low levels of infection. Low quantities of initial CLas renders difficulties in comparing effectiveness of treatments, especially low and moderate effects since changes in $\mathrm{Ct}$ will be reduced. Furthermore, streptomycin is an antibiotic that is known to kill CLas; yet, statistical analysis indicated no significant difference between streptomycin and initial nor between streptomycin and control.

Initial cells (no treatment) had an average $\mathrm{Ct}$ value of 32.07 , cells in the control treatments (TBS) had an average Ct value of 34.14 , and cells treated with $0.5 \mathrm{mM}$ 
streptomycin had an average $\mathrm{Ct}$ value of 33.72. The bacterial extracts (6-10) resulted in $\mathrm{Ct}$ values of $33.60,34.61,33.71,33.51$, and 33.41, respectively. While the Ct values of all five bacterial extract treatments were greater than that of the initial values, there were no statistical differences. Extract 7 had a higher $\mathrm{Ct}$ value (34.61) than that of the control (34.14) and positive control (33.72), while all other extracts had lower Ct values than the both controls. Still, there was no statistical difference between any of the extracts and any of the controls. The only statistical difference in these data were found between the initial and the control, with a p-value of 0.0228 .

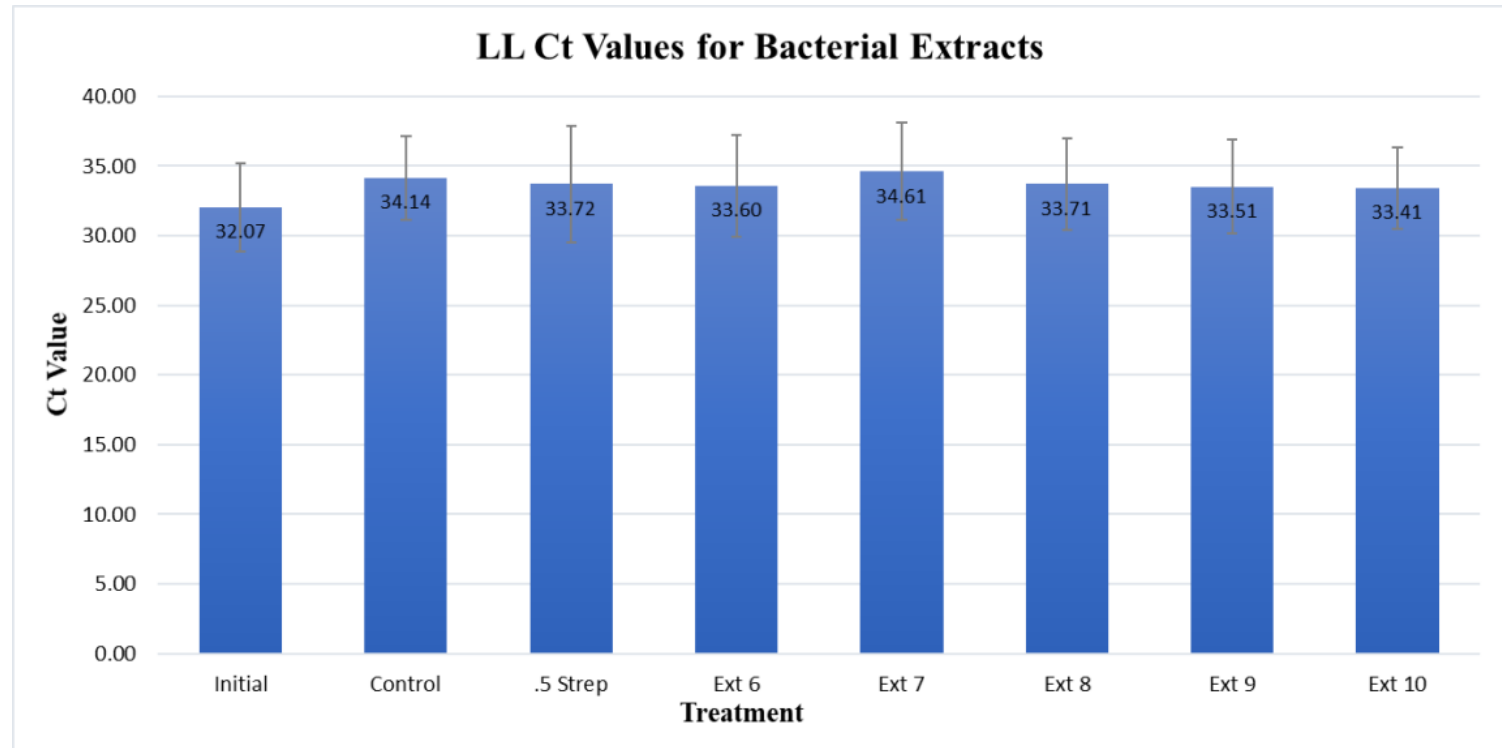

Figure 30: Average LL Ct values after bacterial extract treatments, as compared to $0.5 \mathrm{mM}$ of streptomycin (positive control), TSB (control), and initial (no treatment). Bacterial extracts $6-10$ are isolates B-25, B-9, B-17, B-24, and B-27, respectively.

\subsubsection{Average LL Ct Values for Plant Extracts}

Figure 31 compares the average $\mathrm{Ct}$ values of the LL primers (representing CLas quantities, inversely) after plant extract treatments. Again, initial Ct values (32.07) were relatively low, indicating low initial CLas infection levels, and also streptomycin was again not statistically different than the initial values. Plant extracts 1-5 had the following average 
Ct values: $38.18,35.40,37.40,37.76$ and 36.89 , respectively. The initial $\mathrm{Ct}$ value was statistically lower than that of all 5 plant extract's Ct values, with the following p-Values: 0.0007, 0.0039, 0.0035, 0.0002, and 0.001 (extracts 1-5 respectively). Furthermore, the $\mathrm{Ct}$ value of extracts 1, 4 and 5 were statistically greater than streptomycin; with the following p-Values: $0.0377,0.0279$, and 0.0222 , respectively.

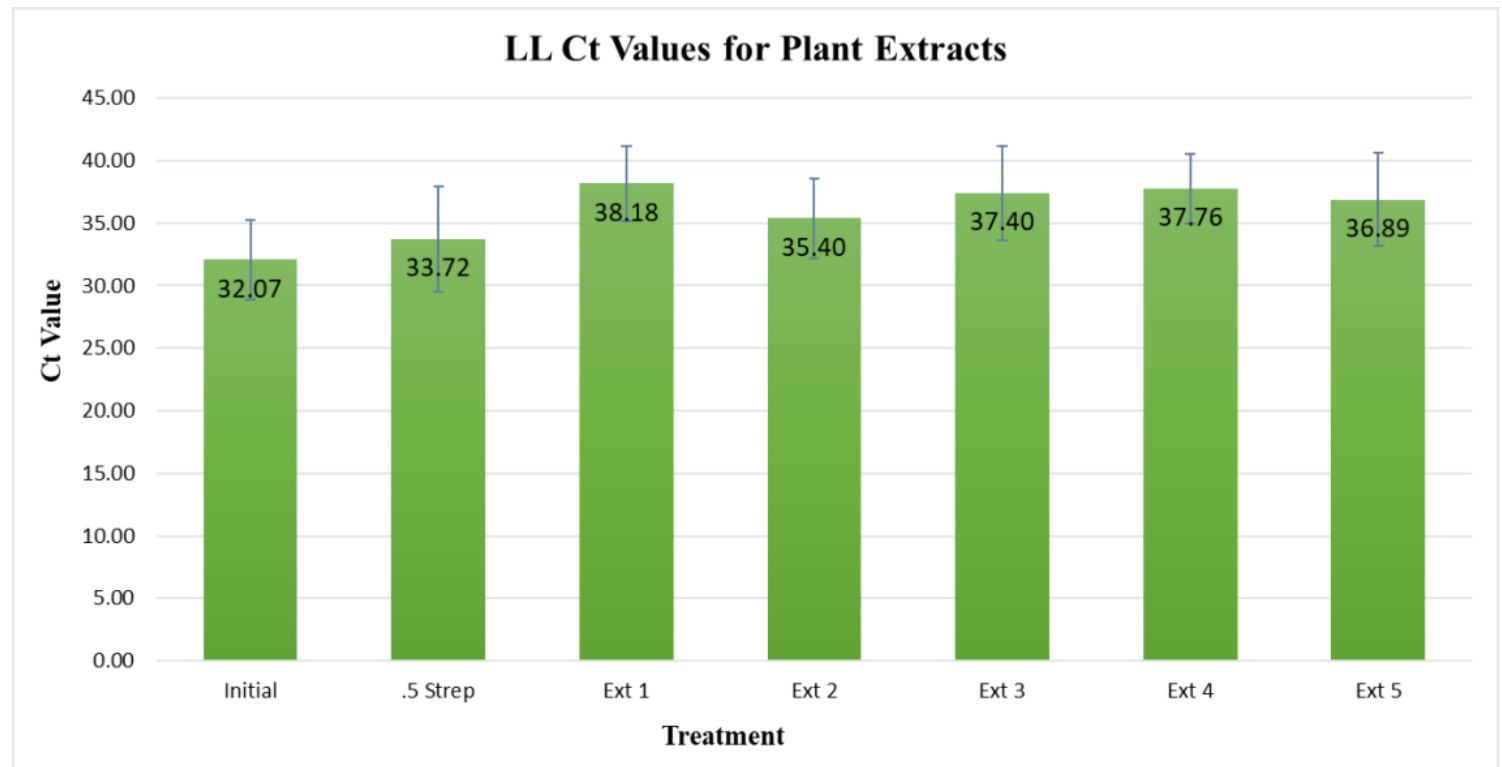

Figure 31: Average LL Ct values after plant extract treatments as compared to $0.5 \mathrm{mM}$ streptomycin (positive control), and initial (no treatment). Plant extracts 1-5 are oregano, alchornea, thyme, cinnamon, and turmeric, respectively.

\subsubsection{Average CD Ct Values for Bacterial Extracts}

Figure 32 compares the average $\mathrm{Ct}$ values of the citrus endo-gene after treatment with bacterial extracts, which represents citrus cell quantities (inversely). The average $\mathrm{Ct}$ value of the control was 29.09 and of streptomycin was 28.20 , and no statistical difference was found between the two. Furthermore, untreated cells (initial) had an average $\mathrm{Ct}$ value of 27.39 , which was not found to be statistically different than streptomycin but was found to be statistically different than that of the control (p-Value 0.0416$)$. The $\mathrm{Ct}$ values for the bacterial extracts (6-10) were as follows: 27.74, 29.46, 27.97, 28.92, and 28.46, 
respectively. There was no statistical difference between extracts $6,8,9$ or 10 and either of the controls/initial. However, while extract 7 was initially found to be statistically different than initial ( $p$-Value of 0.0127), the data indicate a single outlier (leaf L), that when removed no longer renders a statistical difference between extract 7 and the initial. Figure32 represents data excluding the outlier for extract 7 . Thus, no statistical difference was found between any of the extracts and any of the controls.

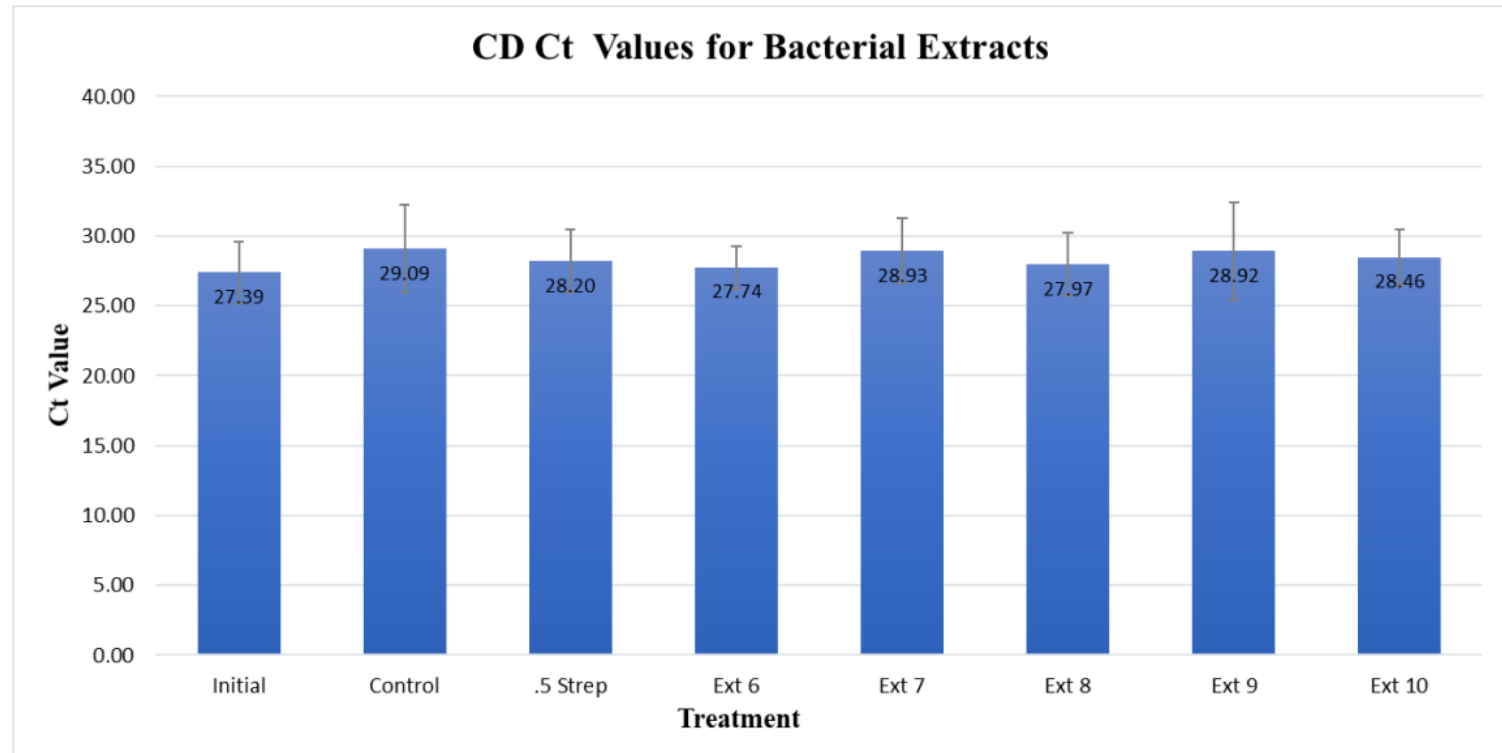

Figure 32: The average CD Ct values after bacterial extract treatments, as compared to $0.5 \mathrm{mM}$ streptomycin (positive control), TSB (control) and initial (no treatment). Bacterial extracts $6-10$ are isolates B-25, B-9, B-17, B-24, and B-27, respectively.

\subsubsection{Average CD Ct Values for Plant Extracts}

Figure 33 compares the average $\mathrm{Ct}$ values of the citrus endo-gene after being treated with plant extracts, representing citrus cell quantities (inversely). The average $\mathrm{Ct}$ value for initial was 27.39 and for streptomycin was 28.20 ; there was no statistical difference found between the two. However, all 5 plant extract $\mathrm{Ct}$ values were statistically different than both the initial and streptomycin $\mathrm{Ct}$ values. The p-Values for plant extracts 1-5 when compared to streptomycin were: $0.0016,0.0014,0.0009,<.0001$, and <.0001, respectively, 
and when compared to initial were: $0.0004,<.0001,0.0001,<.0001$, and $<0.0001$, respectively.

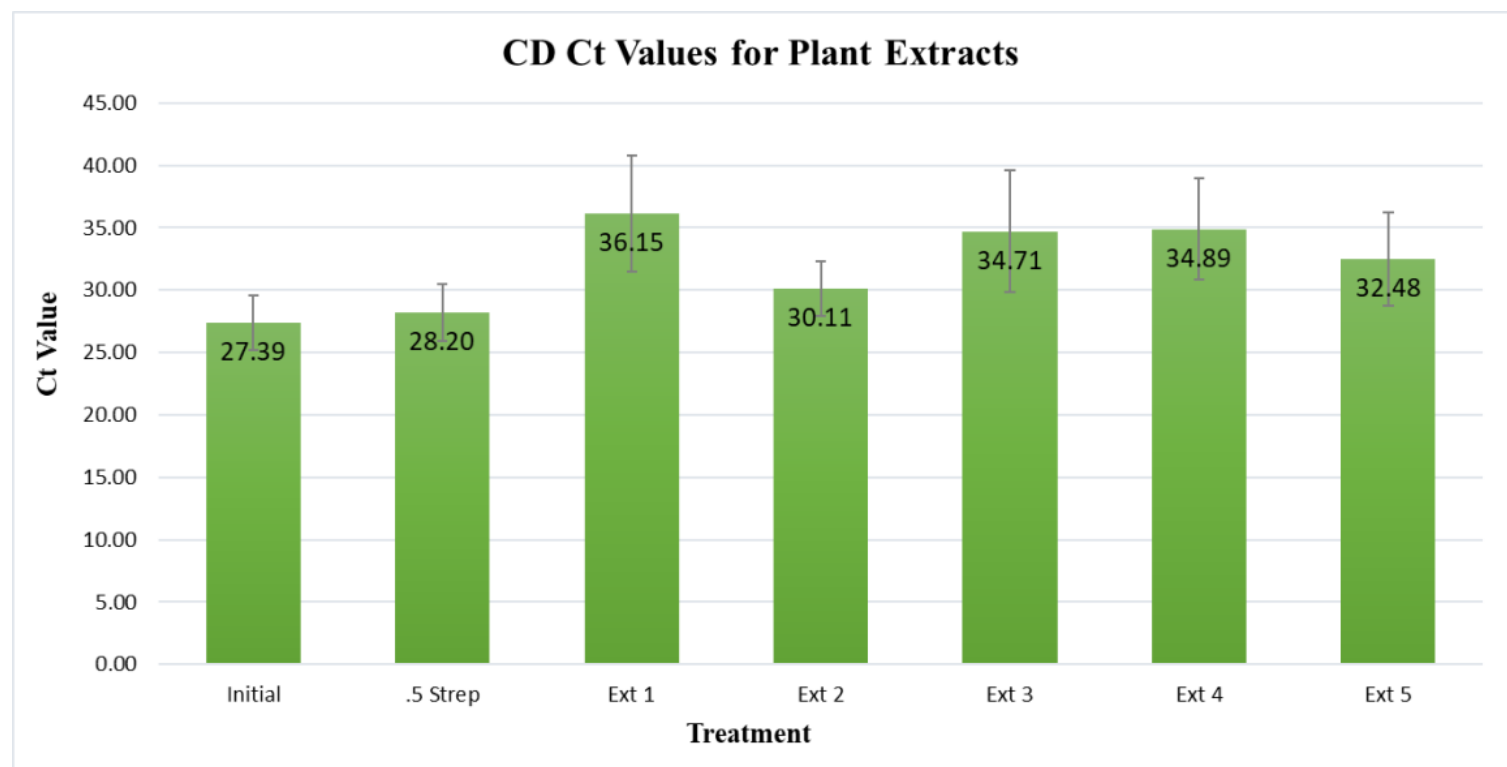

Figure 33: Average CD Ct values after plant extract treatments as compared to $0.5 \mathrm{mM}$ streptomycin (positive control) and initial (no treatment). Plant extracts 1-5 are oregano, alchornea, thyme, cinnamon, and turmeric, respectively.

\subsection{Psyllid Homogenate Assay}

\subsubsection{Average Ct Values for No-PMAxx}

The average $\mathrm{Ct}$ value and standard deviation of each treatment and control under No-PMAxx conditions are shown in Figures 34 and 35. For plate 1 (Figure 34), the average Ct values of each of the 10 treatment were the following: 22.67, 22.65, 22.89, 23.08, 23.47, $22.14,22.91,23.03,21.92$, and 22.77 , respectively. The average $\mathrm{Ct}$ value of $0.1 \%$ triton was 24.13 and the average $\mathrm{Ct}$ value of the TSB control was 24.05. There was no statistical difference between any of the no-PMAxx samples on plate 1, indicating no significant difference in the initial number of cells in each sample. For plate 2 (Figure 35), the average $\mathrm{Ct}$ values of each of the 10 treatments were as follows: 25.23, 25.71, 24.86, 25.20, 25.74, $25.92,26.07,25.92,25.14$ and 25.77 , respectively. The average $\mathrm{Ct}$ value of $0.1 \%$ triton 
was 25.14 and the average $\mathrm{Ct}$ value of the TSB control was 25.28. Again, there were no statistical differences between any of the no-PMAxx samples on plate 2; thus, all samples began with the relatively the same number of CLas cells.

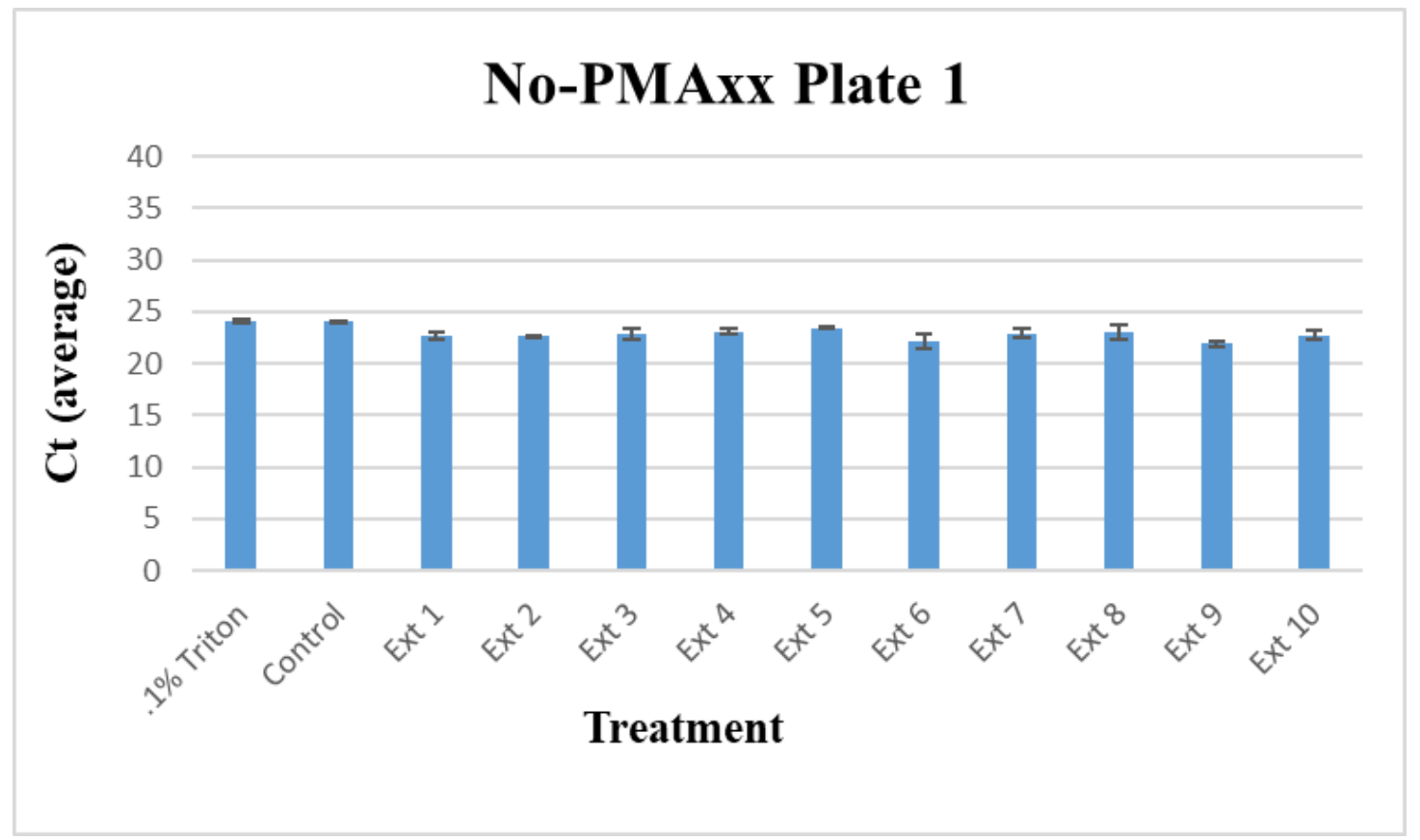

Figure 34: Average Ct values for No-PMAxx on plate 1. Extracts 1-10 are oregano, alchornea, thyme, cinnamon, turmeric, B-25, B-9, B-17, B-24 and B-27, respectively.

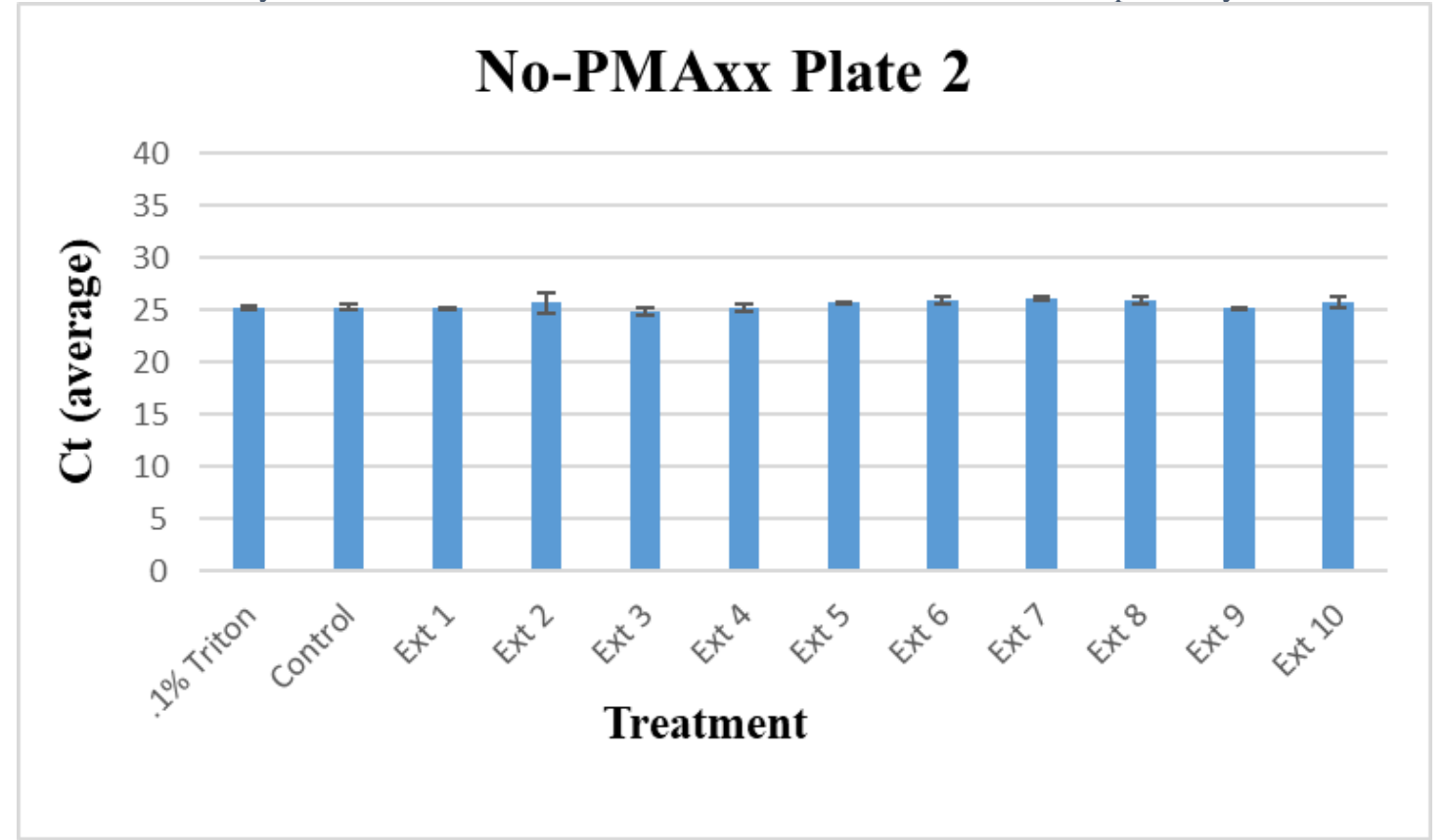

Figure 35: Average Ct values for No-PMAxx on plate 2. Extracts 1-10 are oregano, alchornea, thyme, cinnamon, turmeric, B-25, B-9, B-17, B-24 and B-27, respectively. 


\subsubsection{PMAxx vs No-PMAxx}

Since all samples began with the same number of cells (no significant difference), comparing the Ct values of the No-PMAxx samples to that of the PMAxx samples indicates the change in number of live cells. Table 19 contains the $\mathrm{Ct}$ average, standard deviation, standard error, upper and lower 95\% confidence levels for No-PMAxx as well as for PMAxx on plate 1 . Table 19 also shows the change in Ct from the No-PMAxx to PMAxx samples for each treatment (No-PMAxx Ct average - PMAxx Ct average). Furthermore, Figure 36 directly compares the average $\mathrm{Ct}$ value of samples not treated with PMAxx to that of samples treated with PMAxx for each treatment on plate 1. Figure 36 also includes the reduction in $\mathrm{Ct}$ value (above each set of bars) for each treatment. The changes in $\mathrm{Ct}$ value for the 10 treatments on plate 1 were the following: $-3.08,-0.64,-3.57,-1.06,-5.92$, $-6.05,-2.05,-1.25,-2.95$, and -7.63 , respectively. The Ct change in $0.1 \%$ triton was -4.21 , and the Ct change in the TSB control was -0.271 .

\begin{tabular}{|c|c|c|c|c|c|c|c|c|c|c|c|}
\hline \multicolumn{12}{|c|}{ Plate 1} \\
\hline & \multicolumn{5}{|c|}{ No PMAxx } & \multicolumn{5}{|c|}{ PMAxx } & \multirow{2}{*}{$\begin{array}{c}\text { Ct Reduction } \\
\text { No PMAxx- PMAxx }\end{array}$} \\
\hline Treatment & Ct Mean & Std Dev & Std Err M & Lower 95\% & Upper 95\% & Ct Mean & Std Dev & Std Err M L & Lower 95\% & Upper 95\% & \\
\hline $.1 \%$ Triton & 24.125 & 0.233345 & 0.165 & 22.028 & 26.222 & 28.332 & 1.42145 & 0.6357 & 26.567 & 30.097 & -4.207 \\
\hline Control & 24.045 & 0.120208 & 0.085 & 22.965 & 25.125 & 24.316 & 1.12462 & 0.5029 & 22.92 & 25.712 & -0.271 \\
\hline Ext 1 & 22.67 & 0.339411 & 0.24 & 19.621 & 25.719 & 25.754 & 1.00358 & 0.4488 & 24.508 & 27 & -3.084 \\
\hline Ext 2 & 22.645 & 0.120208 & 0.085 & 21.565 & 23.725 & 23.286 & 1.09699 & 0.4906 & 21.924 & 24.648 & -0.641 \\
\hline Ext 3 & 22.885 & 0.544472 & 0.385 & 17.993 & 27.777 & 26.458 & 1.79295 & 0.8018 & 24.232 & 28.684 & -3.573 \\
\hline Ext 4 & 23.075 & 0.247487 & 0.175 & 20.851 & 25.299 & 24.138 & 0.82181 & 0.3675 & 23.118 & 25.158 & -1.063 \\
\hline Ext 5 & 23.465 & 0.06364 & 0.045 & 22.893 & 24.037 & 29.386 & 0.75401 & 0.3372 & 28.45 & 30.322 & -5.921 \\
\hline Ext 6 & 22.135 & 0.700036 & 0.495 & 15.845 & 28.425 & 28.184 & 1.14273 & 0.511 & 26.765 & 29.603 & -6.049 \\
\hline Ext 7 & 22.91 & 0.480833 & 0.34 & 18.59 & 27.23 & 24.962 & 1.03541 & 0.463 & 23.676 & 26.248 & -2.052 \\
\hline Ext 8 & 23.025 & 0.742462 & 0.525 & 16.354 & 29.696 & 24.278 & 0.39461 & 0.1765 & 23.788 & 24.768 & -1.253 \\
\hline Ext 9 & 21.915 & 0.304056 & 0.215 & 19.183 & 24.647 & 24.868 & 2.91824 & 1.3051 & 21.245 & 28.491 & -2.953 \\
\hline Ext 10 & 22.77 & 0.494975 & 0.35 & 18.323 & 27.217 & 30.4 & 0.72218 & 0.323 & 29.503 & 31.297 & -7.63 \\
\hline
\end{tabular}

Table 19: Data comparison between PMAxx and No-PMAxx samples on Plate 1 


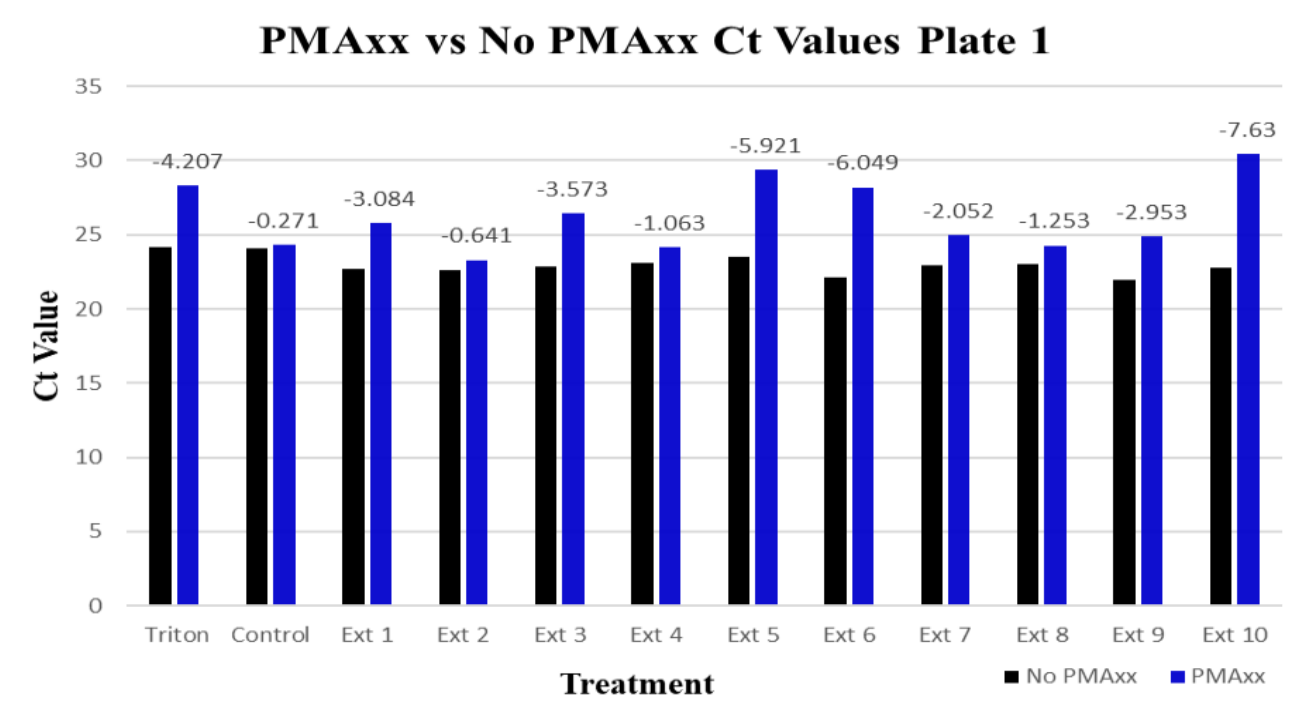

Figure 36: Changes in Ct value between PMAxx and No-PMAxx for each treatment on Plate 1. Extracts 110 are oregano, alchornea, thyme, cinnamon, turmeric, B-25, B-9, B-17, B-24, and B-27, respectively.

Table 20 includes the $\mathrm{Ct}$ mean, standard deviation, standard error, upper and lower 95\% confidence levels for No-PMAxx samples as well as for PMAxx samples in plate 2. Table 20 also lists the changes in $\mathrm{Ct}$ from the no-PMAxx to PMAxx for each treatment. The changes in $\mathrm{Ct}$ value for the 10 treatments on plate 2 were the following: $-5.31,-1.46$, $-8.81,-2.70,-6.10,-7.79,-4.95,-3.45,-4.58$, and -6.57 , respectively. The change in $0.1 \%$ triton $\mathrm{Ct}$ value was -5.51 , and the change in the TSB control was -1.775 . Figure 37 directly compares the average $\mathrm{Ct}$ value of samples not treated with PMAxx to that of samples treated with PMAxx, as well as the change between the two (above each set of bars), for each treatment on plate 2 . 


\begin{tabular}{|c|c|c|c|c|c|c|c|c|c|c|c|}
\hline \multicolumn{12}{|c|}{ Plate 2} \\
\hline & \multicolumn{5}{|c|}{ No PMAxx } & \multicolumn{5}{|c|}{ PMAxx } & \multirow{2}{*}{$\begin{array}{l}\text { Ct Reduction } \\
\text { No PMAxx- PMAxx }\end{array}$} \\
\hline Treatment & Ct Mean & Std Dev & Std Err M & Lower 95\% & Upper $95 \%$ & CCt Mean & Std Dev & Std Err M & Lower 95\% & Upper 95\% & \\
\hline $.1 \%$ Triton & 25.14 & 0.19799 & 0.14 & 23.361 & 26.919 & 30.65 & 0.43399 & 0.1941 & 30.111 & 31.189 & -5.51 \\
\hline Control & 25.275 & 0.23335 & 0.165 & 23.178 & 27.372 & 27.05 & 1.27411 & 0.5698 & 25.468 & 28.632 & -1.775 \\
\hline Ext 1 & 25.23 & 0.04243 & 0.03 & 24.849 & 25.611 & 30.54 & 1.35176 & 0.6045 & 28.862 & 32.218 & -5.31 \\
\hline Ext 2 & 25.705 & 1.01116 & 0.715 & 16.62 & 34.79 & 27.16 & 0.66809 & 0.2988 & 26.33 & 27.99 & -1.455 \\
\hline Ext 3 & 24.86 & 0.28284 & 0.2 & 22.319 & 27.401 & 33.668 & 2.57654 & 1.1523 & 30.469 & 36.867 & -8.808 \\
\hline Ext 4 & 25.195 & 0.30406 & 0.215 & 22.463 & 27.927 & 27.894 & 0.8615 & 0.3853 & 26.824 & 28.964 & -2.699 \\
\hline Ext 5 & 25.735 & 0.07778 & 0.055 & 25.036 & 26.434 & 31.838 & 0.20873 & 0.0933 & 31.579 & 32.097 & -6.103 \\
\hline Ext 6 & 25.92 & 0.43841 & 0.31 & 21.981 & 29.859 & 33.702 & 1.07806 & 0.4821 & 32.363 & 35.041 & -7.782 \\
\hline Ext 7 & 26.065 & 0.2192 & 0.155 & 24.096 & 28.034 & 31.018 & 1.66144 & 0.743 & 28.955 & 33.081 & -4.953 \\
\hline Ext 8 & 25.915 & 0.33234 & 0.235 & 22.929 & 28.901 & 29.36 & 1.29389 & 0.5786 & 27.753 & 30.967 & -3.445 \\
\hline Ext 9 & 25.14 & 0.11314 & 0.08 & 24.124 & 26.156 & 29.72 & 0.63742 & 0.2851 & 28.929 & 30.511 & -4.58 \\
\hline Ext 10 & 25.77 & 0.55154 & 0.39 & 20.815 & 30.725 & 32.34 & 0.98656 & 0.4412 & 31.115 & 33.565 & -6.57 \\
\hline
\end{tabular}

Table 20: Data comparison between PMAxx and No-PMAxx samples on Plate 2

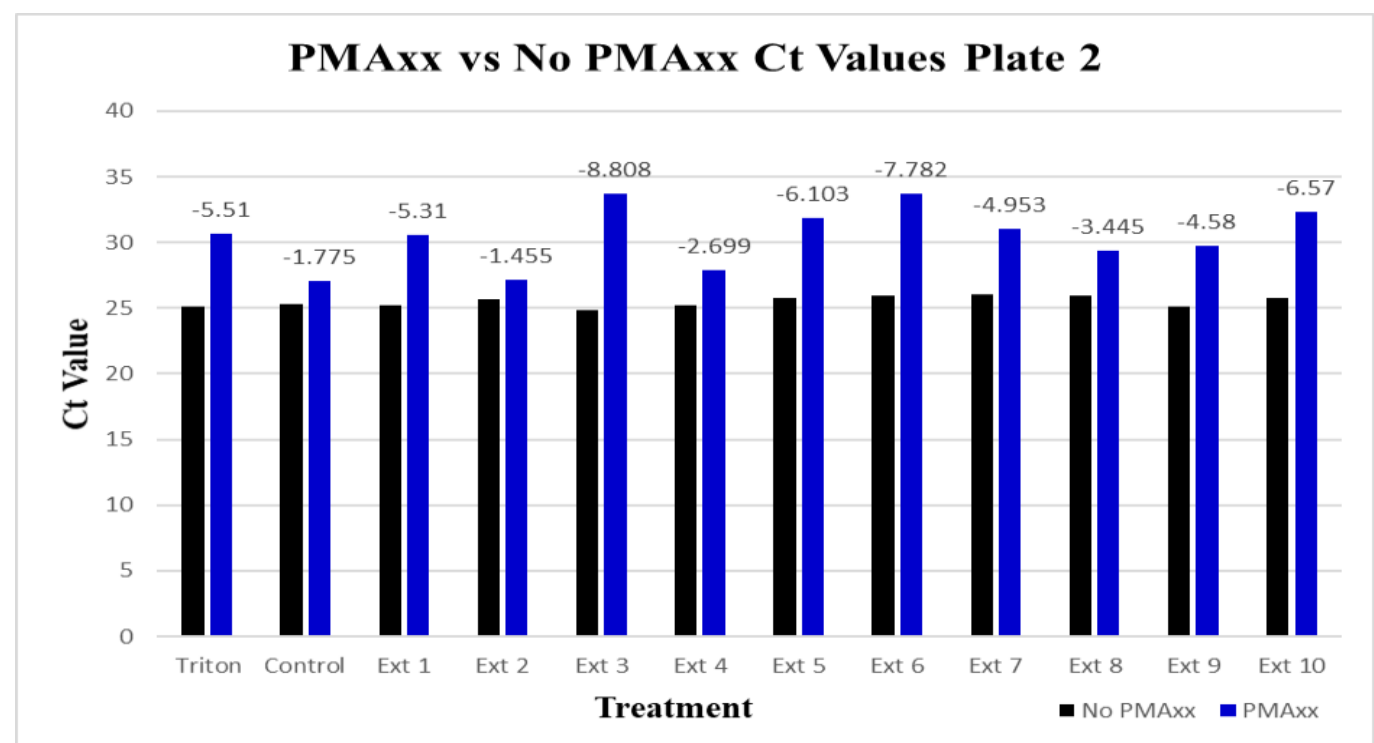

Figure 37: Changes in Ct value between PMAxx and No-PMAxx for each treatment on Plate 2. Extracts 1-

10 are oregano, alchornea, thyme, cinnamon, turmeric, B-25, B-9, B-17, B-24, and B-27, respectively.

\subsubsection{Live Cell Assays}

Figure 38 shows the average $\mathrm{Ct}$ values of each treatment after PMAxx (cells that remained alive), for plate 1 . The change in $\mathrm{Ct}$ value relative to the control, was also determined for each of the bacterial extracts ( $\mathrm{Ct}$ of control - $\mathrm{Ct}$ of each extract), and is referred to as the "effect." A significant difference (p-Value of 0.0122) was observed between the control (TSB) and the positive control (0.1\% triton), with Ct values of 24.32 and 28.33 , respectively. Thus, the effect of $0.1 \%$ triton was -4.01 . Extracts $1,2,4,7,8$ and 
9 were all statistically worse than $0.1 \%$ triton, with the following respective p-Values: $0.0119,0.0122,0.0122,0.0122,0.0122$ and 0.0367 . Hence, neither of these were statistically different than the control. The effect of these 6 extracts were: $-1.44,1.03,0.18$, $-0.64,0.04$, and -0.55 , respectively. Extract 3 had a $\mathrm{Ct}$ value of 26.46 and was not statistically different than the control nor than $0.1 \%$ triton (in between both). Extracts 5, 6 and 10 were each statistically better than TSB control, by means of the following p-values: $0.0122,0.0122$, and 0.0122 . Correspondingly, these three extracts had the greatest effect: $-5.07,-3.87$, and -8.08 , respectively. Additionally, extract 10 was also statistically better than $0.1 \%$ triton, with a $\mathrm{p}-\mathrm{V}$ alue of 0.367.

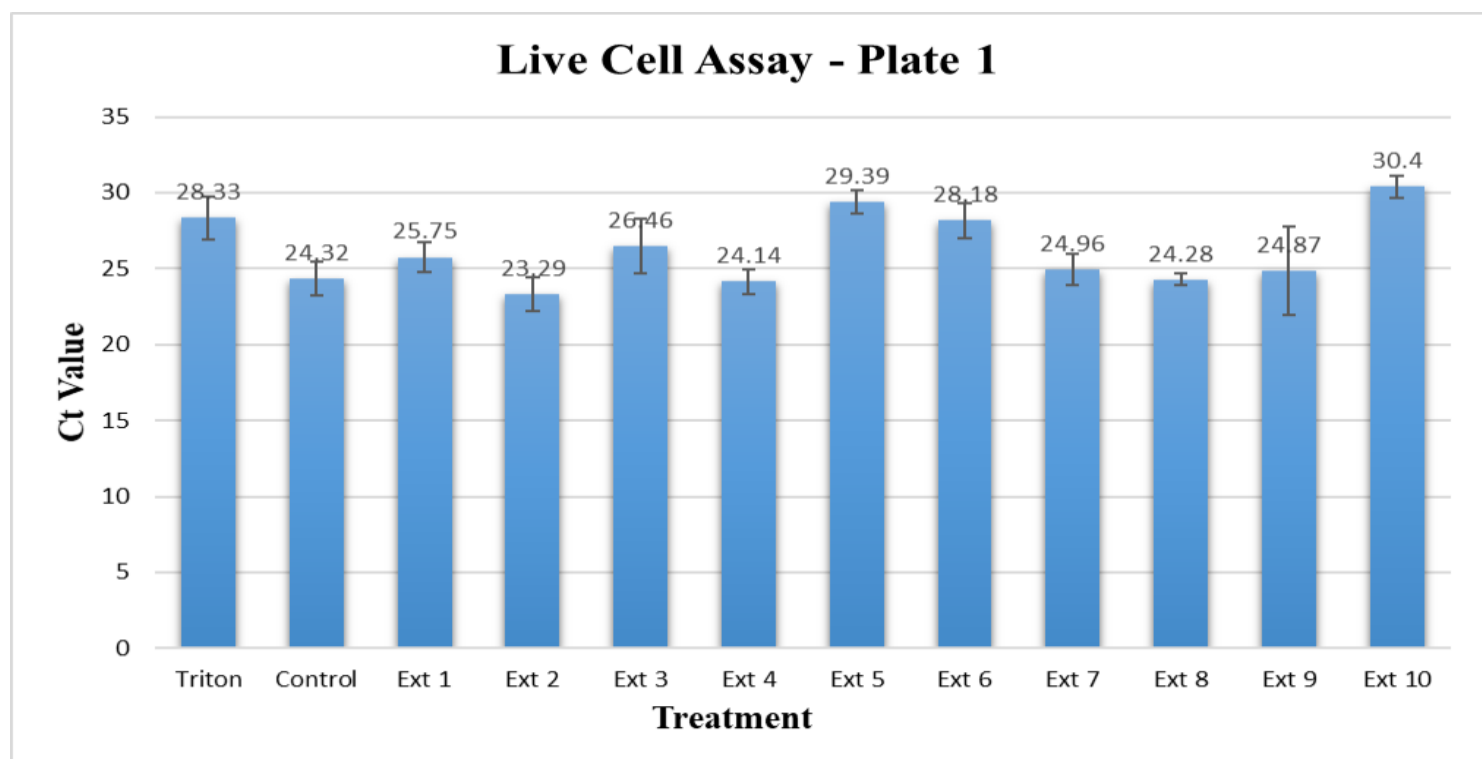

Figure 38: Ct values of live cells remaining after PMAxx treatment for Plate 1. Extracts 1-10 are oregano, alchornea, thyme, cinnamon, turmeric, B-25, B-9, B-17, B-24, and B-27, respectively.

Figure 39 shows the average Ct values of each treatment after PMAxx (viable cells) for plate 2. Once again, a significant difference (p-Value of 0.0122) was observed between the control (TSB) and the positive control ( $0.1 \%$ triton). The average $\mathrm{Ct}$ for the TSB was 27.05, while the average $\mathrm{Ct}$ for $.1 \%$, triton was 30.65, having a $\mathrm{Ct}$ effect of -3.6. Extracts 2, 4 and 9 were not statistically different than the control $(27.16,27.89$ and 29.72 , 
respectively), and were each statistically worse than triton (p-Values: $0.0122,0.0122$ and 0.0367, respectively). Their corresponding effects were: $-0.11,-0.84$, and -2.67 . On the other hand, extracts $1,3,5,6,7,9$ and 10 were all statistically better than the control, with the following p-Values: $0.216,0.122,0.122,0.122,0.216,0.216$, and 0.0122 , and the following effects: $-3.49,-6.62,-4.79,-6.65,-3.97$, and -5.29 , respectively. Additionally, extracts 3,5 and 6 were each statistically better than $0.1 \%$ triton, having the following pValues: $0.0122,0.0 .122$ and 0.0122 , respectively. There was no statistical difference between $0.1 \%$ triton and extracts $1,7,9$ or 10 .

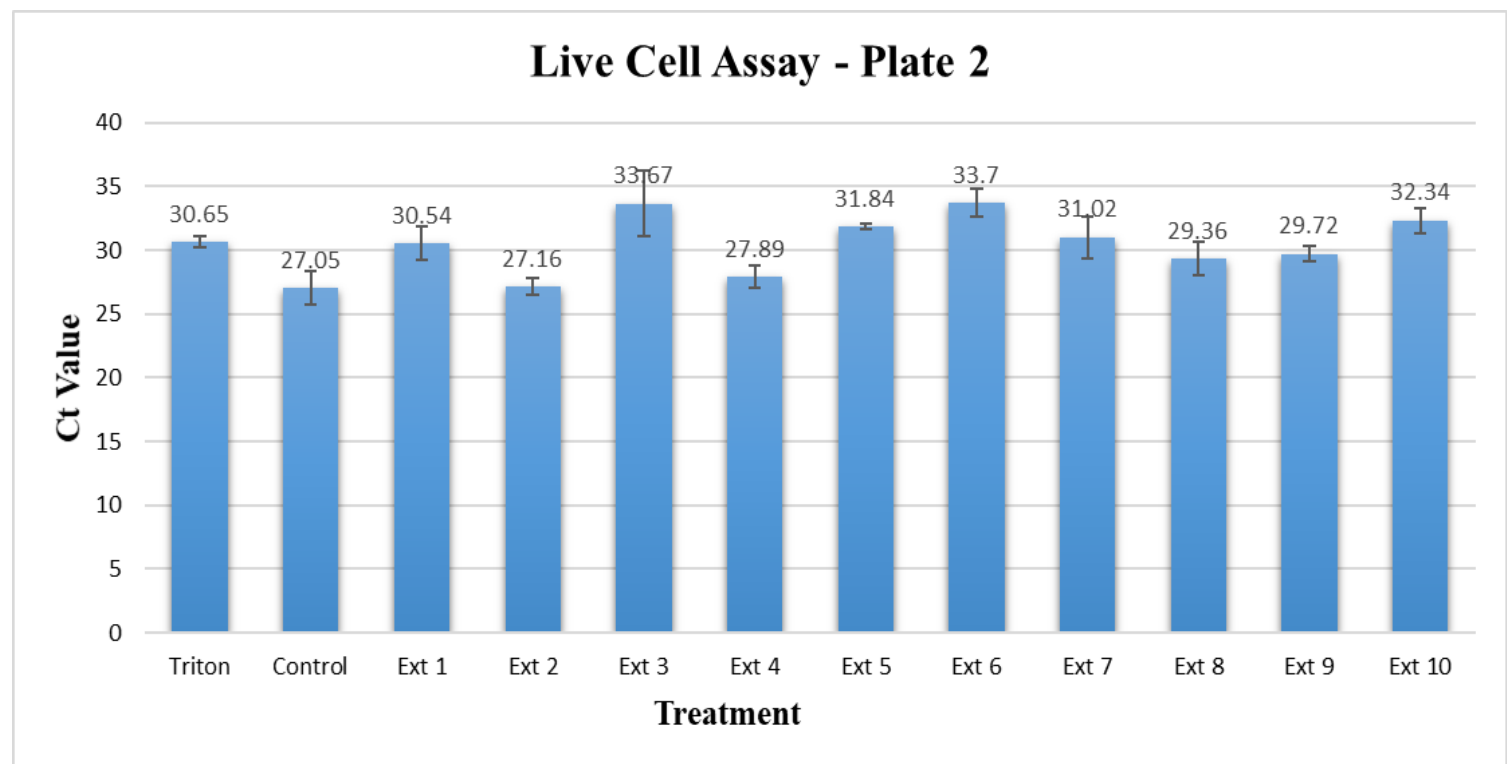

Figure 39: Ct values of live cells remaining after PMAxx treatment for Plate 2. Extracts 1-10 are oregano, alchornea, thyme, cinnamon, turmeric, B-25, B-9, B-17, B-24, and B-27, respectively.

\section{DISCUSSION}

\subsection{Hypothesis 1}

The results from the endophyte isolations and dual culture partially support my first hypothesis which was that endophytes isolated from survivor citrus trees would be a valuable source of antimicrobials capable of inhibiting the growth of S. meliloti. While eight $(2.3 \%)$ of the total 342 isolated endophytes were capable of completely inhibiting 
(100\%) the growth of S. meliloti, a total of $23(6.7 \%)$ were capable of causing at least moderate inhibition. Nonetheless, these results include that of three distinct citrus species. That is, not a single endophyte isolated from Blood Orange (Tree \#5) was capable of inhibiting the growth of S. meliloti. Furthermore, five of the endophytes isolated from Valencia Orange (Tree \#4) were capable of moderately inhibiting the growth of S. meliloti, though not one was capable of complete (100\%) inhibition. On the other hand, 18 of the 23 endophytes that produced at least some inhibition, were obtained from Naval Orange (Tree's \#1, \#2, and \#3). Ten endophytes isolated from Naval Orange were able to cause moderate inhibition, and an additional eight endophytes were able to completely inhibit the growth of S. meliloti. In fact, all of the isolates that completely inhibited (100\%) the growth of S. meliloti had been isolated from Naval Orange trees. Thus, the results indicate that both Valencia and Naval Orange trees harbor bacterial endophytes that are capable of inhibiting the growth of $S$. meliloti, with those derived from Naval Orange having stronger inhibitory effects than those of Valencia Orange. Also noteworthy is that all endophytes demonstrating successful inhibition of S. meliloti were bacteria (not a single fungus).

\subsection{Hypothesis 2}

The results from this research partially support my second hypothesis, which was that the CFCS of endophytes exhibiting antimicrobial properties against S. meliloti are equally capable of inhibiting the in vitro growth of L. crescens. Eight of the 23 CFCS were capable of inhibiting the growth of $L$. crescens, (though none was able to cause complete inhibition). Furthermore, of the 15 endophytes that moderately inhibited S. meliloti, 11 (73.3\%) did not cause any inhibition on L. crescens, while four $(26.7 \%)$ did cause at least some inhibition. Similarly, of the eight endophytes that were able to completely $(100 \%)$ 
inhibit $S$. meliloti, four (50\%) were also able to cause at least some inhibition on $L$. crescens, while the other four $(50 \%)$ did not have any effect on $L$. crescens. Thus, a direct relationship between the strength of inhibition on $S$. meliloti and the strength of inhibition on L. crescens was not found.

\subsection{Hypothesis 3}

Results from the agar diffusion assay do support my third hypothesis which states that plant derived antimicrobials that inhibit the growth of $S$. meliloti are also capable of inhibiting the growth of $L$. crescens. Nine of the screened plant extracts showed at least

some inhibition of S. meliloti: five of which were able to completely inhibit (100\%) and four of which caused some inhibition, though less than $100 \%$. Of the five plant extracts that completely inhibited (100\%) S. meliloti, four (80\%) of them also completely inhibited L. crescens at concentrations of even 5\%, yet one (20\%) of the plant extracts was not able to cause any inhibition of $L$. crescens (at 5\%). Similarly, of the four that caused some inhibition of S. meliloti (less than 100\%), three (75\%) were not able to cause any inhibition of $L$. crescens, and one (25\%) was able to completely inhibit the growth of L. crescens, even at $5 \%$. Hence, plant extracts that cause growth inhibition of S. meliloti are more likely to cause growth inhibition of $L$. crescens as well, though it is not always the case.

\subsection{Hypothesis 4}

The results from this study support the fourth hypothesis, which was that antimicrobial agents that inhibit the growth of $L$. crescens in vitro, will also be able to show activity against CLas in planta and in vivo (psyllids). Since this hypothesis was evaluated using two distinct assays (leaf-disc and psyllid homogenate), the discussion for this hypothesis will have two separate sections. 


\subsubsection{Leaf-Disc Assay}

The leaf-disc assay is particularly challenging due to variations of CLas titer along the plant. Lack of homogeneity of CLas even within a single leaf may impede effective evaluations of treatments with low efficacy. Thus, the uneven distribution of CLas may cause substantial inconsistencies in the results of this assay. Notwithstanding, results of the current study were primarily affected by low quantities of initial CLas. Low initial infection rates are a hurdle to analyzing and comparing the effectiveness of treatments, particularly due to the minimized effect potential. Consequently, unless the treatments are substantially more effective that the control, a statistical analysis comparing the treatments to the unsuccessful positive control will render no statistically significant results.

\subsubsection{Bacterial Extracts on CLas}

In present study, streptomycin was used as the positive control because it is an antibiotic that is known to reduce CLas. However, there was no statistical difference between the average $\mathrm{Ct}$ of leaf-discs treated with streptomycin and that of leaf-discs under no treatment. Thus, without a statistical difference between the positive control (streptomycin) and no treatment (initial), the efficacy of the bacterial extracts relative to streptomycin, could not be accurately determined. Subsequently, the data indicate no significant difference between any of the treatments and the initial nor any of the treatments and the positive control. Further analysis would be necessary in order to have a more accurate control for the treatments.

\subsubsection{Bacterial Extracts on Citrus}

The effect of the bacterial treatments on the citrus endo-gene was also determined. The citrus endo-gene is used in this assay primarily because of its stability; even under 
streptomycin treatments it generally has minimal changes. Hence, during the leaf-disc assay, no statistical difference was found between streptomycin and the initial (untreated) samples. Moreover, there was no statistical difference found between any of bacterial extracts nor with either of the initial values either. Thus, after a 48 hour incubation period none of the bacterial extracts were phytotoxic to citrus; still, future studies with much longer incubation times (weeks, months) would be necessary to state whether the bacterial endophytes have any phytotoxic effects on citrus.

\subsubsection{Plant Extracts on CLas}

The results for the plant extracts also indicated low initial CLas infection rates. Similarly, discs treated with streptomycin were not statistically different than leaves that were not treated (initial). However, a statistical difference was still found between each of the 5 plant extracts and the initial. Thus, these results indicate that the effects of all 5 plant extracts (oregano, alchornea, thyme, cinnamon and turmeric) are each so effective at reducing CLas, that their effect can be observed even under minimal levels of CLas infection. Furthermore, plant extracts 1, 4 and 5, were also statistically greater than that of streptomycin (the positive control), indicating that oregano, cinnamon and turmeric can reduce CLas titer statistically better than streptomycin can. These results are encouraging.

\subsubsection{Plant Extracts on Citrus}

The effects of the plant extracts on the citrus endo-gene were also determined. All 5 plant extracts were not only statistically different than the initial, but were also statistically different than streptomycin. Thus, all 5 plant extracts have statistically greater 
effects on the citrus endo-gene than streptomycin does. These results indicate that oregano, alchornea, thyme, cinnamon and turmeric are all phytotoxic to citrus.

\subsubsection{Leaf-Disc Summation}

Based off the leaf-disc assay, the fourth hypothesis which states that antimicrobial agents capable of inhibiting the growth of L. crescens in vitro would also be able to reduce CLas in planta, was partially supported. Due to the fact that there was no statistical difference between streptomycin and the initial LL Ct values, further studies are necessary in order to appropriately evaluate the effectiveness of all bacterial extracts. Also, neither of the bacterial extracts had any effect on the citrus endo-gene, and may therefore be promising biocontrol agents if found to be effective against CLas. Nonetheless, phytotoxicity assays may be useful to further confirm that none of these extracts are phytotoxic to citrus. As for the plant extracts, even though 3 of the 5 were statistically better at killing CLas than streptomycin, all 5 were statistically "better" at killing citrus than streptomycin. Therefore, oregano, alchornea, thyme, cinnamon, and turmeric are all phytotoxic to citrus (at the tested concentrations) and cannot be considered as potential disease control agents.

\subsubsection{Psyllid Homogenate Assay}

\subsubsection{PMAxx}

After cell death, DNA can persist in the given environment for long periods of time (Josephson et al., 1993). Thus, one of the drawbacks of qPCR (when used to detect microorganism viability) is that it cannot differentiate between live and dead cells. That is, qPCR signals can originate from both live and dead cells, which can lead to false-positive results (Nocker, Sossa, \& Camper, 2007). Therefore, Propidium monoazide (PMA) was designed 
to address this problem. PMA and PMAxx (a Biotium proprietary PMA formulation) are fluorescent dyes that are commonly used prior to $\mathrm{qPCR}$, for distinction between viable and dead cells (Nocker et al., 2007). The PMA compound has an azide group that binds to DNA when exposed to light (Kim \& Ko, 2012). Still, PMA cannot permeate intact cell membranes, and instead only penetrates dead or membrane-damaged cells (Kim \& Ko, 2012; Nocker, Cheung, \& Camper, 2006). Once penetrated, PMA intercalates covalently to DNA, which causes modifications in the DNA that impede its amplification in subsequent PCR reactions (Randazzo, López-Gálvez, Allende, Aznar, \& Sánchez, 2016). Thus, several studies have indicated that the application of PMA prior to DNA extraction, result in the exclusive amplification of DNA from living cells in the subsequent PCR reactions (Kim \& Ko, 2012; Nocker et al., 2006).

\subsubsection{No-PMAxx}

The first set of results involved the comparison of each of the No-PMAxx values, which is designed to ensure that all samples had begun with relatively the same quantities of CLas (should have been obtained from the CLas isolation procedure). Given that on both 96-well plates, no statistical differences were found between any of the No-PMAxx samples (including initial, both controls and all treatments) it was confirmed that there was indeed initial homogeneity of CLas across all samples.

\subsubsection{PMAxx vs No-PMAxx}

Since No-PMAxx values confirmed that all samples began with relatively the same number of CLas cells, subtracting PMAxx from No-PMAxx would then give the change in number of live cells. That is, No-PMAxx samples indicate the number of total cells, 
while PMAxx samples indicate the number of remaining cells (not killed by the treatments); thus, No-PMAxx - PMAxx denotes the cells that were killed by the treatments.

The fact that on both plates there were minimal changes in $\mathrm{Ct}$ values (with and without PMAxx) for the TSB control, indicated that TSB does not have an effect on the cells, and was thus an appropriate control. Nonetheless, the minimal changes observed were likely due to the natural death of a few cells (as a result of taking them out of their environment and removing all food source). Moreover, significant changes were observed between $0.1 \%$ triton and the initial on both plates; again, indicating that $0.1 \%$ triton was indeed an appropriate positive control. Given that the TSB (no effect on CLas) and 0.1\% triton (statistical difference on CLas) these were both appropriate controls, all treatments were compared to that of these two values. Additionally, when comparing TSB to $0.1 \%$ triton (both with PMAxx), there was a statistically significant difference live CLas cells.

\subsubsection{Live Cell Assay Plate 1}

The results from Plate 1 show that extracts 5 and 6 (turmeric and B-25) were each statistically better than TSB, though not statistically different than $0.1 \%$ triton. Furthermore, extract 10 (B-27) was not only statistically better than TSB, but was also statistically better than $0.1 \%$ triton. Thus, the results on Plate 1 indicate that turmeric, and B-25 are as effective at lysing CLas cells as $0.1 \%$ triton, and B-27 is statistically better at lysing CLas cells than $0.1 \%$ triton. As for plate 2, extracts 1, 7, 9, and 10 (oregano, B-9, B-24, and B-27) were all statistically better than TSB, though not statistically different than $0.1 \%$ triton. Additionally, extracts 3, 5, and 6 (thyme, turmeric and B-25) were not only statistically better TSB, but were also statistically better than $0.1 \%$ triton. These results indicate that oregano, B-9, B-24 and B-27 are all as effective at lysing CLas cells as $0.1 \%$ 
triton, and thyme, turmeric and B-25 are each statistically better at lysing CLas cells than $0.1 \%$ triton is.

\section{Live Cell Assay Plate 2}

In general, all values from Plate 2 were slightly greater than those of Plate 1 . There are two possible reasons for this. The first is that there was simply a plate to plate variation since the two plates were run separately (variation in initial CLas quantities between the two plates). The second possibility is that the differences were due to additional PMAxx exposure. Because the two plates were exposed to the PMAxx light one at a time (15 minutes each), the second plate received an additional 15 minutes of PMAxx exposure (while waiting for the $1_{\text {st }}$ plate to be completed). Given enough time, there may be some leakage of PMAxx within the cells. PMAxx leakage would lead to higher $\mathrm{Ct}$ values, due to PMAxx binding of additional cells, and thus result in fewer cells available to be amplified in subsequent qPCR readings. Nonetheless, consistent changes were observed between both plates. That is, differences between No-PMAxx and PMAxx within each plate were relatively the same for both plates; the same consistencies were observed in changes of live cells within each plate. For example, the p-Value between the control and extract 10 was exactly the same in both plates (0.0122). Thus, while the true value of initial CLas cells may be unknown, the changes in CLas live cells within each given plate, remains highly valuable.

\subsubsection{Psyllid Homogenate Assay Summation}

Therefore, the combined results (both plates) from the psyllid homogenate assay indicate that oregano, B-9 and B-24 are effective at lysing CLas cells at a rate similar to that of $0.1 \%$ triton, and thus should be further evaluated. Thyme, turmeric, B-25 and B-27 
are even more promising, demonstrating statistically better efficiencies at lysing CLas cells than $0.1 \%$ triton on at least one of the two plates, and statistically similar at lysing CLas as $0.1 \%$ triton, on the other (second) plate. Thus, it is evident that thyme, turmeric, B-25 and B-27 are highly effective at lysing CLas cells in a matter of 4 hours and thus, should be further evaluated. As a result, the fourth hypothesis which stated that antimicrobial agents that were capable of inhibiting L. crescens in vitro would be able to inhibit CLas in planta; hence, was partially supported by the psyllid homogenate assay as well.

Nevertheless, it is important to note that the psyllid homogenate assay was strictly designed to assess cell lysis in 4 hours. This is limiting, because if any of the extracts work using another mechanism (bacteriostatic effect), this assay will not show their effectiveness. Therefore, extracts that did not show any activity on this assay, may still be valuable, and may just be working through some other mode of action. Similarly, it is also possible that an extract may work through cell lysis, but may take longer than 4 hours to show any effectiveness (like antibiotics). In fact, this is the reason triton was used instead of streptomycin for the psyllid homogenate assay, streptomycin does indeed work through lysing cells, but can take much longer than 4 hours to do so effectively.

\section{CONCLUSION}

Expedited screening and selection of endophyte and plant derived extracts for potential antimicrobial activity against CLas is possible by using S. meliloti and L. crescens as culturable proxy organisms. Extracts from oregano, thyme and turmeric at a concentration of $1 \%$ were found to be significantly effective at reducing live CLas cell numbers, although their phytotoxicity was not evaluated at this concentration. Thus, more

detailed phytotoxicity studies of these extracts and their chemical components needs be 
done to assess their potential for managing citrus greening disease. As for the extracts from bacterial endophytes, isolates B-9, B-24, B-25 and B-27 were found to be significantly effective at reducing live CLas cell numbers; none of them demonstrated any phytotoxicity towards citrus. Thus, these four bacterial extracts need to be further characterized to understand the active biochemical components and their activity against CLas both in vitro and in planta. Availability of effective plant or endophyte derived antimicrobial treatment in combination with other control methods may help augment the tools available for citrus greening disease management. Finally, survivor citrus trees were found to harbor antimicrobial producing endophytes as part of their microbiome. Further studies using multi-omics may provide novel functional insight into complex interactions between the plant host and its microbiome. 


\section{REFERENCES}

Abdullah, T. L., Shokrollah, H., Sijam, K., Nor, S., \& Abdullah, A. (2009). Control of Huanglongbing (HLB) disease with reference to its occurrence in Malaysia. African Journal of Biotechnology, 8(17), 4007-4015. Retrieved from http://www.academicjournals.org/AJB

Abdullah, T. L., Shokrollah, H., Sijam, K., Nor, S., Abdullah, A., Zhang, M., ... Bové, J. M. (2012). Impact APSnet Feature : Citrus Huanglongbing: The Pathogen and Its Impact. Phytopathology, I(17), 239-245. https://doi.org/10.1094/PHYTO-09-110265

Adeshina, G. O., Onaolapo, J. A., Olorunmola, J., \& Odama, L. E. (2010). Phytochemical and antimicrobial studies of the ethyl acetate extract of Alchornea cordifolia leaf found in Abuja, Nigeria. Journal of Medicinal Plants Research. https://doi.org/10.5897/JMPR09.315

Algamal, M. A., Marei, G. I. K., Saad, M. M. G., \& Abdelgaleil, S. A. M. (2013). Antimicrobial and phytotoxic properties of Artemisinin and related derivatives. World Applied Sciences Journal, 28(10), 1382-1388. https://doi.org/10.5829/idosi.wasj.2013.28.10.1726

Alvarez, S., Rohrig, E., Solís, D., \& Thomas, M. H. (2016). Citrus Greening Disease (Huanglongbing) in Florida: Economic Impact, Management and the Potential for Biological Control. Agricultural Research. https://doi.org/10.1007/s40003-0160204-z

Ammar, E.-D., Walter, A. J., \& Hall, D. G. (2013). New Excised-Leaf Assay Method to Test Inoculativity of Asian Citrus Psyllid (Hemiptera: Psyllidae) With \&lt;I\&gt;Candidatus\&lt;/I\&gt; Liberibacter asiaticus Associated With Citrus Huanglongbing Disease. Journal of Economic Entomology. https://doi.org/10.1603/EC12245

Andreote, F. D., Rossetto, P. B., Souza, L. C. A., Marcon, J., Maccheroni, W., Azevedo, J. L., \& Araújo, W. L. (2008). Endophytic population of Pantoea agglomerans in citrus plants and development of a cloning vector for endophytes. Journal of Basic Microbiology. https://doi.org/10.1002/jobm.200700341

Anjum, N., \& Chandra, R. (2015a). Endophytic bacteria: Optimizaton of isolation procedure from various medicinal plants and their preliminary characterization. Asian Journal of Pharmaceutical and Clinical Research, 8(4), 233-238.

Anjum, N., \& Chandra, R. (2015b). Endophytic bacteria: Optimizaton of isolation procedure from various medicinal plants and their preliminary characterization. Article in Asian Journal of Pharmaceutical and Clinical Research, 8. Retrieved 
from https://www.researchgate.net/publication/282240458

Appalasamy, S., Lo, K. Y., Ch'Ng, S. J., Nornadia, K., Othman, A. S., \& Chan, L. K. (2014). Antimicrobial activity of artemisinin and precursor derived from in vitro plantlets of Artemisia annua L. BioMed Research International, 2014. https://doi.org/10.1155/2014/215872

Araújo, Welington L., Marcon, J., Maccheroni, W., Van Elsas, J. D., Van Vuurde, J. W. L., \& Azevedo, J. L. (2002). Diversity of endophytic bacterial populations and their interaction with Xylella fastidiosa in citrus plants. Applied and Environmental Microbiology. https://doi.org/10.1128/AEM.68.10.4906-4914.2002

Araújo, Welington Luiz, Maccheroni, W., Barroso, P., Araújo, W. L., Aguilar-Vildoso, C. I., Barroso, P. A. V, ... Lúcio De Azevedo, J. (2001). Variability and interactions between endophytic bacteria and fungi isolated from leaf tissues of citrus rootstocks. Article in Canadian Journal of Microbiology. https://doi.org/10.1139/cjm-47-3-229

Ashafa, A., \& Afolayan, A. (2009). Screening the root extracts from Biden pilosa L. var. radiata (Asteraceae) for antimicrobial potentials. Journal of Medicinal Plants Research.

Author, F., Halbert, S. E., \& Manjunath, K. L. (2004). Asian Citrus Psyllids (Sternorrhyncha: Psyllidae) and Greening Disease of Citrus: A Literature Review and Assessment of Risk in. Source: The Florida Entomologist (Vol. 87). Retrieved from https://www.jstor.org/stable/3496747

Bacon, C. W., \& Hinton, D. M. (2011). In planta reduction of maize seedling stalk lesions by the bacterial endophyte Bacillus mojavensis . Canadian Journal of Microbiology. https://doi.org/10.1139/w11-031

Bendix, C., \& Lewis, J. D. (2018). The enemy within: Phloem-limited pathogens. Molecular Plant Pathology. https://doi.org/10.1111/mpp.12526

Biba, V. S., Amily, A., Sangeetha, S., \& Remani, P. (2014). Anticancer, antioxidant and antimicrobial activity of annonaceae family. World Journal of Pharmacy and Pharmaceutical Sciences, 3(3), 1595-1604.

Blaustein, R. A., Lorca, G. L., \& Teplitski, M. (2018). Challenges for Managing Candidatus Liberibacter spp. (Huanglongbing Disease Pathogen): Current Control Measures and Future Directions. Phytopathology, 108(4), 424-435. https://doi.org/10.1094/PHYTO-07-17-0260-RVW

Boakye-Yiadom, K. (1979). Antimicrobial Properties of Some West African Medicinal Plants II. Antimicrobial Activity of Aqueous Extracts of Cryptolepis Sanguinolenta (Lindl.) Schlechter. Quarterly Journal of Crude Drug Research, 17(2), 78-80. 
https://doi.org/10.3109/13880207909067453

Bové, J. M. (2006a). Huanglongbing: A destructive, newly-emerging, century-old disease of citrus. Journal of Plant Pathology. https://doi.org/10.4454/jpp.v88i1.828

Bové, J. M. (2006b). Huanglongbing: A destructive, newly-emerging, century-old disease of citrus. Journal of Plant Pathology. https://doi.org/10.4454/jpp.v88i1.828

Cansaran, D., Kahya, D., Yurdakulol, E., \& Atakol, O. (2006). Identification and quantitation of usnic acid from the lichen Usnea species of anatolia and antimicrobial activity. Zeitschrift Fur Naturforschung - Section C Journal of Biosciences.

Cao, J., Cheng, C., Yang, J., \& Wang, Q. (2015). Pathogen infection drives patterns of nutrient resorption in citrus plants. Scientific Reports. https://doi.org/10.1038/srep14675

Cazorla, F. M., \& Mercado-Blanco, J. (2016). Biological control of tree and woody plant diseases: an impossible task? BioControl. https://doi.org/10.1007/s10526-016-97370

Chakraborty, A., Chowdhury, B. K., \& Bhattacharyya, P. (1995). Clausenol and clausenine - Two carbazole alkaloids from Clausena anisata. Phytochemistry, 40, 295-298. https://doi.org/10.1016/0031-9422(95)00047-B

Chandra, H., Bishnoi, P., Yadav, A., Patni, B., Mishra, A., \& Nautiyal, A. (2017). Antimicrobial Resistance and the Alternative Resources with Special Emphasis on Plant-Based Antimicrobials-A Review. Plants. https://doi.org/10.3390/plants6020016

Chang, Q., Wang, W., Regev-Yochay, G., Lipsitch, M., \& Hanage, W. P. (2014). Antibiotics in agriculture and the risk to human health: how worried should we be? https://doi.org/10.1111/eva.12185

Chanway, C. (1998). Bacterial endophytes: ecological and practical implications. Sydowia.

Chiyaka, C., Singer, B. H., Halbert, S. E., Morris, J. G., \& van Bruggen, A. H. C. (2012). Modeling huanglongbing transmission within a citrus tree. Proceedings of the National Academy of Sciences. https://doi.org/10.1073/pnas.1208326109

Chu, Y. I., \& Chien, C. C. (1991). Utilization of Natural Enemies to Control of Psyllid Vectors Transmitting Citrus Greening. Integrated Control of Plant Virus Diseases.

Chun, S. S., Vattem, D. A., Lin, Y. T., \& Shetty, K. (2005). Phenolic antioxidants from 
clonal oregano (Origanum vulgare) with antimicrobial activity against Helicobacter pylori. Process Biochemistry. https://doi.org/10.1016/j.procbio.2004.02.018

Chung, K. R., \& Brlansky, R. (2009). Citrus diseases exotic to Florida: Huanglongbing (citrus greening). Plant Pathology, 1-4. Retrieved from http://edis.ifas.ufl.edu/pp133

Conner, H. (2017). EPA shouldn't approve human antibiotics for citrus greening. Retrieved January 9, 2019, from https://www.tampabay.com/opinion/columns/column-epa-shouldnt-approve-humanantibiotics-for-citrus-greening/2324787

Court, C. D., \& Hodges, A. W. (2017). FLORIDA CITRUS INDUSTRY IN 2015-16.

Cowan, M M. (1999). Plant products as antimicrobial agents. Clinical Microbiology Reviews, 12(4), 564-582. https://doi.org/0893-8512/99/\$04.00 $\square 0$

Croxton, S. D., \& Stansly, P. A. (2014). Metalized polyethylene mulch to repel Asian citrus psyllid, slow spread of huanglongbing and improve growth of new citrus plantings. Pest Management Science. https://doi.org/10.1002/ps.3566

da Graça, J. V., \& Korsten, L. (2004). Citrus Huanglongbing: Review, Present status and Future Strategies. Diseases of Fruits and Vegetables Volume I, I, 229-245. https://doi.org/10.1007/1-4020-2606-4_4

Da Graca, John V, Setamou, M., \& Salas, B. (2008). Survey for the Asian Citrus Psyllid, Diaphorina citri, and Citrus Huanglongbing (Greening Disease) in Texas. Retrieved from https://www.researchgate.net/publication/263612070

Dagulo, L., Danyluk, M. D., Spann, T. M., Valim, M. F., Goodrich-Schneider, R., Sims, C., \& Rouseff, R. (2010). Chemical Characterization of Orange Juice from Trees Infected with Citrus Greening (Huanglongbing). Journal of Food Science. https://doi.org/10.1111/j.1750-3841.2009.01495.x

Datar, A., Navroop, K., Patel, S., Luecke, D. F., \& Sapi, E. (2010). In Vitro Effectiveness of Samento and Banderol Herbal Extracts on the Different Morphological Forms of Borrelia Burgdorferi. Lancet Neurology.

Dewdney, M. M., Rogers, M. E., \& Brlansky, R. H. (2016). Ch.27 Huanglongbing (citrus greening). 2016 Florida Citrus Pest Management Guide, PP-225.

Dorman, H. J. D., \& Deans, S. G. (2000). Antimicrobial agents from plants: Antibacterial activity of plant volatile oils. Journal of Applied Microbiology. https://doi.org/10.1046/j.1365-2672.2000.00969.x 
dos Santos, B. S., da Silva, L. C. N., da Silva, T. D., Rodrigues, J. F. S., Grisotto, M. A. G., Correia, M. T. do. S., ... Paiva, P. M. G. (2016). Application of omics technologies for evaluation of antibacterial mechanisms of action of plant-derived products. Frontiers in Microbiology. https://doi.org/10.3389/fmicb.2016.01466

Doud, M. M., Wang, Y., Hoffman, M. T., Latza, C. L., Luo, W., Armstrong, C. M., ... Duan, Y. (2017). Solar thermotherapy reduces the titer of Candidatus Liberibacter asiaticus and enhances canopy growth by altering gene expression profiles in HLBaffected citrus plants. Horticulture Research.

https://doi.org/10.1038/hortres.2017.54

Douglas, A. E. (2006). Phloem-sap feeding by animals: problems and solutions. Journal of Experimental Biology. https://doi.org/10.1093/jxb/erj067

Duan, Y., Zhou, L., Hall, D. G., Li, W., Doddapaneni, H., Lin, H., ... Gottwald, T. (2009). Complete Genome Sequence of Citrus Huanglongbing Bacterium, ' Candidatus Liberibacter asiaticus' Obtained Through Metagenomics. Molecular Plant-Microbe Interactions. https://doi.org/10.1094/MPMI-22-8-1011

Durán, E. L., Ploper, L. D., Ramallo, J. C., Piccolo Grandi, R. A., Hupper Giancoli, Á. C., \& Azevedo, J. L. (2005). The foliar fungal endophytes of Citrus limon in Argentina. Canadian Journal of Botany, 83(4), 350-355. https://doi.org/10.1139/b05-009

Ebi, G. C. (2001). Antimicrobial activities of Alchornea cordifolia. Fitoterapia. https://doi.org/10.1016/S0367-326X(00)00254-9

Eevers, N., Gielen, M., Sánchez-López, A., Jaspers, S., White, J. C., Vangronsveld, J., \& Weyens, N. (2015). Optimization of isolation and cultivation of bacterial endophytes through addition of plant extract to nutrient media. Microbial Biotechnology, 8(4), 707-715. https://doi.org/10.1111/1751-7915.12291

Eljounaidi, K., Lee, S. K., \& Bae, H. (2016). Bacterial endophytes as potential biocontrol agents of vascular wilt diseases - Review and future prospects. Biological Control. https://doi.org/10.1016/j.biocontrol.2016.07.013

Fagen, J. R., Leonard, M. T., Coyle, J. F., McCullough, C. M., Davis-Richardson, A. G., Davis, M. J., \& Triplett, E. W. (2014). Liberibacter crescens gen. nov., sp. nov., the first cultured member of the genus Liberibacter. International Journal of Systematic and Evolutionary Microbiology, 64(PART 7), 2461-2466. https://doi.org/10.1099/ijs.0.063255-0

Fahey, J. W., Dimock, M. B., Tomasino, S. F., Taylor, J. M., \& Carlson, P. S. (1991). Genetically Engineered Endophytes as Biocontrol Agents: A Case Study from Industry (pp. 401-411). Springer, New York, NY. https://doi.org/10.1007/978-1- 
4612-3168-4_20

Falowo, A. B., Muchenje, V., Hugo, C. J., \& Charimba, G. (2016). In vitro antimicrobial activities of Bidens pilosa and Moringa oleifera leaf extracts and their effects on ground beef quality during cold storage . CyTA - Journal of Food. https://doi.org/10.1080/19476337.2016.1162847

Fan, J., Chen, C., Brlansky, R. H., Gmitter, F. G., \& Li, Z. G. (2010). Changes in carbohydrate metabolism in Citrus sinensis infected with "Candidatus Liberibacter asiaticus.” Plant Pathology. https://doi.org/10.1111/j.1365-3059.2010.02328.x

Farag, R. S., Daw, Z. Y., Hewedi, F. M., \& El- Baroty, G. S. A. (1987). Antimicrobial Activity of Some Egyptian Spice Essential Oils. Journal of Food Protection. https://doi.org/10.4315/0362-028x-52.9.665

Fatima, U., \& Senthil-Kumar, M. (2015). Plant and pathogen nutrient acquisition strategies. Frontiers in Plant Science. https://doi.org/10.3389/fpls.2015.00750

Ferdinand, J. (2009). Evaluation of the antimicrobial properties of unripe banana (Musa sapientum L.), lemon grass (Cymbopogon citratus S.) and turmeric (Curcuma longa L.) on pathogens. African Journal of Biotechnology.

Fleites, L. A., Jain, M., Zhang, S., \& Gabriel, D. W. (2014). "Candidatus Liberibacter asiaticus" prophage late genes may limit host range and culturability. Applied and Environmental Microbiology, 80(19), 6023-6030. https://doi.org/10.1128/AEM.01958-14

Fletcher, J., \& Wayadanda, A. (2002). Fastidious Vascular-Colonizing Bacteria. The Plant Health Instructor. https://doi.org/10.1094/PHI-I-2002-1218-02

Folimonova, S. Y., Robertson, C. J., Garnsey, S. M., Gowda, S., \& Dawson, W. O. (2009). Examination of the Responses of Different Genotypes of Citrus to Huanglongbing (Citrus Greening) Under Different Conditions. Phytopathology. https://doi.org/10.1094/PHYTO-99-12-1346

French, J. ., Kahlke, C. ., \& \& da Graca J.V. (2001). First record of the Asian Citrus Psylla, Diaphorina citri Kuwayama (Homoptera: Psyllidae), in Texas. Retrieved from http://www.stoppinginvasives.com/dotAsset/1363291b-7410-42ab-b41a836805ee6523.pdf

Gamboa, F., \& Chaves, M. (2012). Antimicrobial potential of extracts from Stevia rebaudiana leaves against bacteria of importance in dental caries. Acta Odontologica Latinoamericana : AOL.

Gardner, C. L., Pagliai, F. A., Pan, L., Bojilova, L., Torino, M. I., Lorca, G. L., \& 
Gonzalez, C. F. (2016). Drug Repurposing: Tolfenamic Acid Inactivates PrbP, a Transcriptional Accessory Protein in Liberibacter asiaticus. Frontiers in Microbiology, 7, 1630. https://doi.org/10.3389/fmicb.2016.01630

Garnier, M., \& Bove, J.-M. (1983). Transmission of the organism associated with citrus greening disease from sweet orange to periwinkle by dodder. Phytopathology. https://doi.org/10.1094/Phyto-73-1358

Garnier, M., Jagoueix-Eveillard, S., Cronje, P. R., Le Roux, H. F., \& Bové, J. M. (2000). Genomic characterization of a liberibacter present in an ornamental rutaceous tree, Calodendrum capense, in the Western Cape province of South Africa. Proposal of "Candidatus liberibacter africanus subsp. capensis." International Journal of Systematic and Evolutionary Microbiology. https://doi.org/10.1099/00207713-50-62119

Ghanim, M., Achor, D., Ghosh, S., Kontsedalov, S., Lebedev, G., \& Levy, A. (2017). "Candidatus Liberibacter asiaticus" Accumulates inside Endoplasmic Reticulum Associated Vacuoles in the Gut Cells of Diaphorina citri. Scientific Reports. https://doi.org/10.1038/s41598-017-16095-w

Ghosh, S., Subudhi, E., \& Nayak, S. (2008). Antimicrobial assay of Stevia rebaudiana Bertoni leaf extracts against 10 pathogens. International Journal of Integrative Biology.

Giles, F. (2017). The Grower's Take: Citrus, HLB, and Biological Control. Florida Grower, 1-6.

Gond, S. K., Verma, V. C., Kumar, A., Kumar, V., \& Kharwar, R. N. (2007). Study of endophytic fungal community from different parts of Aegle marmelos Correae (Rutaceae) from Varanasi (India). World Journal of Microbiology and Biotechnology, 23(10), 1371-1375. https://doi.org/10.1007/s11274-007-9375-x

Goswami, S., Bhakuni, R. S., Chinniah, A., Pal, A., Kar, S. K., \& Das, P. K. (2012). Anti-Helicobacter pylori Potential of Artemisinin and Its Derivatives. Antimicrobial Agents and Chemotherapy. https://doi.org/10.1128/aac.00407-12

Gottwald, T. (2007). Citrus Huanglongbing: The Pathogen and Its Impact. Plant Health Progress. https://doi.org/10.1094/PHP-2007-0906-01-RV

Gottwald, T. R., Graham, J. H., Irey, M. S., McCollum, T. G., \& Wood, B. W. (2012). Inconsequential effect of nutritional treatments on huanglongbing control, fruit quality, bacterial titer and disease progress. Crop Protection. https://doi.org/10.1016/j.cropro.2012.01.004

Gottwald, Tim R. (2010). Current Epidemiological Understanding of Citrus 
Huanglongbing. Annual Review of Phytopathology. https://doi.org/10.1146/annurevphyto-073009-114418

Govaris, A., Solomakos, N., Pexara, A., \& Chatzopoulou, P. S. (2010). The antimicrobial effect of oregano essential oil, nisin and their combination against Salmonella Enteritidis in minced sheep meat during refrigerated storage. International Journal of Food Microbiology. https://doi.org/10.1016/j.ijfoodmicro.2009.12.017

Graca, J V. (1991). Citrus Greening Disease. Annual Review of Phytopathology. https://doi.org/10.1146/annurev.py.29.090191.000545

Grafton-cardwell, E. E., \& Kearney, U. C. (2003). Asian Citrus Psyllid.

Grafton-Cardwell, E. E., Stelinski, L. L., \& Stansly, P. A. (2013). Biology and Management of Asian Citrus Psyllid, Vector of the Huanglongbing Pathogens. Annual Review of Entomology. https://doi.org/10.1146/annurev-ento-120811153542

Gupta, C., \& Garg, A. (2008). Comparative analysis of the antimicrobial activity of cinnamon oil and cinnamon extract on some food-borne microbes. African Journal of Microbiology Research, Vol. 2(9) pp. 247-251

Gupta, P. D., \& Birdi, T. J. (2017). Development of botanicals to combat antibiotic resistance. Journal of Ayurveda and Integrative Medicine.

https://doi.org/10.1016/j.jaim.2017.05.004

Halbert, S., \& Manjunath, K. (2004). Asian Citrus Psyllids (Sternorrhyncha: psyllidae) and Greening Disease of Citrus: A Literature Review and Assessment of Risk in Florida. Retrieved from https://www.jstor.org/stable/pdf/3496747.pdf?casa_token=gS7ejc57oSQAAAAA:4 wdUXg_eIwWTylcFv7YJ13EwpIsLgXmHk3mgH0_aOAVSBPeTipu2mT4SbAXS HBIuy0Wy4XY26EYj_d8NsWGPiGt5gx1OXizwAxWHFAgRGfQqauSo

Hall, D. G. (2018). Incidence of "Candidatus Liberibacter asiaticus" in a Florida population of Asian citrus psyllid. Journal of Applied Entomology. https://doi.org/10.1111/jen.12466

Hall, David G., \& Albrigo, L. G. (2007). Estimating the relative abundance of flush shoots in citrus with implications on monitoring insects associated with flush. HortScience.

Hallmann, J., Quadt-Hallmann, A., Mahaffee, W. F., \& Kloepper, J. W. (1997). Bacterial endophytes in agricultural crops. Canadian Journal of Microbiology. https://doi.org/10.1139/m97-131 
Hijaz, F., Nehela, Y., \& Killiny, N. (2016). Possible role of plant volatiles in tolerance against huanglongbing in citrus. Plant Signaling and Behavior. https://doi.org/10.1080/15592324.2016.1138193

Hilf, M. E., \& Lewis, R. S. (2016a). Transmission and Propagation of ' Candidatus Liberibacter asiaticus ' by Grafting with Individual Citrus Leaves, 452-458.

Hilf, M. E., \& Lewis, R. S. (2016b). Transmission and Propagation of ' Candidatus Liberibacter asiaticus' by Grafting with Individual Citrus Leaves. Phytopathology, 106(5), 452-458. https://doi.org/10.1094/PHYTO-09-15-0221-R

Ho, M. Y., Chung, W. C., Huang, H. C., Chung, W. H., \& Chung, W. H. (2012). Identification of endophytic fungi of medicinal herbs of Lauraceae and Rutaceae with antimicrobial property. Taiwania, 57(3), 229-241.

Hoffman, M. T., Doud, M. S., Williams, L., Zhang, M.-Q., Ding, F., Stover, E., ... Duan, Y.-P. (2013). Heat Treatment Eliminates ' Candidatus Liberibacter asiaticus' from Infected Citrus Trees Under Controlled Conditions. Phytopathology. https://doi.org/10.1094/PHYTO-06-12-0138-R

Hu, J., \& Wang, N. (2016). Evaluation of the Spatiotemporal Dynamics of Oxytetracycline and Its Control Effect Against Citrus Huanglongbing via Trunk Injection. https://doi.org/10.1094/PHYTO-02-16-0114-R

Hudson, E. M. (2018). Florida Citrus Statistics 2016-2017.

Hufford, C. D., Jia, Y., Croom, E. M., Muhammed, I., Okunade, A. L., Clark, A. M., \& Rogers, R. D. (1993). Antimicrobial compounds from Petalostemum purpureum. Journal of Natural Products, 56(11), 1878-1889. https://doi.org/10.1021/np50101a003

Hung, T. H., Hung, S. C., Chen, C. N., Hsu, M. H., \& Su, H. J. (2004). Detection by PCR of Candidatus Liberibacter asiaticus, the bacterium causing citrus huanglongbing in vector psyllids: Application to the study of vector-pathogen relationships. Plant Pathology. https://doi.org/10.1111/j.1365-3059.2004.00948.x

Hyde, K. D., \& Soytong, K. (2008). The fungal endophyte dilemma. Fungal Diversity.

Imelouane, B., Amhamdi, H., Wathelet, J. P., Ankit, M., Khedid, K., \& El Bachiri, A. (2009). Chemical composition and antimicrobial activity of essential oil of thyme (Thymus vulgaris) from eastern Morocco. International Journal of Agriculture and Biology.

Jaggi, R. K., Madaan, R., \& Singh, B. (2003). Anticonvulsant potential of holy basil, Ocimum sanctum Linn., and its cultures. Indian Journal of Experimental Biology. 
Jagoueix, S., Bove, J.-M., \& Garnier, M. (1994). The Phloem-Limited Bacterium of Greening Disease of Citrus Is a Member of the Subdivision of the Proteobacteria. International Journal of Systematic Bacteriology. https://doi.org/10.1099/0020771344-3-379

Jain, M., Fleites, L. A., \& Gabriel, D. W. (2017). A Small Wolbachia Protein Directly, 2(3), 1-12. https://doi.org/10.1128/mSphereDirect.00171-17

Jain, M., Munoz-Bodnar, A., \& Gabriel, D. W. (2017). Concomitant Loss of the Glyoxalase System and Glycolysis Makes the Uncultured Pathogen \&quot;Candidatus Liberibacter asiaticus\&quot; an Energy Scavenger. https://doi.org/10.1128/AEM

Jain, R. P. S. \& D. A. (2012). Evaluation of antimicrobial activity of curcuminoids isolated from turmeric. INTERNATIONAL JOURNAL OF PHARMACY LIFE SCIENCES.

Johnson, E. G., Wu, J., Bright, D. B., \& Graham, J. H. (2014). Association of "Candidatus Liberibacter asiaticus" root infection, but not phloem plugging with root loss on huanglongbing-affected trees prior to appearance of foliar symptoms. Plant Pathology. https://doi.org/10.1111/ppa.12109

Kadota, S., Basnet, P., Ishii, E., Tamura, T., \& Namba, T. (1997). Antibacterial activity of trichorabdal a from Rabdosia trichocarpa against Helicobacter pylori. Zentralblatt Fur Bakteriologie, 286(1), 63-67. https://doi.org/10.1016/S0934-8840(97)80076-X

Killiny, N. (2016). Plant Physiology and Biochemistry Generous hosts : What makes Madagascar periwinkle ( Catharanthus roseus ) the perfect experimental host plant for fastidious bacteria? Plant Physiology et Biochemistry, 109, 28-35. https://doi.org/10.1016/j.plaphy.2016.09.002

Killiny, N., \& Hijaz, F. (2016). Amino acids implicated in plant defense are higher in candidatus liberibacter asiaticus-tolerant citrus varieties. Plant Signaling and Behavior. https://doi.org/10.1080/15592324.2016.1171449

Kim, S. Y., \& Ko, G. (2012). Using propidium monoazide to distinguish between viable and nonviable bacteria, MS2 and murine norovirus. Letters in Applied Microbiology, 55(3), 182-188. https://doi.org/10.1111/j.1472-765X.2012.03276.x

Knudsmark Jessing, K., Duke, S. O., \& Cedergreeen, N. (2014). Potential ecological roles of artemisinin produced by Artemisia annua L. Journal of Chemical Ecology. https://doi.org/10.1007/s10886-014-0384-6

Koh, E. J., Zhou, L., Williams, D. S., Park, J., Ding, N., Duan, Y. P., \& Kang, B. H. 
(2012). Callose deposition in the phloem plasmodesmata and inhibition of phloem transport in citrus leaves infected with "Candidatus Liberibacter asiaticus." Protoplasma. https://doi.org/10.1007/s00709-011-0312-3

Krystel, J., Shi, Q., Shaw, J., Gupta, G., Hall, D., \& Stover, E. (2019). An in vitro protocol for rapidly assessing the effects of antimicrobial compounds on the unculturable bacterial plant pathogen, Candidatus Liberibacter asiaticus. Plant Methods. https://doi.org/10.1186/s13007-019-0465-1

Lacava, P. T., Araújo, W. L., Marcon, J., Maccheroni, W., \& Azevedo, J. L. (2004). Interaction between endophytic bacteria from citrus plants and the phytopathogenic bacteria Xylella fastidiosa, causal agent of citrus-variegated chlorosis. Letters in Applied Microbiology, 39(1), 55-59. https://doi.org/10.1111/j.1472765X.2004.01543.x

Lacava, Paulo Teixeira, Araújo, W. L., \& Azevedo, J. L. (2007). Evaluation of endophytic colonization of Citrus sinensis and Catharanthus roseus seedlings by endophytic bacteria. Journal of Microbiology (Seoul, Korea), 45(1), 11-14. Retrieved from http://www.ncbi.nlm.nih.gov/pubmed/17342049

Lacava, Paulo Teixeira, Li, W., Araújo, W. L., Azevedo, J. L., \& Hartung, J. S. (2007). The endophyte Curtobacterium flaccumfaciens reduces symptoms caused by Xylella fastidiosa in Catharanthus roseus. Journal of Microbiology (Seoul, Korea).

Lai, K.-K., Davis-Richardson, A. G., Dias, R., \& Triplett, E. W. (2016). Identification of the Genes Required for the Culture of Liberibacter crescens, the Closest Cultured Relative of the Liberibacter Plant Pathogens. Frontiers in Microbiology, 7, 547. https://doi.org/10.3389/fmicb.2016.00547

LeFevre, K. (2018). The Big Squeeze: Florida's \$10 Billion Citrus Industry Is In Trouble. Retrieved June 1, 2019, from https://www.jupitermag.com/features/big-squeezefloridas-10-billion-citrus-industry-trouble

Leonard, M. T., Fagen, J. R., Davis-Richardson, A. G., Davis, M. J., \& Triplett, E. W. (2012). Complete genome sequence of Liberibacter crescens BT-1. Standards in Genomic Sciences, 7(2), 271-283. https://doi.org/10.4056/sigs.3326772

Li, B., Li, X., Lin, H., \& Zhou, Y. (2018). Curcumin as a Promising Antibacterial Agent: Effects on Metabolism and Biofilm Formation in S. mutans . BioMed Research International. https://doi.org/10.1155/2018/4508709

Li, Z. F., Wang, L. F., Feng, Z. L., Zhao, L. H., Shi, Y. Q., \& Zhu, H. Q. (2014). Diversity of endophytic fungi from different Verticillium-wilt-resistant Gossypium hirsutum and evaluation of antifungal activity against Verticillium dahliae in vitro. Journal of Microbiology and Biotechnology. 
https://doi.org/10.4014/jmb.1402.02035

LIN, K.-H. (1956). Zhiwu-bingli-xuebao jikan = Acta phytopathologica Sinica. Acta Phytopathologica Sinica (Vol. 2). Retrieved from https://www.cabdirect.org/cabdirect/abstract/19581100135

Liu, Y., Heying, E., \& Tanumihardjo, S. A. (2012). History, Global Distribution, and Nutritional Importance of Citrus Fruits. Comprehensive Reviews in Food Science and Food Safety. https://doi.org/10.1111/j.1541-4337.2012.00201.x

Lòpez-Fernàndez, S., Mazzoni, V., Pedrazzoli, F., Pertot, I., \& Campisano, A. (2017). A phloem-feeding insect transfers bacterial endophytic communities between grapevine plants. Lòpez-Fernàndez, S., Mazzoni, V., Pedrazzoli, F., Pertot, I., \& Campisano, A. (2017). A Phloem-Feeding Insect Transfers Bacterial Endophytic Communities between Grapevine Plants. Frontiers in Microbiology.

Https://Doi.Org/10.3389/Fmicb.2017.00834Frontiers. https://doi.org/10.3389/fmicb.2017.00834

Madamombe, I. T., \& Afolayan, A. J. (2003). Evaluation of Antimicrobial Activity of Extracts from South African Usnea barbata. Pharmaceutical Biology. https://doi.org/10.1076/phbi.41.3.199.15089

Manjunath, K. L., Halbert, S. E., Ramadugu, C., Webb, S., \& Lee, R. F. (2008). Detection of ' Candidatus Liberibacter asiaticus' in Diaphorina citri and Its Importance in the Management of Citrus Huanglongbing in Florida . Phytopathology. https://doi.org/10.1094/phyto-98-4-0387

Mann, R. S., Ali, J. G., Hermann, S. L., Tiwari, S., Pelz-Stelinski, K. S., Alborn, H. T., \& Stelinski, L. L. (2012). Induced Release of a Plant-Defense Volatile 'Deceptively' Attracts Insect Vectors to Plants Infected with a Bacterial Pathogen. PLoS Pathogens, 8(3), e1002610. https://doi.org/10.1371/journal.ppat.1002610

Mann, R. S., Pelz-Stelinski, K., Hermann, S. L., Tiwari, S., \& Stelinski, L. L. (2011). Sexual Transmission of a Plant Pathogenic Bacterium, Candidatus Liberibacter asiaticus, between Conspecific Insect Vectors during Mating. PLoS ONE, 6(12), e29197. https://doi.org/10.1371/journal.pone.0029197

MARINO, M., BERSANI, C., \& COMI, G. (1999). Antimicrobial Activity of the Essential Oils of Thymus vulgaris L. Measured Using a Bioimpedometric Method. Journal of Food Protection. https://doi.org/10.4315/0362-028x-62.9.1017

Martinelli, F., \& Dandekar, A. M. (2017). Genetic Mechanisms of the Devious Intruder Candidatus Liberibacter in Citrus. Frontiers in Plant Science. https://doi.org/10.3389/fpls.2017.00904 
Matan, N., Rimkeeree, H., Mawson, A. J., Chompreeda, P., Haruthaithanasan, V., \& Parker, M. (2006). Antimicrobial activity of cinnamon and clove oils under modified atmosphere conditions. International Journal of Food Microbiology. https://doi.org/10.1016/j.ijfoodmicro.2005.07.007

Mejía, L. C., Rojas, E. I., Maynard, Z., Bael, S. Van, Arnold, A. E., Hebbar, P., ... Herre, E. A. (2008). Endophytic fungi as biocontrol agents of Theobroma cacao pathogens. Biological Control. https://doi.org/10.1016/j.biocontrol.2008.01.012

Menpara, D, and, S. C.-M. P., \& 2013, undefined. (2013). Endophytic bacteriaunexplored reservoir of antimicrobials for combating microbial pathogens. Pdfs.Semanticscholar.Org, 1095-1103. Retrieved from https://pdfs.semanticscholar.org/95c0/d95a3a4f84a70e3dc1a5ee0bdeb2fe3c3b4b.pdf

Menpara, Disha, \& Chanda, S. (2013). Endophytic Bacteria-Unexplored Reservoir of Antimicrobials for Combating Microbial Pathogens. Retrieved from https://pdfs.semanticscholar.org/95c0/d95a3a4f84a70e3dc1a5ee0bdeb2fe3c3b4b.pdf

Michaud, J. (2002). Biological control of Asian Citrus Psyllid, Diaphorina Citri (Hemiptera: Psyllidae) in Florida: a preliminary report. Entomological News. Retrieved from http://swfrec.ifas.ufl.edu/hlb/database/pdf/00000239.pdf

Michaud, J. P. (2002). Biological control of Asian citrus psyllid, Diaphorina citri (Hemiptera: Psyllidae) in Florida : a preliminary report. Entomological News, Philadelphia.

Mills-Robertson, F. C., Tay, S. C. K., Duker-Eshun, G., Walana, W., \& Badu, K. (2012). In vitro antimicrobial activity of ethanolic fractions of Cryptolepis sanguinolenta. Annals of Clinical Microbiology and Antimicrobials, 11(1), 16. https://doi.org/10.1186/1476-0711-11-16

Moffis, B. L., Burrow, J. D., Dewdney, M. M., \& Rogers, M. E. (2016). Frequently Asked Questions About Huanglongbing ( HLB ; citrus greening ) for Homeowners, 1-7. Retrieved from http://edis.ifas.ufl.edu/pdffiles/PP/PP32600.pdf

Munir, S., He, P., Wu, Y., He, P., Khan, S., Huang, M., ... He, Y. (2018). Huanglongbing Control: Perhaps the End of the Beginning. Microbial Ecology. https://doi.org/10.1007/s00248-017-1123-7

Nakabachi, A., Nikoh, N., Oshima, K., Inoue, H., Ohkuma, M., Hongoh, Y., ... Fukatsu, T. (2013). Horizontal gene acquisition of Liberibacter plant pathogens from a bacteriome-confined endosymbiont of their psyllid vector. PLOS ONE. https://doi.org/10.1371/journal.pone.0082612

Nannapanenl, R., Muthaiyan, A., Crandall, P. G., Johnson, M. G., O’bryan, C. A., 
Chalova, V. I., ... Rickel, S. C. (2008). Isolates and Mutant Strains. FOODBORNE PATHOGENS AND DISEASE, 5(5). https://doi.org/10.1089/fpd.2008.0124

National Research Council (U.S.). Committee on the Strategic Planning for the Florida Citrus Industry: Addressing Citrus Greening Disease (Huanglongbing). (2010). Strategic planning for the Florida citrus industry: addressing citrus greening disease. National Academies Press.

Nehela, Y., Hijaz, F., Elzaawely, A. A., El-Zahaby, H. M., \& Killiny, N. (2018). Citrus phytohormonal response to Candidatus Liberibacter asiaticus and its vector Diaphorina citri. Physiological and Molecular Plant Pathology, 102, 24-35. https://doi.org/10.1016/J.PMPP.2017.11.004

Nocker, A., Cheung, C.-Y., \& Camper, A. K. (2006). Comparison of propidium monoazide with ethidium monoazide for differentiation of live vs. dead bacteria by selective removal of DNA from dead cells. Journal of Microbiological Methods, 67(2), 310-320. https://doi.org/10.1016/J.MIMET.2006.04.015

Nocker, A., Sossa, K. E., \& Camper, A. K. (2007). Molecular monitoring of disinfection efficacy using propidium monoazide in combination with quantitative PCR. https://doi.org/10.1016/j.mimet.2007.04.014

Okeke, I. N., Ogundaini, A. O., Ogungbamila, F. O., \& Lamikanra, A. (1999). Antimicrobial spectrum of Alchornea cordifolia leaf extract. Phytotherapy Research. https://doi.org/10.1002/(SICI)1099-1573(199902)13:1<67::AID-PTR366>3.0.CO;2F

Ortiz-Viedma, J., Romero, N., Puente, L., Burgos, K., Toro, M., Ramirez, L., ... Aubourg, S. P. (2017). Antioxidant and antimicrobial effects of stevia (Stevia rebaudiana Bert.) extracts during preservation of refrigerated salmon paste. European Journal of Lipid Science and Technology. https://doi.org/10.1002/ejlt.201600467

Pagliai, F. A., Gardner, C. L., Bojilova, L., Sarnegrim, A., Tamayo, C., Potts, A. H., ... Lorca, G. L. (2014). The Transcriptional Activator LdtR from 'Candidatus Liberibacter asiaticus' Mediates Osmotic Stress Tolerance. PLoS Pathogens, 10(4), e1004101. https://doi.org/10.1371/journal.ppat.1004101

Pagliai, F. A., Gonzalez, C. F., \& Lorca, G. L. (2015). Identification of a Ligand Binding Pocket in LdtR from Liberibacter asiaticus. Frontiers in Microbiology, 6, 1314. https://doi.org/10.3389/fmicb.2015.01314

Pan, L., Gardner, C. L., Pagliai, F. A., Gonzalez, C. F., \& Lorca, G. L. (2017). Identification of the Tolfenamic Acid Binding Pocket in PrbP from Liberibacter asiaticus. Frontiers in Microbiology, 8, 1591. 
https://doi.org/10.3389/fmicb.2017.01591

Panda, S. K., Mohanta, Y. K., Padhi, L., Park, Y. H., Mohanta, T. K., \& Bae, H. (2016). Large scale screening of ethnomedicinal plants for identification of potential antibacterial compounds. Molecules. https://doi.org/10.3390/molecules21030293

Paudyal, K. P. (2015a). Technological Advances in Huanglongbing (HLB) or Citrus Greening Disease Management. Journal of Nepal Agricultural Research Council, Vol. 1. https://doi.org/http://dx.doi.org/10.3126/jnarc.v1i0.15735

Paudyal, K. P. (2015b). Technological Advances in Huanglongbing (HLB) or Citrus Greening Disease Management. Journal of Nepal Agricultural Research Council, Vol. 1, 1(1), 41-50. https://doi.org/http://dx.doi.org/10.3126/jnarc.v1i0.15735

Paulo, A., Duarte, A., \& Gomes, E. T. (1994). In vitro antibacterial screening of Cryptolepis sanguinolenta alkaloids. Journal of Ethnopharmacology. https://doi.org/10.1016/0378-8741(94)90079-5

Pavithra, G. M., Vinayaka, K. S., Rakesh, K. N., Junaid, S., Dileep, N., Kekuda, P. T. R., ... Naik, A. S. (2013). Antimicrobial and antioxidant activities of a macrolichen Usnea pictoides G. Awasthi (Parmeliaceae). Journal of Applied Pharmaceutical Science. https://doi.org/10.7324/JAPS.2013.3827

Pelz-Stelinski, K. S., \& Killiny, N. (2016). Better Together: Association with "Candidatus Liberibacter Asiaticus" Increases the Reproductive Fitness of Its Insect Vector, Diaphorina citri (Hemiptera: Liviidae). Annals of the Entomological Society of America. https://doi.org/10.1093/aesa/saw007

Prior, R., Görges, K., Yurkov, A., \& Begerow, D. (2014). New isolation method for endophytes based on enzyme digestion. Mycological Progress. https://doi.org/10.1007/s11557-014-0968-0

Proença Barros, F. A., \& Rodrigues-Filho, E. (2005). Four spiroquinazoline alkaloids from Eupenicillium sp. isolated as an endophytic fungus from leaves of Murraya paniculata (Rutaceae). Biochemical Systematics and Ecology, 33(3), 257-268. https://doi.org/10.1016/j.bse.2004.09.002

Puttamuk, T., Zhang, S. A., Duan, Y. P., Jantasorn, A., \& Thaveechai, N. (2014). Effect of chemical treatments on "Candidatus Liberibacter asiaticus" infected pomelo (Citrus maxima). Crop Protection. https://doi.org/10.1016/j.cropro.2014.07.018

Qureshi, J. A., Rogers, M. E., Hall, D. G., \& Stansly, P. A. (2009). Incidence of Invasive Diaphorina citri (Hemiptera: Psyllidae) and Its Introduced Parasitoid Tamarixia radiata (Hymenoptera: Eulophidae) in Florida Citrus. Stansly Source: Journal of Economic Entomology J. Econ. Entomol. https://doi.org/10.1603/029.102.0134 
Ramsey, J. S., Chavez, J. D., Johnson, R., Hosseinzadeh, S., Mahoney, J. E., Mohr, J. P., ... Cilia, M. (2017). Protein interaction networks at the host-microbe interface in Diaphorina citri, the insect vector of the citrus greening pathogen. Royal Society Open Science. https://doi.org/10.1098/rsos.160545

Randazzo, W., López-Gálvez, F., Allende, A., Aznar, R., \& Sánchez, G. (2016). Evaluation of viability PCR performance for assessing norovirus infectivity in freshcut vegetables and irrigation water. International Journal of Food Microbiology, 229, 1-6. https://doi.org/10.1016/j.ijfoodmicro.2016.04.010

Raut, D., \& Aruna, K. (2017). Antimicrobial activity of Stevia rebaudiana against antibiotic resistant ESBL producing uropathogens and evaluation of its antioxidant activity. International Journal of Advanced Research in Biological Sciences, 4(3), 110-118. https://doi.org/10.22192/ijarbs.2017.04.03.013

Riera, N., Handique, U., Zhang, Y., Dewdney, M. M., \& Wang, N. (2017a). Characterization of antimicrobial-producing beneficial bacteria isolated from Huanglongbing escape citrus trees. Frontiers in Microbiology. https://doi.org/10.3389/fmicb.2017.02415

Riera, N., Handique, U., Zhang, Y., Dewdney, M. M., \& Wang, N. (2017b). Characterization of Antimicrobial-Producing Beneficial Bacteria Isolated from Huanglongbing Escape Citrus Trees. Frontiers in Microbiology, 8, 2415. https://doi.org/10.3389/fmicb.2017.02415

Roistacher, C. N. (n.d.). The Economics of Living with Citrus Diseases: Huanglongbing (Greening) in Thailand. Retrieved from https://cloudfront.escholarship.org/dist/prd/content/qt3kg8m6jr/qt3kg8m6jr.pdf

Rosenblueth, M., \& Martínez-Romero, E. (2007). Bacterial Endophytes and Their Interactions with Hosts. Molecular Plant-Microbe Interactions. https://doi.org/10.1094/mpmi-19-0827

Rota, M. C., Herrera, A., Martínez, R. M., Sotomayor, J. A., \& Jordán, M. J. (2008). Antimicrobial activity and chemical composition of Thymus vulgaris, Thymus zygis and Thymus hyemalis essential oils. Food Control. https://doi.org/10.1016/j.foodcont.2007.07.007

Ryan, R. P., Germaine, K., Franks, A., Ryan, D. J., \& Dowling, D. N. (2007). Bacterial endophytes: recent developments and applications. https://doi.org/10.1111/j.15746968.2007.00918.x

Sandoval-Chacón, M., Thompson, J. H., Zhang, X. J., Liu, X., Mannick, E. E., Sadowska-Krowicka, H., ... Miller, M. J. S. (1998). Antiinflammatory actions of 
cat's claw: The role of NF-кB. Alimentary Pharmacology and Therapeutics. https://doi.org/10.1046/j.1365-2036.1998.00424.x

Sandoval, M., Okuhama, N. N., Zhang, X. J., Condezo, L. A., Lao, J., Angeles, F. M., ... Miller, M. J. S. (2002). Anti-inflammatory and antioxidant activities of cat's claw (Uncaria tomentosa and Uncaria guianensis) are independent of their alkaloid content. Phytomedicine. https://doi.org/10.1078/0944-7113-00117

Shen, W., Cevallos-Cevallos, J. M., Nunes da Rocha, U., Arevalo, H. A., Stansly, P. A., Roberts, P. D., \& van Bruggen, A. H. C. (2013). Relation between plant nutrition, hormones, insecticide applications, bacterial endophytes, and Candidatus Liberibacter $\mathrm{Ct}$ values in citrus trees infected with Huanglongbing. European Journal of Plant Pathology. https://doi.org/10.1007/s 10658-013-0283-7

Sher, A. (2009). Antimicrobial activity of natural products from medicinal plants. Gjms, 7(1), 72-78. Retrieved from http://www.ncbi.nlm.nih.gov/pubmed/12385884

Shetty, K. G., Rivadeneira, D. V, Jayachandran, K., \& Walker, D. M. (2016). Erratum to: Isolation and molecular characterization of the fungal endophytic microbiome from conventionally and organically grown avocado trees in South Florida (Mycol Progress, 10.1007/s11557-016-1219-3). Mycological Progress. https://doi.org/10.1007/s11557-016-1226-4

Shokrollah, H., Lee Abdullah, T., Sijam, K., \& Akmar Abdullah, S. N. (2011). Potential use of selected citrus rootstocks and interstocks against HLB disease in Malaysia. Crop Protection. https://doi.org/10.1016/j.cropro.2010.09.005

Shokrollah, H., Lee Abdullah, T., Sijam, K., \& Nor Akmar Abdullah, S. (2010). Ultrastructures of Candidatus Liberibacter asiaticus and its damage in huanglongbing (HLB) infected citrus. African Journal of Biotechnology, 9(36), 5897-5901. Retrieved from http://www.academicjournals.org/AJB

Silva, O., Duarte, A., Cabrita, J., Pimentel, M., Diniz, A., \& Gomes, E. (1996). Antimicrobial activity of Guinea-Bissau traditional remedies. Journal of Ethnopharmacology. https://doi.org/10.1016/0378-8741(95)01323-7

Singh, G., Maurya, S., deLampasona, M. P., \& Catalan, C. A. N. (2007). A comparison of chemical, antioxidant and antimicrobial studies of cinnamon leaf and bark volatile oils, oleoresins and their constituents. Food and Chemical Toxicology. https://doi.org/10.1016/j.fct.2007.02.031

Singh, S., \& Majumdar, D. K. (1999). Evaluation of the gastric antiulcer activity of fixed oil of Ocimum sanctum (Holy Basil). Journal of Ethnopharmacology. https://doi.org/10.1016/S0378-8741(98)00142-1 
Sofia, P. K., Prasad, R., Vijay, V. K., \& Srivastava, A. K. (2007). Evaluation of antibacterial activity of Indian spices against common foodborne pathogens. International Journal of Food Science and Technology. https://doi.org/10.1111/j.1365-2621.2006.01308.x

Soliman, S. S. M., Trobacher, C. P., Tsao, R., Greenwood, J. S., \& Raizada, M. N. (2013). A fungal endophyte induces transcription of genes encoding a redundant fungicide pathway in its host plant. BMC Plant Biology. https://doi.org/10.1186/1471-2229-13-93

Spreen, T. (2013). HLB, Economics Costly for Florida Citrus. Florida Grower, 106(6), 14.

Stefanović, O. D., Stanojević, D. D., \& Čomić, L. R. (2012). Synergistic antibacterial activity of Salvia officinalis and Cichorium intybus extracts and antibiotics. Acta Poloniae Pharmaceutica - Drug Research.

Stewart, E. J. (2012). Growing unculturable bacteria. Journal of Bacteriology, 194(16), 4151-4160. https://doi.org/10.1128/JB.00345-12

Stokstad, E. (2006). New disease endangers Florida's already-suffering citrus trees: researchers are mobilizing to stop a wily bacterial marauder spread by invasive insects, but massive losses appear inevitable. Science, 312(5773), 523-524.

Stover, E., Stange, R. R., Mccollum, T. G., Jaynes, J., Irey, M., \& Mirkov, E. (2013). Screening Antimicrobial Peptides In Vitro for Use in Developing Transgenic Citrus Resistant to Huanglongbing and Citrus Canker. J. Amer. Soc. Hort. Sci. https://doi.org/10.1016/j.scienta.2014.07.041

Strategic Planning for the Florida Citrus Industry. (2010). Washington, D.C.: National Academies Press. https://doi.org/10.17226/12880

Sturz, A. V., Christie, B. R., \& Nowak, J. (2000). Bacterial endophytes: Potential role in developing sustainable systems of crop production. Critical Reviews in Plant Sciences. https://doi.org/10.1080/07352680091139169

Tabay Zambon, F., Plant, K., \& Etxeberria, E. (2017). Leaf-disc grafting for the transmission of Candidatus Liberibacter asiaticus in citrus (Citrus sinensis; Rutaceae) seedlings. Applications in Plant Sciences, 5(1), apps.1600085. https://doi.org/10.3732/apps.1600085

Tamborindeguy, C., Huot, O. B., Ibanez, F., \& Levy, J. (2017). The influence of bacteria on multitrophic interactions among plants, psyllids, and pathogen. Insect Science. https://doi.org/10.1111/1744-7917.12474 
Teow, S. Y., Liew, K., Ali, S. A., Khoo, A. S. B., \& Peh, S. C. (2016). Antibacterial Action of Curcumin against Staphylococcus aureus: A Brief Review. Journal of Tropical Medicine. https://doi.org/10.1155/2016/2853045

Theophilus, P. a. S., Victoria, M. J., Socarras, K. M., Filush, K. R., Gupta, K., Luecke, D. F., \& Sapi, E. (2015). Effectiveness of Stevia rebaudiana whole leaf extract against the various morphological forms of Borrelia burgdorferi in vitro. European Journal of Microbiology and Immunology, 5, 1-13. https://doi.org/10.1556/1886.2015.00031

Tomczykowa, M., Tomczyk, M., Jakoniuk, P., \& Tryniszewska, E. (2008). Antimicrobial and antifungal activities of the extracts and essential oils of Bidens tripartita. Folia Histochemica et Cytobiologica. https://doi.org/10.2478/v10042-008-0082-8

Trivedi, P., Sagaram, U. S., Kim, J.-S., Brlansky, R. H., Rogers, M. E., Stelinski, L. L., ... Wang, N. (2009). Quantification of viable Candidatus Liberibacter asiaticus in hosts using quantitative PCR with the aid of ethidium monoazide (EMA). European Journal of Plant Pathology, 124(4), 553-563. https://doi.org/10.1007/s10658-0099439-x

Trivedi, Pankaj, Spann, T., \& Wang, N. (2011). Isolation and Characterization of Beneficial Bacteria Associated with Citrus Roots in Florida. Microbial Ecology. https://doi.org/10.1007/s00248-011-9822-y

Trivedi, Pankaj, Trivedi, C., Grinyer, J., Anderson, I. C., \& Singh, B. K. (2016). Harnessing Host-Vector Microbiome for Sustainable Plant Disease Management of Phloem-Limited Bacteria. Frontiers in Plant Science. https://doi.org/10.3389/fpls.2016.01423

Ukuda-Hosokawa, R., Sadoyama, Y., Kishaba, M., Kuriwada, T., Anbutsu, H., \& Fukatsuf, T. (2015). Infection density dynamics of the citrus greening bacterium "Candidatus liberibacter asiaticus" in field populations of the psyllid Diaphorina citri and its relevance to the efficiency of pathogen transmission to citrus plants. Applied and Environmental Microbiology. https://doi.org/10.1128/AEM.00707-15

Ungphaiboon, S., Supavita, T., Singchangchai, P., Sungkarak, S., Rattanasuwan, P., \& Itharat, A. (2005). Study on antioxidant and antimicrobial activities of turmeric clear liquid soap for wound treatment of HIV patients. Songklanakarin Journal of Science and Technology.

Vinatzer, B. A. (2012). "Listening in" on how a bacterium takes over the plant vascular system. MBio. https://doi.org/10.1128/mBio.00269-12

Wang, N., Pierson, E. A., Setubal, J. C., Xu, J., Levy, J. G., Zhang, Y., .. Martins, J. (2017). The Candidatus Liberibacter-Host Interface: Insights into Pathogenesis Mechanisms and Disease Control. Annual Review of Phytopathology, 55(1), 451- 
482. https://doi.org/10.1146/annurev-phyto-080516-035513

Wang, Y., \& Dai, C. C. (2011). Endophytes: A potential resource for biosynthesis, biotransformation, and biodegradation. Annals of Microbiology.

https://doi.org/10.1007/s13213-010-0120-6

Weiss, J. (2019). Herb-drug interaction potential of anti-borreliae effective extracts from uncaria tomentosa (samento) and otoba parvifolia (banderol) assessed in vitro. Molecules. https://doi.org/10.3390/molecules24010137

Wu, L. W., Chiang, Y. M., Chuang, H. C., Wang, S. Y., Yang, G. W., Chen, Y. H., ... Shyur, L. F. (2004). Polyacetylenes function as anti-angiogenic agents.

Pharmaceutical Research. https://doi.org/10.1023/B:PHAM.0000048204.08865.41

Xu, C. F., Xia, Y. H., \& Li, K. B. (1988). Further Study of the Transmission of Citrus Huanglungbin by a Psyllid, Diaphorina citri Kuwayama Publication Date, (10), 10. Retrieved from https://escholarship.org/uc/item/0w42q0r7

Zhang, M., Guo, Y., Powell, C. A., \& Duan, Y. (2014). Antimicrobial Compounds to Combat Citrus Huanglongbing. Journal of Citrus Pathology.

Zhang, Muqing, Duan, Y., Zhou, L., Turechek, W. W., Stover, E., \& Powell, C. A. (2010). Screening Molecules for Control of Citrus Huanglongbing Using an Optimized Regeneration System for ' Candidatus Liberibacter asiaticus'-Infected Periwinkle ( Catharanthus roseus ) Cuttings. Phytopathology, 100(3), 239-245. https://doi.org/10.1094/PHYTO-100-3-0239

Zhang, Muqing, Guo, Y., Powell, C. A., Doud, M. S., Yang, C., \& Duan, Y. (2014). Effective antibiotics against "Candidatus Liberibacter asiaticus" in HLB-affected citrus plants identified via the graft-based evaluation. PLoS ONE, 9(11), 17-21. https://doi.org/10.1371/journal.pone.0111032

Zhang, Muqing, Powell, C. A., Guo, Y., Benyon, L., \& Duan, Y. (2013). Characterization of the microbial community structure in Candidatus Liberibacter asiaticus-infected citrus plants treated with antibiotics in the field. BMC Microbiology, 13(1), 1. https://doi.org/10.1186/1471-2180-13-112

Zhang, Muqing, Powell, C. A., Guo, Y., Doud, M. S., \& Duan, Y. (2012). A Graft-Based Chemotherapy Method for Screening Effective Molecules and Rescuing Huanglongbing-Affected Citrus Plants. Phytopathology, 102(6), 567-574. https://doi.org/10.1094/PHYTO-09-11-0265

Zhang, Muqing, Powell, C. A., Zhou, L., He, Z., Stover, E., \& Duan, Y. (2011). Chemical Compounds Effective Against the Citrus Huanglongbing Bacterium ‘ Candidatus Liberibacter asiaticus' In Planta. Phytopathology, 101(9), 1097-1103. 
https://doi.org/10.1094/PHYTO-09-10-0262

Zinoviadou, K. G., Koutsoumanis, K. P., \& Biliaderis, C. G. (2009). Physico-chemical properties of whey protein isolate films containing oregano oil and their antimicrobial action against spoilage flora of fresh beef. Meat Science. https://doi.org/10.1016/j.meatsci.2009.02.004 